\title{
Detection and attribution of observed impacts
}

Cramer, Wolfgang ; Yohe, Gary ; et al

DOI: https://doi.org/10.1017/CBO9781107415379.005

Posted at the Zurich Open Repository and Archive, University of Zurich

ZORA URL: https://doi.org/10.5167/uzh-105700

Book Section

Published Version

Originally published at:

Cramer, Wolfgang; Yohe, Gary; et al (2014). Detection and attribution of observed impacts. In: Field, Christopher B; et al. Climate Change 2014 Impacts, Adaptation, and Vulnerability Part A: Global and Sectoral Aspects. Working Group II Contribution to the Fifth Assessment Report of the Intergovernmental Panel on Climate Change. Cambridge: Cambridge University Press, 979-1037.

DOI: https://doi.org/10.1017/CBO9781107415379.005 


\section{Detection and Attribution of Observed Impacts}

Coordinating Lead Authors:

Wolfgang Cramer (Germany/France), Gary W. Yohe (USA)

Lead Authors:

Maximilian Auffhammer (USA), Christian Huggel (Switzerland), Ulf Molau (Sweden), Maria Assunção Faus da Silva Dias (Brazil), Andrew Solow (USA), Dáithí A. Stone (Canada/South Africa/USA), Lourdes Tibig (Philippines)

\section{Contributing Authors:}

Laurens Bouwer (Netherlands), Mark Carey (USA), Graham Cogley (Canada), Dim Coumou (Germany), Yuka Otsuki Estrada (USA/Japan), Eberhard Faust (Germany), Gerrit Hansen (Germany), Ove Hoegh-Guldberg (Australia), Joanna House (UK), Solomon Hsiang (USA), Lesley Hughes (Australia), Sari Kovats (UK), Paul Leadley (France), David Lobell (USA), Camille Parmesan (USA), Elvira Poloczanska (Australia), Hans Otto Pörtner (Germany), Andy Reisinger (New Zealand)

\section{Review Editors:}

Rik Leemans (Netherlands), Bernard Seguin (France), Neville Smith (Australia)

Volunteer Chapter Scientist:

Gerrit Hansen (Germany) 


\section{Table of Contents}

Executive Summary

18.1. Introduction

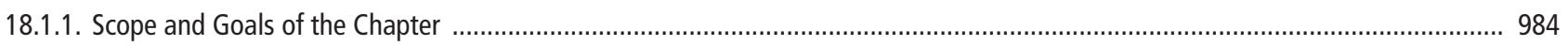

18.1.2. Summary of Findings from the Fourth Assessment Report ........................................................................................... 984

18.2. Methodological Concepts for Detection and Attribution of Impacts of Climate Change ................................. 984

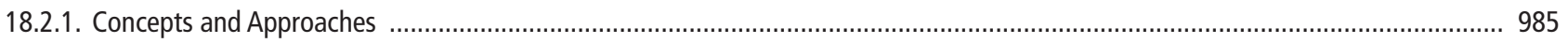

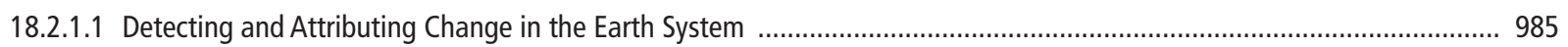

18.2.1.2 Concepts of Detection and Attribution of Climate Change Impacts Used in this Chapter ............................................ 985

Box 18-1. Quantitative Synthesis Assessment of Detection and Attribution Studies in Ecological Systems ................ 986

18.2.2. Challenges to Detection and Attribution ................................................................................................................ 986

18.3. Detection and Attribution of Observed Climate Change Impacts in Natural Systems ..................................... 986

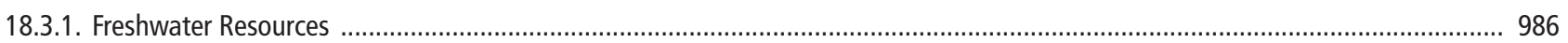

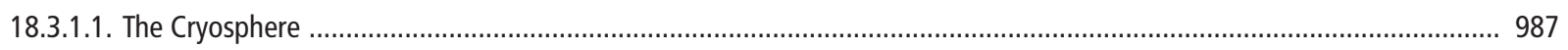

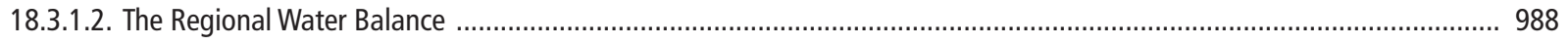

18.3.1.3. Erosion, Landslides, and Avalanches ............................................................................................................ 988

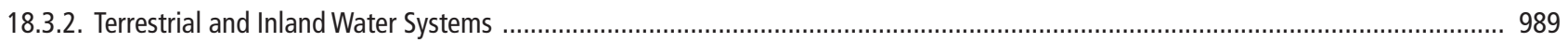

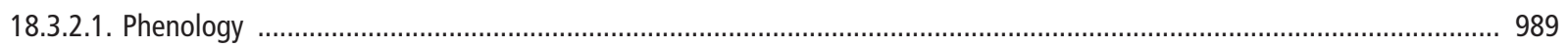

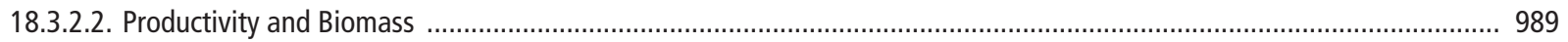

18.3.2.3. Species Distributions and Biodiversity .......................................................................................................... 990

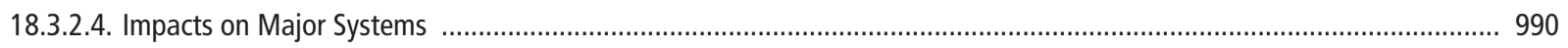

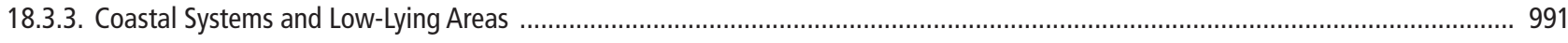

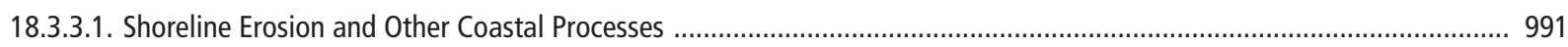

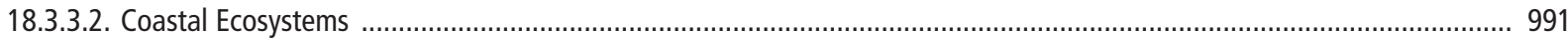

Box 18-2. Attribution of Mass Coral Bleaching Events to Climate Change ............................................................ 992

18.3.3.3. Coastal Settlements and Infrastructure ....................................................................................................... 993

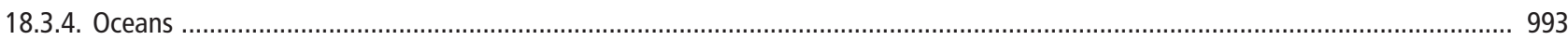

18.3.4.1. Impacts on Ocean System Properties and Marine Organisms and Ecosystems ......................................................... 994

18.3.4.2. Observed Climate Change Effects across Ocean Regions .................................................................................... 994

Box 18-3. Differences in Detection and Attribution of Ecosystem Change on Land and in the Ocean ........................ 995

18.4. Detection and Attribution of Observed Climate Change Impacts in Human and Managed Systems ................... 996

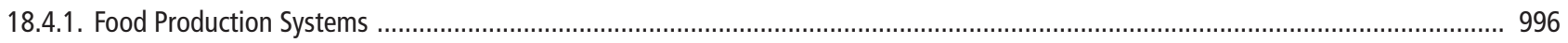

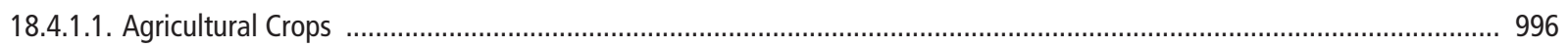

Box 18-4. The Role of Sensitivity to Climate and Adaptation for Impact Models in Human Systems ........................... 997

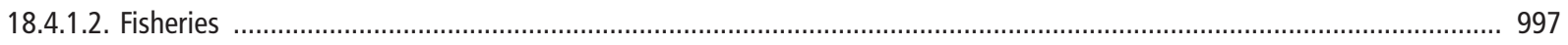




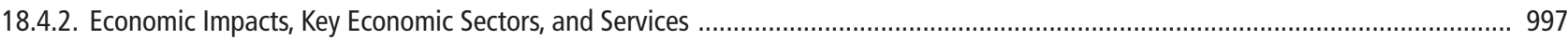

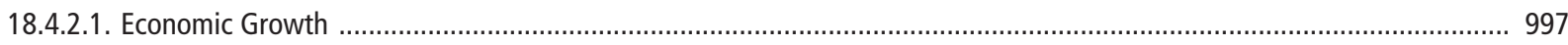

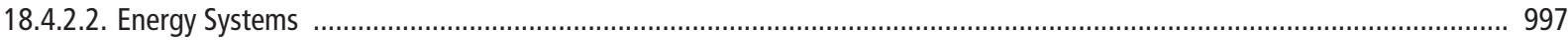

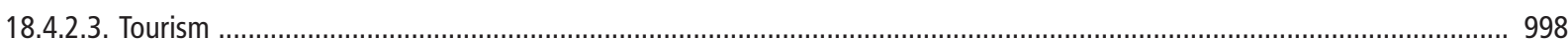

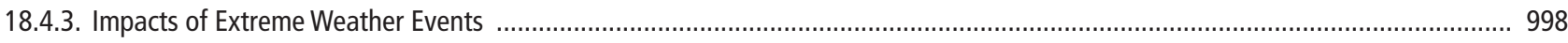

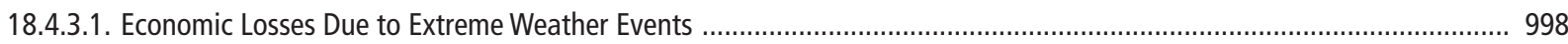

18.4.3.2. Detection and Attribution of the Impacts of Single Extreme Weather Events to Climate Change ................................... 998

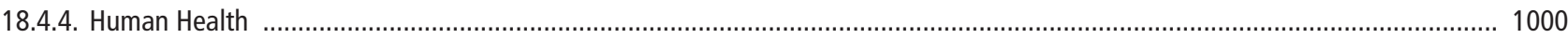

Box 18-5. Detection, Attribution, and Traditional Ecological Knowledge ............................................................... 1001

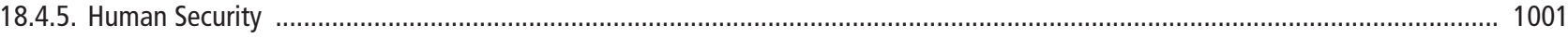

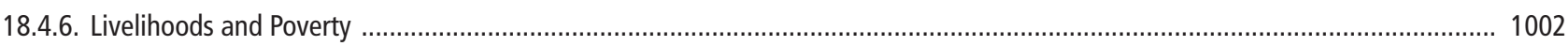

18.5. Detection and Attribution of Observed Climate Change Impacts across Regions ...........................................1003

18.6. Synthesis: Emerging Patterns of Observed Impacts of Climate Change ..................................................... 1010

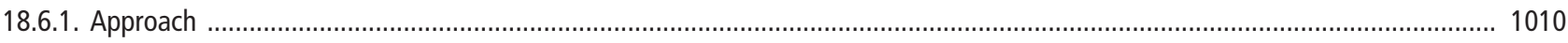

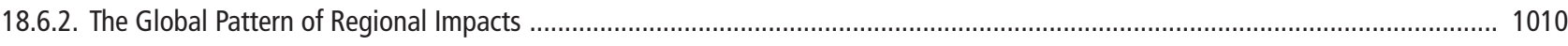

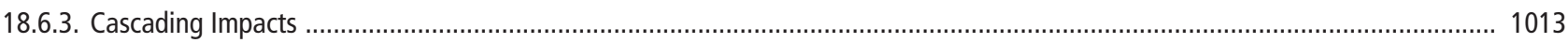

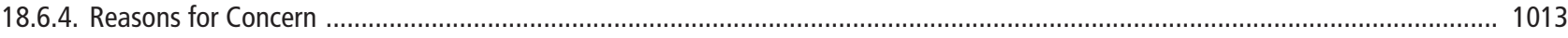

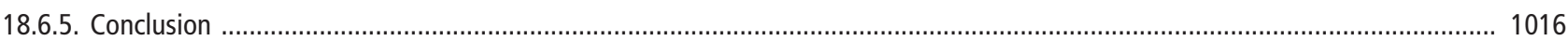

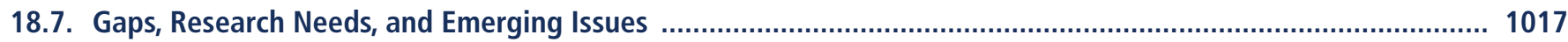

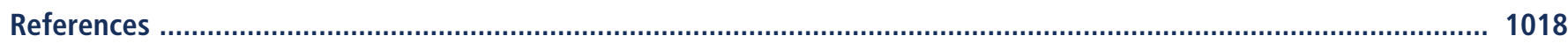

\section{Frequently Asked Questions}

18.1: Why are detection and attribution of climate impacts important? .................................................................................. 1017

18.2: Why is it important to assess impacts of all climate change aspects, and not only impacts of anthropogenic climate change? .... 1017

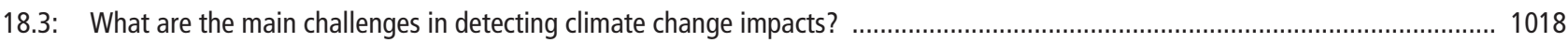

18.4: What are the main challenges in attributing changes in a system to climate change? ........................................................ 1018

18.5: Is it possible to attribute a single event, such as a disease outbreak, or the extinction of a species, to climate change? .............. 1018 


\section{Executive Summary}

Evidence has grown since the Fourth Assessment Report (AR4) that impacts of recent changes in climate on natural and human systems occur on all continents and across the oceans. This conclusion is strengthened both by new and longer term observations and through more extensive analyses of existing data. $\{18.3-6\}$

Reported impacts are caused by changes in climate that deviate from historical conditions, irrespective of the driver of climate change. Most reported impacts of climate change are attributed to warming and/or shifts in precipitation patterns. There is also emerging evidence of impacts of ocean acidification. Only some robust attribution studies and meta-analyses link responses in physical and biological systems to anthropogenic climate change. $\{18.1,18.3-5\}$

For many natural systems there is new or stronger evidence for substantial and wide-ranging impacts of climate change. These systems include the cryosphere, water resources, coastal systems, and ecosystems on land and in the ocean. $\{18.3\}$

Impacts of climate change on the hydrological cycle, and notably the availability of freshwater resources, have been observed on all continents and many islands. Glaciers continue to shrink worldwide, as a result of climate change (high confidence), affecting runoff and water resources downstream. Climate change is the main driver of permafrost warming and thawing in both high-latitude and high-elevation mountain regions (high confidence). Hydrological systems have changed in many regions because of changing precipitation or melting cryosphere, affecting water resources, water quality, and sediment transport (medium confidence). \{18.3.1, 18.5, Figure 18-2\}

Across all climate zones and continents, the major role of climate change and increasing atmospheric carbon dioxide $\left(\mathrm{CO}_{2}\right)$ on terrestrial and freshwater ecosystems has been confirmed by new and stronger evidence on phenology (high confidence), productivity (low confidence), distribution ranges (medium confidence), and other processes, affecting an increasing number of species and ecosystems. The majority of species extinctions and the recession of the Amazon forest cannot be attributed reliably to climate change. Major climate-driven changes occur in the Arctic region (high confidence), the boreal forest (low confidence), and many freshwater ecosystems (low to high confidence, regiondependent). $\{18.3 .2,18.5\}$

Despite the known sensitivity of coastal systems to sea level rise, local natural and human perturbations preclude a confident detection of sea level-related impacts of climate change. Climate change has had a major role in observed changes in abundance and distribution of many coastal species (medium confidence). \{18.3.3\}

The physical and chemical properties of oceans (including the extent of Arctic sea ice) have changed significantly over the past 6 decades, due to anthropogenic climate change. Marine organisms have moved to higher latitudes and changed their depth distribution or their phenology, mostly as a result of the warming (high confidence). Coral reefs have experienced increased mass bleaching and mortality, driven mainly by warming (high confidence). \{18.3.3-4, 18.5, Table 18-8, Box 18-2\}

Substantial new evidence has been collected on sensitivities of human systems to climate change. Climate change-related impacts on human systems are often dominated by effects of changing social and economic factors. $\{18.4\}$

Production of wheat and maize globally and in many regional systems has been impacted by climate change over the past several decades (medium confidence). The impacts of climate change on rice and soybean have been small in major production regions and globally (medium confidence). Crop production has increased in some mid-latitude regions (United Kingdom, Northeast China) (high confidence). Evidence of observed climate change impacts on food systems other than agricultural crops and fisheries is limited. \{18.4.1\}

Economic losses due to extreme weather events have increased globally, mostly due to increase in wealth and exposure, with a possible influence of climate change (low confidence). \{18.4.3\} 
There has been a shift from cold- to heat-related mortality in some regions as a result of warming (medium confidence), but despite many welldocumented sensitivities of human health to other aspects of weather, clear evidence of an additional observed climate change impact on health outcomes is lacking. $\{18.4 .4\}$

Livelihoods of indigenous peoples in the Arctic have been altered by climate change, through impacts on food security and traditional and cultural values (medium confidence). There is emerging evidence of climate change impacts on livelihoods of indigenous people in other regions. \{18.4.6, Box 18-5, Table 18-9\}

There is emerging literature on the impact of climate change on poverty, working conditions, violent conflict, migration, and economic growth from various parts of the world, but evidence for detection or attribution to climate change remains limited. $\{18.4\}$

Regional impacts of climate change have now been observed at more locations than before, on all continents and across ocean regions. In many regions, impacts of climate change are now detected also in the presence of strong confounding factors such as pollution or land use change. $\{18.6 .2\}$

"Cascading" impacts of climate change from physical climate through ecosystems on people can now be detected along chains of evidence. Examples include systems in the cryosphere, the oceans, and forests. In these cases, confidence in attribution to observed climate change decreases for effects further down the impact chain. $\{18.6 .3\}$

Evaluation of observed impacts of climate change supports risk assessment of climate change for four of the "Reasons for Concern" developed by earlier IPCC assessments. (1) Impacts related to Risks to Unique and Threatened Systems are now manifested for several systems (Arctic, glaciers on all continents, warm-water coral systems). (2) High-temperature spells have impacted one system with high confidence (coral reefs), indicating Risks Associated with Extreme Weather Events. Elsewhere, extreme events have caused increasing impacts and economic losses, but there is only low confidence in attribution to climate change for these. (3) Though impacts of climate change have now been documented globally with unprecedented coverage, observations are still insufficient to address the spatial or social disparities underlying the Risks Associated with the Distribution of Impacts. (4) Risks Associated with Aggregated Impacts: large-scale impacts, indicated by unified metrics, have been found for the cryosphere (ice volume, high confidence), terrestrial ecosystems (net productivity, carbon stocks, medium-high confidence), and human systems (crop yields, disaster losses, low-medium confidence). (5) Risks Associated with Large-Scale Singular Events: impacts that demonstrate irreversible shifts with significant feedback potential in the Earth system have yet to be observed, but there is now robust evidence of early warning signals in observed impacts of climate change that indicate climate-driven large-scale regime shifts for the Arctic region and the tropical coral reef systems. $\{18.6 .4\}$

Though evidence is improving, there is a persistent gap in the knowledge regarding how certain parts of the world are being affected by observed climate change. Data collection and monitoring are in need to gain wider coverage. Research to improve the conceptual basis, timeliness, and knowledge about detection and attribution is needed in particular for human systems. \{18.2, 18.7\} 


\subsection{Introduction}

This chapter synthesizes the scientific literature on the detection and attribution of observed changes in natural and human systems in response to observed recent climate change. For policy makers and the public, detection and attribution of observed impacts will be a key element to determine the necessity and degree of mitigation and adaptation efforts. For most natural and essentially all human systems, climate is only one of many drivers that cause change- other factors such as technological innovation, social and demographic changes, and environmental degradation frequently play an important role as well. Careful accounting of the importance of these and other confounding factors is therefore an important part of the analysis.

At any given location, observed recent climate change has happened as a result of a combination of natural, longer term fluctuations and anthropogenic alteration of forcings. To inform about the sensitivity of natural and human systems to ongoing climate change, the chapter assesses the degree to which detected changes in such systems can be attributed to all aspects of recent climate change. For the development of adaptation policies, it is less important whether the observed changes have been caused by anthropogenic climate change or by natural climate fluctuations. Where possible, the relative importance of anthropogenic drivers of climate change is assessed as well.

\subsubsection{Scope and Goals of the Chapter}

Previous assessments, notably in the IPCC Fourth Assessment Report (AR4; Rosenzweig et al., 2007), indicated that numerous physical and biological systems are affected by recent climate change. Owing to a limited number of published studies, human systems received comparatively little attention in these assessments, with the exception of the food system, which is a coupled human-natural system. This knowledge base is growing rapidly, for all types of impacted systems, but the disequilibrium remains (see also Section 1.1.1, Figure 1-1). The great majority of published studies attribute local to regional changes in affected systems to local to regional climate change.

The objective of the assessment was to cover the growing knowledge about detection and attribution of impacts as exhaustively as possible. To improve coverage across sectors and regions, the work was linked directly to the assessments made by most other chapters of the report. This ensured that knowledge gained in the expert assessments of any given sector, system, or region found its way into this chapter. This chapter uses a consistent set of definitions for detection and attribution (elaborated in Section 18.2.1—these differ from those found in some other chapters).

This chapter first reviews methodologies and definitions for detection and attribution, including the uncertainties that are inherent in such assessments (Section 18.2). It then assesses the scientific knowledge base that has developed since the AR4, focusing on the different types of impacted systems. The assessment covers the state of knowledge across major natural (Section 18.3) and human systems (Section 18.4), based largely on the respective sectoral chapters of this report (Chapters 3 to 7, 10 to 13). Assessment in confidence of the existence and cause of impacts is made according to the definitions elaborated in Section 18.2.1.2. Based on this material, and on regional assessments mostly drawn from the regional chapters of this report (Chapters 22 to 30), an assessment is made to highlight regional impacts and also to identify the regional pattern of observed impacts around the globe (Section 18.5). A synthesis (Section 18.6) and an analysis of research and knowledge gaps (Section 18.7) conclude the chapter.

\subsubsection{Summary of Findings from the Fourth Assessment Report}

Based on Rosenzweig et al. (2007), IPCC (2007a, p. 8) reported that "observational evidence from all continents and most oceans shows that many natural systems are being affected by regional climate changes, particularly temperature increases." In particular, they highlighted several areas where this general conclusion was supported by specific conclusions that were reported with high confidence:

- Changes in snow, ice, and frozen ground had increased ground instability in mountains and other permafrost regions; these changes had led to changes in some Arctic and Antarctic ecosystems and produced increases in the number and size of glacial lakes.

- Some hydrological systems had been affected by increased runoff and earlier spring peak discharges; in particular many glacier- and snow-fed rivers and lakes had warmed, producing changes in their thermal structures and water quality.

- Spring events had appeared earlier in the year so that some terrestrial ecosystems had moved poleward and upward; these shifts in plant and animal ranges were attributed to recent warming.

- Shifts in ranges and changes in algal, plankton, and fish abundance as well as changes in ice cover, salinity, oxygen levels, and circulation had been associated with rising water temperatures in some marine and freshwater systems.

In terms of a global synthesis, this assessment noted "that it is likely that anthropogenic warming over the last three decades has had a discernible influence on many physical and biological systems" (IPCC, $2007 a$, p. 9). Though it was based on analyses of a very large number of observational data sets, the assessment noted a lack of geographic balance in data and literature on observed changes, with marked scarcity in low- and middle-income countries.

Evidence reported for human systems was scarce. IPCC (2007a, p. 9) concluded with medium confidence only that, "other effects of regional climate change on [...] human environments are emerging, although many are difficult to discern due to adaptation and non-climatic drivers." They especially noted effects of temperature increases on agricultural and forestry management practices in the higher latitudes of the Northern Hemisphere (NH), various aspects of human health, and some human activities in snow- and glacier-dominated environments.

\subsection{Methodological Concepts for Detection and Attribution of Impacts of Climate Change}

There are substantial challenges to the detection and assessment of the impacts of climate change on natural and human systems. Virtually all 
such systems are affected by factors other than climate change. Isolating the impacts of climate change therefore requires controlling for the effects of other factors. The problem is further complicated by the ability of many systems to adapt to climate change. In this section we summarize the concepts underlying the detection and attribution of impacts of climate change and the requirements for addressing the main challenges.

\subsubsection{Concepts and Approaches}

\subsubsection{Detecting and Attributing Change in the Earth System}

Detection and attribution is concerned with assessing the causal relationship between one or more drivers and a responding system. From an analysis perspective, the Earth system can be separated into three coupled subsystems, referred to here as the climate system, the natural system, and the human system (Figure 18-1). Separation of drivers from a responding system is a crucial element of formal detection and attribution analysis. Many external drivers may influence any system, including the changing climate and other confounding factors (Hegerl et al., 2010). Each of the three subsystems affects the other two directly or indirectly. For example, the human system may directly affect the natural system through deforestation, which in turn affects the climate system through changes in albedo; this can alter surface temperatures, which in turn feed back on natural and human systems. If an observed change in the human system impacts the climate system, we call this an anthropogenic driver of climate change.

In this chapter we assess the impacts of climate change, where climate change refers to any long-term trend in climate, irrespective of its cause (see Glossary). The great majority of published scientific studies support this type of assessment only. Some studies directly address the detection of and attribution to anthropogenic climate change, relating observed impacts, via the climate, to anthropogenic emissions of greenhouse gases and other human activities. Because of the complexity of the causal chain, investigation of this relationship is exceptionally challenging (Parmesan et al., 2011). The findings from such studies are explicitly highlighted in the chapter.

\subsubsection{Concepts of Detection and Attribution of Climate Change Impacts Used in this Chapter}

"Detection of impacts" of climate change addresses the question of whether a natural or human system is changing beyond a specified baseline that characterizes its behavior in the absence of climate change (Stone et al., 2013). The baseline may be stationary or non-stationary (e.g., due to land use change), and needs to be clearly defined. This definition of the detection of climate change impacts differs from that in WGI AR5 Chapter 10 which concerns any change in a climate variable, regardless of its cause. The definition adopted here focuses explicitly
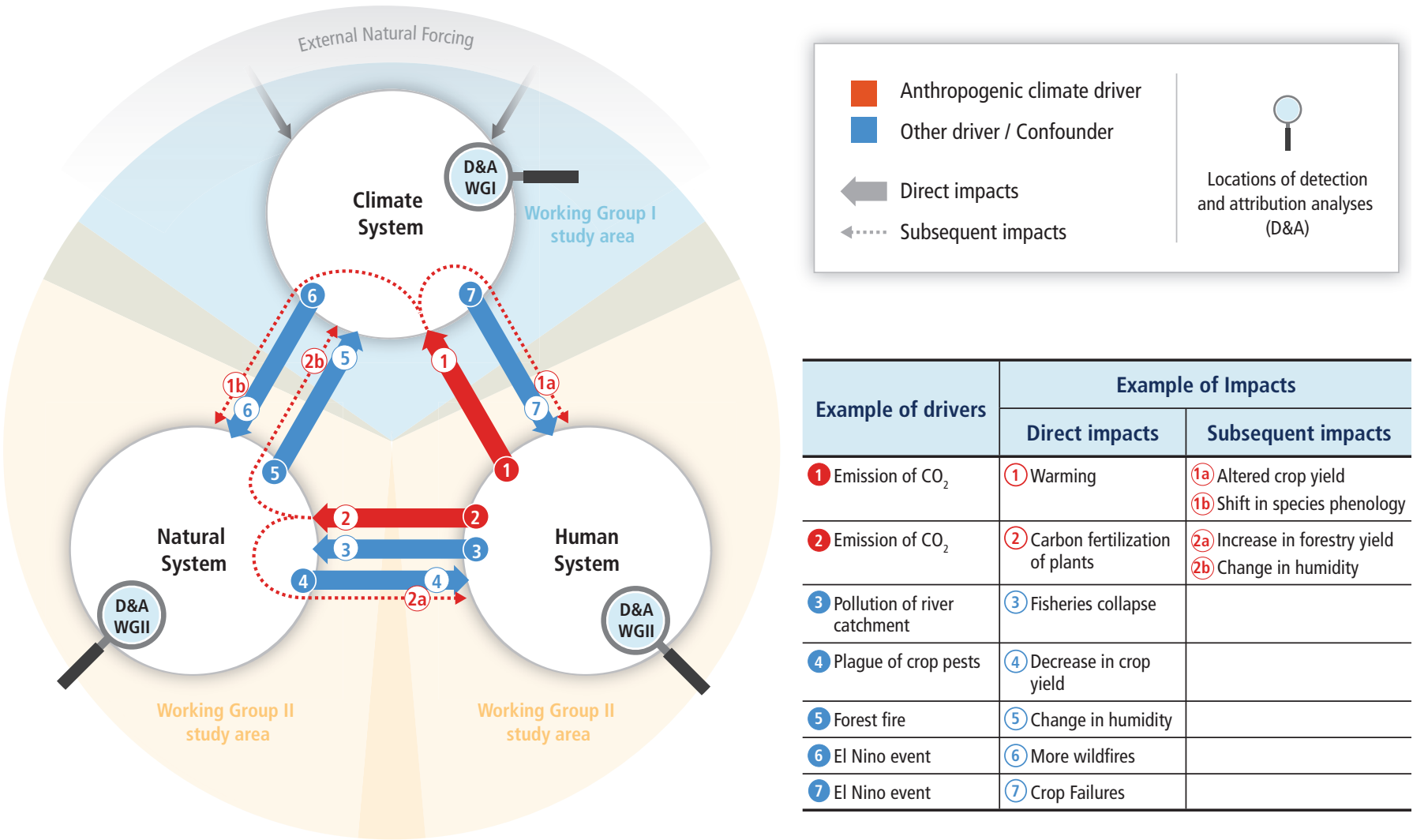

\begin{tabular}{l|l|l}
\hline \multirow{2}{*}{ Example of drivers } & \multicolumn{2}{|c}{ Example of Impacts } \\
\cline { 2 - 3 } & \multicolumn{1}{|c}{ Direct impacts } & Subsequent impacts \\
\hline (1) Emission of $\mathrm{CO}_{2}$ & (1) Warming & $\begin{array}{l}\text { (1a) Altered crop yield } \\
\text { (1D) Shift in species phenology }\end{array}$ \\
\hline 2) Emission of $\mathrm{CO}_{2}$ & $\begin{array}{l}\text { 2) Carbon fertilization } \\
\text { of plants }\end{array}$ & $\begin{array}{l}\text { (2a) Increase in forestry yield } \\
\text { (2b) Change in humidity }\end{array}$ \\
\hline $\begin{array}{l}\text { 3) Pollution of river } \\
\text { catchment }\end{array}$ & (3) Fisheries collapse & \\
\hline 4) Plague of crop pests & $\begin{array}{l}\text { (4) Decrease in crop } \\
\text { yield }\end{array}$ & \\
\hline 5) Forest fire & 5) Change in humidity & \\
\hline 6 $\mathrm{El}$ Nino event & 6) More wildfires & \\
\hline (7) El Nino event & (7) Crop Failures & \\
\hline
\end{tabular}

Figure 18-1 | Schematic of the subject covered in this chapter. The Earth system consists of three coupled and overlapping systems. Direct drivers of the human system on the climate system are denoted with a red arrow; some of these drivers may also directly affect natural systems. These effects can in turn influence other systems (dashed red arrows). Further influences of each of the systems on each other (confounding factors) that do not involve climate drivers are represented by blue arrows. Examples of drivers and their impacts are given in the table. Adapted from Stone et al. (2013). 


\section{Box 18-1 | Quantitative Synthesis Assessment of Detection and Attribution Studies in Ecological Systems}

The wealth of observations in ecological systems now permits the application of quantitative tools for synthesis assessment of detection and attribution (Root et al., 2005). These tools include associative pattern analyses (e.g., Rosenzweig et al., 2008) and regression analyses (Chen, I.C. et al., 2011), which compare expected changes due to anthropogenic climate change across multiple studies against observed changes.

Quantitative synthesis assessments have been particularly prominent in ecology, where measures of phenology (timing of seasonal events) and geographical range can be assembled across species into standardized indices (Parmesan and Yohe, 2003; Rosenzweig et al., 2008; Chen, I.C. et al., 2011; Poloczanska et al., 2013; Rosenzweig and Neofotis, 2013). Confidence in the detection of general patterns of change in these indices can increase with the number of species/ecosystems observed, the number of independent studies, the geographical distribution of these observations, the temporal depth and resolution of the data, and the representativeness of species/ecosystems and locations studied. However, increasing spatial coverage, numbers of species, and so forth does not a priori increase confidence that climate change is a more credible explanation for biological change than alternative hypotheses. Additional data can contribute to increased confidence in causal relationships, that is, attribution, in a synthesis assessment when it provides new evidence for explicit testing against a credible range of alternative hypotheses.

on the impact of climate change and not on trends related to other factors. The statement of detection is binary: an impact has or has not been detected.

"Attribution" addresses the question of the magnitude of the contribution of climate change to a change in a system. In practice, an attribution statement indicates how much of the observed change is due to climate change with an associated confidence statement. Hence, attribution requires the evaluation of the contributions of all external drivers to the system change. In this chapter we simplify the assessment of this relative contribution by specifying whether observed climate change has had a "minor role" or a "major role" in the overall change in the impacted system. A major role is assessed if the past behavior of the system would have been grossly different in the absence of the observed climate change.

\subsubsection{Challenges to Detection and Attribution}

Two broad challenges to the detection and attribution of climate change impacts relate to observations and process understanding. On the observational side, high-quality, long-term data relating to natural and human systems and the multiple factors affecting them are rare. In addition, the detection and attribution of climate change impacts requires an understanding of the processes by which climate change, in conjunction with other factors, may affect the system in question (see also Box 18-1). These processes can be nonlinear-for example, involving threshold effects (e.g., De Young and Jarre, 2009; Wassmann and Lenton, 2012)_and non-local in both space and time, involving lagged responses and trans-regional effects due, for example, to trade or migration.

Conclusions about the effect of climate change on natural and human systems in this report are based on a synthesis of findings in the scientific literature. A potential problem arises through the preferential publication of papers reporting statistically significant findings (Parmesan and Yohe, 2003). Methods exist for detecting and correcting for publication bias in formal quantitative synthesis analysis (Rothstein et al., 2005; Menzel et al., 2006), but these methods cannot be applied in all situations (Kovats et al., 2001). While the assessment in this chapter considers findings in the context of consistency across studies, regions, and similar systems, it has not been possible to quantitatively account for selection bias and to fully differentiate it from the lack of monitoring for some regions and systems.

\subsection{Detection and Attribution of Observed Climate Change Impacts in Natural Systems}

The following section provides a synthesis of findings with regard to freshwater resources, terrestrial and inland water systems, coastal systems, and oceans, which are documented in greater detail in Chapters 3, 4, 5,6 , and 30 , respectively. It also incorporates evidence from regional chapters and further available literature.

\subsubsection{Freshwater Resources}

Impacts of climate change on the hydrological cycle, and notably the availability of freshwater resources, have been observed on all continents and many islands, with different characteristics of change in different regions (Chapters 3, 22 to 29; WGI AR5 Chapters 2 and 10). Figure 18-2 presents a synthesis of confidence in detection of global scale changes in freshwater resources and related systems (notably slope stability and erosion), and their attribution to climate change. Frozen components of freshwater systems tend to show higher confidence in detection and attribution, while components that are strongly influenced by nonclimatic drivers, such as river flow, have lower confidence. 


\subsubsection{The Cryosphere}

Most components of the cryosphere (glaciers, ice sheets, and floating ice shelves; sea, lake, and river ice; permafrost and snow) have undergone significant changes during recent decades (high confidence), related to climatic forcing (high confidence; WGI AR5 Chapter 4). It is likely that there is an anthropogenic component in the changes observed in Arctic sea ice, Greenland's surface melt, glaciers, and snow cover (WGI AR5 Section 10.5). Glaciers continue to shrink worldwide, with regional variations. It is likely that a substantial part of the glacier mass loss is due to anthropogenic warming (WGI AR5 Section 10.5.2.2). Climate change has a major role in the absolute contribution of ice loss from glaciers and ice caps to sea level rise, which has increased since the early 20th century and has now been close to $1 \mathrm{~mm} \mathrm{yr}^{-1}$ for the past 2 decades (WGI AR5 Sections 4.3.3, 4.4.3), around a third of total observed sea level rise. Recent mass loss of ice sheets and glaciers has accelerated isostatic land uplift in the North Atlantic Region (Jiang et al., 2010). In several high-mountain regions, slope instabilities have occurred as a consequence of recent glacier downwasting (high confidence; Vilímek et al., 2005; Haeberli and Hohmann, 2008; Huggel et al., 2011).

The role of climate in changes in runoff decreases from major to minor as the distance from glaciers increases and other non-climatic factors become more important. Runoff from glacier areas has increased for catchments in western and southwestern China over the past several decades, and in western Canada and Europe (Collins, 2006; Zhang, Y. et al., 2008; Moore et al., 2009; Li et al., 2010; Pellicciotti et al., 2010; Stahl et al., 2010). Glacier runoff has decreased in the European Alps (Collins, 2006; Huss, 2011), in the central Andes of Chile (Casassa et al., 2009), and in the Cordillera Blanca (Baraer et al., 2012; medium confidence), a trend that has also been confirmed by qualitative observations made by local people (Bury et al., 2010; Carey et al., 2012a). For lake and river ice, there is generally high confidence in detection of, and a major role of climate change in, later freeze-up and earlier break-up over the past $100+$ years for several sites in the $\mathrm{NH}$, yet with regional differences and warmer regions showing higher sensitivities in interannual variability (Livingstone et al., 2010; Voigt et al., 2011; Weyhenmeyer et al., 2011; Benson et al., 2012). Changes in lake and river ice can have effects on freshwater ecosystems, transport and traffic over frozen lakes and rivers, and ice-induced floods during freeze-up and break-up events (Voigt et al., 2011). Some evidence exists in Europe that ice-jam floods were reduced during the last century due to reduced freshwater freezing (Svensson et al., 2006).

The rate of Arctic sea ice decline has increased significantly during the first decade of the 21st century, due to warming (WGI AR5 Section 4.2.2). It is very likely that at least some of the decline in Arctic sea ice extent can be attributed to anthropogenic climate forcing (WGI AR5 Section 10.5.1). Observations by Inuit people in the Canadian Arctic confirm with high confidence the instrumental observations on the various changes of sea ice (see Box 18-5). Antarctic sea ice has slightly increased over the past 30 years, yet with strong regional differences (WGI AR5 Section 4.2.3).

Combined in situ and satellite observations indicate a decline of $8 \%$ in NH spring snow cover extent since 1922 (WGI AR5 Section 4.5.2). A limited number of studies indicate an anthropogenic influence on snow cover reduction (high confidence; WGI AR5 Section 10.5.3), including a significant contribution of anthropogenic climate forcing on changes in snow pack and runoff timing between 1950 and 1999 in the western USA (Table 18-6; Barnett et al., 2008).

Climate change generally exerts a major role on permafrost changes. Widespread permafrost warming and thawing, and active layer thickening

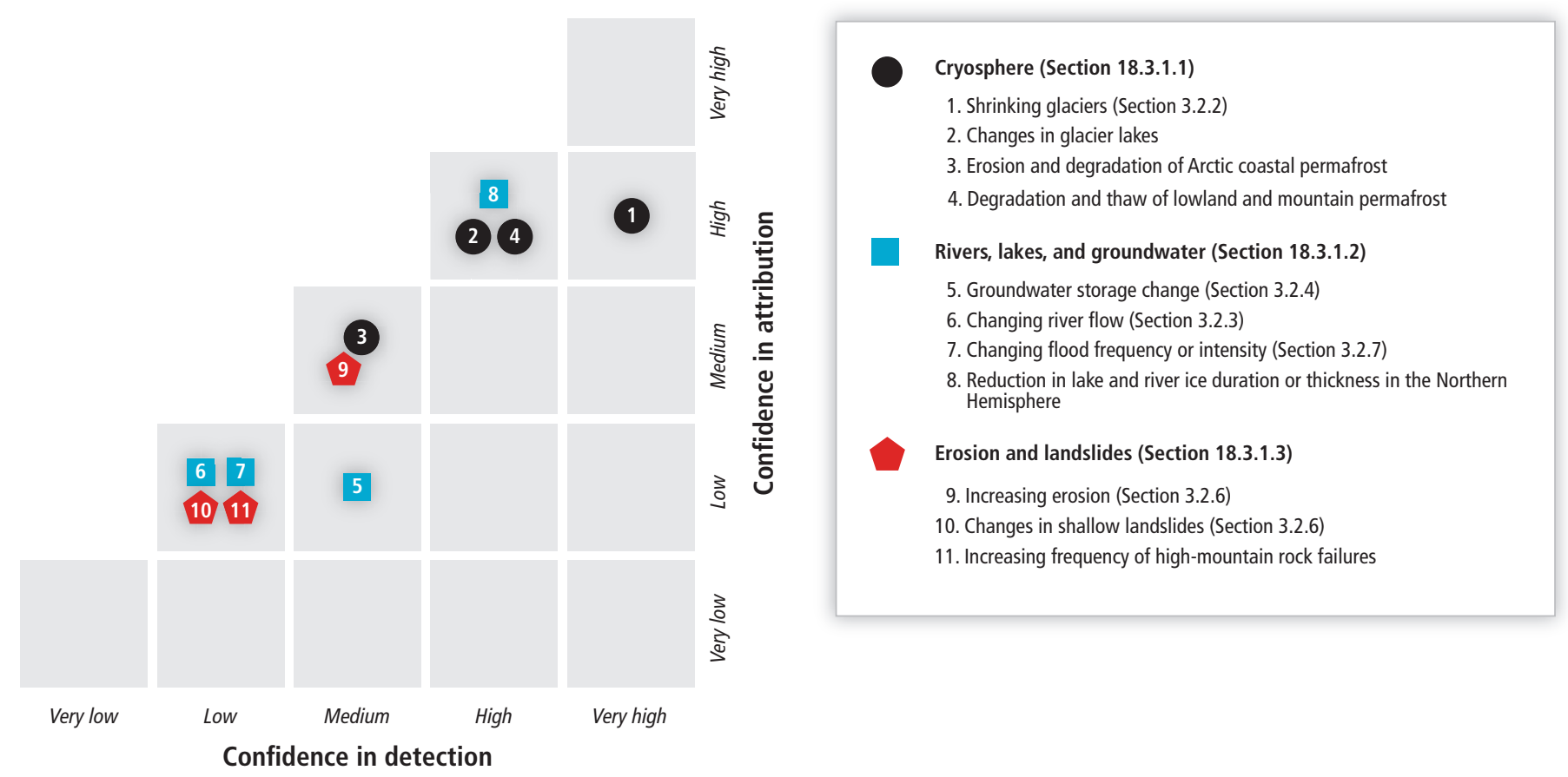

Figure 18-2 | Assessment of confidence in detection of observed climate change impacts in global freshwater systems over the past several decades, with confidence in attribution of a major role of climate change, based on expert assessment contained in Section 18.3.1 and augmented by subsections of Chapter 3 as indicated. 
in both high-latitude lowlands and high-elevation mountain regions, have been observed over the past decades (high confidence; WGI AR5 Section 4.7.2). Climate change impacts have been related to permafrost changes, including an increase of flow speed of rock glaciers and debris lobes in the European Alps and Alaska (high confidence), resulting in rockfall, debris flows, and potential hazards to transport and energy systems (Kääb et al., 2007; Delaloye et al., 2010; Daanen et al., 2012), expansion, deepening and higher dynamics of thermokarst lakes and ponds in the Arctic (Rowland et al., 2010), and a doubled erosion rate of Alaska's northern coastline over the past 50 years (high confidence; Section 18.3.3.1, Table 18-8; Mars and Houseknecht, 2007; Karl et al., 2009; Forbes, 2011). Expansion of channel networks (Toniolo et al., 2009), increased river bank erosion (Costard et al., 2007), and an increase in hillslope erosion and landsliding in northern Alaska since the 1980s (Gooseff et al., 2009) have all been related to climate. Warming and thawing of permafrost in Alaska has adversely affected transport and energy structures and their operation (Karl et al., 2009). Feedbacks and interactions complicate detection of drivers and effects. For example, drying of land surface due to permafrost degradation may cause an increase in wildfires, in turn resulting in a loss of ground surface insulation and change in surface albedo that accelerates permafrost thawing (Rowland et al., 2010; Forkel et al., 2012).

\subsubsection{The Regional Water Balance}

The regional water balance is the net result of gains (precipitation, ice and snow melt, river inflow, and groundwater recharge) and losses (evapotranspiration, water use and river outflow, and groundwater discharge). Impacts of climate change include reduced availability of freshwater for use (one of the variables defining drought) or excess water (floods). Evapotranspiration, being a function of solar radiation, surface temperature, vegetation cover, soil moisture, and wind, is affected by the changing climate, but also by changing vegetation processes and land cover. At the global scale, human influence has contributed to largescale changes in precipitation patterns over land and, since the mid20th century, in extreme precipitation (medium confidence; WGI AR5 Section 10.6.1.2; Min et al., 2011). More locations worldwide have experienced an increase than a decrease in heavy rainfall events, yet with significant regional and seasonal variations (Seneviratne et al., 2012; Westra et al., 2013). In some regions, however, there is medium confidence that anthropogenic climate change has affected streamflow and evapotranspiration (WGI AR5 Section 10.3.2.3).

Change in river flow is a direct indicator of a changing regional water balance. Globally, about one-third of the top 200 rivers (ranked by river flow) show statistically significant trends during 1948-2004, with more rivers having reduced flow (45) than rivers with increased flow (Dai et al., 2009). Regional reductions in precipitation in southwestern South America are primarily due to internal variability (Dai, 2011; see also Section 27.2.1.1). River floods, defined as impacts caused by the overtopping of river banks and levées, have shown statistically significant increasing and decreasing trends in some regions. The role of climate change in these changes is uncertain, as they may reflect decadal climate variability and be affected by other confounding factors such as human alteration of river channels and land use (Section 3.2.7). In regions with detected increases in heavy rainfall events (North America,
Europe), both increases and decreases in floods have been found (medium confidence in detection; Petrow and Merz, 2009; Villarini et al., 2009). In the UK, flood risk has increased due to anthropogenic forcing for events comparable to the 2000 floods (Kay et al., 2011; Pall et al., 2011; see also Section 18.4.3).

Expanding or new lakes as a result of ice melt at the margin of many shrinking glaciers in the Alps of Europe, Himalayas, Andes, and other mountain regions have altered the risk of glacier lake outburst floods (GLOFs) and required substantial risk reduction measures in the 21st century (Huggel et al., 2011; Carey et al., 2012b). Though there is no evidence for a change in frequency or magnitude of GLOFs (Seneviratne et al., 2012), climate change has had a major role in the substantial increase in glacial lake area in the eastern Himalaya region between 1990 and 2009 (Gardelle et al., 2011), and the similarly strong increase in lake numbers in the Andes of Peru in the second half of the 20th century (Carey, 2005), and in northern Patagonia from 1945 to 2011 (Loriaux and Casassa, 2013; high confidence in detection). New glacier lakes are not only an additional source of floods but also have become a tourist attraction, led to additional infrastructure, and stimulated assessment of potential for hydropower generation (Terrier et al., 2011).

Since the 1950s some regions of the world have experienced more intense and longer droughts, although a global trend currently cannot be established (Seneviratne et al., 2012; see also Section 3.2.2 and WGI AR5 Section 2.6.2.3). Longer drought periods have affected groundwater recharge (Leblanc et al., 2009; Taylor et al., 2013), but changes in groundwater storage are generally difficult to attribute to climate change, due to confounding factors from human activities (Table 3-1; Rodell et al., 2009; Taylor et al., 2013). Likewise, confounding factors do not permit attribution of observed changes in water quality to climate change (Kundzewicz and Krysanova, 2010; see also Section 3.2.5).

\subsubsection{Erosion, Landslides, and Avalanches}

Erosion and landsliding typically increase in phase with deglaciation in mountain areas (Ballantyne, 2002; Korup et al., 2012), and there is emerging evidence for this to occur during contemporary deglaciation (Schneider et al., 2011; Uhlmann et al., 2013). In the western Himalaya, sediment flux has increased (medium confidence; Wulf et al., 2012) and been related to hydrologic extreme events over the past 60 years (low confidence; Malik et al., 2011), with important consequences for hydropower schemes. In China, a drastic decrease of sediment load in the Yangtze River was observed since the 1980s. There have been local variations in precipitation and runoff since 1950, but changes in sediment load are attributed primarily to more than 50,000 dams and vegetation changes (medium confidence; $X u$ et al., 2008). There is clear evidence for decline in sediment load in the Zhujiang (Pearl River) basin since the early 1990s (Zhang, S. et al., 2008).

In the European Alps, no clear evidence exists so far for any change in frequency of shallow landslides and debris flows from recently deglaciated mountain areas (Jomelli et al., 2004; Stoffel and Huggel, 2012). In some cases climate change has had a major role in influencing frequency and magnitude of alpine shallow landslides and debris flows 
by altering sediment yield, for example, from rockfall or disintegration of rock glaciers (low confidence; Lugon and Stoffel, 2010).

Glacier shrinkage, permafrost degradation, and high-temperature events have contributed to many high-mountain rock slope failures since the 1990s (medium confidence in major role of climate change; Allen et al., 2010; Ravanel and Deline, 2011; Schneider et al., 2011; Fischer et al., 2012; Huggel et al., 2012a). Rock slope failures have increased over this period in the Western Alps of Europe (high confidence), the New Zealand Alps (medium confidence), and globally (low confidence). Cascading processes of permafrost and ice-related landslides impacting lakes and downstream areas have been observed in many high-mountain regions, causing major damages and risk reduction measures (high confidence), with climate change exerting a major role (medium confidence; e.g., Xin et al., 2008; Bajracharya and Mool, 2009; Künzler et al., 2010; Carey et al., 2012a; Huggel et al., 2012b). For landslide types other than the above, there is no clear evidence that their frequency or magnitude has changed over the past decades (Huggel et al., 2012b). In general, detection of changes in the occurrence of landslides is complicated by incomplete inventories, both in time and space, and inconsistency in terminology.

Physical understanding suggests that climate change has a major role in changes of snow avalanche activity but no such changes have been reported so far (medium confidence; Laternser and Schneebeli, 2002; Voigt et al., 2011), except for the French Alps (Eckert et al., 2013; medium confidence in detection). The detection of changes in snow avalanche impacts, such as fatalities and property loss, is difficult over the past decades because of changes in snow sport activities and avalanche defense measures.

\subsubsection{Terrestrial and Inland Water Systems}

As documented by previous IPCC reports (notably Rosenzweig et al., 2007), climate-driven changes in terrestrial and inland water systems are widespread and numerous. Confidence in such detection of change is often very high, reflecting high agreement among many independent sources of evidence of change, and robust evidence that changes in ecosystems or species are outside of their natural variation. Confidence in attribution to climate change is also often high, due to process understanding of responses to climate change, or strong correlations with climate trends and where confounding factors are understood to have limited importance (Sections 4.3.2, 4.3.3, Figure 4-4). The scientific literature in this field is growing quickly; detailed traceability is provided in Chapter 4.

Organisms respond to changing climate in a multitude of ways, including through their phenology (the timing of key life history events such as flowering in plants or migration of birds), productivity (the assimilation of carbon and nutrients in biomass), spatial distribution, mortality/ extinction, or by invading new territory. Noticeable changes may occur at the level of individual organisms, ecosystems, landscapes, or by modification of entire biomes. Organisms and ecosystems are adapted to a variable environment, and they are capable of adapting to gradual change to some degree. Assessing confidence in the detection of such change therefore involves assumptions about natural variability in these ecosystems, while assessment of confidence in the attribution of detected change to climate drivers (or carbon dioxide $\left(\mathrm{CO}_{2}\right)$ ) implies the assessment of confounding drivers such as pollution or land use change.

\subsubsection{Phenology}

Since the AR4 there has been a further substantial increase in observations, showing that hundreds of (but not all) species of plants and animals have changed functioning to some degree over the last decades to centuries on all continents (high confidence due to robust evidence but only medium agreement across all species; Section 4.3.2.1; Menzel et al., 2006; Cook et al., 2012b; Peñuelas et al., 2013). New satellite-based analyses confirm earlier trends, showing, for example, that the onset of the growing season in the NH has advanced by 5.4 days from 1982 to 2008 and its end has been delayed by 6.6 days (Jeong et al., 2011). Significant changes have been detected, by direct observation, for many different species, for example, for amphibians (e.g., Phillimore et al., 2010), birds (e.g., Pulido, 2007; Devictor et al., 2008), mammals (e.g., Adamík and Král, 2008), vascular plants (e.g., Cook et al., 2012a), freshwater plankton (Adrian et al., 2009), and others (Section 4.3.2.1); a number of new meta-analyses have been carried out summarizing this literature (e.g., Cook et al., 2012a). Attribution of these changes to climate change is supported by more refined analyses that consider also the regional changes in several variables such as temperature, growing season length, precipitation, snow cover duration, and others, as well as experimental evidence (Xu et al., 2013). The high confidence in attributing many observed changes in phenology to changing climate is a result of these analyses, as well as of improved knowledge of confounding factors such as land use and land management (see also Section 4.3.2.1).

\subsubsection{Productivity and Biomass}

Many terrestrial ecosystems are now net sinks for carbon over much of the $\mathrm{NH}$ and also in parts of the Southern Hemisphere (high confidence; see also Sections 4.3.2.2-3). This is shown, for example, by inference from atmospheric chemistry, but also by direct observations of increased tree growth in many regions including Europe, the USA, tropical Africa, and the Amazon. During the decade 2000 to 2009, global land net primary productivity was approximately $5 \%$ above the preindustrial level, contributing to a net carbon sink on land of $2.6 \pm 1.2 \mathrm{PgC} \mathrm{yr}^{-1}$ (Section 4.3.2.2;WGI AR5 6.3.2.6; for primary literature, see also Raupach et al., 2008; Le Quéré et al., 2009), despite ongoing deforestation. Forests have increased in biomass for several decades in Europe (Luyssaert et al., 2010) and the USA (Birdsey et al., 2006). These trends are in part due to nitrogen deposition, afforestation, and altered land management which makes direct attribution of the increase to climate change difficult. The degree to which rising atmospheric $\mathrm{CO}_{2}$ concentrations contribute to this trend remains a particularly important source of uncertainty (Raupach et al., 2008). Canadian managed forests increased in biomass only slightly during 1998-2008, because growth was offset by significant losses due to fires and beetle outbreaks (Stinson et al., 2011). In the Amazon forest biomass has generally increased in recent decades, dropping temporarily after a drought in 2005 (Phillips et al., 2009). A global analysis of long-term measurements suggests that soil respiration has increased over the past 2 decades by approximately 
0.1 $\mathrm{PgC} \mathrm{yr}^{-1}$, some of which may be due to increased productivity (BondLamberty and Thomson, 2010). Man-made impoundments in freshwater ecosystems represent an increasing and short-lived additional carbon store with conservative annual estimates of 0.16 to $0.2 \mathrm{PgC} \mathrm{yr}^{-1}$ (Cole et al., 2007).

\subsubsection{Species Distributions and Biodiversity}

Each species responds differently to a changing environment; therefore the composition of species, genotypes, communities, and even ecosystems varies in different ways from place to place, in response to climate change. The consequences are changing ranges of species, changing composition of the local species pool, invasions, mortality, and ultimately extinctions. For different species and species groups, detected range shifts vary, and so do the confidence of detection and the degree of attribution to climate change. The number of species studied has considerably increased since the AR4. Overall, many terrestrial species have recently moved, on a global average, $17 \mathrm{~km}$ poleward and $11 \mathrm{~m}$ up in altitude per decade (e.g., Europe, North America, Chile, Malaysia), which corresponds to predicted range shifts due to warming (Chen, I.C. et al., 2011) and is two to three times faster than previous estimates (Parmesan and Yohe, 2003; Fischlin et al., 2007), with high confidence in detection. Europe forest species are moving up in altitude, probably due to climate warming at the end of the 20th century (Gehrig-Fasel et al., 2007; Lenoir et al., 2008). Species with short life cycles and high dispersal capacity - such as butterflies (high confidence in a major role of climate change) - are generally tracking climate more closely than longer-lived species or those with more limited dispersal such as trees (Devictor et al., 2012; medium confidence in a major role of climate change). There are many less well-studied species for which detection of change and its attribution to climate change are more uncertain.

Changes in abundance, as measured by changes in the population size of individual species or shifts in community structure within existing range limits, have occurred in response to recent global warming (Thaxter et al., 2010; Bertrand et al., 2011; Naito and Cairns, 2011; Rubidge et al., 2011; Devictor et al., 2012; Tingley et al., 2012; Vadadi-Fülöp et al., 2012; Cahill et al., 2013; Ruiz-Labourdette et al., 2013), but owing to confounders, confidence in a major role of climate change is often low. Across the world, species extinctions are at or above the highest rates of species extinction in the fossil record (high confidence; Barnosky et al., 2011). However, only a small fraction of observed species extinctions have been attributed to climate change-most have been ascribed to non-climatic factors such as invasive species, overexploitation, or habitat loss (Cahill et al., 2013). For those species where climate change has been invoked as a causal factor in extinction (such as for the case of Central American amphibians), there is low agreement among investigators concerning the importance of climate variation in driving extinction and even less agreement that extinctions were caused by climate change (Pounds et al., 2006; Kiesecker, 2011). Confidence in the suggested attribution of extinctions across all species to climate change is very low (see also Section 4.3.2.5).

Species invasions have increased over the last several decades worldwide, notably in freshwater ecosystems (very high confidence), often causing biodiversity loss or other negative impacts. There is only low confidence that species invasions have generally been assisted by recent climatic trends because of the overwhelming importance of human facilitated (intentional or non-intentional) dispersal in the transfer from the area of origin. Once established in a new environment, many introduced species have recently become invasive due to climate change (medium to high confidence, depending on the taxon; see also Section 4.2.4.6).

\subsubsection{Impacts on Major Systems}

Field and satellite measurements indicate substantial changes in freshwater and terrestrial ecosystems (often linked to permafrost thawing) in many areas of the Arctic tundra (high confidence; Hinzman et al., 2005; Axford et al., 2009; Jia et al., 2009; Post et al., 2009; Prowse and Brown, 2010; Myers-Smith et al., 2011; Walker et al., 2012). Vegetation productivity has systematically increased over the past few decades in both North America and northern Eurasia (Goetz et al., 2007; Jia et al., 2009; Elmendorf et al., 2012). Most subpopulations of the polar bear are declining in number (Vongraven and Richardson, 2011). These changes correspond to expectations, based on experiments, models, and paleoecological responses to past warming, of broad-scale boreal forest encroachment into tundra, a process that takes decades and that would have very large impacts on ecosystem structure and function. The particular strength of warming over the last 50 years for most of the Arctic further facilitates attribution of a major role of climate change (high confidence). The change affects a significant area of the tundra biome and can be considered an early warning for an ongoing regime shift (Section 4.3.3.4, Figure 4-4).

For the boreal forest, increases in tree mortality are observed in many regions, including widespread dieback related to insect infestations and/or fire disturbances in North America (Fauria and Johnson, 2008; Girardin and Mudelsee, 2008; Kasischke et al., 2010; Turetsky et al., 2010; Wolken et al., 2011) and in Siberia (Soja et al., 2007), but there is low confidence in detection of a global trend. Many areas of boreal forest have experienced productivity declines (high confidence; Goetz et al., 2007; Parent and Verbyla, 2010; Beck and Goetz, 2011), related to warming-induced drought, specifically the greater drying power of air (Williams et al., 2012), inducing photosynthetic down-regulation of boreal tree species not adapted to the warmer conditions (Welp et al., 2007; Bonan, 2008). Conversely, productivity has increased along the boreal-tundra ecotone where more mesic (moist) conditions may be generating the expected warming-induced positive growth response (McGuire et al., 2007; Goldblum and Rigg, 2010; Beck and Goetz, 2011). Overall, these multiple impacts in the boreal forest biome can be considered an early warning for an ongoing regime shift only with low confidence (Section 4.3.3.1.1, Figure 4-4). Many of the aforementioned changes take place in the tundra-boreal ecotone, affecting both biomes significantly (Box 4-4, Figure 4-10).

In tropical forests, climate change effects are difficult to identify against the confounding effects of direct human influence as is well illustrated for the Amazon forest (Davidson et al., 2012) but also applies elsewhere. Since AR4, there is new evidence of more frequent severe drought episodes in the Amazon region that are associated with observed sea 
surface temperature increases in the tropical North Atlantic (medium confidence; Marengo et al., 2011a). There is low confidence, however, that these changes can be attributed to climate change (Section 4.3.3.1.3). There is medium confidence that tree mortality in the Amazon region has increased due to severe drought and increased forest fire occurrence and low confidence that this can be attributed to warming (Section 4.3.3.1.3, Figures 4-4, 4-8).

In freshwater ecosystems of most continents and climate zones, rising temperatures have been linked to shifts in invertebrate and fish community composition, especially in headwater streams where species are more sensitive to warming (Brown et al., 2007; Durance and Ormerod, 2007; Chessman, 2009; see also Section 4.3.3.3; high confidence in detection, low confidence in a major role of climate change due to numerous confounding factors). Long-term shifts in macroinvertebrate communities have been observed in European lakes where temperatures have increased (Burgmer et al., 2007).

\subsubsection{Coastal Systems and Low-Lying Areas}

Coastal systems are influenced by many anthropogenic and natural processes. Important climate-related drivers include changes in ocean temperature, salinity, and pH; and sea level (see Table 5-2). In coastal waters, both annual and seasonal changes in temperature tend to be larger than the average rate for the open ocean (Section 5.3.3). Sea surface temperatures have increased significantly during the past 30 years along more than $70 \%$ of the world's coastlines, with large spatial and seasonal variation, and the frequency of extreme temperature events in coastal waters has changed in many areas (Lima and Wethey, 2012). Seawater $\mathrm{pH}$ spans larger ranges and exhibits higher variability near coastlines, and anthropogenic ocean acidification can be enhanced or reduced by coastal geochemical processes (Borges and Gypens, 2010; Feely et al., 2010; Duarte et al., 2013, see also Box CC-OA).

While it is likely that extreme sea levels have increased globally since the 1970s, mainly as a result of mean sea level rise due in part to anthropogenic warming (WGI AR5 Sections 3.7.5-6, 10.4.3), local sea level trends are also influenced by factors such as regional variability in ocean and atmospheric circulation, subsidence, isostatic adjustment, coastal erosion, and coastal modification (see also Section 5.3.2). As a consequence, the detection of the impact of climate change in observed changes in relative sea level remains challenging (Nicholls et al., 2007, 2009; Menéndez and Woodworth, 2010). An exception is lower sea level in regions of isostatic rebound in response to reduced ice cover due to climate change (Kopp et al., 2010; Tamisiea and Mitrovica, 2011). In these regions, climate change has played a major role in the lowering sea level (medium confidence).

\subsubsection{Shoreline Erosion and Other Coastal Processes}

Throughout the world, the rate of shoreline erosion is increasing (Section 5.4.2.1). While processes related to climate change, such as rising mean sea levels (Leatherman et al., 2000; Ranasinghe and Stive, 2009), more frequent extreme sea levels (Woodworth et al., 2011), or permafrost degradation and sea ice retreat (Forbes, 2011) can be expected to enhance global erosion, there are multiple drivers involved in shoreline erosion that are unrelated to climate change including long shore sediment transport; the diversion of sediments by dams; and subsidence due to resource extraction, mining, and coastal engineering and development (see also Table 5-3). Owing to the fragmentary nature of the information available, and to the multiple natural and anthropogenic stressors contributing to coastal erosion, confidence in detection of a climate change contribution to observed shoreline changes is very low, with the exception of polar regions (Table 18-8; Mars and Houseknecht, 2007; Forbes, 2011).

Coastal lagoons and estuaries, as well as deltas, are highly susceptible to alterations of sediment input and accumulation (Syvitski et al., 2005; Ravens et al., 2009), processes that can be influenced by climate change via changes in mean and extreme sea levels, storminess, and precipitation. However, the primary drivers of widespread observed changes in those systems are human drivers other than climate change so that there is very low confidence in the detection of impacts related to climate change (Section 5.4.2).

Coastal aquifers are crucial for the water supply of densely populated coastal areas, in particular in small island environments and dry climates. Aquifer recharge is sensitive to changes in temperature and precipitation, and rising sea levels and saltwater overwash from storm surges can contribute to saline intrusion into groundwater (Post and Abarca, 2010; Terry and Falkland, 2010; White and Falkland, 2010; see also Section 29.3.2, Table 18-8). However, groundwater extraction for coastal settlements and agriculture is the main cause for widely observed groundwater degradation in coastal aquifers (e.g., White et al., 2007a; Barlow and Reichard, 2010). It is not yet possible to detect the impact of climate change on coastal aquifers with any degree of confidence (Rozell and Wong, 2010; White and Falkland, 2010).

Changes in water column mixing have combined with other factors such as nutrient loading to drive down oxygen concentrations and increase the number and extent of hypoxic zones (Vaquer-Sunyer and Duarte, 2011). These zones are characterized by very low oxygen and high $\mathrm{CO}_{2}$ levels and, in some cases, exert strong local and regional effects on marine biota such as distribution shifts, habitat contraction or loss, and fish kills (Diaz and Rosenberg, 2008). The operation of other factors makes the detection of a climate change impact on the frequency, distribution, and intensity of hypoxia possible with only medium confidence and it is difficult to assess the relative magnitude of this impact (see Table 18-1).

\subsubsection{Coastal Ecosystems}

Coastal habitats and ecosystems experience cumulative impacts of land- and ocean-based anthropogenic stressors (Halpern et al., 2008). Most coral reefs, seagrass beds, mangroves, rocky reefs, and shelves have undergone substantial changes over the course of the last century. Fishing and other extractive activities, land use changes, and pollution have been responsible for a large proportion of these historical changes (Lotze et al., 2006). Biological responses to changes in the temperature, chemistry, and circulation of the ocean are complex and often interact with other anthropogenic factors. 


\section{Box 18-2 | Attribution of Mass Coral Bleaching Events to Climate Change}

A critical source of energy for the maintenance and growth of coral is provided by symbiotic brown algae. Coral bleaching occurs when these symbionts leave their host. Bleaching events have deleterious impacts on corals and, depending on their severity and duration, can cause death. It is known that thermal stress can trigger coral bleaching (Muscatine, 1986; Hoegh-Guldberg and Smith, 1989; Jones et al., 1998). Mass bleaching events that affect entire reefs or coastal regions can occur when local or regional temperatures exceed the typical summer maximum for a period of a few weeks (Hoegh-Guldberg, 1999; Baker et al., 2008; Strong et al., 2011). The effect of elevated temperature is exacerbated by strong solar irradiance (Hoegh-Guldberg, 1999).

Since 1980, mass coral bleaching events have occurred throughout the tropics and subtropics at a rate without precedent in the literature (see also Boxes CC-CR and CC-OA, and Section 5.4.2.4). These events have often been followed by mass mortality (HoeghGuldberg, 1999; Baker et al., 2008). In the very warm year of 1998, for example, mass bleaching occurred in almost every part of the tropics and subtropics and resulted in the loss of a substantial fraction of the world's corals (Wilkinson et al., 1999). A large-scale bleaching event also occurred in the Caribbean during 2005 (Eakin et al., 2010).

Declining water quality, coastal development, increased fishing, and even tourism have also been implicated in the decline of coral communities over the past 50 years (Bryant et al., 1998; Gardner et al., 2003; Bruno and Selig, 2007; Sheppard et al., 2010; Burke et al., 2011; De'ath et al., 2012). However, given the scope of recent mass bleaching events, their co-occurrence with elevated temperatures, and a physiological understanding of the role of temperature in bleaching, there is very high confidence in the detection of the impact of climate change and high confidence in the finding that climate change has played a major role.

Coral reefs have been degraded due both to local anthropogenic factors such as fishing, land use changes, and pollution and to ocean warming related to climate change and also possibly to acidification (see Box (C-CR). Over the past 30 years, mass coral bleaching has been detected with very high confidence on all coasts, and warming is a major contributor (high confidence; for further discussion see Boxes 18-2, CC-OA).

Changes in abundance and distribution of rocky shore species have been observed since the late 1940s in the Northeast Atlantic (Hawkins et al., 2008), and the role of temperature has been demonstrated by experiments and modelling (Poloczanska et al., 2008; Wethey and Woodin, 2008; Peck et al., 2009; Somero, 2012; see also Section 5.4.2.2). Globally, the ranges of many rocky shore species have shifted up to $50 \mathrm{~km}$ per decade, much faster than most recorded shifts of terrestrial species (Helmuth et al., 2006; Poloczanska et al., 2013; see also Box 18-3). However, distinguishing the response of these communities to climate change from those due to other natural and anthropogenic causes is challenging. Weak warming, overriding effects of confounding factors, or biogeographic barriers can explain the fact that geographical distribution of some species did not change over the past decades (Helmuth et al., 2002, 2006; Rivadeneira and Fernández, 2005; Poloczanska et al., 2011).

Ocean warming has contributed to observed range shifts in vegetated coastal habitats such as coastal wetlands, mangrove forests and seagrass meadows (Section 5.4.2.3). Poleward expansion of mangrove forests, consistent with expected behavior under climate change, has been observed in the Gulf of Mexico (Perry and Mendelssohn, 2009; Comeaux et al., 2012; Raabe et al., 2012) and New Zealand (Stokes et al., 2010). High temperatures have impacted seagrass biomass in the Atlantic Ocean (Reusch et al., 2005; Díez et al., 2012; Lamela-Silvarrey et al., 2012), the Mediterranean Sea (Marbà and Duarte, 2010), and Australian waters (Rasheed and Unsworth, 2011). Extreme weather events also contributed to the overall degradation of seagrass meadows in a Portuguese estuary (Cardoso et al., 2008).

Decline in kelp populations attributed to ocean warming has occurred off the north coast of Spain (Fernández, 2011), as well as in southern Australia, where the poleward range expansion of some herbivores have also contributed to observed kelp decline (Ling, 2008; Ling et al., 2009a,b; Johnson et al., 2011; Wernberg et al., 2011a). The spread of subtropical invasive macroalgal species (e.g., Lima et al., 2007) may be adding to the stresses temperate seagrass meadows experience from ocean warming. Extreme temperature events can alter marine and coastal communities, as shown, for example, for the European 2003 heat wave (Garrabou et al., 2009), and the early 2011 heat wave off the Australian west coast (Wernberg et al., 2012).

In summary, there is high confidence in the detection of the impact of climate change on the abundance and distribution of a range of coastal species and medium confidence that climate change has played a major role in many cases. In specific cases, such as the decline of salt marshes and mangroves, the impact of climate change has been detected with very low confidence owing to the overriding effect of land use changes, pollution, and other factors unrelated to climate change. 


\subsubsection{Coastal Settlements and Infrastructure}

Total damages from coastal flooding have increased globally over the last decades (high confidence); however, with exposure and subsidence constituting the major drivers, confidence in detection of a climate change impact is very low (Seneviratne et al., 2012, see also Sections 5.4.3.2, 5.4.4).

Recent global (e.g., Menéndez and Woodworth, 2010; Woodworth et al., 2011) and regional (e.g., Marcos et al., 2009; Haigh et al., 2010, 2011) studies have found increases in extreme sea levels consistent with mean sea level trends (see also Table 5-2), indicating that the increasing frequency of extreme water levels affecting coastal infrastructures observed so far is related to rising mean sea level rather than to changes in the behavior of severe storms. While vulnerability of coastal settlements and infrastructure to future climate change, in particular sea level rise and coastal flooding, is widely accepted and well documented (see Section 5.5), there is a shortage of studies discussing the role of climate change in observed impacts on coastal systems.

Increases in saltwater intrusion and flooding have been observed in low-lying agricultural areas of deltaic regions and small islands, but the contribution of climate change to this is not clear (e.g., Rahman et al., 2011; see also Sections 5.4.2.5, 5.4.3.3). While both climate change impacts on physiological and ecological properties of fish (e.g., Barange and Perry, 2009; see also Section 18.3.4) and vulnerability of coastal communities and fisherfolks to climate fluctuations and change (Badjeck et al., 2010; Cinner et al., 2012) are well established in the literature, there is limited evidence for observed effects of climate change on coastal fishery operations (see also Section 18.4.1.2).

\subsubsection{Oceans}

Since 1970 , ocean temperatures have increased by around $0.1^{\circ} \mathrm{C}$ per decade in the upper $75 \mathrm{~m}$ and approximately $0.015^{\circ} \mathrm{C}$ per decade at $700 \mathrm{~m}$ (see Section 30.3.1.1). It is very likely that the increase in global ocean heat content observed in the upper $700 \mathrm{~m}$ since the 1970s has a substantial contribution from anthropogenic forcing (WGI AR5 Section 10.4.1).

The increased flux of $\mathrm{CO}_{2}$ from the atmosphere to the ocean has reduced the average $\mathrm{pH}$ of sea water by about $0.1 \mathrm{pH}$ units over the past century, with the greatest reduction occurring at high latitudes (see also Box CC$\mathrm{OA})$. These changes have been attributed to increases in the atmospheric concentration of greenhouse gases as result of human activities (very high confidence; WGI AR5 Section 10.4.4). Changes in wind speed, upwelling, water column stratification, surface salinity, ocean currents, and oxygen depth profile have also been been detected with at least medium confidence (WGI AR5 Chapter 3; Figures 30-5, 30-6).

Changes in the physical and chemical nature of ocean environments are predicted to have impacts on marine organisms and ecosystems, with many already having been observed across most ocean regions (Sections 6.2-3, 30.4-5). However, the detection of these predicted changes and the assessment of the role of climate change in them are complicated by the influence of long-term variability such as the Pacific Decadal Oscillation (PDO) and the Atlantic Multi-decadal Oscillation (AMO). The fragmentary nature of ocean observations and the influence of confounding factors such as fishing, habitat alteration, and pollution also represent significant challenges to detection and attribution (Hoegh-Guldberg et al., 2011; Parmesan et al., 2011; see also Box 18-3).

Table 18-1 | Observed changes in ocean system properties and their effects, with confidence levels for the detection of the effect of climate change and an assessment of the magnitude of its role.

\begin{tabular}{|c|c|c|c|c|c|}
\hline \multirow{2}{*}{ Process } & \multicolumn{2}{|c|}{ Confidence in } & \multirow{2}{*}{ Role } & \multirow{2}{*}{ Context } & \multirow{2}{*}{ Reference } \\
\hline & Detection & Attribution & & & \\
\hline $\begin{array}{l}\text { Impacts of ocean acidification } \\
\text { on pelagic marine biota }\end{array}$ & Low & Very low & Minor & $\begin{array}{l}\text { For example, reduction in foraminiferan, coccolithophores, and pteropod shell } \\
\text { weight. Attribution supported by experimental evidence and physiological } \\
\text { knowledge. }\end{array}$ & 1 \\
\hline $\begin{array}{l}\text { Expansion of midwater } \\
\text { hypoxic zones }\end{array}$ & Medium & Low & Minor & $\begin{array}{l}\text { Oxygen minimum zones caused by enhanced stratification and bacterial } \\
\text { respiration due to effects of warming }\end{array}$ & 2 \\
\hline $\begin{array}{l}\text { Regional and local impacts of } \\
\text { expanding hypoxic zones }\end{array}$ & Medium & Low & Minor & $\begin{array}{l}\text { Reduction of biodiversity, compression of oxygenated habitat for intolerant } \\
\text { species, range expansion for tolerant taxa }\end{array}$ & 3 \\
\hline $\begin{array}{l}\text { Direct temperature effects on } \\
\text { marine biota related to limited } \\
\text { physiological tolerance ranges }\end{array}$ & Very high & High & Major & $\begin{array}{l}\text { For example, large-scale latitudinal shifts of species distribution, changes in } \\
\text { community composition; attribution supported by experimental and statistical } \\
\text { evidence as well as physiological knowledge }\end{array}$ & 4 \\
\hline $\begin{array}{l}\text { Increase in net primary } \\
\text { production at high latitudes }\end{array}$ & Medium & Medium & Major & $\begin{array}{l}\text { At higher latitudes, net primary production is increasing owing to sea ice } \\
\text { decline and warming. At the global scale, estimates vary regionally, and there is } \\
\text { a discrepancy between satellite observations and open ocean time series sites. }\end{array}$ & 5 \\
\hline $\begin{array}{l}\text { Changes in microbial } \\
\text { processes }\end{array}$ & Low & Very low & Minor & $\begin{array}{l}\text { Limited understanding of microbial processes, drivers, and interactions, and } \\
\text { subsequently of large-scale shifts in biogeochemical pathways such as oxygen } \\
\text { production, carbon sequestration, and export production and nitrogen fixation }\end{array}$ & 6 \\
\hline
\end{tabular}

Key references and further related information for the assessment in this table:

'Wootton et al. (2008); De Moel et al. (2009); Moy et al. (2009); Bednaršek et al. (2012); Section 6.3.2; Box CC-OA

25tramma et al. (2008); Stolper et al. (2010); Sections 6.1.1.3 and 6.3.3

${ }^{3}$ Levin et al. (2009); Ekau et al. (2010); Stramma et al. (2010, 2012); Sections 6.3.3, 6.3.5, and 30.5

${ }^{4}$ Merico et al. (2004); Perry et al. (2005); Pörtner and Farrell (2008); Beaugrand et al. (2010); Alheit et al. (2012); Section 6.3.1

${ }^{5}$ Behrenfeld et al. (2006); Saba et al. (2010); Arrigo and Van Dijken (2011); Section 6.3.4; Box CC-PP

${ }^{6}$ Sections 6.3.1.2, 6.3.2.2, 6.3.3.2, and 6.3.5.2 


\subsubsection{Impacts on Ocean System Properties and Marine Organisms and Ecosystems}

Greater thermal stratification in many regions has reduced ocean ventilation and mixing depth. As this reduces the availability of inorganic nutrients, it can reduce primary productivity in surface layers. However, trends in primary production from different observational methods disagree (Sections 6.1.1, 6.3.4; Box CC-PP). Coastal upwelling has increased in some regions bringing greater concentrations of nutrients to surface waters, boosting productivity and enhancing fisheries output (see Section 30.5.5). Increases in productivity also occurred with warming and sea ice loss at high latitude (medium confidence; Table 18-1).

Poleward shifts in the distributions of zooplankton, fish, seabirds, and benthic invertebrates related to climate change have been detected with high confidence in the well-studied Northeast Atlantic. There is also high confidence that climate change has played a major role in these shifts (Box 6-1; Sections 6.3, 30.5.1). In many regions, temperature exerts the strongest influence on ecosystems and the responses of ecological systems to changing temperature are well studied. However, it is often difficult to clearly identify the interaction of temperature with other factors (Section 6.3.5). Some studies have found changes in the abundance of fish species that are consistent with regional warming, with differences in response between species, in line with differential specializations of coexisting species (Sections 6.2, 6.3.1; see also Pörtner, 2012). Anthropogenic influences modulate responses to climate, for example, due to exploitation status (Tasker, 2008; Belkin, 2009; Overland et al., 2010; Schwing et al., 2010), with more heavily exploited species being more sensitive to environmental variability in general, including temperature trends and extremes (Hsieh et al., 2005, 2008; Stige et al., 2006).

Laboratory experiments have shown that a broad range of marine organisms (e.g., corals, fish, pteropods, coccolithophores, and macroalgae), physiological processes (e.g., skeleton formation, gas exchange, reproduction, growth, and neural function), and ecosystems processes (e.g., productivity, reef building, and erosion) are sensitive to changes in $\mathrm{pH}$ and carbonate chemistry of seawater (Section 6.2, Box CC-OA). However, few field studies have been able to detect specific changes in marine ecosystems to ocean acidification owing to the inability to identify the effect of ocean acidification from ocean warming or local factors (Wootton et al., 2008; De Moel et al., 2009; Moy et al., 2009; Bednaršek et al., 2012; see also Section 6.3.2).

There has been a substantial increase in the number of studies documenting significant changes in marine species and processes since the AR4. A new meta-analysis using a database of long-term observations from peer-reviewed studies of biological systems, with nearly half of the time series extending prior to 1960, shows that more than $80 \%$ of observed responses are consistent with regional climate change (see Section 30.4, Box CC-MB). Poloczanska et al. (2013) argue that the high consistency of marine species' responses across geographic regions (coastal to open ocean, polar to tropical), taxonomic groups (phytoplankton to top predators), and types of responses (distribution, phenology, abundance) reported in their analysis support the detection of a widespread impact of climate change on marine populations and ecosystems (see Sections 30.4 and 30.5 for more detail). Table 18-2 gives examples of the manifestation of climate change on marine species and ecosystems.

\subsubsection{Observed Climate Change Effects across Ocean Regions}

Climate change has affected physical properties across the ocean, with regional variations (Table 30-1; Figures 30-2 to 30-5; WGI AR5 Chapter $3)$. Confidence in the detection and attribution of these impacts also varies regionally, reflecting differences in system understanding, data availability, influence of long-term natural variability, and the impact of factors unrelated to climate change. The attribution of changes in heat content to climate change is less certain regionally than globally, but warming has been detected with high confidence in all basins except

Table 18-2 | Observed changes in marine species and ecosystems, with confidence levels for the detection of the effect of climate change and an assessment of the magnitude of its role (see also Sections 6.2, 6.3, and 30.4; Box CC-MB).

\begin{tabular}{|c|c|c|c|c|c|}
\hline \multirow{2}{*}{ Process } & \multicolumn{2}{|c|}{ Confidence in } & \multirow{2}{*}{ Role } & \multirow{2}{*}{ Context } & \multirow{2}{*}{ Reference } \\
\hline & Detection & Attribution & & & \\
\hline Range shifts of fish and macroalgae & High & High & Major & Changes in species biogeographical ranges to higher latitudes or greater depths & 1 \\
\hline Changes in community composition & High & High & Major & Due to effects of warming, hypoxia, and sea ice retreat & 1 \\
\hline Changes in abundance & High & Medium & Major & Observed in fish, corals, and intertidal species & 1 \\
\hline $\begin{array}{l}\text { Impacts on large non-fish species, } \\
\text { e.g., walruses, penguins, and other } \\
\text { sea birds }\end{array}$ & High & High & Major & $\begin{array}{l}\text { Observed effects include changing abundance, phenology, species distribution } \\
\text { and turtle sex ratios, and are mediated mostly through changes in resource } \\
\text { availability, including prey. }\end{array}$ & 2 \\
\hline Impacts on reef-building corals & Very high & High & Major & $\begin{array}{l}\text { Effects attributed mostly to warming and rising extreme temperatures, though } \\
\text { ocean acidification may contribute }\end{array}$ & 3 \\
\hline $\begin{array}{l}\text { Changes in fish species richness in } \\
\text { temperate and high-latitude zones }\end{array}$ & High & Medium & Major & $\begin{array}{l}\text { Effect associated with loss of sea ice and latitudinal species shifts due to } \\
\text { warming trends }\end{array}$ & 4 \\
\hline
\end{tabular}

Key references and further related information for the assessment in this table:

'Müller et al. (2009); Stige et al. (2010); Sections 6.3.1 and 30.4; Box CC-MB

2Grémillet and Boulinier (2009); McIntyre et al. (2011); Section 6.3.7

${ }^{3}$ Hoegh-Guldberg (1999); Hoegh-Guldberg et al. (2007); Baker et al. (2008); Veron et al. (2009); Sections 6.3.1.4 and 6.3.1.5; Box CC-CR

${ }^{4}$ Hiddink and ter Hofstede, (2008); Beaugrand et al. (2010); Box 6-1; Section 6.3.1.5 


\section{Box 18-3 | Differences in Detection and Attribution of Ecosystem Change on Land and in the Ocean}

Marine and terrestrial ecosystems differ in fundamental ways. Gradients in turbulence, light, pressure, and nutrients uniquely drive fundamental characteristics of organisms and ecosystems in the ocean. While the critical factor for transporting nutrients to marine primary producers is ocean mixing driven by wind, water is the primary mode for transporting nutrients to land plants. In addition to these characteristics, marine ecosystems are often more technically difficult and costly to explore than terrestrial equivalents, which explains the low number and shorter scientific studies of marine ecosystems (Hoegh-Guldberg and Bruno, 2010). The latter has restricted the extent to which changes within the ocean can be detected and attributed.

Impacts of climate change in terrestrial and marine systems differ significantly for the same types of measures, for example, species phenology and range shifts, leading to differences in experts' interpretations of the data and possibly divergent levels of confidence in detection and attribution. There are also fundamental differences in exposure of organisms to recent warming, their biological responses, and our ability to detect change through observations. Changes in temperature of ocean systems have generally been less than those of terrestrial ecosystems over the last 4 decades (Burrows et al., 2011). Furthermore, despite higher variability the horizontal spatial gradient of temperature change $\left({ }^{\circ} \mathrm{C} \mathrm{km}^{-1}\right)$ is generally much higher in terrestrial ecosystems than in marine ecosystems. All else being equal, the net result is that species have generally needed to move much shorter distances in terrestrial ecosystems to stay within their preferred climates, also due to the influence of the topography such as mountain ranges (Burrows et al., 2011), although many marine species can potentially exploit strong vertical thermal gradients to attenuate the need for range shifts in response to warming.

Species and ecosystems may respond very differently to these climate signals in ways that influence the ability to detect change. For example, a comparison of ectotherm species (i.e., species that do not actively regulate their body temperatures, such as reptiles and fish) indicates that marine species' ranges have tracked recent warming at both their poleward and equatorial range limits, while many terrestrial species' ranges have tracked warming only at their poleward range limits (Sunday et al., 2012). Biological processes influencing phenological shifts may also differ substantially between systems. For example, the effect of climate on the timing of flowering of terrestrial plants at high latitudes is only moderately influenced by confounding effects, whereas the timing of phytoplankton blooms in high-latitude marine systems is highly dependent on ocean temperature and associated stratification and changes in nutrient availability.

Eastern boundary upwelling systems (Table 30-1, Figure 30-2). Recent research shows declining oxygen levels (medium confidence; Section 30.3.2.3) and deep penetration of warming in some regions. Regional estimates of $\mathrm{CO}_{2}$ uptake are in line with global estimates, and ocean acidification has been detected with high confidence in most regions (Section 30.3.2.2; WGI AR5 Section 3.8.2).

The high latitude spring bloom systems of the NH show strong warming and associated effects (see above). In the North Pacific, the Bering Sea has undergone major changes in recent decades as a result of climate variability, climate change, and fishing impacts (Litzow et al., 2008; Mueter and Litzow, 2008; Jin et al., 2009; Hunt et al., 2010). Loss of sea ice has led to the retreat of the cold pool in parts of the Bering Sea, and northward expansion of productivity (Wang et al., 2006; Mueter and Lizow, 2008; Brown and Arrigo 2012; see also Section 30.5.1.1.2).

Marginal seas such as the East China Sea are also warming rapidly, with subsequent impacts such as declining primary productivity and fisheries yields as well as other ecological changes (Section 30.5.4.1). However, other human pressures including over-fishing, habitat alteration, and nutrient loading are important contributing factors and it is difficult to disentangle these from the impacts of climate change.

Semi-enclosed seas such as the Black and Baltic Seas and the Arabian/ Persian Gulf show differing patterns of change over the past decades (Section 30.5.3.1). Expansions of hypoxic zones in the Baltic and Black Seas have been detected. Although there is high confidence that climate change has had a role, its magnitude is difficult to assess in light of other contributing factors. Coral reefs in the Arabian/Persian Gulf and Red Sea have experienced widespread bleaching in 1996 and 1998 associated with elevated temperature with high confidence that climate change has played a major role.

Warming of the Mediterranean has been associated with mass mortality events as well as invasions and spread of new warm water species, 
resulting in the "tropicalization" of fauna with high confidence in a major role for climate change (Section 30.5.3.1.5). In many tropical regions and the subtropical gyres of the Pacific, Indian, and Atlantic, periodic heat stress related to climate change has combined with other local stresses to cause mass coral bleaching and mortality (see also Box CC-CR, Section 30.5).

In other regions, such as the California Current upwelling system, there is very high confidence in both the detection and attribution of ecological changes associated with climate change, but separating the effects of El Niño-Southern Oscillation (ENSO) and the PDO from those of anthropogenic climate change is not possible.

In overall terms, attributing observed local and regional changes in marine species and ecosystems to climate change remains an important question for ongoing research (Stock et al., 2010).

\subsection{Detection and Attribution of Observed Climate Change Impacts in Human and Managed Systems}

Observed impacts on human systems have received considerably less attention in previous IPCC reports and the scientific literature, compared to observed impacts on natural systems. Human systems' "normal state in the absence of climate change" is almost never stationary. Confounders other than climate change have been and continue to drive the normal evolution of these systems, with climate often playing a relatively minor role. Further, monitoring in many of the systems has been and continues to be inadequate. It is therefore difficult to detect and attribute the signal of climate change in the majority of human systems, food production systems constituting one noteworthy exception. There is emerging literature estimating the sensitivity to climate of many sectors within the human system (see Box 18-4), yet climate impacts are often not detectable over the impacts from nonclimate confounders.

For some human systems, the clearest situations where a climate signal had a detectable and sometimes attributable impact are during extreme weather events. Impacts of extreme events and single event attribution are therefore discussed in Section 18.4.3, and the discussion is expanded to include responses to extreme weather for some sectors. Overall, the literature has made significant progress for certain sectors, such as food systems, since AR4. The following sections provide a synthesis of findings with regard to food systems, economic systems, human health, human security, and human livelihoods and poverty, which are documented in greater detail in Chapters 7, 9, 10,11, 12, and 13. They also incorporate evidence from regional chapters and further available literature, especially for the discussion of extreme events, human security, and observed changes in indigenous communities.

\subsubsection{Food Production Systems}

Detection and attribution of climate change impacts in food systems is challenging, given that the behavior of the system in the absence of climate change is driven by a large number of other factors (Section 7.2.1).
For cropping systems, these confounders include, but are not limited to, cultivar improvement and increased use of synthetic fertilizers, herbicides, and irrigation. These confounders are often not well measured in terms of their distribution across space and time. Further, it is difficult to quantify or model the exact relationship between these confounders and outcomes of interest (e.g., crop yield or pasture productivity). In addition, the role of farmers' behavior in response to climate change requires significant assumptions and has been shown to change over time (Section 7.2.1). The discussion below is limited to crop systems and fisheries, as literature is scarce on observed impacts for other important sources of food.

\subsubsection{Agricultural Crops}

A significant number of studies have provided impact estimates of observed changes in climate on cropping systems over the past few decades (e.g., Auffhammer et al., 2006; Kucharik and Serbin, 2008; Ludwig et al., 2009; Lobell et al., 2011; Tao et al., 2012; see also Figure 7-2). Over the past several decades, observed climate trends have adversely affected wheat and maize production for many regions, as well as the total global production of these crops (medium confidence in a minor role of climate change in overall production). Climate change impacts on rice and soybean yields over this time period have been small in major production regions and globally (medium confidence; Figure 7-2). In some high-latitude regions, such as the UK and northeast China, warming has benefitted crop production during recent decades (high confidence in a minor role of climate change; Section 7.2.1.1; Jaggard et al., 2007; Chen. C. et al., 2011). At the continental or global scale, observed trends in some climatic variables, including mean summer temperatures, attributed to anthropogenic activity (see Section 7.2.1.1; WGI AR5 Section 10.3.1 and Table 10-1) have had significant negative impacts on trends in yields for certain crops (Lobell and Field, 2007; You et al., 2009; Lobell et al., 2011).

Attributable trends have been found not only in the seasonal averages of climate variables, but also for extremes (WGI AR5 Section 10.6). Extreme rainfall events are widely recognized as important to cropping systems (Rosenzweig et al., 2002), and global scale changes in the patterns of rainfall extremes have been attributed to anthropogenic activity (Min et al., 2011). High nighttime temperatures are harmful to most crops, particularly for rice yield (Peng et al., 2004; Wassmann et al., 2009; Welch et al., 2010) and quality (Okada et al., 2009). Daytime extreme heat is also damaging and sometimes lethal to crops (Porter and Gawith, 1999; Schlenker and Roberts, 2009). At the global scale, trends in annual maximum daytime temperatures have been attributed to greenhouse gas emissions (Christidis et al., 2011; Zwiers et al., 2011), and similar observations have been made for the occurrence of very hot nights (WGI AR5 Section 10.6.1.1; Seneviratne et al., 2012).

Changing atmospheric conditions are affecting crops both positively and negatively. It is virtually certain that the increase in atmospheric $\mathrm{CO}_{2}$ concentrations since preindustrial times has improved water use efficiency and yields most notably in $C_{3}$ crops. These effects are however of relatively minor importance when explaining total yield trends (Amthor, 2001; McGrath and Lobell, 2011). Emissions of $\mathrm{CO}_{2}$ have been associated with tropospheric ozone $\left(\mathrm{O}_{3}\right)$ precursors (Morgan et al., 2006; 


\section{Box 18-4 | The Role of Sensitivity to Climate and Adaptation for Impact Models in Human Systems}

Impacts of climate change on a measurable attribute of a human system occur only if (1) the attribute is sensitive to climate and (2) a change in climate has occurred. Many studies now attempt to quantify both climate sensitivity of various systems and observed changes in climate.

Assessment of the sensitivity of an outcome such as crop yields, heat-related mortality, or migration to climate relies on observed climate variability either across space (e.g., Schlenker et al., 2005), time (e.g., Mann and Emanuel, 2012), or space and time (e.g., Dell et al., 2012). Though there are many studies using climate variability across space, the lack of long observational weather time series required for exploring climate variability across space and time have limited the opportunities for study. A number of studies have instead estimated the sensitivity of outcomes to short-run fluctuations (e.g., weather) in order to project the future impacts of climate change (Deschênes and Greenstone, 2007, 2011), or attribute impacts for the past (Auffhammer et al., 2006). The issue with impact studies using a weather-based sensitivity measure is that they cannot provide estimates of impacts based on the sensitivity to climate. For example, farmers may respond to an unusually hot summer, which is a weather event, by applying more irrigation water. However, in the long run farmers may respond to a warmer climate by switching crops, changing irrigation technology, or abandoning farming altogether. The two sensitivities and resulting magnitudes of attributable impacts due to a change in weather versus a change in climate are therefore different. To detect and attribute a change in a system to climate change, one needs to combine a measure of sensitivity of the outcome to climate with climate observations under climate change.

Mills et al., 2007; see also Section 7.3.2.1.2). $0_{3}$ suppresses global output of major crops, with reductions estimated at roughly $10 \%$ for wheat and soy and 3 to $5 \%$ for maize and rice (Van Dingenen et al., 2009). Detected impacts are most significant for India and China, but can also be found for soybean and maize production in the USA in recent decades (Fishman et al., 2010).

\subsubsection{Fisheries}

Many new studies focus on the relationship between the dynamics of marine fish stocks and climate, suggesting a sensitivity to climate of these stocks and on the fisheries that exploit them (Hollowed et al., 2001; Roessig et al., 2004; Shriver et al., 2006; Brander, 2007). Some fisheries and aquaculture do not show evidence of climate change impacts (e.g., aquaculture in the UK and Ireland; Callaway et al., 2012), while many others do with both positive and negative changes (see also Sections 7.2.1.1, 18.3.4, 30.6.2.1).

There is high confidence in the detection of a climate change impact on the spatial distributions of marine fishes (Perry et al., 2005) and in the timing of events like spawning and migration (Sydeman and Bograd, 2009), with high confidence of a major role of climate change (see Sections 18.3.4, 30.4; Box (C-MB). This distributional shift is reflected in the species composition of harvest, with the relative share of warm water species increasing (Cheung et al., 2013). The impacts of ocean warming and acidification on fish stocks vary from region to region (Section 30.6.2.1). To date, the role of climate change in change in fish stocks and fishery yields is, in most cases, minor (high confidence) in relation to other factors such as harvesting, habitat modification, technological development, and pollution (Brander, 2010).

\subsubsection{Economic Impacts, Key Economic Sectors, and Services}

\subsubsection{Economic Growth}

In low-income countries, careful tracking of incomes and temperatures over an extended period, taking into account important confounders, shows that higher annual temperatures as well as higher temperatures averaged over 15-year periods result in substantially lower economic growth (Dell et al., 2012). This effect is not limited to the level of per capita income, but also to its rate of growth. Declining rainfall over the 20th century partly explains the slower growth of sub-Saharan economies relative to those of other developing regions (Barrios et al., 2006; Brown et al., 2011). Dell et al. (2009) find that $1^{\circ} \mathrm{C}$ of warming reduces income by $1.2 \%$ in the short run and by $0.5 \%$ in the long run. The difference is argued to be due to adaptation. Horowitz (2009) finds a much larger effect: a $3.8 \%$ drop in income in the long run for $1{ }^{\circ} \mathrm{C}$ of warming. One proposed mechanism for this is the impact of heat stress on workers in the workplace (Dash and Kjellström, 2011; Dunne et al., 2013). Temperature shocks have negatively affected the growth of developing countries' exports, for which $1^{\circ} \mathrm{C}$ of warming in a given year reduced the growth rate of its exports by 2.0 to 5.7 percentage points (Jones and Olken, 2010). The export sectors most affected are agricultural and light manufacturing exports.

\subsubsection{Energy Systems}

Energy production and consumption is growing rapidly globally, with much of the growth taking place in low-income and emerging economies. Various parts of the energy sector are known to be sensitive 
to climate change (cf. Ebinger and Vegara, 2011). Higher temperatures raise the demand for cooling and lower the demand for heating. Cooling demand is largest in the summer and in some areas peak loads during the summer months have increased, this peak being highly correlated with summer maximum temperatures (Franco and Sanstad, 2008). There are also opposing effects of warmer winters and summers on electricity and gas demand. Statistical studies have confirmed this U-shaped relationship of energy and electricity demand in temperature for the USA and elsewhere (Isaac and van Vuuren, 2009; Akpinar-Ferrand and Singh, 2010; Deschênes and Greenstone, 2011).

On the supply side, sensitivity to climatic factors such as ambient temperature, wind speeds, or snow and ice is well known for many energy technologies and part of the transmission infrastructure (see Sections 10.2.2-3); however, there are no studies available that discuss observed effects of climate change on the energy sector.

\subsubsection{Tourism}

Tourism is a climate sensitive economic sector and ample research has been performed to understand its sensitivity to climate change and impacts of (future) climate change on tourism, yet few studies have focused on detection and attribution of observed impacts (cf. Scott et al., 2008; see also Section 10.6).

A comparatively well-studied area is the sensitivity of the winter sports industry in lower lying areas to climate. For example, the increase in investment in artificial snow machines in the European Alps can be attributed with high confidence to a general decrease of snow depth, snow cover duration, and snowfall days since the end of the 1980s for low-elevation mountain stations (Durand et al., 2009; Valt and Cianfarra, 2010; Voigt et al., 2011), which in turn has been attributed to anomalous higher winter temperatures over the past 20 years (Marty, 2008).

Variability in precipitation, shrinking glaciers, and milder winters has been shown to negatively affect visitor numbers in winter sports areas in Europe and North America (Becken and Hay, 2007). Another indirect effect of climate change that has been reported is a rise in popularity of destinations that are perceived to be at risk from climate change (e.g., Eijgelaar et al. (2010) for Antarctic glaciers, or Farbotko (2010) for Tuvalu).

\subsubsection{Impacts of Extreme Weather Events}

The impacts of extreme weather events depend on the frequency and intensity of the events, as well as exposure and vulnerability of society and assets. The last several decades have seen changes in the frequency and intensity of extreme weather events including extreme temperature, droughts, heavy rainfall, and tropical and extratropical cyclones with low to very high confidence, depending on the type of extreme event (IPCC, 2012; WGI AR5 Chapter 2). However, the impacts of extreme weather events also depend on the vulnerability and exposure of systems. It is possible that climate change can affect vulnerability and exposure, but typically both are influenced primarily by non-climate confounders, most notably economic development.

\subsubsection{Economic Losses Due to Extreme Weather Events}

Extreme weather events can result in economic impacts related to damage to private and public assets as well as the temporary disruption of economic and social activities, long-term impacts, and impacts beyond the areas affected. Some economic and especially social impacts are not readily monetizable and are thus excluded from most economic assessments (Handmer et al., 2012, their Sections 4.5.1, 4.5.3).

Economic costs of extreme weather events have increased over the period 1960-2000 (high confidence), with insured losses increasing more rapidly than overall losses (Section 10.7.3; Handmer et al., 2012, their Sections 4.5.3.3, 4.5.4.1). This is also reflected by an increase in the frequency of extreme weather-related disasters over the same period (Neumayer and Barthel, 2011). Recent studies from Mexico and Colombia highlight both variability and positive trends in disaster frequency (unadjusted) losses and other damage metrics (Saldaña-Zorrilla and Sandberg, 2009; Marulanda et al., 2010; Rodriguez-Oreggia et al., 2013). However, the greatest contributor to increased cost is rising exposure associated with population growth and growing value of assets (high confidence; Bouwer et al., 2007; Bouwer, 2011; Barthel and Neumayer, 2012; Handmer et al., 2012, their Sections 4.2.2, 4.5.3.3, Box 4-2). To account for changes over time in the value of exposed assets, many studies attempt to normalize monetary losses by an overall measure of changes in asset value. A majority of studies have found no detectable trend in normalized losses (Bouwer, 2011). Studies on insured losses that in general meet higher data quality standards than data on overall losses due to thoroughly monitored payouts have focused on developed countries including Australia, Germany, Spain, the USA (Changnon, 2007, 2008, 2009a,b; Barredo et al., 2012; Barthel and Neumayer, 2012; Sander et al., 2013; see also Section 10.7.3). Studies of normalized losses from extreme winds associated with hurricanes in the USA (Miller et al., 2008; Pielke Jr. et al., 2008; Schmidt et al., 2010; Bouwer and Botzen, 2011) and the Caribbean (Pielke Jr. et al., 2003), tornadoes in the USA (Brooks and Doswell, 2002; Boruff et al., 2003; Simmons et al., 2013), and wind storms in Europe (Barredo, 2010) have failed to detect trends consistent with anthropogenic climate change, although some studies were able to find signals in loss records related to climate variability, such as damage and loss of life due to wildfires in Australia related to ENSO and Indian Ocean dipole phenomena (Crompton et al., 2010), or typhoon loss variability in the western North Pacific (Welker and Faust, 2013). Effects of adaptation measures (disaster risk prevention) on disaster loss changes over time cannot be excluded as research is currently not able to control for this factor (Neumayer and Barthel, 2011).

In conclusion, although there is limited evidence of a trend in the economic impacts of extreme weather events that is consistent with a change driven by observed climate change, climate change cannot be excluded as at least one of the drivers involved in changes of normalized losses over time in some regions and for some hazards.

\subsubsection{Detection and Attribution of the Impacts of Single Extreme Weather Events to Climate Change}

Although most studies on the relationship between climate change and extreme weather events have focused on changes over time in their 
Table 18-3 | Illustrative selection of recent disasters related to extreme weather events, with description of the impact event, the associated climate hazard, recent climate trends relating to the weather event, and recent trends relating to the consequences of such a weather event.

\begin{tabular}{|c|c|c|c|c|}
\hline $\begin{array}{l}\text { Date } \\
\text { and locale }\end{array}$ & Impact event & Associated climate hazard & $\begin{array}{l}\text { Trends relating to likelihood } \\
\text { of climate hazard }\end{array}$ & $\begin{array}{l}\text { Trends relating to consequence } \\
\text { of climate hazard }\end{array}$ \\
\hline $\begin{array}{l}\text { France, summer } \\
2003\end{array}$ & $\begin{array}{l}\text { Approximately 15,000 excess } \\
\text { deaths (Hémon and Jougla, } \\
\text { 2003; Fouillet et al., 2006) }\end{array}$ & $\begin{array}{l}\text { Record hot days/heat wave (Hémon } \\
\text { and Jougla, 2003; Fouillet et al., 2006) }\end{array}$ & $\begin{array}{l}\text { Increasingly frequent hot days and } \\
\text { heat waves in recent decades (Perkins } \\
\text { et al., 2012; Seneviratne et al., 2012) } \\
\text { (high confidence) }\end{array}$ & $\begin{array}{l}\text { - Aging population, increasing population, trends in } \\
\text { marital status (Hémon and Jougla, 2003; Prioux, } \\
\text { 2005; Fouillet et al., 2006; Rey et al., 2007) } \\
\text { - Difficulties staffing health services, undeveloped } \\
\text { early warning system (Lalande et al., 2003; Fouillet } \\
\text { et al., 2008) }\end{array}$ \\
\hline $\begin{array}{l}\text { Atlantic and } \\
\text { Gulf coasts } \\
\text { of the United } \\
\text { States, } 2005\end{array}$ & $\begin{array}{l}\text { More than 1,000 deaths and } \\
\text { more than US\$100 billion in } \\
\text { damage (Beven et al., 2008) }\end{array}$ & $\begin{array}{l}\text { Record number of tropical storms, } \\
\text { hurricanes, and category } 5 \text { hurricanes } \\
\text { (Bell et al., 2006) }\end{array}$ & $\begin{array}{l}\text { Recent increase in frequency but } \\
\text { no clear century-scale trends in } \\
\text { USA landfalling tropical storms or } \\
\text { hurricanes (WGI AR5 Section 2.6.3, } \\
\text { Knutson et al., 2010) (high confidence) }\end{array}$ & $\begin{array}{l}\text { - More population, settlement, and wealth in coastal } \\
\text { areas (Pielke Jr. et al., 2008; Schmidt et al., 2010) } \\
\text { - Strengthening of building codes (IntraRisk, 2002) }\end{array}$ \\
\hline $\begin{array}{l}\text { Mozambique, } \\
\text { early } 2007\end{array}$ & $\begin{array}{l}\text { More than } 100,000 \text { people } \\
\text { displaced by flooding (Foley, } \\
\text { 2007; Artur and Hilhorst, } \\
\text { 2012) }\end{array}$ & $\begin{array}{l}\text { High rainfall in upper Zambezi Basin in } \\
\text { preceding months; passage of Cyclone } \\
\text { Favio (Thiaw et al., 2008) }\end{array}$ & $\begin{array}{l}\text { Warming and decreasing rainfall } \\
\text { leading to lower discharge of the } \\
\text { Zambezi (Dai et al., 2009) (low } \\
\text { confidence) } \\
\text { Decreasing frequency of tropical } \\
\text { cyclones in the Mozambique Channel } \\
\text { during past } 50 \text { years (Mavume et al., } \\
\text { 2009) (medium confidence) }\end{array}$ & $\begin{array}{l}\text { - Increased settlement of Zambezi flood plain } \\
\text { following dam construction (Foley, 2007) } \\
\text { - Development of emergency response plans } \\
\text { (Cosgrave et al., 2007; Foley, 2007) }\end{array}$ \\
\hline $\begin{array}{l}\text { Colombia, } \\
\text { October- } \\
\text { December } 2010\end{array}$ & $\begin{array}{l}\text { Floods affecting } 4 \text { million } \\
\text { people; US } \$ 7.8 \text { billion total } \\
\text { damage (Hoyos, N. et al., } \\
\text { 2013) }\end{array}$ & $\begin{array}{l}\text { Wettest year since records began } 40 \\
\text { years ago (Martinez et al., 2011) }\end{array}$ & $\begin{array}{l}\text { No clear trend in discharge of rivers in } \\
\text { flood-affected areas since } 1940 \text { (Hoyos, } \\
\text { N. et al., 2013) (low confidence) }\end{array}$ & $\begin{array}{l}\text { - Rapid urbanization, with high concentration of } \\
\text { residential areas in flood-prone areas (OSSO, 2013; } \\
\text { Álvarez-Berríos et al., 2013) } \\
\text { - Increasing vulnerability of rural population over the } \\
\text { past decades and highly fragile urban systems (e.g., } \\
\text { water and gas) (OSSO, 2013) }\end{array}$ \\
\hline $\begin{array}{l}\text { Pakistan, } \\
\text { July-September } \\
2010\end{array}$ & $\begin{array}{l}\text { Flooding leading to } 2,000 \\
\text { deaths; } 20 \text { million affected; } \\
\text { total loss US\$10 billion } \\
\text { (NDMA, 2011) }\end{array}$ & $\begin{array}{l}\text { Exceptionally high monsoon rainfall } \\
\text { over northern Pakistan during July and } \\
\text { August (Houze Jr. et al., 2011; Rajeevan } \\
\text { et al., 2011; Webster et al., 2011) }\end{array}$ & $\begin{array}{l}\text { No substantial trend in heavy rainfall } \\
\text { event frequency in northern Pakistan } \\
\text { in past several decades (Wang, S.-Y. } \\
\text { et al., 2011; Webster et al., 2011) (low } \\
\text { confidence) }\end{array}$ & $\begin{array}{l}\text { - Rapid population growth and expansion of formal } \\
\text { and informal human settlements (Oxley, 2011) } \\
\text { - Decreased risk through development of flood and } \\
\text { disease warning systems and disaster planning } \\
\text { (NDMA, 2011) } \\
\text { - Increased risk from deforestation on mountainous } \\
\text { slopes (Ali et al., 2006) } \\
\text { - Recent unrest in north constrains ability of } \\
\text { institutions to deliver basic services (World Bank } \\
\text { and ADB, 2010) }\end{array}$ \\
\hline $\begin{array}{l}\text { European } \\
\text { Russia, July- } \\
\text { August } 2010\end{array}$ & $\begin{array}{l}\text { Burned area }>12,500 \mathrm{~km} \\
\text { (Müller, 2011) }\end{array}$ & $\begin{array}{l}\text { Record hot days (Barriopedro et al., } \\
\text { 2011; Müller, 2011) } \\
\text { Unusually dry June-August (Bulygina } \\
\text { et al., 2011) }\end{array}$ & $\begin{array}{l}\text { Trends in temperature, precipitation, } \\
\text { humidity, soil moisture, and snow } \\
\text { cover toward less conducive climatic } \\
\text { conditions for fire (Groisman et al., } \\
\text { 2007) (medium confidence) }\end{array}$ & $\begin{array}{l}\text { - Increased risk from draining of peat bogs in 1960s } \\
\text { and earlier (Global Fire Monitoring Center, 2010; } \\
\text { Müller, 2011) } \\
\text { - Increased risk from poorly implemented devolution } \\
\text { of forest management and forest fire protection } \\
\text { in } 2007 \text { to regional administrations (Global Fire } \\
\text { Monitoring Center, 2010) }\end{array}$ \\
\hline $\begin{array}{l}\text { Russia, summer } \\
2010\end{array}$ & $\begin{array}{l}\text { Grain harvest 30\% lower } \\
\text { than forecast (Wegren, 2011) }\end{array}$ & $\begin{array}{l}\text { Hottest June-August in at least } 130 \\
\text { years, unusually dry June-August } \\
\text { (Bulygina et al., 2011) }\end{array}$ & $\begin{array}{l}\sim 1^{\circ} \mathrm{C} \text { summer warming trend over last } \\
70 \text { years (Gruza and Mescherskaya, } \\
\text { 2008; Bulygina et al., 2011) (very high } \\
\text { confidence) }\end{array}$ & $\begin{array}{l}\text { - Increase in grain production partially due to } \\
\text { government support programs (Wegren, 2011) }\end{array}$ \\
\hline $\begin{array}{l}\text { Southeast } \\
\text { Queensland, } \\
\text { Australia, } \\
\text { January } 2011\end{array}$ & $\begin{array}{l}\text { Floods affecting }>200,000 \\
\text { people; }>30,000 \text { homes } \\
\text { flooded; damages and cost } \\
\text { to economy of US\$2.5-10 } \\
\text { billion (Hayes and } \\
\text { Goonetilleke, 2012) }\end{array}$ & $\begin{array}{l}2010 \text { was the wettest year since 1974, } \\
\text { with landfall of tropical cyclone in } \\
\text { December and wet start to January } \\
\text { resulting in highest flood since } 1974 \\
\text { (Van den Honert and McAneney, 2011; } \\
\text { Hayes and Goonetilleke, 2012). }\end{array}$ & $\begin{array}{l}\text { Decreasing frequency of intense floods } \\
\text { since } 1840 \text { (Van den Honert and } \\
\text { McAneney, 2011) (medium confidence) }\end{array}$ & $\begin{array}{l}\text { - Increased development in flood-prone urban areas } \\
\text { (Van den Honert and McAneney, 2011) } \\
\text { - Lack of development of riverine flood insurance } \\
\text { (Van den Honert and McAneney, 2011; Ma et al., } \\
\text { 2012) }\end{array}$ \\
\hline Thailand, 2011 & $\begin{array}{l}\text { Prolonged inundation of } \\
\text { urban and industrialized } \\
\text { areas; manufacturing losses } \\
\text { of about US\$32 billion (World } \\
\text { Bank, 2012) }\end{array}$ & $\begin{array}{l}\text { One of the wettest monsoon seasons } \\
\text { on record in middle and upper Chao } \\
\text { Phraya Basin, resulting in flooding } \\
\text { (Komori et al., 2012; Van Oldenborgh } \\
\text { et al., 2012) }\end{array}$ & $\begin{array}{l}\text { No detectable change in precipitation } \\
\text { over the basin (Van Oldenborgh et al., } \\
\text { 2012) (low confidence) }\end{array}$ & $\begin{array}{l}\text { - Economic development focused on large industrial } \\
\text { estates built in flood plains (Chongvilaivan, 2012; } \\
\text { Courbage et al., 2012) } \\
\text { - Recent spell of political instability (Courbage et } \\
\text { al., 2012) } \\
\text { - Subsidence from groundwater pumping (Phien-Wej } \\
\text { et al., 2006) }\end{array}$ \\
\hline $\begin{array}{l}\text { Contiguous } \\
\text { United States, } \\
\text { summer } 2012\end{array}$ & $\begin{array}{l}\text { Agricultural drought, with } \\
57 \% \text { of cropland and } 43 \% \text { of } \\
\text { farms experiencing at least } \\
\text { severe drought (Crutchfield, } \\
2013 \text { ) }\end{array}$ & $\begin{array}{l}\text { Second warmest summer and warmest } \\
\text { month (July) in the contiguous USA, } \\
\text { and one of the driest March-July } \\
\text { periods in the central USA in the 118- } \\
\text { year record (Crouch et al., 2013; Kumar } \\
\text { et al., 2013) }\end{array}$ & $\begin{array}{l}\sim 0.5^{\circ} \mathrm{C} \text { warming in summer over the } \\
\text { last century (Menne et al., 2009) (very } \\
\text { high confidence) } \\
\text { No substantial long-term trend in } \\
\text { drought occurrence (Peterson et al., } \\
\text { 2013) (medium confidence) }\end{array}$ & $\begin{array}{l}\text { Significant growth in area dedicated to soy and } \\
\text { maize (FAOSTAT, 2013) }\end{array}$ \\
\hline
\end{tabular}


frequency and intensity, a few studies have focused on the contribution of climate change to specific events (WGI AR5 Section 10.6.2). Assessing the contribution of climate change to a specific event poses particular challenges, both in terms of methodology and communication of results (Allen, 2011; Curry, 2011; Hulme et al., 2011; Trenberth, 2011). Only a few studies have attempted to evaluate the role of climate change in the impacts of individual extreme weather events. For instance, Pall et al. (2011) and Kay et al. (2011), using observational constraints on climate and hydrologic model simulations, concluded that greenhouse gas emissions have increased the probability of occurrence of a comparable flooding event in autumn 2000 over the UK.

In highly temperature-sensitive regions, such as high mountains, several extreme impact events of recent decades can be qualitatively attributed to effects of long-term warming (high confidence), namely glacier lake outburst floods due to glacier recession and subsequent formation of unstable lakes (Evans and Clague, 1994; Carey, 2005; Bajracharya and Mool, 2009), debris flows from recently deglaciated areas, and rock fall and avalanches following the loss of mechanical support accompanying glacier retreat (Haeberli and Beniston, 1998; Oppikofer et al., 2008; Huggel et al., 2012b; Stoffel and Huggel, 2012; see also Section 18.3.1.3). Multi-step approaches can be used to evaluate the contributions of anthropogenic emissions to recent damaging extreme events (Hegerl et al., 2010).

Irrespective of whether a specific event can be attributed in part to climate change, there is ample evidence of the severity of related impacts on people and various assets. Both low- and high-income countries have been strongly impacted by extreme weather events in recent years, but the impacts relative to economic strength have been higher in low-income countries (Handmer et al., 2012). Similarly, at the national scale, poor or elderly people have been disproportionately affected, as documented for Hurricane Katrina in the USA in 2005 (Elliott and Pais, 2006; Bullard and Wright, 2010) or the 2003 European heat wave (Fouillet et al., 2008). Exacerbating effects of extreme weather events are mostly of non-climatic nature, including increasing exposure and urbanization, land use changes including deforestation, or vulnerable infrastructure. Table 18-3 lists a selection of recent weather-related disasters, and lists various factors contributing to long-term changes in the risk of damage, including recent climate change.

\subsubsection{Human Health}

IPCC AR4 (Confalonieri et al., 2007) concluded that there was weak to moderate evidence of effects of recent observed climate change on three main categories of health exposure (ranging from low to medium confidence): vectors of human infectious diseases (changes in distribution), allergenic pollen (changes in phenology), and extreme heat exposures (trend in increased frequency of very hot days and heat wave events). Overall, there was a lack of evidence for observed effects of climate change on human health outcomes, and this generally remains the case (see Chapter 11). Evaluation of the detection and attribution of impacts on health outcomes requires disentangling the roles of changes in exposures (e.g. patterns), control measures (e.g., vaccination, drug resistance), population structures (e.g., population aging), and reporting practices.
The most direct potential health impact of climate change is through exposure to higher temperatures, as the association between very hot days and increases in mortality is very robust (Section 11.4.1). Recent decades have seen a shift toward more frequent hot extremes and less frequent cold extremes (high confidence; Seneviratne et al., 2012; WGI AR5 Table 2.13). However, the translation of this trend in hazard to a trend in exposure is complicated by changes in social, environmental, and behavioral factors (e.g., Carson et al., 2006; see also Table 18-3) and interseasonal mortality relationships (Rocklöv et al., 2009; Ha et al., 2011). Climate change has contributed to a shift from cold-related mortality to heat-related mortality during recent decades in Australia (medium confidence; Bennett et al., 2013). In a similar shift in England and Wales, a contribution from anthropogenic climate change has been detected (medium confidence; Christidis et al., 2010).

For pollen production, changes in phenology have been consistently observed in mid- to high latitudes with, for example, earlier onset in Finland (e.g., Yli-Panula et al., 2009) and Spain (D'Amato et al., 2007; García-Mozo et al., 2010; see also Section 4.3) over the past few decades. In North America, the pollen season of ragweed (Ambrosia spp.) has been extended by 13 to 27 days since 1995 at latitudes above $44^{\circ} \mathrm{N}$ (Ziska et al., 2011). Allergic sensitization of humans has changed over a 25-year period in Italy, but the attribution to observed warming remains unclear (Ariano et al., 2010).

There is limited evidence regarding the role of observed warming in changes in tick-borne disease in mid- to high latitudes. While patterns of changes in tick-borne encephalitis (TBE) incidence in the Czech Republic match those expected from observed warming (Kriz et al., 2012), the upsurge of TBE in the 1980-1990s in Central and Eastern Europe generally has been attributed to socioeconomic factors (human behavior) rather than temperature (Šumilo et al., 2008, 2009). Changes in the latitudinal and altitudinal distribution of ticks in Europe and North America are consistent with observed warming trends (e.g., Gray et al., 2009; Ogden et al., 2010), but there is no evidence so far of any associated changes in the distribution of human cases of tick-borne diseases. There is limited evidence of a change in the distribution of rodent-borne infections in the USA (plague and tularemia) consistent with observed warming (Nakazawa et al., 2007). Specifically, a northward shift of the southern edge of the distributions of the diseases (based on human case data for period 1965-2003) was observed. There was no change detected in the northern edge of the distributions, however.

Globally, the dominant trend concerning malaria has been a contraction of the geographical range and a decrease in endemicity over the past century due to changes in land cover, behavior, and health care (Gething et al., 2010). Given that the mosquito vector is climate sensitive, however, there may be specific locations where climate change matches the influence of these other factors. In the Kericho region of Kenya, both increasing incidence and warming have been observed over several decades (Omumbo et al., 2011). Modelling suggests that the gradual warming is inducing an amplified nonlinear response in malaria incidence (Alonso et al., 2011). A detailed review concluded that decadal temperature changes have played at least a minor role in these malaria trends in the East African highlands (low confidence; Chaves and Koenraadt, 2010). 


\section{Box 18-5 | Detection, Attribution, and Traditional Ecological Knowledge}

Indigenous and local peoples often possess detailed knowledge of climate change that is derived from observations of environmental conditions over many generations. Consequently, there is increasing interest in merging this traditional ecological knowledge (TEK)—also referred to as indigenous knowledge — with the natural and social sciences in order to better understand and detect climate change impacts (Huntington et al., 2004; Parry et al., 2007; Salick and Ross, 2009; Green and Raygorodetsky, 2010; Ford et al., 2011; Diemberger et al., 2012). TEK, however, does not simply augment the sciences, but rather stands on its own as a valued knowledge system that can, together with or independently of the natural sciences, produce useful knowledge for climate change detection or adaptation (Agrawal, 1995; Cruikshank, 2001; Hulme, 2008; Berkes, 2009; Byg and Salick, 2009; Maclean and Cullen, 2009; Wohling, 2009; Ziervogel and Opere, 2010; Ford et al., 2011; Herman-Mercer et al., 2011).

Cases in which TEK and scientific studies both detect the same phenomenon offer a higher level of confidence about climate change impacts and environmental change (Huntington et al., 2004; Laidler, 2006; Krupnik and Ray, 2007; Salick and Ross, 2009; Gamble et al., 2010; Green and Raygorodetsky, 2010; Alexander et al., 2011; Cullen-Unsworth et al., 2012). Evidence is available in particular from Nordic and Mountain peoples, for example, from Peru's Cordillera Blanca mountains (Bury et al., 2010; Carey, 2010; Baraer et al., 2012; Carey et al., 2012b), Tibet (Byg and Salick, 2009), and Canada (Nichols et al., 2004; Laidler, 2006; Krupnik and Ray, 2007; Ford et al., 2009; Aporta et al., 2011). TEK can also inspire scientists to study new issues in the detection of climate change impacts. In one case, experienced Inuit weather forecasters in Baker Lake, Nunavut, Canada, reported that it had become increasingly difficult for them to predict weather, suggesting an increase of weather variability and anomalies in recent years. To test Inuit observations, scientists analyzing hourly temperature data over a 50 -year period confirmed that afternoon temperatures fluctuated much more during springtime during the last 20 years — precisely when Inuit forecasters noted unpredictability —-than they had during the previous 30 years (Weatherhead et al., 2010).

Despite frequent confluence between TEK and scientific observations, there are sometimes discrepancies between them, indicating uncertainty in the identification of climate change impacts. They can arise because TEK and scientific studies frequently focus on different and distinct scales that make comparison difficult. Local knowledge may fail to detect regional environmental changes while scientific regional or global scale analyses may miss local variation (Wohling, 2009; Gamble et al., 2010). Furthermore, TEKbased observations and related interpretations necessarily need to be viewed within the context of the respective cultural, social, and political backgrounds (Agrawal, 1995). Therefore, a direct translation of TEK into a natural science perspective is often not feasible.

\subsubsection{Human Security}

A small number of studies have examined the connection between the collapse of civilizations and large-scale climate disruptions such as severe or prolonged drought. However, both the detection of a climate change effect and an assessment of the importance of its role can be made only with low confidence owing to limitations on both historical understanding and data. Some studies have suggested that levels of warfare in Europe and Asia were relatively high during the Little Ice Age (Parker, 2008; Brook, 2010; Tol and Wagner, 2010; White, 2011; Zhang et al., 2011), but for the same reasons the detection of the effect of climate change and an assessment of its importance can be made only with low confidence. There is no evidence of a climate change effect on interstate conflict in the post-World War II period.

Most recent research in this area has focused on the relationship between interannual climate variability in temperature, precipitation, and other climate variables and civil conflict, with most studies focusing on Africa (Hsiang et al., 2013; see also Section 12.5). A number of studies have identified statistical relationships (Miguel et al., 2004; Hendrix and Glaser, 2007; Hsiang et al., 2011), but the results have been challenged (Buhaug et al., 2010; Theisen et al., 2011; Buhaug and Theisen, 2012; Slettebak, 2012) on both technical and substantive grounds. The issue is further complicated by the focus on interannual variability — rather than climate change - and civil conflict. Though a plausible argument could be made that climate change has increased interannual variability and has, therefore, contributed positively to the rate of civil conflict, this argument has not been tested in the literature. For these reasons, neither the detection of an effect of climate change on civil conflict nor an assessment of the magnitude of such an effect can currently be made with a degree of confidence.

Several studies have examined links between climate variability and small-scale communal violence (Adano et al., 2012; Butler and Gates, 2012; Hendrix and Salehyan, 2012; Raleigh and Kniveton, 2012; Theisen, 2012). As with larger-scale civil conflict, this work has focused on climate 
Table 18-4 | Cases of regional livelihood impacts associated with weather- and climate-related events, inter-annual climate variability, or climate change (see also Table 18-3; Section 13.2.1.1).

\begin{tabular}{|c|c|c|c|}
\hline Impacted population & Climate-related driver & Impact on livelihood & Reference \\
\hline Small-scale farmers, Ghana & Drought (past 20-30 years) & $\begin{array}{l}\text { Landscape transformation causing emotional distress, sense of loss } \\
\text { of belonging }\end{array}$ & Tschakert et al. (2013) \\
\hline Middle-class farmers, Australia & Drought (2000s) & $\begin{array}{l}\text { Landscape transformation, income loss from agriculture, social } \\
\text { conflict, poverty }\end{array}$ & Alston (2011) \\
\hline Arctic indigenous peoples & Warming (past decades) & $\begin{array}{l}\text { Changing ice and snow conditions, dwindling access to hunting } \\
\text { grounds }\end{array}$ & $\begin{array}{l}\text { Section 28.2.4; Table 18-9; Hovelsrud et } \\
\text { al. (2008); Ford (2009a); Brubaker et al. } \\
\text { (2011); Arctic Council (2013); Crate (2013 }\end{array}$ \\
\hline Industry workers in India & $\begin{array}{l}\text { Temperature variability and heat waves } \\
\text { (1960s to present) }\end{array}$ & $\begin{array}{l}\text { Decrease of fully workable days since 1960; limited ability to carry } \\
\text { out physical work; health impacts }\end{array}$ & $\begin{array}{l}\text { Ayyappan et al. (2009); Balakrishnan et al } \\
\text { (2010); Dash and Kjellström (2011) }\end{array}$ \\
\hline $\begin{array}{l}\text { Farmers in Subarnabad, } \\
\text { Bangladesh }\end{array}$ & Sea level rise ( $\sim 1980$ s to present) & $\begin{array}{l}\text { Salt water intrusion; shift from agriculture to shrimp farming; loss of } \\
\text { agricultural livelihoods }\end{array}$ & Pouliotte et al. (2009) \\
\hline Women farmers, Ghana & $\begin{array}{l}\text { Rainfall-related climate variability } \\
(\sim 1990 \text { s and } 2000 \mathrm{~s})\end{array}$ & Adaptation practices in agriculture produce gender inequalities. & Carr (2008) \\
\hline $\begin{array}{l}\text { Smallholder farmers in } \\
\text { highlands of Bolivia }\end{array}$ & $\begin{array}{l}\text { Locally perceived changes in } \\
\text { temperature means and extremes, and } \\
\text { rainfall seasonality ( 1990s and 2000s) }\end{array}$ & $\begin{array}{l}\text { Stress on household resources due to need to respond to increasing } \\
\text { plant pests; switching to other crop types or livestock }\end{array}$ & McDowell and Hess (2012) \\
\hline
\end{tabular}

variability rather than on climate change, so neither the detection of the effect of climate change nor an assessment of its magnitude can currently made with a degree of confidence.

Finally, efforts have been made to establish a link between high temperatures and violent crime (Anderson, 1987; Field, 1992; Anderson, 2001; Rotton and Cohn, 2001; Butke and Sheridan, 2010; Breetzke and Cohn, 2012; Gamble and Hess, 2012). However, the findings remain controversial with other studies identifying non-climate factors as explaining variations in the rate of violent crime (Kawachi et al., 1999; Fajnzylber et al., 2002; Neumayer, 2003; Cole and Gramajo, 2009). Again, the focus in this work has been on weather rather than climate and, in light of this and the equivocal nature of the results, neither the detection of a climate change effect nor an assessment of its magnitude can currently be made with a degree of confidence.

The impact of future climate change on human displacement and migration has been identified as an emerging risk (Section 19.4.2.1). The social, economic, and environmental factors underlying migration are complex and varied (see, e.g., Black et al., 2011) and it has not been possible to detect the effect of observed climate change nor assess its magnitude with any degree of confidence (see also Section 12.4.1.1). Migration in response to climate-related events has been identified in sub-Saharan Africa (Marchiori et al., 2012), with evidence from North America a subject of disagreement (Auffhammer and Vincent, 2012; Feng et al., 2012; Feng and Oppenheimer, 2012).

\subsubsection{Livelihoods and Poverty}

The vulnerability of the world's poor to climate change, and more generally the sensitivity of many livelihood aspects to climate variability, has been shown in this and earlier IPCC reports (see Chapter 13).
However, available research about climate-related effects on livelihood and poverty has focused on impacts of climate extremes or year to year climate variability rather than long-term climatic trends, resulting in a paucity of evidence on observed impacts of climate change on livelihoods and poverty. Moreover, detection of changes in livelihood aspects is often difficult due to a lack of observations (Section 13.2.1), while multiple confounding factors and lack of both adequate climate data and system understanding preclude attribution (Nielsen and Reenberg, 2010).

Table 18-4 summarizes examples of impacts on livelihoods related to climatic trends, climate variability, and extreme weather events. Impacted natural assets include land, water, fish stocks, and livestock (Osbahr et al., 2008; Bunce et al., 2010). There is growing concern about negative effects of climate change and ocean acidification on marine and coastal fisheries, and the livelihoods of fisherfolks (Cooley and Doney, 2009; Badjeck et al., 2010); however, there are no studies evaluating observed impacts.

Climate-related impacts disproportionately affect poor populations, thus increasing social and economic inequalities, both in urban and rural areas, and in low-, middle-, and high-income countries (Sections 13.1.4, 13.2.1). Evidence for poor people in high-income nations being disproportionately affected by extreme weather events comes, for instance, from 2005 U.S. Hurricane Katrina (Elliott and Pais, 2006; Bullard and Wright, 2010; see also Section 13.2.1.5) or severe drought in Australia (Alston, 2011). Glacial lake outburst floods in the Peruvian Andes also affected different populations depending on their degree of exposure, level of vulnerability, race, ethnicity, and socioeconomic class (Carey, 2010; Carey et al., 2012b). Owing to gender-specific roles within the household, communities, and wider sociopolitical and institutional networks, a gender bias has been found in observations of impacts of extreme weather events and climate variability (Carr, 2008; Arora-Jonsson, 2011; Nightingale, 2011; see also Box 13-1). 
Poor people living in hazard exposed areas in Africa and Latin America were increasingly affected by floods and landslides in the 1990s and 2000s (high confidence; Handmer et al., 2012); however, most of this trend was due to increased urbanization in such areas (Douglas et al., 2008; Hardoy and Pandiella, 2009). There is evidence of a decline in average precipitation in West Africa since 1960 (Lacombe et al., 2012), including repeated droughts (Dietz et al., 2004; Armah et al., 2011), which in some cases has been partly attributed to anthropogenic climate forcing (Held et al., 2005; Jenkins et al., 2005; Biasutti and Giannini, 2006). However, there is only limited evidence of changes in poverty among affected small-holder and subsistence farmers that can be attributed to climate drivers such as rainfall decline and droughts (Section 13.2.1).

Livelihoods of indigenous people in the Arctic have been identified as among the most severely affected by climate change, including food security aspects, traditional travel and hunting, and cultural values and references (Hovelsrud et al., 2008; Ford et al., 2009; Ford, 2009a,b; Beaumier and Ford, 2010; Pearce et al., 2010; Olsen et al., 2011; Eira, 2012; Crate, 2013; see also Box 18-5, Table 18-9). Impacts of rising temperatures, increased variability, and weather extremes on crops and livestock of indigenous people in highlands were reported from Tibet Autonomous Region, China (Byg and Salick, 2009), and the Andes of Bolivia (McDowell and Hess, 2012).

\subsection{Detection and Attribution of Observed Climate Impacts across Regions}

Since the AR4, significant new knowledge about detected impacts of recent climate change has been gained from all continents and oceans

Table 18-5 | Observed impacts of climate change reported since AR4 on mountains, snow, and ice, over the past several decades, across major world regions, with descriptors for (1) the confidence in detection of a climate change impact; (2) the relative contribution of climate change to the observed change, compared to that of non-climatic drivers; (3) the main climatic driver(s) causing the impacts; (4) the reference behavior of the system in the absence of climate change; and (5) the confidence in attribution of the impacts to climate change. References to related chapters in this report are given as well as key references to other IPCC reports and the scientific literature. Absence of climate change impacts from this table does not imply that such impacts have not occurred.

\begin{tabular}{|c|c|c|c|c|c|c|c|}
\hline & Mountains, snow and ice & References & $\begin{array}{l}\text { Confidence } \\
\text { in } \\
\text { detection }\end{array}$ & $\begin{array}{l}\text { Role of } \\
\text { climate }\end{array}$ & $\begin{array}{l}\text { Climate } \\
\text { driver }\end{array}$ & $\begin{array}{l}\text { Reference } \\
\text { behavior }\end{array}$ & $\begin{array}{l}\text { Confidence } \\
\text { in } \\
\text { attribution }\end{array}$ \\
\hline Africa & $\begin{array}{l}\text { Retreat of tropical highland glaciers in } \\
\text { East Africa }\end{array}$ & Mölg et al. $(2008,2012)$; Taylor et al. (2009) & Very high & Major & $\begin{array}{l}\text { Warming, } \\
\text { drying }\end{array}$ & No change & High \\
\hline Europe & $\begin{array}{l}\text { Retreat of Alpine, Scandinavian, and } \\
\text { Icelandic glaciers }\end{array}$ & $\begin{array}{l}\text { WGI AR5 Section 4.3.3; Bauder et al. (2007); Björnsson } \\
\text { and Pálsson (2008); Paul and Haeberli (2008); WGMS } \\
\text { (2008); Zemp et al. (2009); Andreassen et al. (2012); } \\
\text { Marzeion et al. (2012); Gardner et al. (2013) }\end{array}$ & Very high & Major & Warming & No change & High \\
\hline \multirow[t]{2}{*}{ Asia } & $\begin{array}{l}\text { Permafrost degradation in Siberia, } \\
\text { Central Asia, and the Tibetan Plateau }\end{array}$ & $\begin{array}{l}\text { WGI AR5 Section 4.7.2; Section 24.4.2.2; Romanovsky } \\
\text { et al. (2010); Yang et al. (2013) }\end{array}$ & High & Major & Warming & No change & High \\
\hline & $\begin{array}{l}\text { Shrinking mountain glaciers across most } \\
\text { of Asia }\end{array}$ & $\begin{array}{l}\text { WGI AR5 Section 4.3.3; Section 24.4.1.2; Box 3-1; } \\
\text { Bolch et al. (2012); Cogley (2012); Gardelle et al. } \\
\text { (2012); Kääb et al. (2012); Yao et al. (2012); Gardner et } \\
\text { al. (2013); Stokes et al. (2013) }\end{array}$ & High & Major & Warming & No change & Medium \\
\hline \multirow[t]{2}{*}{$\begin{array}{l}\text { North } \\
\text { America }\end{array}$} & $\begin{array}{l}\text { Shrinkage of glaciers across western and } \\
\text { northern North America }\end{array}$ & WGI AR5 Section 4.3.3; Gardner et al. (2013) & High & Major & Warming & No change & High \\
\hline & $\begin{array}{l}\text { Decreasing amount of water in spring } \\
\text { snowpack in western North America } \\
1960-2002\end{array}$ & Stewart et al. (2005); Mote (2006); Barnett et al. (2008) & High & Major & Warming & No change & High \\
\hline $\begin{array}{l}\text { South and } \\
\text { Central } \\
\text { America }\end{array}$ & Shrinkage of Andean glaciers & $\begin{array}{l}\text { WGI AR5 Section 4.3.3; Section 27.3.1.1; Table 27-3; } \\
\text { Vuille et al. (2008); Bradley et al. (2009); Jomelli et } \\
\text { al. (2009); Poveda and Pineda (2009); Marzeion et al. } \\
\text { (2012); Gardner et al. (2013); Rabatel et al. (2013) }\end{array}$ & High & Major & Warming & No change & High \\
\hline \multirow[t]{2}{*}{$\begin{array}{l}\text { Polar } \\
\text { regions }\end{array}$} & $\begin{array}{l}\text { Decreasing Arctic sea ice cover in } \\
\text { summer }\end{array}$ & WGI AR5 Section 4.2.2.1; ACIA (2005); AMAP (2011) & Very high & Major & $\begin{array}{l}\text { Air and } \\
\text { ocean } \\
\text { warming, } \\
\text { change } \\
\text { in ocean } \\
\text { circulation }\end{array}$ & No change & High \\
\hline & Ice mass loss along coastal Antarctica & $\begin{array}{l}\text { WGI AR5 Sections 4.3.3, 4.4, and 10.5.2.1; Gardner et } \\
\text { al. (2013); Miles et al. (2013) }\end{array}$ & Medium & Major & Warming & No change & Medium \\
\hline
\end{tabular}


Table 18-6 | Observed impacts of climate change reported since AR4 on rivers, lakes, and soil moisture, over the past several decades, across major world regions, with descriptors for (1) the confidence in detection of a climate change impact; (2) the relative contribution of climate change to the observed change, compared to that of non-climatic drivers; (3) the main climatic driver(s) causing the impacts; (4) the reference behavior of the system in the absence of climate change; and (5) the confidence in attribution of the impacts to climate change. References to related chapters in this report are given as well as key references to other IPCC reports and the scientific literature. Absence of climate change impacts from this table does not imply that such impacts have not occurred.

\begin{tabular}{|c|c|c|c|c|c|c|c|}
\hline & Rivers, lakes, and soil moisture & References & $\begin{array}{l}\text { Confidence } \\
\text { in } \\
\text { detection }\end{array}$ & $\begin{array}{l}\text { Role of } \\
\text { climate }\end{array}$ & Climate driver & $\begin{array}{l}\text { Reference } \\
\text { behavior }\end{array}$ & $\begin{array}{l}\text { Confidence } \\
\text { in } \\
\text { attribution }\end{array}$ \\
\hline \multirow[t]{3}{*}{ Africa } & $\begin{array}{l}\text { Reduced discharge in West African } \\
\text { rivers }\end{array}$ & $\begin{array}{l}\text { d'Orgeval and Polcher (2008); Dai et al. } \\
\text { (2009); Di Baldassarre et al. (2010) }\end{array}$ & Medium & Major & $\begin{array}{l}\text { Reduced } \\
\text { precipitation }\end{array}$ & No change & Low \\
\hline & $\begin{array}{l}\text { Lake surface warming and water } \\
\text { column stratification increases in the } \\
\text { Great Lakes and Lake Kariba }\end{array}$ & $\begin{array}{l}\text { Section 22.3.2.2; Tierney et al. (2010); } \\
\text { Ndebele-Murisa et al. (2011); Powers et al. } \\
(2011)\end{array}$ & High & Major & Warming & No change & High \\
\hline & $\begin{array}{l}\text { Increased soil moisture drought in } \\
\text { the Sahel since 1970, partially wetter } \\
\text { conditions since } 1990\end{array}$ & $\begin{array}{l}\text { Section 22.2.2.1; Hoerling et al. (2006); } \\
\text { Giannini et al. (2008); Greene et al. (2009); } \\
\text { Seneviratne et al. (2012) }\end{array}$ & Medium & Major & $\begin{array}{l}\text { Change in } \\
\text { precipitation }\end{array}$ & No change & Medium \\
\hline Europe & $\begin{array}{l}\text { Changes in the occurrence of extreme } \\
\text { river discharges and floods }\end{array}$ & $\begin{array}{l}\text { Section 23.2.3; Schmocker-Fackel and Naef } \\
\text { (2010); Beniston et al. (2011); Cutter et } \\
\text { al. (2012); Vorogushyn and Merz (2012); } \\
\text { Kundzewicz et al. (2013) }\end{array}$ & Low & Minor & $\begin{array}{l}\text { Change in } \\
\text { precipitation; } \\
\text { change in extreme } \\
\text { precipitation }\end{array}$ & No change & Very low \\
\hline \multirow[t]{5}{*}{ Asia } & $\begin{array}{l}\text { Changes in water availability in many } \\
\text { Chinese rivers }\end{array}$ & $\begin{array}{l}\text { Table SM24-4; Zhang et al. (2007); Zhang, S. } \\
\text { et al. (2008) }\end{array}$ & High & Minor & $\begin{array}{l}\text { Change in } \\
\text { precipitation }\end{array}$ & $\begin{array}{l}\text { Changes due } \\
\text { to land use }\end{array}$ & Low \\
\hline & $\begin{array}{l}\text { Increased flow in several rivers in China } \\
\text { due to shrinking glaciers }\end{array}$ & $\begin{array}{l}\text { Casassa et al. (2009); Li et al. (2010); } \\
\text { Zhang, Y. et al. (2008) }\end{array}$ & High & Major & Warming & No change & High \\
\hline & $\begin{array}{l}\text { Earlier timing of maximum spring flood } \\
\text { in Russian rivers }\end{array}$ & $\begin{array}{l}\text { Section 28.2.1.1; Shiklomanov et al. (2007); } \\
\text { Tan et al. (2011) }\end{array}$ & High & Major & Warming & No change & Medium \\
\hline & $\begin{array}{l}\text { Reduced soil moisture in North Central } \\
\text { and Northeast China 1950-2006 }\end{array}$ & $\begin{array}{l}\text { Sections } 24.3 .1 \text { and 24.4.1.2; Sheffield } \\
\text { and Wood (2007); Wang, A. et al. (2011); } \\
\text { Seneviratne et al. (2012) }\end{array}$ & Medium & Major & $\begin{array}{l}\text { Warming; change in } \\
\text { precipitation }\end{array}$ & No change & Medium \\
\hline & $\begin{array}{l}\text { Surface water degradation in parts } \\
\text { of Asia }\end{array}$ & $\begin{array}{l}\text { Section 24.4.1.2; Prathumratana et al. (2008); } \\
\text { Delpla et al. (2009); Huang et al. (2009) }\end{array}$ & Medium & Minor & $\begin{array}{l}\text { Warming; change in } \\
\text { precipitation }\end{array}$ & $\begin{array}{l}\text { Changes due } \\
\text { to land use }\end{array}$ & Medium \\
\hline \multirow[t]{2}{*}{ Australasia } & $\begin{array}{l}\text { Intensification of hydrological drought } \\
\text { due to regional warming in Southeast } \\
\text { Australia }\end{array}$ & Table 25-1; Nicholls (2006); Cai et al. (2009) & Low & Minor & Warming & No change & Low \\
\hline & $\begin{array}{l}\text { Reduced inflow in river systems in } \\
\text { southwestern Australia (since the } \\
\text { mid-1970s) }\end{array}$ & $\begin{array}{l}\text { Table 25-1; Section 25.5.1; Cai and Cowan } \\
\text { (2006); Nicholls (2010) }\end{array}$ & High & Major & $\begin{array}{l}\text { Change in } \\
\text { precipitation; } \\
\text { warming }\end{array}$ & No change & High \\
\hline \multirow[t]{2}{*}{$\begin{array}{l}\text { North } \\
\text { America }\end{array}$} & $\begin{array}{l}\text { Shift to earlier peak flow in snow } \\
\text { dominated rivers in western North } \\
\text { America }\end{array}$ & Barnett et al. (2008) & High & Major & $\begin{array}{l}\text { Warming; change } \\
\text { in snow }\end{array}$ & No change & High \\
\hline & $\begin{array}{l}\text { Runoff increases in the midwestern and } \\
\text { northeastern USA }\end{array}$ & Georgakakos et al. (2013) & High & Minor & $\begin{array}{l}\text { Change in } \\
\text { precipitation; } \\
\text { warming }\end{array}$ & No change & Medium \\
\hline \multirow[t]{3}{*}{$\begin{array}{l}\text { South and } \\
\text { Central } \\
\text { America }\end{array}$} & $\begin{array}{l}\text { Changes in extreme flows in Amazon } \\
\text { River }\end{array}$ & $\begin{array}{l}\text { Section 27.3.1.1; Butt et al. (2011); Wang, G. } \\
\text { et al. (2011); Espinoza et al. (2013) }\end{array}$ & High & Major & $\begin{array}{l}\text { Change in } \\
\text { precipitation; } \\
\text { change in extreme } \\
\text { precipitation }\end{array}$ & No change & Medium \\
\hline & $\begin{array}{l}\text { Changing discharge patterns in rivers } \\
\text { in the Western Andes; for major river } \\
\text { basins in Colombia discharge has } \\
\text { decreased during the last } 30-40 \text { years }\end{array}$ & $\begin{array}{l}\text { Section 27.3.1.1; Table 27-3; Vuille et al. } \\
\text { (2008); Casassa et al. (2009); Poveda and } \\
\text { Pineda (2009); Baraer et al. (2012); Rabatel } \\
\text { et al. (2013) }\end{array}$ & Medium & Major & Warming & No change & Medium \\
\hline & $\begin{array}{l}\text { Increased streamflow in sub-basins of } \\
\text { the La Plata River }\end{array}$ & $\begin{array}{l}\text { Section 27.3.1.1; Pasquini and Depetris } \\
\text { (2007); Krepper et al. (2008); Saurral et al. } \\
\text { (2008); Conway and Mahé (2009); Krepper } \\
\text { and Zucarelli (2010); Doyle and Barros (2011) }\end{array}$ & High & Major & $\begin{array}{l}\text { Change in } \\
\text { precipitation }\end{array}$ & $\begin{array}{l}\text { Increase due } \\
\text { to land use }\end{array}$ & High \\
\hline \multirow[t]{4}{*}{$\begin{array}{l}\text { Polar } \\
\text { regions }\end{array}$} & $\begin{array}{l}\text { Increased river discharge for large } \\
\text { circumpolar rivers (1997-2007) }\end{array}$ & $\begin{array}{l}\text { Section 28.2.1.1; Overeem and Syvitsky, } \\
(2010)\end{array}$ & High & Major & $\begin{array}{l}\text { Warming; change in } \\
\text { precipitation; change } \\
\text { in snow cover }\end{array}$ & No change & Low \\
\hline & $\begin{array}{l}\text { Winter minimum river flow increase in } \\
\text { most sectors of the Arctic }\end{array}$ & Section 28.2.1.1; Tan et al. (2011) & High & Major & $\begin{array}{l}\text { Warming; change in } \\
\text { snow cover }\end{array}$ & No change & Medium \\
\hline & $\begin{array}{l}\text { Increasing lake water temperatures } \\
\text { 1985-2009, prolonged ice-free seasons }\end{array}$ & $\begin{array}{l}\text { Section 28.2.1.1; Callaghan et al. (2010); } \\
\text { Schneider and Hook (2010) }\end{array}$ & Medium & Major & Warming & No change & Medium \\
\hline & $\begin{array}{l}\text { Thermokarst lakes disappear due to } \\
\text { permafrost degradation in the low } \\
\text { Arctic, new ones created in areas of } \\
\text { formerly frozen peat }\end{array}$ & $\begin{array}{l}\text { Section 28.2.1.1; Riordan et al. (2006); Marsh } \\
\text { et al. (2008); Prowse and Brown (2010) }\end{array}$ & High & Major & Warming & No change & High \\
\hline $\begin{array}{l}\text { Small } \\
\text { islands }\end{array}$ & Increased water scarcity in Jamaica & Gamble et al. (2010); Jury and Winter (2010) & Low & Minor & $\begin{array}{l}\text { Change in } \\
\text { precipitation }\end{array}$ & $\begin{array}{l}\text { Increase due } \\
\text { to water use }\end{array}$ & Very low \\
\hline
\end{tabular}


Table 18-7 | Observed impacts of climate change reported since AR4 on terrestrial ecosystems, over the past several decades, across major world regions, with descriptors for: (1) the confidence in detection of a climate change impact; (2) the relative contribution of climate change to the observed change, compared to that of non-climatic drivers; (3) the main climatic driver(s) causing the impacts; (4) the reference behavior of the system in the absence of climate change; and (5) the confidence in attribution of the impacts to climate change. References to related chapters in this report are given as well as key references to other IPCC reports and the scientific literature. Absence of climate change impacts from this table does not imply that such impacts have not occurred.

\begin{tabular}{|c|c|c|c|c|c|c|c|}
\hline & Terrestrial ecosystems & References & $\begin{array}{c}\text { Confidence } \\
\text { in } \\
\text { detection }\end{array}$ & $\begin{array}{l}\text { Role of } \\
\text { climate }\end{array}$ & $\begin{array}{l}\text { Climate } \\
\text { driver }\end{array}$ & $\begin{array}{l}\text { Reference } \\
\text { behavior }\end{array}$ & $\begin{array}{l}\text { Confidence } \\
\text { in } \\
\text { attribution }\end{array}$ \\
\hline \multirow[t]{3}{*}{ Africa } & $\begin{array}{l}\text { Tree density decreases in Western Sahel } \\
\text { and semi-arid Morocco }\end{array}$ & $\begin{array}{l}\text { Section 22.3.2.1; Gonzalez et al. (2012); Le } \\
\text { Polain de Waroux and Lambin (2012) }\end{array}$ & Medium & Major & $\begin{array}{l}\text { Change in } \\
\text { precipitation }\end{array}$ & $\begin{array}{l}\text { Changes due to } \\
\text { land use }\end{array}$ & Medium \\
\hline & $\begin{array}{l}\text { Range shifts of several southern plants } \\
\text { and animals: South African bird species } \\
\text { polewards; Madagascan reptiles and } \\
\text { amphibians upwards; Namib aloe } \\
\text { contracting ranges }\end{array}$ & $\begin{array}{l}\text { Table 22-3; Foden et al. (2007); Raxworthy et } \\
\text { al. (2008); Hockey and Midgley (2009); Hockey } \\
\text { et al. (2011) }\end{array}$ & High & Major & Warming & $\begin{array}{l}\text { Changes due to } \\
\text { land use }\end{array}$ & Medium \\
\hline & Wildfires increase on Mt. Kilimanjaro & Table 22-3; Hemp (2005) & Medium & Major & $\begin{array}{l}\text { Warming; } \\
\text { drying }\end{array}$ & No change & Low \\
\hline \multirow[t]{3}{*}{ Europe } & $\begin{array}{l}\text { Earlier greening, earlier leaf emergence } \\
\text { and fruiting in temperate and boreal trees }\end{array}$ & Section 4.3.2.1; Menzel et al. (2006) & High & Major & Warming & No change & High \\
\hline & $\begin{array}{l}\text { Increased colonization of alien plant } \\
\text { species in Europe }\end{array}$ & $\begin{array}{l}\text { Section 4.2.4.6; Table 23-6; Walther et al. } \\
\text { (2009) }\end{array}$ & Medium & Major & Warming & Some invasion & Medium \\
\hline & $\begin{array}{l}\text { Increasing burnt forest areas during } \\
\text { recent decades in Portugal and Greece }\end{array}$ & $\begin{array}{l}\text { Table 23-6; Camia and Amatulli (2009); } \\
\text { Hoinka et al. (2009); Costa et al. (2011); } \\
\text { Koutsias et al. (2012) }\end{array}$ & High & Major & $\begin{array}{l}\text { Warming; } \\
\text { change in } \\
\text { precipitation }\end{array}$ & $\begin{array}{l}\text { Some increase } \\
\text { due to land use }\end{array}$ & High \\
\hline \multirow[t]{4}{*}{ Asia } & $\begin{array}{l}\text { Changes in plant phenology and growth } \\
\text { in many parts of Asia (earlier greening), } \\
\text { particularly in the north and the east }\end{array}$ & $\begin{array}{l}\text { Sections 4.3.2.1 and 24.4.2.2; Figure 4-4; Ma } \\
\text { and Zhou (2012); Panday and Ghimire (2012); } \\
\text { Shrestha et al. (2012); Ogawa-Onishi and } \\
\text { Berry (2013) }\end{array}$ & High & Major & Warming & No change & Medium \\
\hline & $\begin{array}{l}\text { Distribution shifts in many plant and } \\
\text { animal species, particularly in the north of } \\
\text { Asia, upwards in elevation or polewards }\end{array}$ & $\begin{array}{l}\text { Sections 4.3.2.5 and 24.4.2.2; Figure 4-4; } \\
\text { Moiseev et al. (2010); Chen et al. (2011); Jump } \\
\text { et al. (2012); Ogawa-Onishi and Berry (2013) }\end{array}$ & High & Major & Warming & No change & Medium \\
\hline & $\begin{array}{l}\text { Invasion of Siberian larch forests by pine } \\
\text { and spruce during recent decades }\end{array}$ & $\begin{array}{l}\text { Section 24.4.2.2; Kharuk et al. (2010); Lloyd } \\
\text { et al. (2011) }\end{array}$ & Medium & Major & Warming & No change & Low \\
\hline & $\begin{array}{l}\text { Advance of shrubs into the Siberian } \\
\text { tundra }\end{array}$ & $\begin{array}{l}\text { Sections 4.3.3.4, 24.4.2.2, and 28.2.3.1; Henry } \\
\text { and Elmendorf (2010); Blok et al. (2011) }\end{array}$ & High & Major & Warming & No change & High \\
\hline \multirow{2}{*}{ Australasia } & $\begin{array}{l}\text { Expansion of monsoon rainforest at } \\
\text { expense of savannah and grasslands in } \\
\text { north Australia }\end{array}$ & $\begin{array}{l}\text { Table 25-3; Banfai and Bowman (2007); } \\
\text { Bowman et al. (2010) }\end{array}$ & Medium & Major & $\begin{array}{l}\text { Change in } \\
\text { precipitation; } \\
\text { increased } \mathrm{CO}_{2}\end{array}$ & No change & Medium \\
\hline & $\begin{array}{l}\text { Migration of glass eels advanced by } \\
\text { several weeks in Waikato River, New } \\
\text { Zealand }\end{array}$ & Table 25-3; Jellyman et al. (2009) & Medium & Major & Warming & No change & Low \\
\hline
\end{tabular}

of the world, as assessed in Chapters 22 to 30 of this report. Tables 18-5 to 18-9 summarize impacts in major natural and human systems, at the local to continental scale, for which assessment of the role of climate as one driver has been possible. The following paragraphs provide a summary of recent climate changes in these regions along with notes about particular challenges in the regional assessments.

For much of Africa, knowledge about recent climate change is limited, owing to weak climate monitoring and gaps in coverage that continue to exist. On the other hand, the low natural temperature variability over the continent allows earlier detection of warming signals. Thus there is medium to high confidence in regional warming, with low to high confidence in attribution to anthropogenic emissions. A main regional feature has been the drying of the Sahel during the decades following 1970, but that trend has halted during the most recent decade (Hoerling et al., 2006; Giannini et al., 2008; Greene et al., 2009; Seneviratne et al., 2012). African natural and human systems present challenges for the potential detection and attribution of responses to climate change. Given the weak spatial and temporal variations in temperature, there is smaller scope for migrational and phenological 
Table 18-7 (continued)

\begin{tabular}{|c|c|c|c|c|c|c|c|}
\hline & Terrestrial ecosystems & References & $\begin{array}{c}\text { Confidence } \\
\text { in } \\
\text { detection }\end{array}$ & $\begin{array}{l}\text { Role of } \\
\text { climate }\end{array}$ & $\begin{array}{l}\text { Climate } \\
\text { driver }\end{array}$ & $\begin{array}{l}\text { Reference } \\
\text { behavior }\end{array}$ & $\begin{array}{l}\text { Confidence } \\
\text { in } \\
\text { attribution }\end{array}$ \\
\hline \multirow[t]{4}{*}{$\begin{array}{l}\text { North } \\
\text { America }\end{array}$} & $\begin{array}{l}\text { Phenology changes and species } \\
\text { distribution shifts upward in elevation and } \\
\text { northward across multiple taxa }\end{array}$ & $\begin{array}{l}\text { Section 26.4.1; Parmesan and Galbraith } \\
\text { (2004); Parmesan (2006); Kelly and Goulden } \\
\text { (2008); Moritz et al. (2008); Tingley et al. } \\
\text { (2009) }\end{array}$ & High & Major & Warming & No change & Medium \\
\hline & $\begin{array}{l}\text { Increased wildfire frequency in subarctic } \\
\text { conifer forests and tundra }\end{array}$ & $\begin{array}{l}\text { Section 28.2.3.1; Mack et al. (2011); Mann et } \\
\text { al. (2012) }\end{array}$ & High & Major & Warming & No change & Medium \\
\hline & $\begin{array}{l}\text { Regional increases in tree mortality and } \\
\text { insect infestations in forests }\end{array}$ & $\begin{array}{l}\text { Section 26.4.2.1; Van Mantgem et al. (2009); } \\
\text { Peng et al. (2011) }\end{array}$ & Medium & Minor & Warming & No change & Low \\
\hline & $\begin{array}{l}\text { Increase in wildfire activity, fire frequency } \\
\text { and duration, and burnt area in forests } \\
\text { of the western US and boreal forests in } \\
\text { Canada }\end{array}$ & $\begin{array}{l}\text { Box 26-2; Gillett et al. (2004); Westerling et al. } \\
\text { (2006); Girardin et al. (2013) }\end{array}$ & High & Minor & $\begin{array}{l}\text { Warming; } \\
\text { change in } \\
\text { precipitation }\end{array}$ & $\begin{array}{l}\text { Changes due to } \\
\text { land use and fire } \\
\text { management }\end{array}$ & Medium \\
\hline \multirow{2}{*}{$\begin{array}{l}\text { South and } \\
\text { Central } \\
\text { America }\end{array}$} & $\begin{array}{l}\text { Increased tree mortality and forest fire in } \\
\text { the Amazon }\end{array}$ & Section 4.3.3.1.3; Phillips et al. (2009) & Medium & Minor & Warming & No change & Low \\
\hline & $\begin{array}{l}\text { Degrading and receding rainforest in the } \\
\text { Amazon }\end{array}$ & $\begin{array}{l}\text { Sections 18.3.2.4, 27.2.2.1, and 27.3.2.1; Etter } \\
\text { et al. (2006); Nepstad et al. (2006); Oliveira et } \\
\text { al. (2007); Wassenaar et al. (2007); Killeen et } \\
\text { al. (2008); Nepstad and Stickler (2008) }\end{array}$ & Low & Minor & Warming & $\begin{array}{l}\text { Deforestation } \\
\text { and land } \\
\text { degradation }\end{array}$ & Low \\
\hline \multirow[t]{7}{*}{$\begin{array}{l}\text { Polar } \\
\text { regions }\end{array}$} & $\begin{array}{l}\text { Increase in shrub cover in tundra in North } \\
\text { America and Eurasia }\end{array}$ & $\begin{array}{l}\text { Section 28.2.3.1.2; Tape et al. (2006); Walker } \\
\text { et al. (2006); Henry and Elmendorf (2010); } \\
\text { Blok et al. (2011); Elmendorf et al. (2012); } \\
\text { Tape et al. (2012) }\end{array}$ & High & Major & Warming & No change & High \\
\hline & $\begin{array}{l}\text { Advance of Arctic tree-line in latitude and } \\
\text { altitude }\end{array}$ & $\begin{array}{l}\text { Section 28.2.3.1.2; AMAP (2011); Hedenås et } \\
\text { al. (2011); Van Bogaert et al. (2011) }\end{array}$ & High & Major & Warming & No change & Medium \\
\hline & $\begin{array}{l}\text { Loss of snow-bed ecosystems and tussock } \\
\text { tundra }\end{array}$ & $\begin{array}{l}\text { Section 28.2.3.1.2; Björk and Molau (2007); } \\
\text { Molau (2010a); Hedenås et al. (2011); } \\
\text { Callaghan et al. (2013) }\end{array}$ & High & Major & $\begin{array}{l}\text { Warming; } \\
\text { change in } \\
\text { precipitation }\end{array}$ & No change & High \\
\hline & $\begin{array}{l}\text { Impacts on tundra animals from increased } \\
\text { ice layers in snow pack, following rain-on- } \\
\text { snow events }\end{array}$ & $\begin{array}{l}\text { Section 28.2.3.1.3; Callaghan et al. (2011); } \\
\text { Hansen et al. (2013) }\end{array}$ & Medium & Major & $\begin{array}{l}\text { Change in } \\
\text { precipitation; } \\
\text { warming }\end{array}$ & No change & Medium \\
\hline & $\begin{array}{l}\text { Changes in breeding area and } \\
\text { population size of subarctic birds, due to } \\
\text { snowbed reduction and/or tundra shrub } \\
\text { encroachment }\end{array}$ & Molau (2010b); Callaghan et al. (2013) & High & Major & Warming & No change & Medium \\
\hline & $\begin{array}{l}\text { Increase in plant species ranges in the } \\
\text { West Antarctic Peninsula and nearby } \\
\text { islands over the past } 50 \text { years }\end{array}$ & $\begin{array}{l}\text { Section 28.2.3.2; Fowbert and Smith (1994); } \\
\text { Parnikoza et al. (2009) }\end{array}$ & High & Major & Warming & No change & High \\
\hline & $\begin{array}{l}\text { Increasing phytoplankton productivity in } \\
\text { Signy Island lake waters }\end{array}$ & Quayle et al. (2002); Laybourn-Parry (2003) & High & Major & Warming & No change & High \\
\hline \multirow[t]{3}{*}{$\begin{array}{l}\text { Small } \\
\text { islands }\end{array}$} & $\begin{array}{l}\text { Changes in tropical bird populations in } \\
\text { Mauritius }\end{array}$ & Section 29.3.2; Senapathi et al. (2011) & Medium & Major & $\begin{array}{l}\text { Change in } \\
\text { precipitation }\end{array}$ & No change & Medium \\
\hline & Decline of an endemic plant in Hawai'i & Krushelnycky et al. (2013) & Medium & Major & $\begin{array}{l}\text { Warming; } \\
\text { change in } \\
\text { precipitation }\end{array}$ & No change & Medium \\
\hline & $\begin{array}{l}\text { Upward trend in tree lines and associated } \\
\text { fauna on high-elevation islands }\end{array}$ & $\begin{array}{l}\text { Section 29.3.2; Benning et al. (2002); Jump } \\
\text { et al. (2006) }\end{array}$ & Low & Minor & Warming & No change & Low \\
\hline
\end{tabular}

responses to anthropogenic climate change than in other parts of the world. High-quality monitoring is relatively sparse in time and space, and is often unsuitable for detecting changes across margins and borders where responses to climate change are most expected. The dearth of studies examining attribution questions means it is currently difficult to estimate the degree to which studies are selectively published based on results, and thus to determine whether each attribution study is indicative only of local reasons for concern or if it is more generally representative of a broader domain.

Amongst all continents, Europe has the longest tradition in climate monitoring. Warming has been occurring across the continent in all seasons, with an associated decreasing frequency of cold extremes and increasing frequency of hot extremes (Seneviratne et al., 2012). The Mediterranean basin has been getting drier, while northern areas have been getting wetter (Section 23.2.2.1), with a general increase in the frequency of extreme wet events everywhere (Seneviratne et al., 2012).

Asia spans a particularly wide range of climate types. Warming has been observed throughout the continent, with northern areas among the fastest warming on the planet. Precipitation trends vary geographically, with a weaker Indian monsoon (WGI AR5 Section 14.2.2.1) and contrasting increasing and drying trends over coastal and inland China (Section 24.3).

Warming has occurred in Australasia during the past century, with hot extremes becoming more frequent and cold extremes becoming less 
Table 18-8 | Observed impacts of climate change reported since AR4 on coastal and marine ecosystems, over the past several decades, across major world regions, with descriptors for (1) the confidence in detection of a climate change impact; (2) the relative contribution of climate change to the observed change, compared to that of non-climatic drivers; (3) the main climatic driver(s) causing the impacts; (4) the reference behavior of the system in the absence of climate change; and (5) the confidence in attribution of the impacts to climate change. References to related chapters in this report are given as well as key references to other IPCC reports and the scientific literature. Absence of climate change impacts from this table does not imply that such impacts have not occurred.

\begin{tabular}{|c|c|c|c|c|c|c|c|}
\hline & $\begin{array}{l}\text { Coastal and marine } \\
\text { ecosystems }\end{array}$ & References & $\begin{array}{c}\text { Confidence } \\
\text { in } \\
\text { detection }\end{array}$ & $\begin{array}{l}\text { Role of } \\
\text { climate }\end{array}$ & Climate driver & $\begin{array}{l}\text { Reference } \\
\text { behavior }\end{array}$ & $\begin{array}{l}\text { Confidence } \\
\text { in } \\
\text { attribution }\end{array}$ \\
\hline Africa & $\begin{array}{l}\text { Decline in coral reefs in tropical } \\
\text { African waters }\end{array}$ & $\begin{array}{l}\text { Sections 30.5.3.1.2 and 30.5.4.1.5; Baker et al. } \\
\text { (2008); Carpenter et al. (2008); Ateweberhan et } \\
\text { al. (2011) }\end{array}$ & High & Major & Ocean warming & $\begin{array}{l}\text { Decline due to } \\
\text { human impacts }\end{array}$ & High \\
\hline \multirow[t]{3}{*}{ Europe } & $\begin{array}{l}\text { Northward shifts in the } \\
\text { distributions of zooplankton, } \\
\text { fish, seabirds, and benthic } \\
\text { invertebrates in the northeast } \\
\text { Atlantic }\end{array}$ & $\begin{array}{l}\text { Box 6-1; Table 6-2; Sections 6.3.1, 23.6.5, and } \\
\text { 30.5.1.1; Beaugrand et al. (2009); Philippart et } \\
\text { al. (2011) }\end{array}$ & High & Major & Ocean warming & No change & High \\
\hline & $\begin{array}{l}\text { Northward and depth shift in } \\
\text { distribution of many fish species } \\
\text { across European seas }\end{array}$ & $\begin{array}{l}\text { Sections 6.3.1, 23.6.4, 23.6.5, and 30.5.3.1; } \\
\text { Table 6-2; Perry et al. (2005); Pörtner et } \\
\text { al. (2008); Beaugrand et al. (2009, 2010); } \\
\text { Beaugrand and Kirby (2010); Hermant et al. } \\
\text { (2010); Philippart et al. (2011) }\end{array}$ & High & Major & Ocean warming & No change & Medium \\
\hline & $\begin{array}{l}\text { Phenology changes in plankton } \\
\text { in the northeast Atlantic }\end{array}$ & $\begin{array}{l}\text { Box 6-1; Sections 6.3.1, 23.6.5, and 30.5.1.1; } \\
\text { Beaugrand et al. (2002, 2009); Edwards and } \\
\text { Richardson (2004); Philippart et al. (2011) }\end{array}$ & Medium & Major & Ocean warming & No change & Medium \\
\hline \multirow[t]{4}{*}{ Asia } & $\begin{array}{l}\text { Decline in coral reefs in tropical } \\
\text { Asian waters }\end{array}$ & $\begin{array}{l}\text { Sections 24.4.3.2 and 30.5.1.4.3; McLeod et al. } \\
\text { (2010); Krishnan et al. (2011); Coles and Riegl } \\
\text { (2012) }\end{array}$ & High & Major & Ocean warming & $\begin{array}{l}\text { Decline due to } \\
\text { human impacts }\end{array}$ & High \\
\hline & $\begin{array}{l}\text { Northward range extension of } \\
\text { coral in the East China Sea and } \\
\text { western Pacific, and a predatory } \\
\text { fish in the Sea of Japan }\end{array}$ & $\begin{array}{l}\text { Section 24.4.3.2; Yamano et al. (2011); Tian et al. } \\
\text { (2012); Ogawa-Onishi and Berry (2013) }\end{array}$ & Medium & Major & Ocean warming & No change & Medium \\
\hline & $\begin{array}{l}\text { Shift from sardines to anchovies } \\
\text { in the western North Pacific }\end{array}$ & $\begin{array}{l}\text { Sections 6.3.1 and 6.3.6; Table 6-2; Takasuka et } \\
\text { al. }(2007,2008)\end{array}$ & Medium & Major & Ocean warming & $\begin{array}{l}\text { Fluctuations due } \\
\text { to fisheries }\end{array}$ & Low \\
\hline & $\begin{array}{l}\text { Increased coastal erosion in } \\
\text { Arctic Asia }\end{array}$ & $\begin{array}{l}\text { Section 24.4.3.2; Razumov (2010); Forbes } \\
\text { (2011); Lantuit et al. (2011) }\end{array}$ & Medium & Major & $\begin{array}{l}\text { Permafrost } \\
\text { degradation, ocean } \\
\text { warming, change in } \\
\text { sea ice }\end{array}$ & No change & Low \\
\hline \multirow{2}{*}{ Australasia } & $\begin{array}{l}\text { Increase in coral bleaching in the } \\
\text { Great Barrier Reef and Western } \\
\text { Australian Reefs }\end{array}$ & $\begin{array}{l}\text { Sections 6.3.1.4, 6.3.1.5, and 25.6.2.1; Table } \\
\text { 25-3; Cooper et al. (2008); De'ath et al. (2009, } \\
\text { 2012); Moore et al. (2012) }\end{array}$ & High & Major & Ocean warming & $\begin{array}{l}\text { Pollution; } \\
\text { physical } \\
\text { disturbance }\end{array}$ & High \\
\hline & $\begin{array}{l}\text { Changes in coral disease patterns } \\
\text { at Great Barrier Reef }\end{array}$ & $\begin{array}{l}\text { Section 25.6.2.1; Table 25-3; Bruno et al. (2007); } \\
\text { Sato et al. (2009); Dalton et al. (2010) }\end{array}$ & Medium & Major & Ocean warming & Pollution & Medium \\
\hline \multirow[t]{4}{*}{$\begin{array}{l}\text { North } \\
\text { America }\end{array}$} & $\begin{array}{l}\text { Northward shifts in the } \\
\text { distributions of northwest } \\
\text { Atlantic fish species }\end{array}$ & $\begin{array}{l}\text { Section 30.5.1.1; Nye et al. (2009, 2011); Lucey } \\
\text { and Nye (2010) }\end{array}$ & High & Major & Ocean warming & No change & High \\
\hline & $\begin{array}{l}\text { Changes in mussel beds along } \\
\text { the west coast of the USA }\end{array}$ & $\begin{array}{l}\text { Smith et al. (2006); Menge et al. (2008); Harley } \\
\text { (2011) }\end{array}$ & High & Major & Ocean warming & No change & High \\
\hline & $\begin{array}{l}\text { Changes in migration and } \\
\text { survival of salmon in the } \\
\text { northeast Pacific }\end{array}$ & $\begin{array}{l}\text { Table 6-2; Eliason et al. (2011); Kovach et al. } \\
\text { (2012) }\end{array}$ & High & Major & Ocean warming & No change & High \\
\hline & $\begin{array}{l}\text { Increased coastal erosion in } \\
\text { Alaska and Canada }\end{array}$ & $\begin{array}{l}\text { Sections 18.3.1.1 and 18.3.3.1; Mars and } \\
\text { Houseknecht (2007); Forbes (2011); Lantuit et } \\
\text { al. (2011) }\end{array}$ & High & Major & $\begin{array}{l}\text { Permafrost } \\
\text { degradation; ocean } \\
\text { warming, change in } \\
\text { sea ice }\end{array}$ & No change & Medium \\
\hline
\end{tabular}


Table 18-8 (continued)

\begin{tabular}{|c|c|c|c|c|c|c|c|}
\hline & $\begin{array}{l}\text { Coastal and marine } \\
\text { ecosystems }\end{array}$ & References & $\begin{array}{l}\text { Confidence } \\
\text { in } \\
\text { detection }\end{array}$ & $\begin{array}{l}\text { Role of } \\
\text { climate }\end{array}$ & Climate driver & $\begin{array}{l}\text { Reference } \\
\text { behavior }\end{array}$ & $\begin{array}{l}\text { Confidence } \\
\text { in } \\
\text { attribution }\end{array}$ \\
\hline \multirow[t]{2}{*}{$\begin{array}{l}\text { South and } \\
\text { Central } \\
\text { America }\end{array}$} & $\begin{array}{l}\text { Increase in coral bleaching in the } \\
\text { western Caribbean }\end{array}$ & $\begin{array}{l}\text { Section 27.3.3.1; Guzman et al. (2008); Manzello } \\
\text { et al. (2008); Carilli et al. (2009); Eakin et al. } \\
\text { (2010) }\end{array}$ & High & Major & Ocean warming & $\begin{array}{l}\text { Pollution; } \\
\text { physical } \\
\text { disturbance }\end{array}$ & High \\
\hline & $\begin{array}{l}\text { Mangrove degradation on north } \\
\text { coast of South America }\end{array}$ & $\begin{array}{l}\text { Section 27.3.3.1; Alongi (2008); Lampis (2010); } \\
\text { Polidoro et al. (2010); Giri et al. (2011) }\end{array}$ & Low & Minor & Ocean warming & $\begin{array}{l}\text { Degradation due } \\
\text { to pollution and } \\
\text { land use }\end{array}$ & Low \\
\hline \multirow[t]{6}{*}{$\begin{array}{l}\text { Polar } \\
\text { regions }\end{array}$} & $\begin{array}{l}\text { Increased coastal erosion across } \\
\text { the Arctic }\end{array}$ & $\begin{array}{l}\text { Sections 18.3.1.1, 18.3.3.1, 28.2.4.2, and 28.3.4; } \\
\text { Mars and Houseknecht (2007); Razumov (2010); } \\
\text { Forbes (2011); Lantuit et al. (2011) }\end{array}$ & Medium & Major & $\begin{array}{l}\text { Permafrost } \\
\text { degradation; ocean } \\
\text { warming, change in } \\
\text { sea ice }\end{array}$ & No change & Medium \\
\hline & $\begin{array}{l}\text { Negative effects on non- } \\
\text { migratory Arctic species }\end{array}$ & $\begin{array}{l}\text { Section 28.2.2.1; Laidre et al. (2008); Amstrup et } \\
\text { al. (2010); McIntyre et al. (2011) }\end{array}$ & High & Major & $\begin{array}{l}\text { Atmospheric and } \\
\text { ocean warming; } \\
\text { circulation change; } \\
\text { change in sea ice }\end{array}$ & No change & High \\
\hline & $\begin{array}{l}\text { Decreased reproductive success } \\
\text { in Arctic seabirds }\end{array}$ & $\begin{array}{l}\text { Section 28.2.2.1.2; Gaston et al. (2009); } \\
\text { Grémillet and Boulinier (2009) }\end{array}$ & Medium & Major & $\begin{array}{l}\text { Air and ocean } \\
\text { warming; change in } \\
\text { ocean circulation; } \\
\text { change in sea ice }\end{array}$ & No change & Medium \\
\hline & $\begin{array}{l}\text { Decline in Southern Ocean seals } \\
\text { and seabirds }\end{array}$ & $\begin{array}{l}\text { Section 28.2.2.2; Croxall et al. (2002); Patterson } \\
\text { et al. (2003); Jenouvrier et al. (2005); Véran et } \\
\text { al. (2007); Forcada et al. (2008); Trathan et al. } \\
\text { (2011); Chambers et al. (2013a) }\end{array}$ & High & Major & Ocean warming & No change & Medium \\
\hline & $\begin{array}{l}\text { Reduced thickness of } \\
\text { foraminiferal shells in the } \\
\text { Southern Ocean }\end{array}$ & Sections 6.3.2 and 28.2.2.2; Moy et al. (2009) & Medium & Major & Ocean acidification & No change & Medium \\
\hline & $\begin{array}{l}\text { Reduced density of krill in the } \\
\text { Scotia Sea }\end{array}$ & Atkinson et al. (2004); Trivelpiece et al. (2011) & Medium & Major & $\begin{array}{l}\text { Ocean warming; } \\
\text { change in ocean } \\
\text { circulation; change } \\
\text { in sea ice }\end{array}$ & No change & Medium \\
\hline \multirow[t]{4}{*}{$\begin{array}{l}\text { Small } \\
\text { islands }\end{array}$} & $\begin{array}{l}\text { Increased coral bleaching near } \\
\text { many tropical small islands }\end{array}$ & $\begin{array}{l}\text { Section 29.3.1.2; Alling et al. (2007); Bruno and } \\
\text { Selig (2007); Oxenford et al. (2008); Sandin et } \\
\text { al. (2008) }\end{array}$ & High & Major & Ocean warming & $\begin{array}{l}\text { Degradation due } \\
\text { to fishing and } \\
\text { pollution }\end{array}$ & High \\
\hline & $\begin{array}{l}\text { Degradation of mangroves, } \\
\text { wetlands, and seagrass around } \\
\text { small islands }\end{array}$ & $\begin{array}{l}\text { Section 29.3.1.2; McKee et al. (2007); Gilman } \\
\text { et al. (2008); Schleupner (2008); Krauss et al. } \\
\text { (2010); Marbà and Duarte (2010); Rankey (2011) }\end{array}$ & Low & Minor & $\begin{array}{l}\text { Sea level rise; } \\
\text { atmospheric and } \\
\text { ocean warming }\end{array}$ & $\begin{array}{l}\text { Degradation } \\
\text { due to other } \\
\text { disturbances }\end{array}$ & Very low \\
\hline & Increasing flooding and erosion & $\begin{array}{l}\text { Section 29.3.1.1; Webb (2006); Webb (2007); } \\
\text { Yamano et al. (2007); Cambers (2009); Novelo- } \\
\text { Casanova and Suarez (2010); Storey and Hunter } \\
\text { (2010); Ballu et al. (2011); Rankey (2011); Ford } \\
\text { (2012); Romine et al. (2013) }\end{array}$ & Low & Minor & Sea level rise & $\begin{array}{l}\text { Erosion due to } \\
\text { human activities, } \\
\text { natural erosion, } \\
\text { and accretion }\end{array}$ & Low \\
\hline & $\begin{array}{l}\text { Degradation of groundwater and } \\
\text { freshwater ecosystems due to } \\
\text { saline intrusion }\end{array}$ & $\begin{array}{l}\text { Section 29.3.2; White et al. (2007a,b); Ross et al. } \\
\text { (2009); Carreira et al. (2010); Terry and Falkland } \\
\text { (2010); White and Falkland (2010); Goodman } \\
\text { et al. (2012) }\end{array}$ & Low & Minor & Sea level rise & $\begin{array}{l}\text { Degradation due } \\
\text { to pollution and } \\
\text { groundwater } \\
\text { pumping }\end{array}$ & Low \\
\hline
\end{tabular}

frequent (Section 25.2, Table 25-1). Winters in southern areas of Australia have become drier in the past few decades and the northwest has become wetter, and precipitation increased over the south and west of both islands of New Zealand. Though there have been no significant trends in drought frequency over Australia, regional warming may have increased their hydrological intensity, and fire weather increased since 1973 in Australia (Table 25-1; Clarke et al., 2012).

North America spans a wide range of climate types and observed climate changes. While the northwest has been among the fastest warming regions on the planet, the southeast of the USA has experienced slight cooling (Section 26.2.2.1). Hot extremes have been becoming more frequent while cold extremes and frost days have been becoming less frequent over the past several decades. Trends in precipitation over western parts of the continent are strongly influenced by the variability of the ENSO, with a matching drying and decreasing snowpack. The intensity of precipitation events has been increasing over most of the continent, but trends in dryness are spatially heterogeneous (Section 26.2.2.1). Intense tropical storms have increased in the North Atlantic over the past several decades (WGI AR5 Section 2.6.3).

Most of Central and South America has warmed over the past half century, except for a slight cooling over a western coastal strip (Section 27.2.1). Precipitation over much of Central and South America is strongly influenced by the ENSO, with accompanying long-term variability. There has been a reduction in the number of dry summer months in the southern half of the continent, while trends over the Amazon are sensitive to the selection of time period (Section 27.2.1). More frequent and severe droughts in the Amazon have been linked to warming (Marengo et al., 2011a).

The areas of largest observed warming are all polar: the northwest of North America, northern Asia, and the Antarctic Peninsula. The nature of polar regions means that warming can lead to large changes in other 
Table 18-9 | Observed impacts of climate change reported since AR4 on human and managed systems, over the past several decades, across major world regions, with descriptors for (1) the confidence in detection of a climate change impact; (2) the relative contribution of climate change to the observed change, compared to that of non-climatic drivers; (3) the main climatic driver(s) causing the impacts; (4) the reference behavior of the system in the absence of climate change; and (5) the confidence in attribution of the impacts to climate change. References to related chapters in this report are given as well as key references to other IPCC reports and the scientific literature. Absence of climate change impacts from this table does not imply that such impacts have not occurred.

\begin{tabular}{|c|c|c|c|c|c|c|c|}
\hline & $\begin{array}{l}\text { Human and managed } \\
\text { systems }\end{array}$ & References & $\begin{array}{l}\text { Confidence } \\
\text { in } \\
\text { detection }\end{array}$ & $\begin{array}{l}\text { Role of } \\
\text { climate }\end{array}$ & $\begin{array}{l}\text { Climate } \\
\text { driver }\end{array}$ & $\begin{array}{l}\text { Reference } \\
\text { behavior }\end{array}$ & $\begin{array}{l}\text { Confidence } \\
\text { in } \\
\text { attribution }\end{array}$ \\
\hline \multirow[t]{4}{*}{ Africa } & $\begin{array}{l}\text { Adaptative responses to changing } \\
\text { rainfall by South African farmers }\end{array}$ & Section 13.2.1.2; Thomas et al. (2007) & Low & Major & $\begin{array}{l}\text { Change in } \\
\text { precipitation }\end{array}$ & $\begin{array}{l}\text { Changes due } \\
\text { to economic } \\
\text { conditions }\end{array}$ & Very low \\
\hline & Decline in fruit-bearing trees in Sahel & Wezel and Lykke (2006); Maranz (2009) & Medium & Major & $\begin{array}{l}\text { Change in } \\
\text { precipitation }\end{array}$ & No change & Low \\
\hline & $\begin{array}{l}\text { Malaria increases in Kenyan } \\
\text { highlands }\end{array}$ & $\begin{array}{l}\text { Section 11.5.1.1; O'Meara et al. (2010); Alonso et } \\
\text { al. (2011); Stern et al. (2011) }\end{array}$ & Low & Minor & Warming & $\begin{array}{l}\text { Changes due } \\
\text { to vaccination, } \\
\text { drug resistance, } \\
\text { demography, } \\
\text { and livelihoods }\end{array}$ & Low \\
\hline & $\begin{array}{l}\text { Reduced fisheries productivity of } \\
\text { Great Lakes and Lake Kariba }\end{array}$ & $\begin{array}{l}\text { Sections 7.2.1.2, 13.2.1.1, and 22.3.2.2; Descy } \\
\text { and Sarmento (2008); Hecky et al. (2010); } \\
\text { Ndebele-Murisa et al. (2011); Marshall (2012) }\end{array}$ & Low & Minor & Warming & $\begin{array}{l}\text { Changes due } \\
\text { to fisheries } \\
\text { management } \\
\text { and land use }\end{array}$ & Low \\
\hline \multirow[t]{5}{*}{ Europe } & $\begin{array}{l}\text { Shift from cold-related mortality to } \\
\text { heat-related mortality in England } \\
\text { and Wales }\end{array}$ & $\begin{array}{l}\text { Sections } 18.4 .4 \text { and 23.5.1; Christidis et al. } \\
(2010)\end{array}$ & Medium & Major & Warming & $\begin{array}{l}\text { Changes due to } \\
\text { exposure and } \\
\text { health care }\end{array}$ & Low \\
\hline & $\begin{array}{l}\text { Impacts on livelihoods of Sámi } \\
\text { people in northern Europe }\end{array}$ & Eira (2012); Mathiesen et al. (2013) & Medium & Major & Warming & $\begin{array}{l}\text { Economic and } \\
\text { sociopolitical } \\
\text { changes }\end{array}$ & Medium \\
\hline & $\begin{array}{l}\text { Stagnation of wheat yields in some } \\
\text { countries in recent decades }\end{array}$ & $\begin{array}{l}\text { Section 23.4.1; Brisson et al. (2010); Kristensen } \\
\text { et al. (2011) }\end{array}$ & High & Minor & Warming & $\begin{array}{l}\text { Increase due } \\
\text { to improved } \\
\text { technology }\end{array}$ & Medium \\
\hline & $\begin{array}{l}\text { Positive yield impacts for some crops, } \\
\text { mainly in northern Europe }\end{array}$ & $\begin{array}{l}\text { Figure 7-2; Section 23.4.1; Jaggard et al. (2007); } \\
\text { Supit et al. (2010); Gregory and Marshall (2012) }\end{array}$ & High & Minor & Warming & $\begin{array}{l}\text { Increase due } \\
\text { to improved } \\
\text { technology }\end{array}$ & Medium \\
\hline & $\begin{array}{l}\text { Spread of bluetongue virus in sheep, } \\
\text { and of ticks across parts of Europe }\end{array}$ & $\begin{array}{l}\text { Section 23.4.2; Arzt et al. (2010); Randolph and } \\
\text { Rogers (2010); Van Dijk et al. (2010); Guis et al. } \\
\text { (2012); Petney et al. (2012) }\end{array}$ & High & Minor & Warming & No change & Medium \\
\hline \multirow[t]{4}{*}{ Asia } & $\begin{array}{l}\text { Impacts on livelihoods of indigenous } \\
\text { groups in Arctic Russia }\end{array}$ & $\begin{array}{l}\text { Sections 13.2.1.2, 18.4.6, and 28.2.4.2; Table } \\
\text { 18-4; Crate (2013) }\end{array}$ & Medium & Major & $\begin{array}{l}\text { Warming; change } \\
\text { in snow cover; } \\
\text { change in sea ice }\end{array}$ & $\begin{array}{l}\text { Economic and } \\
\text { sociopolitical } \\
\text { changes }\end{array}$ & Low \\
\hline & $\begin{array}{l}\text { Negative impacts on aggregate } \\
\text { wheat yields in South Asia }\end{array}$ & Section 7.2.1; Figure 7-2; Pathak et al. (2003) & Medium & Minor & $\begin{array}{l}\text { Warming; change } \\
\text { in precipitation }\end{array}$ & $\begin{array}{l}\text { Increase due } \\
\text { to improved } \\
\text { technology }\end{array}$ & Medium \\
\hline & $\begin{array}{l}\text { Negative impacts on aggregate } \\
\text { wheat and maize yields in China }\end{array}$ & $\begin{array}{l}\text { Section 7.2.1; Figure 7-2; Tao et al. (2006, 2008, } \\
\text { 2012); You et al. (2009); Chen et al. (2010) }\end{array}$ & Low & Minor & Warming & $\begin{array}{l}\text { Increase due } \\
\text { to improved } \\
\text { technology }\end{array}$ & Low \\
\hline & $\begin{array}{l}\text { Increases in a water-borne disease } \\
\text { in Israel }\end{array}$ & Paz et al. (2007) & Low & Minor & Warming & No change & Low \\
\hline \multirow[t]{3}{*}{ Australasia } & $\begin{array}{l}\text { Advance timing of wine-grape } \\
\text { maturation in recent decades }\end{array}$ & Table 25-3; Webb et al. (2012) & High & Major & Warming & $\begin{array}{l}\text { Advance due } \\
\text { to improved } \\
\text { management }\end{array}$ & Medium \\
\hline & $\begin{array}{l}\text { Shift in winter versus summer human } \\
\text { mortality in Australia }\end{array}$ & $\begin{array}{l}\text { Sections 11.4.1, 18.4.4, and 25.8.1.1; Bennett } \\
\text { et al. (2013) }\end{array}$ & Medium & Major & Warming & $\begin{array}{l}\text { Changes due to } \\
\text { exposure and } \\
\text { health care }\end{array}$ & Low \\
\hline & $\begin{array}{l}\text { Relocation or diversification of } \\
\text { agricultural activities in Australia }\end{array}$ & $\begin{array}{l}\text { Section 25.7.2; Box 25-5; Gaydon et al. (2010); } \\
\text { Howden et al. (2010); Park et al. (2012); Thorburn } \\
\text { et al. (2012) }\end{array}$ & Medium & Minor & Warming & $\begin{array}{l}\text { Changes due to } \\
\text { policy, markets, } \\
\text { and short- } \\
\text { term climate } \\
\text { variability }\end{array}$ & Low \\
\hline \multirow[t]{2}{*}{$\begin{array}{l}\text { Central } \\
\text { and South } \\
\text { America }\end{array}$} & $\begin{array}{l}\text { More vulnerable livelihood } \\
\text { trajectories for indigenous Aymara } \\
\text { farmers in Bolivia, due to water } \\
\text { shortage }\end{array}$ & Section 13.1.4; McDowell and Hess (2012) & Medium & Major & Warming & $\begin{array}{l}\text { Increasing } \\
\text { social and } \\
\text { economic } \\
\text { stress }\end{array}$ & Medium \\
\hline & $\begin{array}{l}\text { Increase in agricultural yields and } \\
\text { expansion of agricultural areas in } \\
\text { southeastern South America }\end{array}$ & $\begin{array}{l}\text { Section 27.3.4.1; Magrin et al. (2007); Barros } \\
\text { (2010); Hoyos et al. (2013) }\end{array}$ & Medium & Major & $\begin{array}{l}\text { Precipitation } \\
\text { increase }\end{array}$ & $\begin{array}{l}\text { Increase due } \\
\text { to improved } \\
\text { technology }\end{array}$ & Medium \\
\hline
\end{tabular}


Table 18-9 (continued)

\begin{tabular}{|c|c|c|c|c|c|c|c|}
\hline & $\begin{array}{l}\text { Human and managed } \\
\text { systems }\end{array}$ & References & $\begin{array}{l}\text { Confidence } \\
\text { in } \\
\text { detection }\end{array}$ & $\begin{array}{l}\text { Role of } \\
\text { climate }\end{array}$ & $\begin{array}{l}\text { Climate } \\
\text { driver }\end{array}$ & $\begin{array}{l}\text { Reference } \\
\text { behavior }\end{array}$ & $\begin{array}{l}\text { Confidence } \\
\text { in } \\
\text { attribution }\end{array}$ \\
\hline $\begin{array}{l}\text { North } \\
\text { America }\end{array}$ & $\begin{array}{l}\text { Impacts on livelihoods of indigenous } \\
\text { groups in the Canadian Arctic }\end{array}$ & $\begin{array}{l}\text { Sections } 18.4 .6 \text { and 28.2.4.2; Table 18-4; } \\
\text { Hovelsrud et al. (2008); Ford et al. (2009); } \\
\text { Beaumier and Ford (2010); Pearce et al. (2010); } \\
\text { Brubaker et al. (2011) }\end{array}$ & Medium & Major & $\begin{array}{l}\text { Warming; change } \\
\text { in snow cover; } \\
\text { change in sea ice }\end{array}$ & $\begin{array}{l}\text { Economic and } \\
\text { sociopolitical } \\
\text { changes }\end{array}$ & Medium \\
\hline \multirow[t]{2}{*}{$\begin{array}{l}\text { Polar } \\
\text { regions }\end{array}$} & $\begin{array}{l}\text { Impact on livelihoods of Arctic } \\
\text { indigenous peoples }\end{array}$ & $\begin{array}{l}\text { Sections 18.4.6 and 28.2.4.2; Table 18-4; } \\
\text { Hovelsrud et al. (2008); Ford et al. (2009); } \\
\text { Beaumier and Ford (2010); Pearce et al. (2010); } \\
\text { Eira (2012); Crate (2013); Mathiesen et al. (2013) }\end{array}$ & Medium & Major & $\begin{array}{l}\text { Warming; change } \\
\text { in snow cover; } \\
\text { change in sea ice }\end{array}$ & $\begin{array}{l}\text { Economic and } \\
\text { sociopolitical } \\
\text { changes }\end{array}$ & Medium \\
\hline & $\begin{array}{l}\text { Increase of shipping traffic across the } \\
\text { Bering Strait }\end{array}$ & Section 28.2.6.1.3; Figure 28-4; Robards (2013) & Medium & Major & $\begin{array}{l}\text { Warming; change } \\
\text { in sea ice }\end{array}$ & No change & Medium \\
\hline $\begin{array}{l}\text { Small } \\
\text { islands }\end{array}$ & $\begin{array}{l}\text { Increased degradation of coastal } \\
\text { fisheries due to direct effects and } \\
\text { effects of increased coral reef } \\
\text { bleaching }\end{array}$ & $\begin{array}{l}\text { Box CC-CR; Sections 18.3.3.3, 18.4.1.2, 29.3.1.2, } \\
\text { and 30.6.2.1 }\end{array}$ & Low & Minor & Ocean warming & $\begin{array}{l}\text { Coastal } \\
\text { fisheries } \\
\text { degraded by } \\
\text { overfishing and } \\
\text { pollution }\end{array}$ & Low \\
\hline
\end{tabular}

aspects of the climate system, in particular the observed decrease in summer sea ice cover, earlier thaw, earlier spring runoff, and thawing of permafrost (Section 28.2).

Despite the widely accepted high vulnerability of many small islands to climate change, there are only few formal studies on observed impacts. Detection of climate change impacts in small islands is challenging due to the strong presence of other anthropogenic drivers of local environmental change. Attribution is further challenged by the strong influence of natural variability compared to incremental changes of climate drivers and by the lack of long-term monitoring and high-quality data.

\subsection{Synthesis: Emerging Patterns of Observed Impacts of Climate Change}

\subsubsection{Approach}

The AR4 precursor of the current chapter (Rosenzweig et al., 2007) provided a geographically distributed empirical analysis of correlations across numerous detailed and localized studies of changing systems (elaborated more later in Rosenzweig et al., 2008). Rather than expand that approach, this synthesis organizes the findings on detection and attribution of observed impacts of climate change aiming at covering the full disciplinary, sectoral, and geographic diversity of impacts, drawn directly from sectoral and regional assessments in this report.

A key motivation for the effort in assessing these observed changes is the possibility that observed impacts could constitute indications of future expected changes. Observed losses in glacial volume, for example, lend important additional plausibility to model-based expectations that sustained warming could result in additional ice loss. Such extrapolation faces important limitations, however. First, owing to the complex nonlinear behavior of most natural and human systems, it cannot always be assumed that past impacts scale linearly to future impacts. Likewise, absence of past impacts cannot constitute evidence against the possibility of future impacts. Nonetheless, detection and attribution of observed impacts may serve as part of the foundation for a climatic risk analysis. To do so, the total body of observed impacts needs to undergo a synthetic assessment pointing toward any conceivable risks.
Virtually all observed impacts of climate change are of regional nature (Section 18.5); however, the occurrence of similar impacts in many regions of the world emerges more strongly with every IPCC assessment. The global pattern emerging from the sum of observed regional impacts is therefore analyzed in Section 18.6.2. The current body of observations provides improved evidence of major impacts in natural and human systems that have "cascading" consequences for other systems-key examples for these are synthesized in Section 18.6.3. Finally, Section 18.6.4 aims to establish current conditions concerning the risk analysis model formulated earlier by the IPCC through the establishment of a limited number of "Reasons for Concern" (RFC) — the risk analysis itself is part of Chapter 19 of this report.

\subsubsection{The Global Pattern of Regional Impacts}

The global pattern of observed climate change differs strongly for the different climate variables. Broadly, more warming has occurred at higher latitudes than in the Tropics, while the pattern of rainfall changes is highly complex (WGI AR5 Chapter 2). Taken together, this provides a heterogeneous pattern of climate change across the globe. In addition, some natural and human systems (and the regions in which they occur) are more vulnerable to changing climate than others. Crucially, observational records are of highly heterogeneous nature: not only do low-income countries report fewer impacts than high-income countries, but there is also a significant shortage of observations from remote areas such as the deep sea or sparsely populated mountains and deserts. Taken together, it is therefore natural to expect an uneven distribution of detected impacts (Figure 18-3).

The outstanding finding about the global pattern of observed impacts is that, on all continents and across major ocean regions, significant impacts have now been observed. Many of these concern systems which are affected directly by warming (the cryosphere, marine systems), but a growing number of observed impacts have been shown to be the result of a combination of changing temperature and precipitation (agricultural and hydrological systems).

The global distribution of observed impacts shown in Figure 18-3 demonstrates that analyses can now detect impacts in systems strongly 


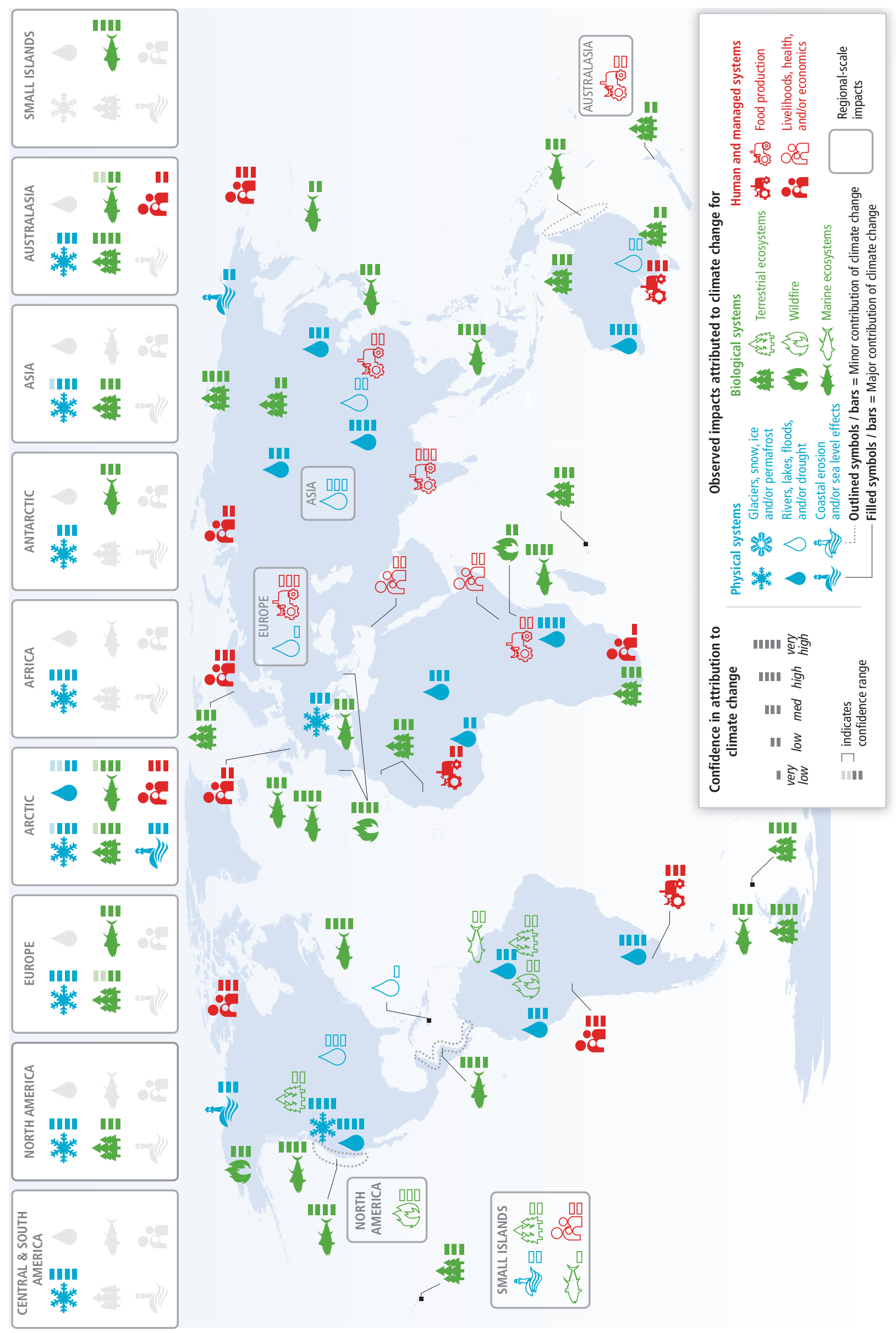

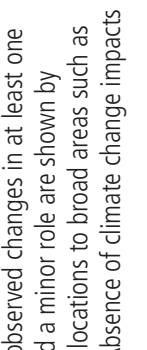

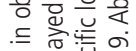

응 응 은

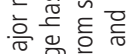

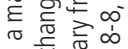

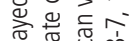

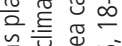

空岕

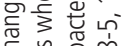

远

龸

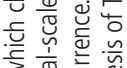

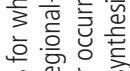

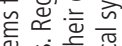

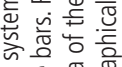

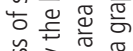

흔흠 苋 든

要

들 흥

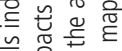

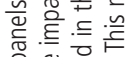

응 훙 훙

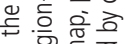

$\subseteq$ बह $\mathrm{E}$

要要

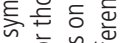

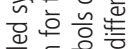

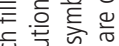

总 흘 产

定. 过

प्ष

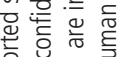

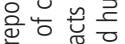

흥

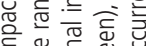

施

元

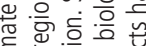

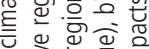

을

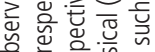

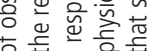

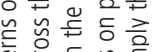

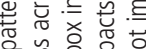

응 잉

즁 증 은 둔

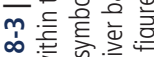

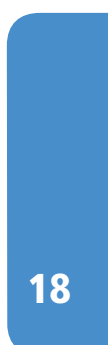




\section{Cryosphere $\square$ Western North America $\quad \square$ Western Andes $\quad \square$ Asia $\quad \square$ Arctic}

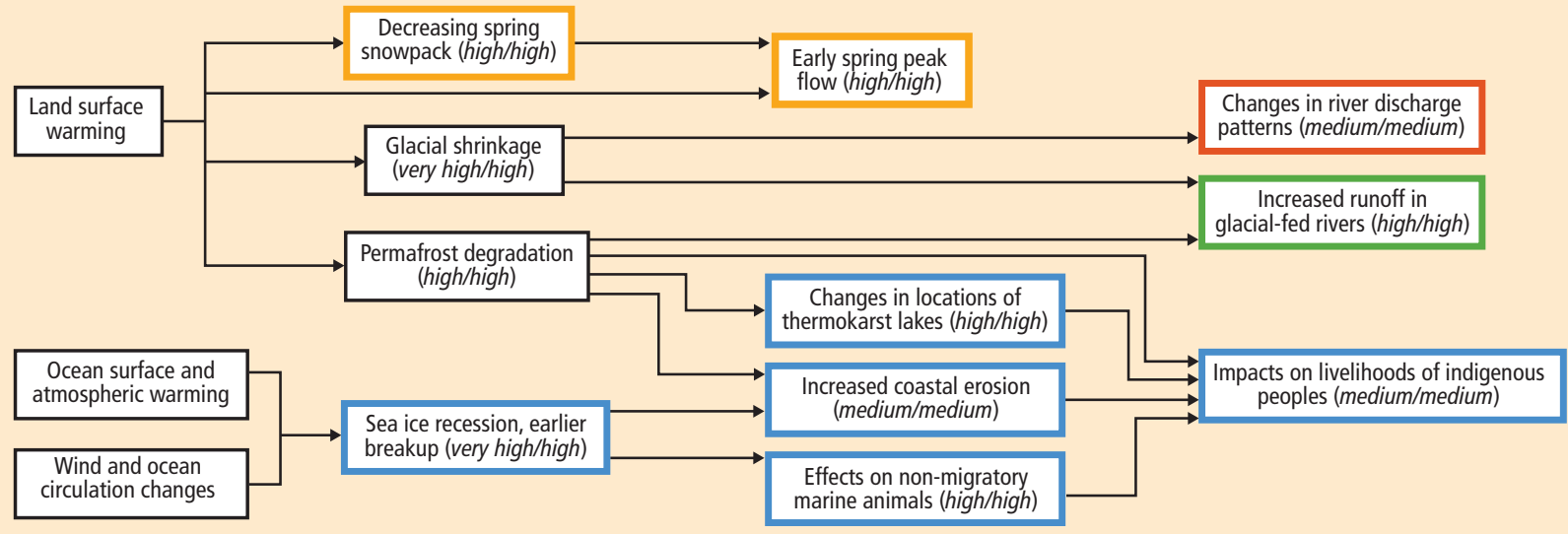
Ocean
Physical impacts
Biological impacts
Impacts on managed systems

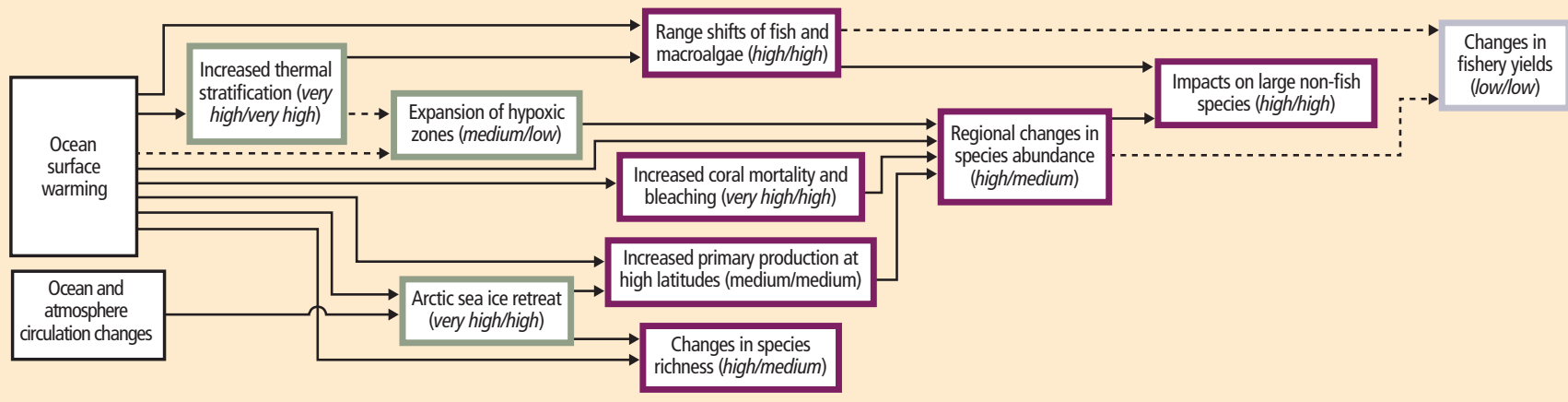

Forests

High elevation islands

Western North America

Western Sahel

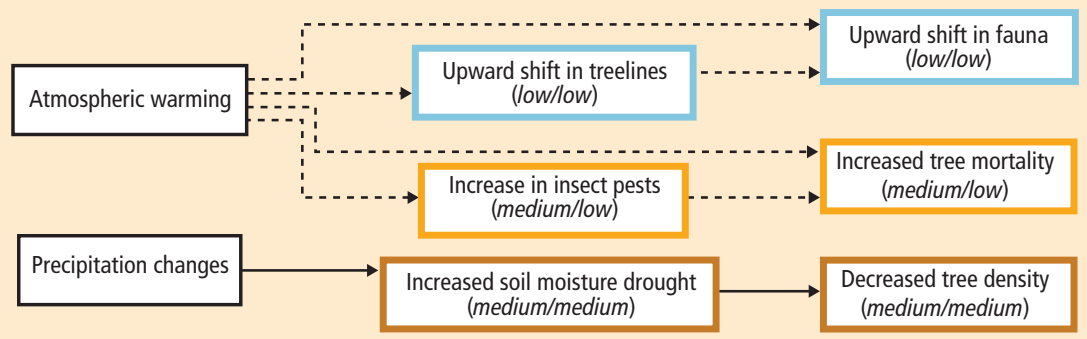

Description of impact (confidence in detection/confidence in attribution)

\section{Attribution of climate change role}

$\longrightarrow$ Major role $\quad \rightarrow$ Minor role

Figure 18-4 | Major systems where new evidence indicates interconnected, "cascading" impacts from recent climate change through several natural and human subsystems. Text in parentheses indicates confidence in the detection of a climate change effect and the attribution of observed impacts to climate change. The role of climate change can be major (solid arrow) or minor (dashed arrow). Confidence is assessed in Sections 18.3, 18.4, 18.5, and 18.6. 
influenced by confounding factors and hence where climate change plays only a minor role. The most outstanding examples for this are agricultural systems where impacts now emerge in a number of places. An identified minor role of climate for some impact does not imply that this role is less important. New studies now identify more clearly such roles even when they are masked by stronger confounding factors such as environmental degradation or improved technology. Examples for such studies include assessments of mangrove degradation, caused by both warming and pollution (Giri et al., 2011), or changes in Inuit livelihoods, influenced by both warming and social changes (Ford et al., 2009). Enhanced research efforts would probably add additional observations of impacts with a minor, but important, role of climate to the global map.

\subsubsection{Cascading Impacts}

Many impacts of climate change are direct cause-effect relationships, such as reduction of glacier volume following higher temperatures. Others may be mediated through impacts on intermediary systems (e.g., Johnson et al., 2011). Enhanced evidence of observed impacts of climate change, and improved research methodologies now allow attribution of effects at various stages along the causal impact chain (Figure 18-4). Within the cryosphere, changes in atmospheric and ocean properties of the climate have driven changes in the cryosphere on the land surface, the land subsurface, and the ocean surface. These changes have in turn led to changes in multiple aspects of hydrology and ecosystems, and in some regions (e.g., the Arctic) changes in these systems have impacted human livelihoods ( $\mathrm{Xu}$ et al., 2009). Within most ocean regions, warming has led to a number of observed impacts on biota, some of which are mediated through the effect of warming on the ocean's thermal stratification or on sea ice. Impacts tend to propagate up the food chain, eventually affecting large mammals, birds, reptiles, and humans. In forests and woodlands, climate change impacts on trees have been transmitted through pests, fire, and drought, while impacts on forests have also been observed to affect the forest fauna. In all these cases, confidence in detection and attribution to observed climate change decreases for effects further down each impact chain.

\subsubsection{Reasons for Concern}

To synthesize its findings in support of a risk analysis the IPCC in its Third Assessment Report (TAR) developed the "Reasons for Concern" (RFC) concept (Smith et al., 2001), which was adopted for a second time in IPCC AR4 (IPCC, 2007b), and elaborated in Smith et al. (2009). It is further developed in Chapter 1 of this report and employed extensively in Chapter 19 for the risk framing approach of WGII AR5. In this chapter, the goal is to establish, qualitatively, the evidence of impacts already observed that are relevant to these categories (names of categories have been adapted for consistency across Chapters 1, 18, and 19; see below). The broad definitions of the RFC continue to imply significant overlap; hence some observed impacts are referred to under more than one RFC.

The RFC Risks to Unique and Threatened Systems is concerned with the potential for increased damage to, or irreversible loss of, systems such as physical systems, ecosystems, and human livelihoods, all of which are known to be highly sensitive to temporal and/or spatial variations in climate. Figure 18-5 displays confidence levels in the current evidence

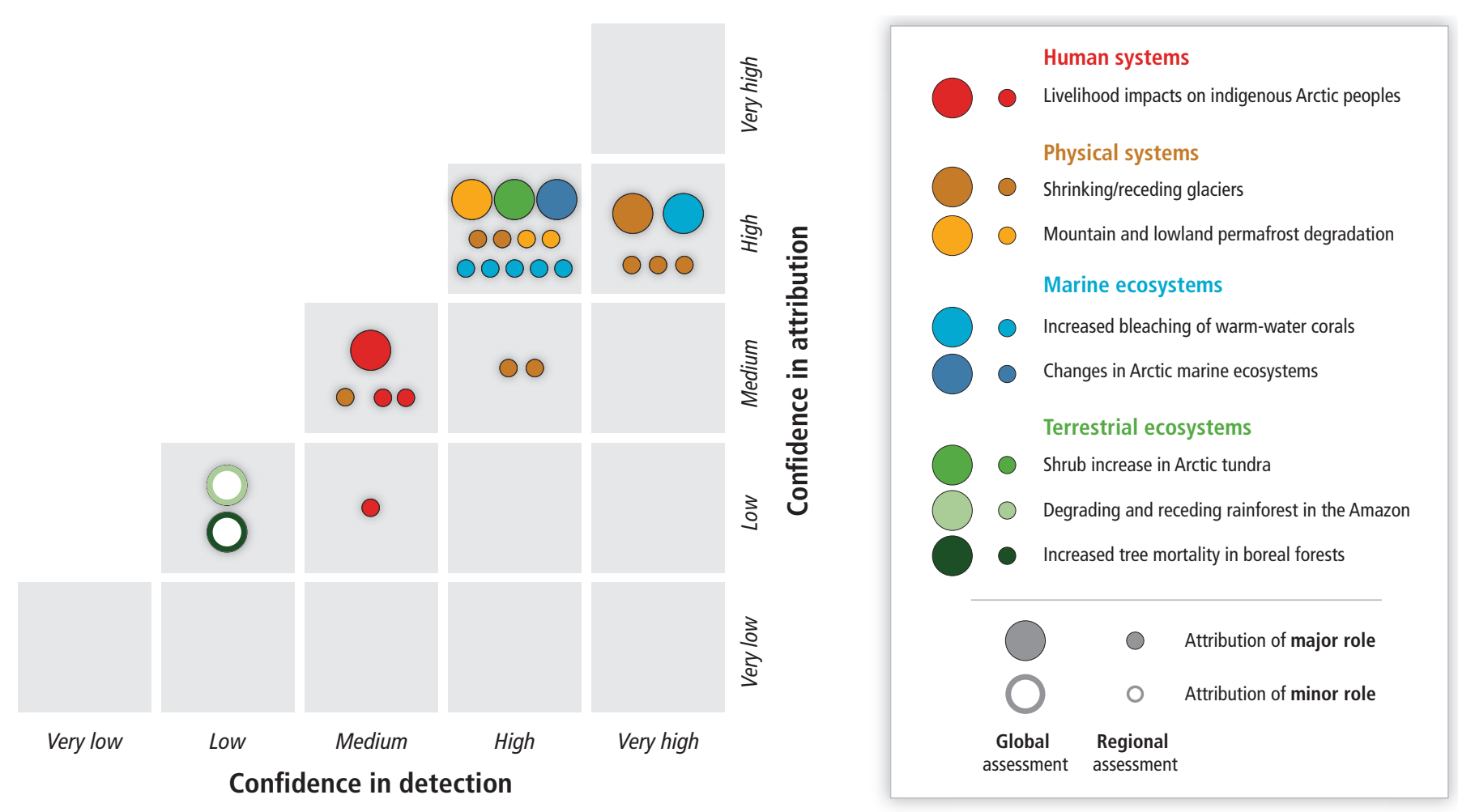

Figure 18-5 | Confidence in detection and attribution of observed impacts on "Unique and Threatened Systems" as a result of recent climate change. Global assessments (large circles) and regional assessments (small circles) are discussed in Sections 18.3.1.1 and 18.3.2.4, Box 18-2, and Tables 18-2 and 18-5 through 18-9. Attribution assessments are for a minor (outlined circles) or major (filled circles) role of climate change, as indicated. 
derived from detection and attribution studies of such observed impacts. Changes in the three indicated main natural systems (physical systems, marine and terrestrial ecosystems) have at least high confidence in attribution of a major role of climate change, with regional assessments also tending to have similar confidence. There is at least medium confidence in attribution of a major role for at least one each of ecosystems, physical systems, and human systems.

The unique and threatened systems with strongest detection and attribution evidence cover the Arctic, warm-water coral reefs, and mountains. In the Arctic, climate change has played a major role in observed impacts on glaciers, permafrost, the tundra, marine ecosystems, and livelihoods of indigenous peoples (at least medium confidence), reflecting large-scale changes across both natural and human systems and across the physical and ecological sub-regions. Evidence for the detection and attribution of shrinkage and recession of glaciers comes from all continents, while evidence for attribution of coral bleaching spans a similarly broad area of the tropical oceans (see Figure 18-5).

The RFC Risks Associated with Extreme Weather Events "tracks increases in extreme events with substantial consequences for societies and natural systems" (Smith et al., 2009, p. 4134). Besides episodic (e.g., coral bleaching) and chronic (e.g., erosion) impacts of extreme weather events, this RFC also considers increased frequency of extreme impact events (e.g., floods), even if their climate drivers are not wholly episodic in nature. A change in the risk of impacts of extreme weather events could be caused by a change in the probability, intensity, or sequencing of the weather event itself (which are manifestations of recent climate change), or by a change in exposure, vulnerability, or the resilience of the impacted system. Trends have been noted for extreme weather hazards. Temperature extremes have changed in most regions over the past half century, with more frequent hot events and less frequent cold events (high confidence; Hansen et al., 2012; Seneviratne et al., 2012; Coumou et al., 2013; see WGI AR5 Section 2.6.1). Some regions have also experienced increasingly frequent periods of heavy precipitation events (medium confidence; Min et al., 2011), while other regions have experienced positive or negative trends in measures of dry spells (Seneviratne et al., 2012). Current evidence does not, however, indicate sustained global trends in tropical cyclone or extratropical cyclone activity (Seneviratne et al., 2012; see WGI AR5 Section 2.6.3).

Table 18-10 summarizes new evidence concerning this RFC. Generally, the strongest evidence of detected impacts related to extremes concerns warm-water corals where bleaching has been linked directly to hightemperature spells (Box 18-2; Baker et al., 2008; Strong et al., 2011). Outside of these coral reef systems, however, evidence for extreme event impacts is limited and mostly local. Overall, a number of trends in observed impacts on natural systems have been documented that indicate changing risks driven by changes in extreme weather (medium confidence), but any similar trends in human systems have not been detected against large shifts in exposure, vulnerability, and resilience.

Table 18-10 | Confidence in detection and attribution of observed trends in impacts related to extreme weather. The assessment, for the impacts on various systems, is of attribution of those trends to climate change and of the confidence in existence of observed trends in that extreme weather. The assessment of confidence in detection is against the specified reference behavior, while the assessment of attribution is for the indicated minor or major role of observed climate trends. The confidence statements refer to a globally balanced assessment.

\begin{tabular}{|c|c|c|c|c|c|c|c|}
\hline \multicolumn{5}{|c|}{ Impacts and impact events } & \multicolumn{2}{|c|}{ Climate/weather drivers } & \multirow[b]{2}{*}{ Reference } \\
\hline Observed trend & $\begin{array}{l}\text { Confidence } \\
\text { in } \\
\text { detection }\end{array}$ & Reference behavior & $\begin{array}{l}\text { Confidence } \\
\text { in } \\
\text { attribution }\end{array}$ & $\begin{array}{l}\text { Role of } \\
\text { climate } \\
\text { change }\end{array}$ & Observed trend & $\begin{array}{l}\text { Confidence } \\
\text { in existence } \\
\text { of trend }\end{array}$ & \\
\hline \multirow{2}{*}{$\begin{array}{l}\text { Earlier timing } \\
\text { and decreasing } \\
\text { magnitude of } \\
\text { snowmelt floods }\end{array}$} & \multirow[t]{2}{*}{ Medium } & \multirow[t]{2}{*}{ No change } & \multirow[t]{2}{*}{ Medium } & \multirow[t]{2}{*}{ Major } & Decreasing snow pack & High & \multirow{2}{*}{$\begin{array}{l}\text { Section 3.2.7; Tables } 18-5 \text { and } 18-6 \text {; WGI } \\
\text { AR5 Section 4.5; Seneviratne et al. (2012) }\end{array}$} \\
\hline & & & & & $\begin{array}{l}\text { Increasing heavy } \\
\text { precipitation amounts }\end{array}$ & Medium & \\
\hline \multirow{2}{*}{$\begin{array}{l}\text { Changes in flood } \\
\text { frequency and } \\
\text { magnitude in non- } \\
\text { snowmelt-fed rivers }\end{array}$} & \multirow[t]{2}{*}{ Low } & \multirow[t]{2}{*}{ Changes due to land use } & \multirow[t]{2}{*}{ Low } & \multirow[t]{2}{*}{ Minor } & $\begin{array}{l}\text { Trends in extreme rainfall } \\
\text { amounts }\end{array}$ & Medium & \multirow[t]{2}{*}{$\begin{array}{l}\text { Min et al. (2011); WGI AR5 Sections 2.5.2 } \\
\text { and 2.6.2 }\end{array}$} \\
\hline & & & & & $\begin{array}{l}\text { Increased evapotranspiration } \\
\text { and decreased soil moisture }\end{array}$ & Medium & \\
\hline $\begin{array}{l}\text { Increased coastal } \\
\text { erosion in low and } \\
\text { mid latitudes }\end{array}$ & Very low & $\begin{array}{l}\text { Erosion due to shoreline } \\
\text { modification and natural } \\
\text { processes }\end{array}$ & Very low & Minor & $\begin{array}{l}\text { Increasingly frequent high } \\
\text { storm waves and surges }\end{array}$ & High & $\begin{array}{l}\text { Sections } 5.4 .2 \text { and 18.3.3.1; WGI AR5 } \\
\text { Section 3.7.5 }\end{array}$ \\
\hline $\begin{array}{l}\text { Increased erosion of } \\
\text { Arctic coasts }\end{array}$ & Medium & No change & Medium & Major & $\begin{array}{l}\text { Lack of sea ice protection } \\
\text { from wind storms }\end{array}$ & Very high & $\begin{array}{l}\text { Table 18-8; Sections 18.3.1.1, 24.4.3.2, } \\
\text { 28.2.4.2, and 28.3.4; Forbes (2011); WGI } \\
\text { AR5 Section 4.2.2 }\end{array}$ \\
\hline $\begin{array}{l}\text { Increase in high- } \\
\text { mountain rock slope } \\
\text { failures }\end{array}$ & Low & No change & Low & Major & $\begin{array}{l}\text { Increasingly frequent and } \\
\text { intense heat waves }\end{array}$ & Medium & $\begin{array}{l}\text { Figure 18-2; Huggel et al. (2012a); } \\
\text { Seneviratne et al. (2012); Allen and } \\
\text { Huggel (2013); WGI AR5 Section 2.6.1 }\end{array}$ \\
\hline $\begin{array}{l}\text { Increased coral } \\
\text { bleaching }\end{array}$ & Very high & $\begin{array}{l}\text { Changes due to pollution, } \\
\text { physical disturbance, and } \\
\text { fishing }\end{array}$ & High & Major & $\begin{array}{l}\text { Increasingly frequent } \\
\text { extreme hot surface waters }\end{array}$ & Very high & $\begin{array}{l}\text { Tables } 18-2 \text { and } 18-8 ; \text { Sections } 5.2 .4 .2 \\
\text { 6.3.1, 24.4.3.2, 27.3.3.1, 29.3.1.2, } \\
\text { 30.3.1.1, and 30.5; Box 18-2 }\end{array}$ \\
\hline \multirow[t]{2}{*}{$\begin{array}{l}\text { Increased monetary } \\
\text { losses }\end{array}$} & \multirow[t]{2}{*}{ Low } & \multirow[t]{2}{*}{$\begin{array}{l}\text { Changes due to exposure } \\
\text { and wealth }\end{array}$} & \multirow[t]{2}{*}{ Low } & \multirow[t]{2}{*}{ Minor } & $\begin{array}{l}\text { Increased frequency of } \\
\text { storms }\end{array}$ & Low & \multirow[t]{2}{*}{$\begin{array}{l}\text { Sections } 10.7 .3 \text { and 18.4.3.1; Seneviratne } \\
\text { et al. (2012); WGI AR5 Section } 2.6\end{array}$} \\
\hline & & & & & Increased frequency of floods & Low & \\
\hline $\begin{array}{l}\text { Increased heat } \\
\text { related mortality }\end{array}$ & Low & $\begin{array}{l}\text { Changes due to exposure } \\
\text { and health care }\end{array}$ & Very low & Minor & $\begin{array}{l}\text { Increased frequency of heat } \\
\text { waves }\end{array}$ & Medium & $\begin{array}{l}\text { Section 11.4.1; Seneviratne et al. } \\
\text { (2012);WGI AR5 Section 2.6.1 }\end{array}$ \\
\hline
\end{tabular}




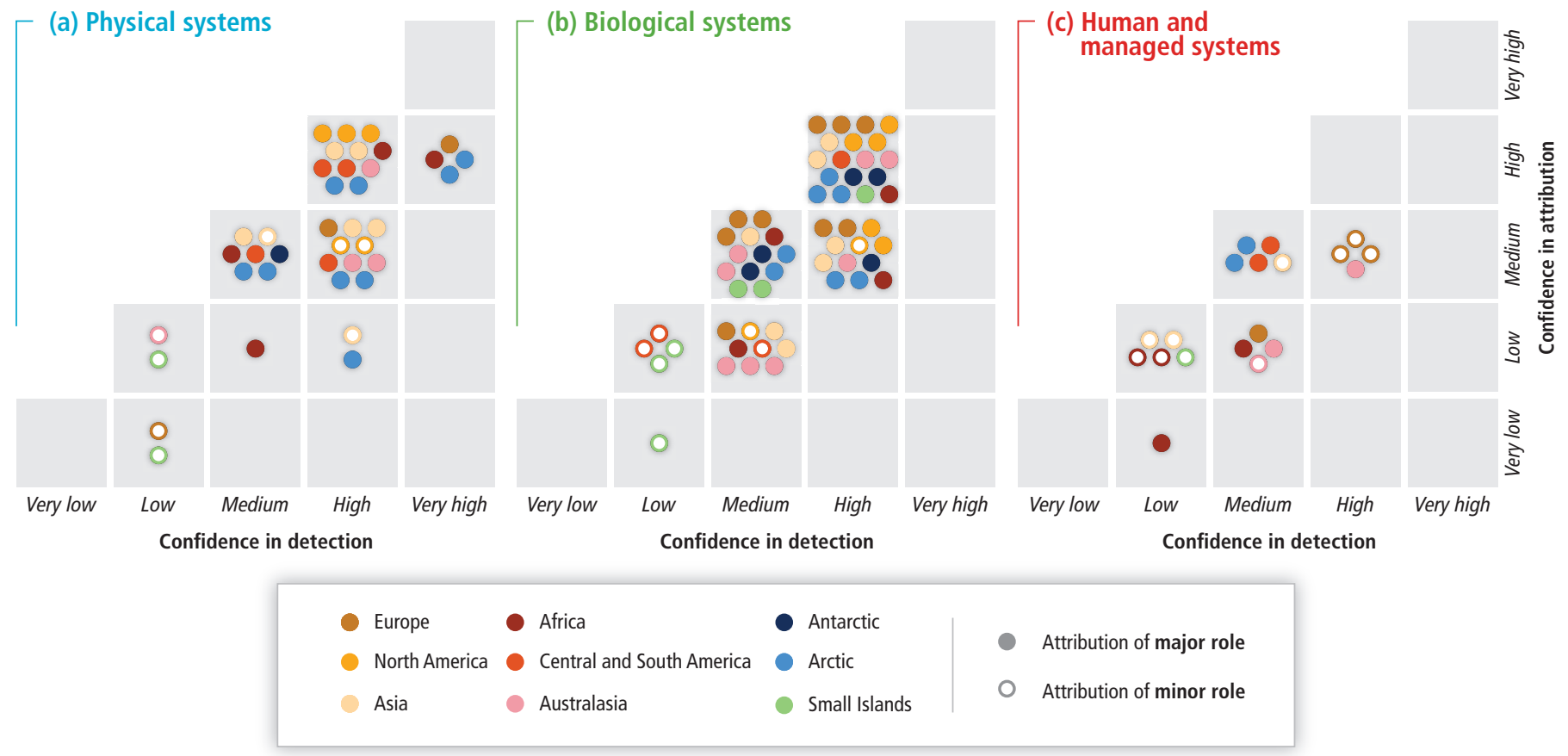

Figure 18-6 | Confidence in detection of observed climate change impacts in physical natural systems, biological systems, and human and managed systems across regions, and confidence in attribution of such trends to observed climate change as a major or minor driver (based on assessments developed in Tables 18-5 to 18-9). (a) Physical systems include the cryosphere, hydrology, and coastal processes; (b) biological systems refer to changes in marine and terrestrial ecosystems, including wildfires; and (c) human and managed systems summarize impacts on food production, health, human livelihoods, and economics.

The RFC Risks Associated with the Distribution of Impacts focuses on the disparities of impacts between regions, countries, and populations. The survey of recent studies presented in Section 18.5 indicates that, while evidence for detected impacts is still more exhaustive from Europe and North America, considerable confidence in conclusions has been developed elsewhere since the AR4, particularly in Central and South America and Australasia (Figure 18-3). It is no longer the case that higher confidence levels of detected impacts are restricted to any particular region (Figure 18-6).

The qualitative conclusion that observed impacts on human and managed systems have now been detected with at least medium confidence on all inhabited continents is new and noteworthy. However, the number of systems with detectable impacts is only an indicative metric of coverage, because many options exist for aggregation and disaggregation of evidence. Thus this synthesis of detection and attribution studies does not, at this time, provide evidence of differing severity of impacts between continents. Throughout its assessments, the IPCC has repeatedly noted the significant disparity between the vulnerability of countries, regions, and social groups, related to differences in adaptive capacity (e.g., Wilbanks et al., 2007). Nevertheless, additional coverage of detection and attribution studies is required for broad evaluation of social disparities in impacts.

The original intent of the category now labeled as Risks Associated with Aggregate Impacts was to assess those economic impacts, damages, and risks that are specifically driven by climate change at a globally aggregated level, using unified monetary metrics. Recognizing the limits of calibrated monetarization of impacts, the scope of this RFC has been expanded over time to also include non-monetary metrics (Smith et al., 2009). Table 18-11 lists various aggregate systems of near-global extent for which the following two conditions apply: there is some form of calibrated metric for comparison of impacts across space and subsystems, and the evidence for detection and attribution of the impacts has sufficient geographical coverage to count as spatially representative sample.

Confidence in such large-scale detection is, again, highest in cryospheric systems (expressed in glacier volume or permafrost active layer thickness), but climate change has also affected ecosystems (expressed as net productivity or carbon stocks, ranging from medium to high confidence) and some human systems (crop yields, losses due to extreme events, ranging from low to medium confidence) according to the listed aggregate measures. Thus, several globally aggregated impacts of recent climate change have now been identified.

The RFC Risks Associated with Large-Scale Singular Events "represents the likelihood that certain phenomena (sometimes called singularities or tipping points) would occur, any of which may be accompanied by very large impacts" (Smith et al., 2009). Several studies have identified "tipping elements" in the Earth system that exhibit nonlinear behavior with potentially strong feedbacks on the Earth system (Lenton et al., 2008; Leadley et al., 2010). For observed impacts, the concern translates into a question of the possible presence of "early warning signals" for discontinuities that may be derived from monitoring changes in some climate or natural systems (Collie et al., 2004; deYoung et al., 2008; Andersen et al., 2009; Lenton, 2011).

For the Arctic region, new evidence indicates a biophysical regime shift is taking place, with cascading impacts on physical systems, ecosystems, and human livelihoods. For Arctic marine biota, the rapid reduction of summer ice cover causes a tipping element that is now severely 
Table 18-11 | Confidence in detection of impacts on aggregate impact measures against the specified reference behavior and confidence in attribution of the specified role of climate change in those observed changes.

\begin{tabular}{l|c|l|c|c|c}
\hline \multicolumn{1}{c|}{ Global aggregated impact } & $\begin{array}{c}\text { Confidence } \\
\text { in detection }\end{array}$ & \multicolumn{1}{|c|}{ Reference behavior } & $\begin{array}{c}\text { Confidence } \\
\text { in attribution }\end{array}$ & $\begin{array}{c}\text { Role of climate } \\
\text { change }\end{array}$ & Reference \\
\hline Glacier ice volume reduction & Very high & No change & High & Major & Sections 3.2.2 and 18.3.1.1 \\
\hline $\begin{array}{l}\text { Permafrost degradation and increase of active layer } \\
\text { thickness }\end{array}$ & High & No change & Major & Section 18.3.1.1 \\
\hline $\begin{array}{l}\text { Increase in terrestrial net primary production and carbon } \\
\text { stocks }\end{array}$ & High & $\begin{array}{l}\text { Changes due to nitrogen deposition, } \\
\text { afforestation, and land management }\end{array}$ & Low & Major & Section 18.3.2.2 \\
\hline Negative yield impacts on global wheat and maize yields & Medium & $\begin{array}{l}\text { Changes due to technology, practice, } \\
\text { and coverage }\end{array}$ & Medium & Minor & Section 18.4.1.1; Figure 7-2 \\
\hline Increase in monetary losses due to extreme weather & Low & Changes due to exposure and wealth & Low & Minor & Sections 10.7.3 and 18.4.3.1 \\
\hline
\end{tabular}

affecting pelagic ecosystems as well as ice-dependent mammals such as seals and polar bears (high confidence; Duarte et al., 2012a; see also Tables 18-2, 18-8; Section 28.2.2.1). On land, thawing of Arctic permafrost and shrub encroachment on the tundra have been driven by warming and prolongation of the growing season (high confidence; Sections 4.3.3.4, 18.3.2.4, 24.4.2.2; Tables 18-5, 18-7; Figure 4-4). Permafrost degradation has contributed to widespread hydrological changes including lake formation or disappearance within a few years' time (high confidence; Prowse and Brown, 2010; Callaghan et al., 2013; Table 18-6), while increasing winter rains have had consequences for the tundra food webs (medium confidence; Post et al., 2009; Callaghan et al., 2013; Hansen et al., 2013). Indigenous people throughout the Arctic are impacted by these changes (Eira, 2012; Crate, 2013; see also Section 18.4.6). In summary, several indicators of the ongoing regime shift in the entire Arctic land-sea socio-ecological system can be interpreted as a warning sign for a large-scale singular event (Post et al., 2009; CAFF, 2010; Callaghan et al., 2010; AMAP, 2011; Duarte et al., 2012b; Figure 18-3; Tables 18-5, 18-7 to 18-9; Section 28.2).

Reef building corals are in rapid decline in many regions, and climate change is one of the major drivers (high confidence; Box 18-2). This irreversible loss of biodiversity has significant feedbacks within the marine biosphere, and significant consequences for regional marine ecosystems as well as the human livelihoods that depend on them (Hoegh-Guldberg and Bruno, 2010; Richardson et al., 2012). The growing evidence for presently ongoing change and its attribution to warming gained since the AR4 strengthens the conclusion that increased mass bleaching of corals constitutes a strong warning signal for the singular event that would constitute the irreversible loss of an entire biome.

Dieback and degradation in the boreal forests as well as the Amazonian rainforest have also been identified as potential tipping elements in the Earth system, due to their large extent and the possible feedbacks with the carbon cycle (Lenton et al., 2008; Leadley et al., 2010; Marengo et al., 2011b; see also Section 4.3.3.1). For the boreal forest, increases in tree mortality have been observed in many regions, including widespread dieback related to insect infestations and fire in North America (Sections 4.3.3.1, 26.4.2.1). Taken together, these may be seen as indicators of an ongoing regime shift in the boreal forest, but there is only low confidence in attribution to climate change (Section 18.3.2.4; Figure 4-4). In the humid tropical forests of the Amazon basin, increased tree turnover (both mortality and growth) and enhanced drought risks have been observed during recent decades. However, the main reason for concern is the interaction between climate change, deforestation, and the high susceptibility of forests to fire, which together could produce positive feedbacks leading to degradation of forests in large areas of the Amazon (Malhi et al., 2009). Currently, there is only low confidence in attribution of observed ecosystem changes in the Amazon to climate change. In conclusion, there is insufficient evidence from observed climate change impacts to support a climate-related warning sign of possible large-scale singular events in the boreal and Amazonian forest.

\subsubsection{Conclusion}

Detection and attribution studies evaluate the agreement between observations of change in a system and process understanding of its causes, whether these are due to climate change or other forces. This sets a higher bar for establishing confidence in the assessment of past changes than is generally applied to the projections of future changes, because observational evidence has important gaps, while plausibility of future changes is established on the basis of process knowledge only. Despite this constraint, the body of evidence on observed impacts of recent climate change demonstrates increasing coverage of the Earth and its various subsystems, including human livelihoods. Increasingly, there is also evidence for complex changes in interconnected systems.

This analysis lends new qualitative support to four out of the five RFCs established by earlier IPCC assessments. Specifically, evidence is notable for risks to unique and threatened systems, risks stemming from extreme weather events, risks associated with globally aggregated impacts, and —in terms of early warnings — risks associated with largescale discontinuities. Only the spatial or social disparities covered under "Risks Associated with the Distribution of Impacts" are still insufficiently studied to permit a synthesis of available observations for the characterization of a global concern. While the Arctic stands out as a region with robust evidence of impacts across numerous systems, current detection and attribution literature does not address whether the severity of those impacts differs from other regions. The Arctic region, warm-water coral reef systems, and mountain glaciers feature strongly in the observational evidence discussed for all the RFCs, but there are also important observations from impacted hydrological systems and human systems, including agriculture.

The evidence gathered since the AR4 on detection and attribution of observed impacts from climate change has reached a level at which it can inform evaluation of many of the aspects of present-day climate change risk as described by the RFCs. In particular, the geographical 
distribution of studies is reaching the point where assessment of the global nature of impacts is possible:

- There is now robust evidence of observed changes in natural systems in all of the regional groupings used in this report. Climate change has played a major role in observed changes in various components of the cryosphere on all continents (high confidence). Climate change has also driven observed changes in terrestrial ecosystems on six continents (high confidence, the exception being low confidence in Central and South America) and on some small islands (medium confidence), and for marine ecosystems surrounding six continents and some small islands (high confidence, with evidence lacking for Africa).

- There is new and stronger evidence of the detection of impacts in human systems on the inhabited continents. There is at least medium confidence in detection of impacts on food production in all the inhabited continents except North America.

- While the current detection and attribution literature does not reveal observational evidence of geographical differences in the severity of climate change impacts between continents, it does indicate that the unique systems of the Arctic region and warm water coral reefs are undergoing rapid changes in response to observed warming in ways that are potentially irreversible.

\subsection{Gaps, Research Needs, and Emerging Issues}

There are three broad areas relating to the detection and attribution of the impacts of climate change on natural and human systems that require more research. The first concerns the formulation of the relevant issues and further development of rigorous scientific methods for addressing them. At present, the terms detection and attribution are used in numerous different ways, and, while there is no need for a single definition, more clarity about usage is important. Methods in this area are closely linked to specific formulations of these terms and there is a parallel need to develop, refine, and evaluate them in light of this. For example, statistical methods are commonly used to detect the impact of variations in climate on human and natural systems while controlling for the effect of other factors. Such detection can be valuable in helping to predict the response of systems to projections of future climate change but a positive correlation does not necessarily imply that the system has already changed in response to historical climate change. A second example is the growing use of methods that combine information from multiple systems - for example, different locations or speciesto draw a conclusion about systems in general. More conceptual work is needed to develop the basis for such ecological meta-analysis and the interpretation of its results.

A second area in which more work is needed is data collection and monitoring. Globally, environmental data are still insufficient for monitoring the impacts of climate change. In addition, developed countries are typically over-represented in impact studies because of their comparable wealth in socioeconomic data. Because the level of economic development is extremely important in determining the impacts of climate change, this over-representation probably gives rise to a distorted picture of the global impacts of climate change.

Finally, this chapter stresses the need to base detection and attribution studies on a scientific understanding of the system in question and the way in which climate change (and other factors) might affect it rather than on relatively simple correlational analysis. This is particularly important for human systems and at least some natural systems in which the combined effect of climate change and other factors is complex and historical adaptation to climate change must be expected. Further development, refinement, and evaluation of both conceptual and processbased models of the human-environment system will be essential for improved conclusions about detection and attribution.

Frequently Asked Questions

\section{FAQ 18.1 Why are detection and attribution of climate impacts important?}

To respond to climate change, it is necessary to predict what its impacts on natural and human systems will be. As some of these predicted impacts are expected to already have occurred, detection and attribution provides a way of validating and refining predictions about the future. For example, one of the clearest predicted ecological impacts of climate is a poleward shift in the ranges of plant and animal species. The detection in historical data of a climate-related shift in species ranges would lend credence to this prediction, and the assessment of its magnitude would provide information about the likely magnitude of future shifts.

Frequently Asked Questions

\section{FAQ 18.2 Why is it important to assess impacts of all climate change aspects, and not only impacts of anthropogenic climate change?}

Natural and human systems are affected by both natural and anthropogenic climate change, operating locally, regionally, and/or globally. To understand the sensitivity of natural and human systems to expected future climate change, and to anticipate the outcome of adaptation policies, it is less important whether the observed changes have been caused by anthropogenic climate change or by natural climate fluctuations. In the context of this chapter, all known impacts of climate change are assessed. 
Frequently Asked Questions

\section{FAQ 18.3 | What are the main challenges in detecting climate change impacts?}

The detection of climate change impacts addresses the question of whether a system has changed beyond its expected behavior in the absence of climate change. This requires an understanding of both the external and internal factors that affect the system. External factors that can affect natural systems include exploitation, land use changes, and pollution. Even in the absence of changes in external factors, many natural systems exhibit substantial internal variability—such as booms and busts in wild populations-that can last for long periods. For example, to detect the impact of climate change on wild fish stocks, it is necessary to understand the effects of fishing, habitat alteration, and possibly pollution, as well as the internal stock dynamics. In the same way, human systems are affected by social and economic factors that are unrelated to climate change. For example, to detect the impact of climate change on human health, it is necessary to understand the effects of changes in public health measures such as improved sanitation.

\section{Frequently Asked Questions}

\section{FAQ 18.4 | What are the main challenges in attributing changes in a system to climate change?}

Whereas the detection of climate change impacts addresses the question only of whether or not a system has changed as a result of climate change, attribution addresses the magnitude of the contribution of climate change to such changes. Even when it is possible to detect the impact of climate change on a system, more detailed understanding may be needed to assess the magnitude of this impact in relation to the influences of other external factors and natural variability.

Frequently Asked Questions

\section{FAQ 18.5 | Is it possible to attribute a single event, like a disease outbreak or the extinction of a species, to climate change?}

It is possible to detect trends in the frequency or characteristics of a class of weather events like heat waves. Similarly, trends in a certain kind of impact of that class of events can also be detected and attributed, although the influence of other drivers of change, such as policy decisions and increasing wealth, can make this challenging. However, any single impact event also results from the antecedent conditions of the impacted system. Thus though damage from a single extreme weather event may occur against the background of trends in many influencing factors, including climate change, there is always a contribution from random chance.

\section{References}

ACIA, 2005: Arctic Climate Impact Assessment. Cambridge University Press, New York, NY, USA, 1042 pp.

Adamík, P. and M. Král, 2008: Climate-and resource-driven long-term changes in dormice populations negatively affect hole-nesting songbirds. Journal of Zoology, 275(3), 209-215.

Adano, W.R., T. Dietz, K. Witsenburg, and F. Zaal, 2012: Climate change, violent conflict and local institutions in Kenya's drylands. Journal of Peace Research, 49, 65-80.

Adelekan, I.0., 2010: Vulnerability of poor urban coastal communities to flooding in Lagos, Nigeria. Environment and Urbanization, 22(2), 433-450.

Adrian, R., C.M. O'Reilly, H. Zagarese, S.B. Baines, D.O. Hessen, W. Keller, D.M. Livingstone, R. Sommaruga, D. Straile, and E. Van Donk, 2009: Lakes as sentinels of climate change. Limnology and Oceanography, 54(6), 2283-2297.

Agrawal, A., 1995: Dismantling the divide between indigenous and scientific knowledge. Development and Change, 26(3), 413-439.

Akpinar-Ferrand, E. and A. Singh, 2010: Modeling increased demand of energy for air conditioners and consequent $\mathrm{CO}_{2}$ emissions to minimize health risks due to climate change in India. Environmental Science \& Policy, 13(8), 702-712.
Alderman, H., 2010: Safety nets can help address the risks to nutrition from increasing climate variability. The Journal of Nutrition, 140(1), 148-152.

Alexander, C., N. Bynum, E. Johnson, U. King, T. Mustonen, P. Neofotis, N. Oettle, C. Rosenzweig, C. Sakakibara, V. Shadrin, M. Vicarelli, J. Waterhouse, and B. Weeks, 2011: Linking indigenous and scientific knowledge of climate change. BioScience, 61, 477-484.

Alheit, J., T. Pohlmann, M. Casini, W. Greve, R. Hinrichs, M. Mathis, K. O'Driscoll, R. Vorberg, and C. Wagner, 2012: Climate variability drives anchovies and sardines into the North and Baltic Seas. Progress in Oceanography, 96(1), 128-139.

Ali, T., B. Shahbaz, and A. Suleri, 2006: Analysis of myths and realities of deforestation in Northwest Pakistan: implications for forestry extension. International Journal of Agriculture and Biology, 8(1), 107-110.

Allen, M., 2011: In defense of the traditional null hypothesis: remarks on the Trenberth and Curry WIREs opinion articles. Wiley Interdisciplinary Reviews: Climate Change, 2, 931-934.

Allen, S. and C. Huggel, 2013: Extremely warm temperatures as a potential cause of recent high mountain rockfall. Global and Planetary Change, 107(8), 59-69.

Allen, S.K., S.C. Cox, and I.F. Owens, 2010: Rock-avalanches and other landslides in the central Southern Alps of New Zealand: a regional assessment of possible climate change impacts. Landslides, 8(1), 33-48. 
Alling, A., O. Doherty, H. Logan, L. Feldman, and P. Dustan, 2007: Catastrophic coral mortality in the remote central Pacific Ocean: Kiribati Phoenix Islands. In: Atoll Research Bulletin. No. 551, National Museum of Natural History, Smithsonian Institution, Washington, DC, USA, 21 pp.

Alongi, D.M., 2008: Mangrove forests: resilience, protection from tsunamis, and responses to global climate change. Estuarine Coastal and Shelf Science, 76(1), 1-13.

Alonso, D., M.J. Bouma, and M. Pascual, 2011: Epidemic malaria and warmer temperatures in recent decades in an East African highland. Proceedings of the Royal Society B, 278, 1661-1669.

Alston, M., 2011: Gender and climate change in Australia. Journal of Sociology, 47(1), 53-70.

Álvarez-Berríos, N.L., I.K. Parés-Ramos, and T.M. Aide, 2013: Contrasting patterns of urban expansion in Colombia, Ecuador, Peru, and Bolivia between 1992 and 2009. Ambio, 42(1), 29-40.

AMAP, 2011: Snow, Water, Ice and Permafrost in the Arctic (SWIPA): Climate Change and the Cryosphere. Arctic Monitoring and Assessment Programme (AMAP), Oslo, Norway, $538 \mathrm{pp}$.

Amstrup, S.C., E.T. DeWeaver, D.C. Douglas, B.G. Marcot, G.M. Durner, C.M. Bitz, and D.A. Bailey, 2010: Greenhouse gas mitigation can reduce sea-ice loss and increase polar bear persistence. Nature, 468(7326), 955-958.

Amthor, J.S., 2001: Effects of atmospheric $\mathrm{CO}_{2}$ concentration on wheat yield. Review of results from experiments using various approaches to control $\mathrm{CO}_{2}$ concentration. Field Crops Research, 73(1), 1-34.

Andersen, T., J. Carstensen, E. Hernández-García, and C.M. Duarte, 2009: Ecological thresholds and regime shifts: approaches to identification. Trends in Ecology \& Evolution, 24(1), 49-57.

Anderson, C.A., 1987: Temperature and aggression: effects on quarterly, yearly, and city rates of violent and nonviolent crime. Journal of Personality and Social Psychology, 52(6), 1161-1173.

Anderson, C.A., 2001: Heat and violence. Current Directions in Psychological Sciences, 10(1), 33-38.

Andreassen, L.M., B. Kjollmoen, A. Rasmussen, K. Melvold, and O. Nordli, 2012: Langfjordjokelen, a rapidly shrinking glacier in northern Norway. Journal of Glaciology, 58(209), 581-593.

Aporta, C., D.R.F. Taylor, and G.J. Laidler, 2011: Geographies of Inuit sea ice use. Introduction. Canadian Geographer / Le Géographe Canadien, 55, 1-5.

Arctic Council, 2013: Arctic Resilience Interim Report 2013. Stockholm Environment Institute (SEI) and Stockholm Resilience Centre, Stockholm, Sweden, 117 pp.

Ariano, R., G.W. Canonica, and G. Passalacqua, 2010: The possible role of climate changes in variations of pollen seasons and allergic sensitizations over 27 years. The Journal of Allergy and Clinical Immunology, 125(2 Suppl. 1), AB192, doi:10.1016/j.jaci.2009.12.753.

Armah, F.A., J.O. Odoi, G.T. Yengoh, S. Obiri, D.O. Yawson, and E.K.A. Afrifa, 2011: Food security and climate change in drought-sensitive savanna zones of Ghana. Mitigation and Adaptation Strategies for Global Change, 16(3), 291-306.

Arora-Jonsson, S., 2011:Virtue and vulnerability: discourses on women, gender and climate change. Global Environmental Change, 21(2), 744-751.

Arrigo, K.R. and G.L. Van Dijken, 2011: Secular trends in Arctic Ocean net primary production. Journal of Geophysical Research, 116(C9), C09011, doi:10.1029/ $2011 \mathrm{JC} 007151$.

Artur, L. and D. Hilhorst, 2012: Everyday realities of climate change adaptation in Mozambique. Global Environmental Change, 22(2), 529-536.

Arzt, J., W.R. White, B.V. Thomsen, and C.C. Brown, 2010: Agricultural diseases on the move early in the third millennium. Veterinary Pathology Online, 47(1), 1527.

Ateweberhan, M., T. McClanahan, N. Graham, and C. Sheppard, 2011: Episodic heterogeneous decline and recovery of coral cover in the Indian Ocean. Coral Reefs, 30(3), 739-752.

Atkinson, A., V. Siegel, E. Pakhomov, and P. Rothery, 2004: Long-term decline in krill stock and increase in salps within the Southern Ocean. Nature, 432(7013), 100-103.

Auffhammer, M. and J.R. Vincent, 2012: Unobserved time effects confound the identification of climate change impacts. Proceedings of the National Academy of Sciences of the United States of America, 109(30), 11973-11974.

Auffhammer, M., V. Ramanathan, and J.R. Vincent, 2006: Integrated model shows that atmospheric brown clouds and greenhouse gases have reduced rice harvests in India. Proceedings of the National Academy of Sciences of the United States of America, 103(52), 19668-19672.
Axford, Y., J.P. Briner, C.A. Cooke, D.R. Francis, N. Michelutti, G.H. Miller, J.P. Smol, E.K. Thomas, C.R. Wilson, and A.P. Wolfe, 2009: Recent changes in a remote Arctic lake are unique within the past 200,000 years. Proceedings of the National Academy of Sciences of the United States of America, 106(44), 18443-18446.

Ayyappan, R., S. Sankar, P. Rajkumar, and K. Balakrishnan, 2009: Work-related heat stress concerns in automotive industries. A case study from Chennai, India. Global Health Action, 2, doi:10.3402/gha.v2i0.2060.

Badjeck, M.C., E.H. Allison, A.S. Halls, and N.K. Dulvy, 2010: Impacts of climate variability and change on fishery-based livelihoods. Marine Policy, 34(3), 375383.

Bajracharya, S.R. and P. Mool, 2009: Glaciers, glacial lakes and glacial lake outburst floods in the Mount Everest region, Nepal. Annals of Glaciology, 50(53), 81-86.

Baker, A.C., P.W. Glynn, and B. Riegl, 2008: Climate change and coral reef bleaching: an ecological assessment of long-term impacts, recovery trends and future outlook. Estuarine, Coastal and Shelf Science, 80(4), 435-471.

Balakrishnan, K., A. Ramalingam, V. Dasu, J.C. Stephen, M.R. Sivaperumal, D. Kumarasamy, K. Mukhopadhyay, S. Ghosh, and S. Sambandam, 2010: Case studies on heat stress related perceptions in different industrial sectors in southern India. Global Health Action, 3, 5635, doi:10.3402/gha.v3i0.5635.

Ballantyne, C.K., 2002: Paraglacial geomorphology. Quaternary Science Reviews, 21(18-19), 1935-2017.

Ballu, V., M.N. Bouin, P. Siméoni, W.C. Crawford, S. Calmant, J.M. Boré, T. Kanas, and B. Pelletier, 2011: Comparing the role of absolute sea-level rise and vertical tectonic motions in coastal flooding, Torres Islands (Vanuatu). Proceedings of the National Academy of Sciences of the United States of America, 108(32), 13019-13022.

Banfai, D.S. and D. Bowman, 2007: Drivers of rain-forest boundary dynamics in Kakadu National Park, Northern Australia. A field assessment. Journal of Tropical Ecology, 23, 73-86.

Baraer, M., B.G. Mark, J.M. McKenzie, T. Condom, J. Bury, K.I. Huh, C. Portocarrero, J. Gómez, and S. Rathay, 2012: Glacier recession and water resources in Peru's Cordillera Blanca. Journal of Glaciology, 58(207), 134-150.

Barange, M. and R.I. Perry, 2009: Physical and ecological impacts of climate change relevant to marine and inland capture fisheries and aquaculture. In: Climate Change Implications for Fisheries and Aquaculture: Overview of Current Scientific Knowledge [Cochrane, K., C. de Young, D. Soto, and T. Bahri (eds.)]. FAO Fisheries and Aquaculture Technical Paper No. 530, Food and Agriculture Organization of the United Nations (FAO), Rome, Italy, pp. 7-106.

Barlow, P.M. and E.G. Reichard, 2010: Saltwater intrusion in coastal regions of North America. Hydrogeology Journal, 18(1), 247-260.

Barnett, T.P., D.W. Pierce, H.G. Hidalgo, C. Bonfils, B.D. Santer, T. Das, G. Bala, A.W. Wood, T. Nozawa, A.A. Mirin, D.R. Cayan, and M.D. Dettinger, 2008: Humaninduced changes in the hydrology of the western United States. Science, 319(5866), 1080-1080.

Barnosky, A.D., N. Matzke, S. Tomiya, G.O. Wogan, B. Swartz, T.B. Quental, C. Marshall, J.L. McGuire, E.L. Lindsey, and K.C. Maguire, 2011: Has the Earth's sixth mass extinction already arrived? Nature, 471(7336), 51-57.

Barredo, J.I., 2010: No upward trend in normalised windstorm losses in Europe: 1970-2008. Natural Hazards and Earth System Sciences, 10, 97-104.

Barredo, J.I., D. Saurí, and M.C. Llasat, 2012: Assessing trends in insured losses from floods in Spain 1971-2008. Natural Hazards Earth System Sciences, 12, 1723 1729.

Barriopedro, D., E.M. Fischer, J. Luterbacher, R.M. Trigo, and R. García-Herrera, 2011: The hot summer of 2010: redrawing the temperature record map of Europe. Science, 332(6026), 220-224.

Barrios, S., L. Bertinelli, and E. Strobl, 2006: Climatic change and rural-urban migration. The case of sub-Saharan Africa. Journal of Urban Economics, 60(3), 357-371.

Barros, V.R., 2010: Capítulo 3: El cambio climático en Argentina. In: Agro y Ambiente: Una Agenda Compartida para el Desarrollo Sustentable. Foro de la Cadena Agroindustrial Argentina, Buenos Aires, Argentina, 35 pp., www.foroagroindustrial. org.ar/pdf/cap3.pdf.

Barthel, F. and E. Neumayer, 2012: A trend analysis of normalized insured damage from natural disasters. Climatic Change, 113(2), 215-237.

Bauder, A., M. Funk, and M. Huss, 2007: Ice-volume changes of selected glaciers in the Swiss Alps since the end of the 19th century. Annals of Glaciology, 46(1), 145-149.

Beaugrand, G. and R.R. Kirby, 2010: Climate, plankton and cod. Global Change Biology, 16(4), 1268-1280. 
Beaugrand, G., P.C. Reid, F. Ibanez, J.A. Lindley, and M. Edwards, 2002: Reorganization of North Atlantic marine copepod biodiversity and climate. Science, 296(5573), 1692-1694

Beaugrand, G., C. Luczak, and M. Edwards, 2009: Rapid biogeographical plankton shifts in the North Atlantic Ocean. Global Change Biology, 15(7), 1790-1803.

Beaugrand, G., M. Edwards, and L. Legendre, 2010: Marine biodiversity, ecosystem functioning, and carbon cycles. Proceedings of the National Academy of Sciences of the United States of America, 107(22), 10120-10124.

Beaumier, M. and J.D. Ford, 2010: Food insecurity among Inuit women exacerbated by socio-economic stresses and climate change. Canadian Journal of Public Health, 101(3), 196-201.

Beck, P.S. and S.J. Goetz, 2011: Satellite observations of high northern latitude vegetation productivity changes between 1982 and 2008: ecological variability and regional differences. Environmental Research Letters, 6(4), 045501 doi:10.1088/1748-9326/6/4/045501.

Becken, S. and J. Hay, 2007: Tourism and Climate Change: Risks and Opportunities. Channel View Publications, Bristol, UK, 289 pp.

Bednaršek, N., G.A. Tarling, D.C.E. Bakker, S. Fielding, E.M. Jones, H.J. Venables, P. Ward, A. Kuzirian, B. Lézé, R.A. Feely, and E.J. Murphy, 2012: Extensive dissolution of live pteropods in the Southern Ocean. Nature Geoscience, $\mathbf{5}$ 881-885.

Behrenfeld, M.J., R.T. O'Malley, D.A. Siegel, C.R. McClain, J.L. Sarmiento, G.C. Feldman, A.J. Milligan, P.G. Falkowski, R.M. Letelier, and E.S. Boss, 2006 Climate-driven trends in contemporary ocean productivity. Nature, 444(7120), 752-755.

Belkin, I.M., 2009: Rapid warming of large marine ecosystems. Progress in Oceanography, 81(1-4), 207-213.

Bell, G.D., E. Blake, K.C. Mo, C.W. Landsea, R. Pasch, M. Chelliah, S.B. Goldenberg, and H.J. Diamond, 2006: The record breaking 2005 Atlantic hurricane season. In: State of the Climate in 2005 [Shein, K.A. (ed.)]. Special Supplement to the Bulletin of the American Meteorological Society, 87(6 Suppl.), S44-S45.

Beniston, M., M. Stoffel, and M. Hill, 2011: Impacts of climatic change on water and natural hazards in the Alps: can current water governance cope with future challenges? Examples from the European "ACQWA" project. Environmental Science \& Policy, 14(7), 734-743.

Bennett, C.M., K.G.B. Dear, and A.J.C. McMichael, 2013: Shifts in the seasonal distribution of deaths in Australia, 1968-2007. International Journal of Biometeorology (in press), doi:10.1007/s00484-013-0663-x.

Benning, T.L., D. LaPointe, C.T. Atkinson, and P.M. Vitousek, 2002: Interactions of climate change with biological invasions and land use in the Hawaiian Islands: modeling the fate of endemic birds using a geographic information system. Proceedings of the National Academy of Sciences of the United States of America, 99(22), 14246-14249.

Benson, B.J., J.J. Magnuson, O.P. Jensen, V.M. Card, G. Hodgkins, J. Korhonen, D.M. Livingstone, K.M. Stewart, G.A. Weyhenmeyer, and N.G. Granin, 2012: Extreme events, trends, and variability in Northern Hemisphere lake-ice phenology (1855-2005). Climatic Change, 112(2), 299-323.

Berkes, F., 2009: Indigenous ways of knowing and the study of environmental change. Journal of the Royal Society of New Zealand, 39, 151-156.

Bertrand, R., J. Lenoir, C. Piedallu, G. Riofrío-Dillon, P. de Ruffray, C. Vidal, J. Pierrat, and J. Gégout, 2011: Changes in plant community composition lag behind climate warming in lowland forests. Nature, 479(7374), 517-520.

Beven, J.L., L.A. Avila, E.S. Blake, D.P. Brown, J.L. Franklin, R.D. Knabb, R.J. Pasch, J.R. Rhome, and S.R. Stewart, 2008: Atlantic hurricane season of 2005. Monthly Weather Review, 136(3), 1109-1173.

Biasutti, M. and A. Giannini, 2006: Robust Sahel drying in response to late 20th century forcings. Geophysical Research Letters, 33(11), L11706, doi:10.1029/ 2006 GL026067.

Birdsey, R., K. Pregitzer, and A. Lucier, 2006: Forest carbon management in the United States. Journal of Environmental Quality, 35(4), 1461-1469.

Björk, R.G. and U. Molau, 2007: Ecology of alpine snow beds and the impact of global change. Arctic, Antarctic and Alpine Research, 39(1), 34-43.

Björnsson, H. and F. Pálsson, 2008: Icelandic glaciers. Jökull, 58, 365-386.

Black, R., W.N. Adger, N.W. Arnell, S. Dercon, A. Geddes, and D. Thomas, 2011: The effect of environmental change on human migration. Global Environmental Change, 21(Suppl. 1), 3-11.

Blok, D., U. Sass-Klaassen, G. Schaepman-Strub, M. Heijmans, P. Sauren, and F Berendse, 2011: What are the main climate drivers for shrub growth in Northeastern Siberian tundra? Biogeosciences, 8(5), 1169-1179.
Boero, F., J. Féral, E. Azzurro, V. Cardin, B. Riedel, M. Despalatović, I. Munda, P. Moschella, J. Zaouali, and S. Fonda Umani, 2008: Climate warming and related changes in Mediterranean marine biota. CIESM Workshop Monographs, 35, 521.

Bolch, T., A. Kulkarni, A. Kääb, C. Huggel, F. Paul, G. Cogley, H. Frey, J.S. Kargel, K. Fujita, M. Scheel, S. Bajracharya, and M. Stoffel, 2012: The state and fate of Himalayan glaciers. Science, 336(6079), 310-314.

Bonan, G.B., 2008: Forests and climate change: forcings, feedbacks, and the climate benefits of forests. Science, 320(5882), 1444-1449.

Bond-Lamberty, B. and A. Thomson, 2010: Temperature-associated increases in the global soil respiration record. Nature, 464(7288), 579-582.

Borges, A. and N. Gypens, 2010: Carbonate chemistry in the coastal zone responds more strongly to eutrophication than to ocean acidification. Limnology and Oceanography, 55(1), 346-353.

Boruff, B.J., J.A. Easoz, S.D. Jones, H.R. Landry, J.D. Mitchem, and S.L. Cutter, 2003: Tornado hazards in the United States. Climate Research, 24(2), 103-117.

Bouwer, L.M., 2011: Have disaster losses increased due to anthropogenic climate change? Bulletin of the American Meteorological Society, 92(1), 39-46.

Bouwer, L.M. and W.J.W. Botzen, 2011: How sensitive are US hurricane damages to climate? Comment on a paper by W.D. Nordhaus. Climate Change Economics, 02(01), 1-7.

Bouwer, L.M., R.P. Crompton, E. Faust, P. Hoppe, and R.A. Pielke Jr., 2007: Confronting disaster losses. Science, 318(11), 753-753.

Bowman, D., B.P. Murphy, and D.S. Banfai, 2010: Has global environmental change caused monsoon rainforests to expand in the Australian monsoon tropics? Landscape Ecology, 25(8), 1247-1260.

Bradley, R.S., F.T. Keimig, H.F. Diaz, and D.R. Hardy, 2009: Recent changes in freezing level heights in the tropics with implications for the deglacierization of high mountain regions. Geophysical Research Letters, 36(17), L17701, doi:10.1029/2009GL037712.

Brander, K.M., 2007: Global fish production and climate change. Proceedings of the National Academy of Sciences of the United States of America, 104(50), 1970919714.

Brander, K., 2010: Impacts of climate change on fisheries. Journal of Marine Systems, 79(3-4), 389-402.

Breetzke, G.D. and E.G. Cohn, 2012: Seasonal assault and neighborhood deprivation in South Africa - some preliminary findings. Environment and Behavior, 44(5), 641-667.

Brisson, N., P. Gate, D. Gouache, G. Charmet, F. Oury, and F. Huard, 2010: Why are wheat yields stagnating in Europe? A comprehensive data analysis for France. Field Crops Research, 119(1), 201-212.

Brook, T., 2010: The Troubled Empire: China in the Yuan and Ming Dynasties. Belknap Press, Cambridge, MA, USA, $329 \mathrm{pp}$.

Brooks, H.E. and C.A. Doswell, 2002: Deaths in the 3 May 1999 Oklahoma City tornado from a historical perspective. Weather and Forecasting, 17(3), 354361.

Brown, C., R. Meeks, K. Hunu, and W. Yu, 2011: Hydroclimate risk to economic growth in sub-Saharan Africa. Climatic Change, 106(4), 621-647.

Brown, L.E., D.M. Hannah, and A.M. Milner, 2007: Vulnerability of alpine stream biodiversity to shrinking glaciers and snowpacks. Global Change Biology, 13(5), 958-966.

Brown, Z.W. and K.R. Arrigo, 2012: Contrasting trends in sea ice and primary production in the Bering Sea and Arctic Ocean. ICES Journal of Marine Science: Journal Du Conseil, 69(7), 1180-1193.

Brubaker, M., J. Berner, R. Chavan, and J. Warren, 2011: Climate change and health effects in Northwest Alaska. Global Health Action, 4, 8445, doi:10.3402/ gha.v4i0.8445.

Bruno, J.F. and E.R. Selig, 2007: Regional decline of coral cover in the Indo-Pacific: timing, extent, and subregional comparisons. PLoS ONE, 2(8), e711, doi:10.1371/ journal.pone.0000711.

Bruno, J.F., E.R. Selig, K.S. Casey, C.A. Page, B.L. Willis, C.D. Harvell, H. Sweatman, and A.M. Melendy, 2007: Thermal stress and coral cover as drivers of coral disease outbreaks. PLoS Biology, 5(6), 1220-1227.

Bryant, D., L. Burke, J. McManus, and M. Spalding, 1998: Reefs at Risk:A Map-Based Indicator of Threats to the World's Coral Reefs. World Resources Institute, Washington, DC, USA, $60 \mathrm{pp}$.

Buhaug, H. and O.M. Theisen, 2012: On environmental change and armed conflict. In: Climate Change, Human Security and Violent Conflict [Scheffran, J. (ed.)]. Springer-Verlag, Berlin Heidelberg, pp. 43-55. 
Buhaug, H., H. Hegre, and H. Strand, 2010: Sensitivity Analysis of Climate Variability and Civil War. PRIO Paper, Peace Research Institute Oslo (PRIO), Oslo, Norway, $19 \mathrm{pp}$.

Bullard, R. and B. Wright, 2010: Race, Place, and Environmental Justice after Hurricane Katrina: Struggles to Reclaim, Rebuild, and Revitalize New Orleans and the Gulf Coast. Westview Press, Boulder, CO, USA, 312 pp.

Bulygina, O.N., N.N. Korshunova, and V.N. Razuvaev, 2011: Russia. In: State of the Climate in 2010 [Blunden, J., D.S. Arndt, and M.O. Baringer (eds.)]. Special Supplement to the Bulletin of the American Meteorological Society, 92(7 Suppl.), S199-S203.

Bunce, M., S. Rosendo, and K. Brown, 2010: Perceptions of climate change, multiple stressors and livelihoods on marginal African coasts. Environment, Development and Sustainability, 12(3), 407-440.

Burgmer, T., H. Hillebrand, and M. Pfenninger, 2007: Effects of climate-driven temperature changes on the diversity of freshwater macroinvertebrates. Oecologia, 151(1), 93-103.

Burke, L., K. Reytar, M. Spalding, and A. Perry, 2011: Reefs at Risk Revisited. World Resources Institute, Washington, DC, USA, $114 \mathrm{pp}$.

Burrows, M.T., D.S. Schoeman, L.B. Buckley, P. Moore, E.S. Poloczanska, K.M. Brander, C. Brown, J.F. Bruno, C.M. Duarte, B.S. Halpern, J. Holding, C.V. Kappel, W. Kiessling, M.I. O'Connor, J.M. Pandolfi, C. Parmesan, F.B. Schwing, W.J. Sydeman, and A.J. Richardson, 2011: The pace of shifting climate in marine and terrestrial ecosystems. Science, 334(6056), 652-655.

Bury, J., B.G. Mark, J. McKenzie, A. French, M. Baraer, K. In Huh, M. Zapata Luyo, and R.J. Gómez López, 2010: Glacier recession and human vulnerability in the Yanamarey Watershed of the Cordillera Blanca, Peru. Climatic Change, 105(1-2), 179-206.

Butke, P. and S.C. Sheridan, 2010: An analysis of the relationship between weather and aggressive crime in Cleveland, Ohio. Weather, Climate, and Society, 2(2), 127-139.

Butler, C. and S. Gates, 2012: African range wars: climate, conflict, and property rights. Journal of Peace Research, 49(1), 23-34.

Butt, N., P.A. De Oliveira, and M.H. Costa, 2011: Evidence that deforestation affects the onset of the rainy season in Rondonia, Brazil. Journal of Geophysical Research:Atmospheres, 116, D11120, doi:10.1029/2010JD015174.

Byg, A. and J. Salick, 2009: Local perspectives on a global phenomenon - climate change in Eastern Tibetan villages. Global Environmental Change, 19(2), 156-166.

CAFF, 2010: Arctic Biodiversity Trends 2010 - Selected Indicators of Change. Arctic Council, Conservation of Arctic Flora and Fauna (CAFF) Working Group, CAFF International Secretariat, Akureyri, Iceland, $121 \mathrm{pp}$.

Cahill, A.E., M.E. Aiello-Lammens, M.C. Fisher-Reid, X. Hua, C.J. Karanewsky, H.Y. Ryu, G.C. Sbeglia, F. Spagnolo, J.B. Waldron, and O. Warsi, 2013: How does climate change cause extinction? Proceedings of the Royal Society $B, 280(1750)$, 20121890, doi: 10.1098/rspb.2012.1890.

Cai, W. and T. Cowan, 2006: SAM and regional rainfall in IPCC AR4 models: can anthropogenic forcing account for southwest Western Australian winter rainfall reduction? Geophysical Research Letters, 33(24), L24708, doi:10.1029/ 2006GL028037.

Cai, W., T. Cowan, P. Briggs, and M. Raupach, 2009: Rising temperature depletes soil moisture and exacerbates severe drought conditions across southeast Australia. Geophysical Research Letters, 36(21), L21709, doi:10.1029/2009GL040334.

Callaghan, T.V., F. Bergholm, T.R. Christensen, C. Jonasson, U. Kokfelt, and M. Johansson, 2010: A new climate era in the sub-Arctic. Accelerating climate changes and multiple impacts. Geophysical Research Letters, 37(14), L14705, doi:10.1029/ 2009 GL042064.

Callaghan, T.V., M. Johansson, R.D. Brown, P.Y. Groisman, N. Labba, V. Radionov, R.G. Barry, R.S. Bradley, S. Blangy, and O.N. Bulygina, 2011: Changing snow cover and its impacts. In: Snow, Water, Ice and Permafrost in the Arctic (SWIPA). Arctic Monitoring and Assessment Programme (AMAP), Oslo, Norway, pp. 1-58.

Callaghan, T.V., C. Jonasson, T. Thierfelder, Z. Yang, H. Hedenås, M. Johansson, U. Molau, R. Van Bogaert, J. Olofsson, D. Jones, S. Bokhorst, G. Phoenix, J. Bjerke, H. Tømmervik, T. Christensen, E. Hanna, E. Koller, and V. Sloan, 2013: Ecosystem change and stability over multiple decades in the Swedish sub-Arctic: complex processes and multiple drivers. Philosophical Transactions of the Royal Society B, 368(1624), 20120488, doi: 10.1098/rstb.2012.0488.

Callaway, R., A.P. Shinn, S.E. Grenfell, J.E. Bron, G. Burnell, E.J. Cook, M. Crumlish, S. Culloty, K. Davidson, and R.P. Ellis, 2012: Review of climate change impacts on marine aquaculture in the UK and Ireland. Aquatic Conservation: Marine and Freshwater Ecosystems, 22(3), 389-421.
Cambers, G., 2009: Caribbean beach changes and climate change adaptation. Aquatic Ecosystem Health and Management, 12(2), 168-176.

Camia, A. and G. Amatulli, 2009: Weather factors and fire danger in the Mediterranean. In: Earth Observation of Wildland Fires in Mediterranean Ecosystems [Chuvieco, E. (ed.)]. Springer, Berlin Heidelberg, pp. 71-82.

Cardoso, P.G., D. Raffaelli, and M.A. Pardal, 2008: The impact of extreme weather events on the seagrass Zostera noltii and related Hydrobia ulvae population. Marine Pollution Bulletin, 56(3), 483-492.

Carey, M., 2005: Living and dying with glaciers. People's historical vulnerability to avalanches and outburst floods in Peru. Global and Planetary Change, 47(2-4), 122-134.

Carey, M., 2010: In the Shadow of Melting Glaciers: Climate Change and Andean Society. Oxford University Press, Inc., New York, NY, USA, 273 pp.

Carey, M., A. French, and E. O'Brien, 2012a: Unintended effects of technology on climate change adaptation. An historical analysis of water conflicts below Andean glaciers. Journal of Historical Geography, 38, 181-191.

Carey, M., C. Huggel, J. Bury, C. Portocarrero, and W. Haeberli, 2012b: An integrated socio-environmental framework for glacier hazard management and climate change adaptation. Lessons from Lake 513, Cordillera Blanca, Peru. Climatic Change, 112(3-4), 733-767.

Carilli, J.E., R.D. Norris, B.A. Black, S.M. Walsh, and M. McField, 2009: Local stressors reduce coral resilience to bleaching. PLOS ONE, 4(7), e6324, doi:10.1371/ journal.pone.0006324.

Carpenter, K.E., M. Abrar, G. Aeby, R.B. Aronson, S. Banks, A. Bruckner, A. Chiriboga, J. Cortes, J.C. Delbeek, L. Devantier, G.J. Edgar, A.J. Edwards, D. Fenner, H.M. Guzman, B.W. Hoeksema, G. Hodgson, O. Johan, W.Y. Licuanan, S.R. Livingstone, E.R. Lovell, J.A. Moore, D.O. Obura, D. Ochavillo, B.A. Polidoro, W.F. Precht, M.C. Quibilan, C. Reboton, Z.T. Richards, A.D. Rogers, J. Sanciangco, A. Sheppard, C. Sheppard, J. Smith, S. Stuart, E. Turak, J.E. Veron, C. Wallace, E. Weil, and E. Wood, 2008: One-third of reef-building corals face elevated extinction risk from climate change and local impacts. Science, 321(5888), 560-563.

Carr, E.R., 2008: Between structure and agency. Livelihoods and adaptation in Ghana's central region. Global Environmental Change, 18(4), 689-699.

Carreira, P.M., J.M. Marques, A. Pina, A.M. Gomes, P.A.G. Fernandes, and F.M. Santos, 2010: Groundwater assessment at Santiago Island (Cabo Verde): a multidisciplinary approach to a recurring source of water supply. Water Resources Management, 24(6), 1139-1159.

Carson, C., S. Hajat, B. Armstrong, and P. Wilkinson, 2006: Declining vulnerability to temperature-related mortality in London over the 20th century. American Journal of Epidemiology, 164, 77-84.

Casassa, G.P., B. Pouyaud, and F. Escobar, 2009: Detection of changes in glacial runoff in alpine basins. Examples from North America, the Alps, central Asia and the Andes. Hydrological Processes, 23(1), 31-41.

Chambers, L.E., 2008: Trends in timing of migration of south-western Australian birds and their relationship to climate. Emu, 108(1), 1-14.

Chambers, L.E., C.A. Devney, B.C. Congdon, N. Dunlop, E.J. Woehler, and P. Dann, 2011: Observed and predicted effects of climate on Australian seabirds. Emu, 111(3), 235-251.

Chambers, L.E., P. Dann, B. Cannell, and E.J. Woehler, 2013a: Climate as a driver of phenological change in southern seabirds. International Journal of Biometeorology (in press), doi:10.1007/s00484-013-0711-6.

Chambers, L., L. Beaumont, and I. Hudson, 2013b: Continental scale analysis of bird migration timing: influences of climate and life history traits - a generalised mixture model clustering and discriminant approach. International Journal Biometeorology (in press), doi:10.1007/s00484-013-0707-2.

Changnon, S.A., 2007: Catastrophic winter storms. An escalating problem. Climatic Change, 84(2), 131-139.

Changnon, S.A., 2008: Assessment of flood losses in the United States. Journal of Contemporary Water Research \& Education, 138(1), 38-44.

Changnon, S.A., 2009a: Characteristics of severe Atlantic hurricanes in the United States: 1949-2006. Natural Hazards, 48(3), 329-337.

Changnon, S.A., 2009b: Increasing major hail losses in the U.S. Climatic Change, 96(1), 161-166.

Chaves, L.F. and C.J.M. Koenraadt, 2010: Climate change and highland malaria. Fresh air for a hot debate. The Quarterly Review of Biology, 85(1), 27-55.

Chen, C., E. Wang, Q. Yu, and Y. Zhang, 2010: Quantifying the effects of climate trends in the past 43 years (1961-2003) on crop growth and water demand in the North China Plain. Climatic Change, 100(3-4), 559-578. 
Chen, C., C. Lei, A. Deng, C. Qian, W. Hoogmoed, and W. Zhang, 2011: Will higher minimum temperatures increase corn production in Northeast China? An analysis of historical data over 1965-2008. Agricultural and Forest Meteorology, 151(12), 1580-1588.

Chen, I.C., J.K. Hill, R. Ohlemüller, D.B. Roy, and C.D. Thomas, 2011: Rapid range shifts of species associated with high levels of climate warming. Science, 333(6045), 1024-1026.

Chessman, B.C., 2009: Climatic changes and 13-year trends in stream macroinvertebrate assemblages in New South Wales, Australia. Global Change Biology, 15(11), 2791-2802.

Cheung, W.W., R. Watson, and D. Pauly, 2013: Signature of ocean warming in global fisheries catch. Nature, 497(7449), 365-368.

Chinn, T.B., B. Fitzharris, A. Willsman, and M.J. Salinger, 2012: Annual ice volume changes (1976-2008) for the New Zealand Southern Alps. Global and Planetary Change, 92(7), 105-118.

Chongvilaivan, A., 2012: Thailand's 2011 Flooding: Its Impact on Direct Exports and Global Supply Chains. ARTNeT Working Paper Series, No 113, ARTNeT Secretariat, United Nations Economic and Social Commission for Asia and the Pacific (ESCAP), Trade and Investment Division, Bangkok, Thailand, 33 pp.

Christidis, N., G.C. Donaldson, and P.A. Stott, 2010: Causes for the recent changes in cold- and heat-related mortality in England and Wales. Climatic Change, 102(3-4), 539-553.

Christidis, N., P.A. Stott, and S.J. Brown, 2011: The role of human activity in the recent warming of extremely warm daytime temperatures. Journal of Climate, 24(7), 1922-1930.

Cinner, J., T. McClanahan, N. Graham, T. Daw, J. Maina, S. Stead, A. Wamukota, K. Brown, and Ö. Bodin, 2012:Vulnerability of coastal communities to key impacts of climate change on coral reef fisheries. Global Environmental Change, 22(1), $12-20$.

Clarke, H., C. Lucas, and P. Smith, 2012: Changes in Australian fire weather between 1973 and 2010. International Journal of Climatology, 33(4), 931-944.

Cogley, J.G., 2012: Climate science: Himalayan glaciers in the balance. Nature, 488(7412), 7412-7469.

Cole, J.H. and A.M. Gramajo, 2009: Homicide rates in a cross-section of countries: evidence and interpretations. Population and Development Review, 35(4), 749776.

Cole, J., Y. Prairie, N. Caraco, W. McDowell, L. Tranvik, R. Striegl, C. Duarte, P. Kortelainen, J. Downing, and J. Middelburg, 2007: Plumbing the global carbon cycle: integrating inland waters into the terrestrial carbon budget. Ecosystems, 10(1), 172-185.

Coles, S.L. and B.M. Riegl, 2012: Thermal tolerances of reef corals in the Gulf: a review of the potential for increasing coral survival and adaptation to climate change through assisted translocation. Marine Pollution Bulletin, 72(2), 323-332.

Collie, J.S., K. Richardson, and J.H. Steele, 2004: Regime shifts: can ecological theory illuminate the mechanisms? Progress in Oceanography, 60(2), 281-302.

Collins, D.N., 2006: Climatic variation and runoff in mountain basins with differing proportions of glacier cover. Nordic Hydrology, 37(4-5), 315-326.

Comeaux, R.S., M.A. Allison, and T.S. Bianchi, 2012: Mangrove expansion in the Gulf of Mexico with climate change: implications for wetland health and resistance to rising sea levels. Estuarine, Coastal and Shelf Science, 96, 81-95.

Confalonieri, U., B. Menne, R. Akhtar, K.L. Ebi, M. Hauengue, R.S. Kovats, B. Revich, and A. Woodward, 2007: Human health. In: Climate Change 2007: Impacts, Adaptation and Vulnerability. Contribution of Working Group II to the Fourth Assessment Report of the Intergovernmental Panel on Climate Change [Parry, M.L., Canziani, O.F., J.P. Palutikof, P.J. van der Linden, and C.E. Hanson (eds.)] Cambridge University Press, Cambridge, UK and New York, NY, USA, pp. 391431.

Conway, D. and G. Mahé, 2009: River flow modelling in two large river basins with non-stationary behaviour: the Paraná and the Niger. Hydrological Processes, 23(22), 3186-3192.

Cook, B.I., E.M. Wolkovich, and C. Parmesan, 2012a: Divergent responses to spring and winter warming drive community level flowering trends. Proceedings of the National Academy of Sciences of the United States of America, 109(23), 9000-9005

Cook, B., E. Wolkovich, T.J. Davies, T. Ault, J. Betancourt, J. Allen, K. Bolmgren, E. Cleland, T. Crimmins, N.B. Kraft, L. Lancaster, S. Mazer, G. McCabe, B. McGill, C. Parmesan, S. Pau, J. Regetz, N. Salamin, M. Schwartz, and S. Travers, 2012b: Sensitivity of spring phenology to warming across temporal and spatial climate gradients in two independent databases. Ecosystems, 15(8), 1283-1294.
Cooley, S.R. and S.C. Doney, 2009: Anticipating ocean acidification's economic consequences for commercial fisheries. Environmental Research Letters, 4(2), 024007, doi:10.1088/1748-9326/4/2/024007.

Cooper, T.F., G. De'ath, K.E. Fabricius, and J.M. Lough, 2008: Declining coral calcification in massive Porites in two nearshore regions of the northern Great Barrier Reef. Global Change Biology, 14(3), 529-538.

Cosgrave, J., C. Goncalves, D. Martyris, R. Polastro, and M. Sikumba-Dils, 2007: InterAgency Real-Time Evaluation of the Response to the February 2007 Floods and Cyclone in Mozambique. Inter-Agency Humanitarian Standing Committee, 91 pp., www.unicef.org/evaldatabase/files/MOZ_RTE_2007_Floodsandcyclone.pdf.

Costa, L., K. Thonicke, B. Poulter, and F. Badeck, 2011: Sensitivity of Portuguese forest fires to climatic, human, and landscape variables: subnational differences between fire drivers in extreme fire years and decadal averages. Regional Environmental Change, 11(3), 543-551.

Costard, F., E. Gautier, D. Brunstein, J. Hammadi, A. Fedorov, D. Yang, and L. Dupeyrat, 2007: Impact of the global warming on the fluvial thermal erosion over the Lena River in Central Siberia. Geophysical Research Letters, 34(14), L14501, doi:10.1029/2007GL030212.

Coumou, D., A. Robinson, and S. Rahmstorf, 2013: Global increase in record-breaking monthly-mean temperatures. Climatic Change, 118(3-4), 771-782.

Courbage, C., M. Orie, and W.R. Stahel, 2012: 2011 Thai floods and insurance. In: Extreme Events and Insurance: 2011 Annus Horribilis [Courbage, C. and W.R. Stahel (eds.)]. The Geneva Reports - Risk and Insurance Research No. 5, The Geneva Association, Geneva, Switzerland, pp. 121-132.

Crate, S.A., 2013: Climate Change and Human Mobility in Indigenous Communities of the Russian North. Project Report, Brookings-LSE Project on Internal Displacement, Brookings Institution, Washington, DC, USA, 45 pp.

Crompton, R.P., K.J. McAneney, K. Chen, R.A. Pielke Jr., and K. Haynes, 2010: Influence of location, population, and climate on building damage and fatalities due to Australian Bushfire: 1925-2009. Weather, Climate, and Society, 2(4), 300-310.

Crouch, J., R.R. Heim Jr., P. Hughes, and C. Fenimore, 2013: United States. In: State of the Climate in 2012 [Blunden, J. and D.S. Arndt (eds.)]. Special Supplement to the Bulletin of the American Meteorological Society, 94(8 Suppl.), S149-S152.

Croxall, J., P. Trathan, and E. Murphy, 2002: Environmental change and Antarctic seabird populations. Science, 297(5586), 1510-1514.

Cruikshank, J., 2001: Glaciers and climate change. Perspectives from oral tradition. Arctic, 54, 377-393.

Crutchfield, S., 2013: U.S. Drought 2012: Farm and Food Impacts. United States Department of Agriculture (USDA) Economic Research Service, www.ers.usda.gov/topics/in-the-news/us-drought-2012-farm-and-foodimpacts.aspx\#.UxiOWfldXTo.

Cullen-Unsworth, L.C., R. Hill, J.R.A. Butler, and M. Wallace, 2012: A research process for integrating indigenous and scientific knowledge in cultural landscapes: principles and determinants of success in the wet tropics world heritage area, Australia. The Geographical Journal, 178(4), 351-365.

Curry, J., 2011: Nullifying the climate null hypothesis. Wiley Interdisciplinary Reviews: Climate Change, 2, 919-924.

Cutter, S., B. Osman-Elasha, J. Campbell, S.M. Cheong, S. McCormick, R. Pulwarty, S. Supratid, and G. Ziervogel, 2012: Managing the risks from climate extremes at the local level. In: Managing the Risks of Extreme Events and Disasters to Advance Climate Change Adaptation. A Special Report of Working Groups I and II of the Intergovernmental Panel on Climate Change [Field, C.B., V. Barros, T.F. Stocker, D. Qin, D.J. Dokken, K.L. Ebi, M.D. Mastrandrea, K.J. Mach, G.-K. Plattner, S.K. Allen, M. Tignor, and P.M. Midgley (eds.)]. Cambridge University Press, Cambridge, UK and New York, NY, USA, pp. 291-338.

D'Amato, G., L. Cecchi, S. Bonini, C. Nunes, I. Annesi-Maesano, H. Behrendt, G. Liccardi, T. Popov, and P. Van Cauwenberge, 2007: Allergenic pollen and pollen allergy in Europe. Allergy, 62(9), 976-990.

Daanen, R.P., G. Grosse, M.M. Darrow, T.D. Hamilton, and B.M. Jones, 2012: Rapid movement of frozen debris-lobes: implications for permafrost degradation and slope instability in the south-central Brooks Range, Alaska. Natural Hazards and Earth System Sciences, 12(5), 1521-1537.

Dai, A., 2011: Drought under global warming: a review. Wiley Interdisciplinary Reviews: Climate Change, 2(1), 45-65.

Dai, A., K.E. Trenberth, and J.D. Milliman, 2009: Changes in continental freshwater discharge from 1948 to 2004. Journal of Climate, 22(10), 2773-2792.

Dalton, S.J., S. Godwin, S.D.A. Smith, and L. Pereg, 2010: Australian subtropical white syndrome: a transmissible, temperature-dependent coral disease. Marine and Freshwater Research, 61(3), 342-350. 
Dash, S. and T. Kjellström, 2011: Workplace heat stress in the context of rising temperature in India. Current Science, 101(4), 496-503.

Davidson, E.A., A.C. de Araújo, P. Artaxo, J.K. Balch, I.F. Brown, M.M. Bustamante, M.T. Coe, R.S. Defries, M. Keller, and M. Longo, 2012: The Amazon basin in transition. Nature, 481(7381), 321-328.

De Moel, H., G.M. Ganssen, F.J.C. Peeters, S.J.A. Jung, D. Kroon, G.J.A. Brummer, and R.E. Zeebe, 2009: Planktic foraminiferal shell thinning in the Arabian Sea due to anthropogenic ocean acidification? Biogeosciences, 6(9), 1917-1925.

De'ath, G., J.M. Lough, and K.E. Fabricius, 2009: Declining coral calcification on the Great Barrier Reef. Science, 323(5910), 116-119.

De'ath, G., K. Fabricius, H. Sweatman, and M. Puotinen, 2012: The 27 year decline of coral cover on the Great Barrier Reef and its causes. Proceedings of the National Academy of Sciences of the United States of America, 109(44), 17995-17999.

Delaloye, R., C. Lambiel, and I. Gärtner-Roer, 2010: Overview of rock glacier kinematics research in the Swiss Alps. Seasonal rhythm, interannual variations and trends over several decades. Geographica Helvetica, 65(2), 135-145.

Dell, M., B.F. Jones, and B.A. Olken, 2009: Temperature and income: reconciling new cross-sectional and panel estimates. American Economic Review, 99(2), 198204.

Dell, M., B.F. Jones, and B.A. Olken, 2012: Temperature shocks and economic growth: evidence from the last half century. American Economic Journal: Macroeconomics, 4(3), 66-95.

Delpla, I., A.V. Jung, E. Baures, M. Clement, and 0. Thomas, 2009: Impacts of climate change on surface water quality in relation to drinking water production. Environment International, 35(8), 1225-1233.

Deschênes, 0. and M. Greenstone, 2007: The economic impacts of climate change: evidence from agricultural output and random fluctuations in weather. The American Economic Review, 97(1), 354-385.

Deschênes, O. and M. Greenstone, 2011: Climate change, mortality, and adaptation: evidence from annual fluctuations in weather in the US. American Economic Journal: Applied Economics, 3(4), 152-185.

Descy, J.P. and H. Sarmento, 2008: Microorganisms of the East African Great Lakes and their response to environmental changes. Freshwater Reviews, 1, 59-73.

Devictor, V., R. Julliard, D. Couvet, and F. Jiguet, 2008: Birds are tracking climate warming, but not fast enough. Proceedings of the Royal Society B, 275, 27432748.

Devictor, V., C. Van Swaay, T. Brereton, L. Brotons, D. Chamberlain, J. Heliola, S. Herrando, R. Julliard, M. Kuussaari, A. Lindström, J. Reif, D.B. Roy, O. Schweiger, J. Settele, C. Stefanescu, A. Van Strien, C. Van Turnhout, Z. Vermouzek, M. Wallis De Vries, I. Wynhoff, and F. Jiguet, 2012: Differences in the climatic debts of birds and butterflies at a continental scale. Nature Climate Change, 2(2), 121124.

deYoung, B. and A. Jarre, 2009: Regime shifts: methods of analysis. In: Encyclopedia of Ocean Sciences [Steele, J.H., K.K. Turekian, and S.A. Thorpe (eds.)]. $2^{\text {nd }}$ edn., Academic Press, Oxford, UK, pp. 717-721.

deYoung, B., M. Barange, G. Beaugrand, R. Harris, R.I. Perry, M. Scheffer, and F. Werner, 2008: Regime shifts in marine ecosystems: detection, prediction and management. Trends in Ecology \& Evolution, 23(7), 402-409.

Di Baldassarre, G., A. Montanari, H. Lins, D. Koutsoyiannis, L. Brandimarte, and G. Blöschl, 2010: Flood fatalities in Africa: from diagnosis to mitigation. Geophysical Research Letters, 37(22), L22402, doi:10.1029/2010GL045467.

Diaz, R.J. and R. Rosenberg, 2008: Spreading dead zones and consequences for marine ecosystems. Science, 321(5891), 926-929.

Diemberger, H., K. Hastrup, S. Schaffer, C.F. Kennel, D. Sneath, M. Bravo, H.F. Graf, J. Hobbs, J. Davis, and M.L. Nodari, 2012: Communicating climate knowledge: proxies, processes, politics. Commentaries. Current Anthropology, 53(2), 226-244.

Dietz, A.J., R. Ruben, and A. Verhagen (eds.), 2004: The Impact of Climate Change on Drylands: With a Focus on West Africa. Environment \& Policy, Vol. 39, Kluwer Academic Publishers, Dordrecht, Netherlands, 465 pp.

Díez, I., N. Muguerza, A. Santolaria, U. Ganzedo, and J. Gorostiaga, 2012: Seaweed assemblage changes in the eastern Cantabrian Sea and their potential relationship to climate change. Estuarine, Coastal and Shelf Science, 99, 108120.

d'Orgeval, T. and J. Polcher, 2008: Impacts of precipitation events and land-use changes on West African river discharges during the years 1951-2000. Climate Dynamics, 31(2-3), 249-262.

Douglas, I., K. Alam, M.A. Maghenda, Y. Mcdonnell, L. McLean, and J. Campbell, 2008: Unjust waters. Climate change, flooding and the urban poor in Africa. Environment and Urbanization, 20(1), 187-205.
Doyle, M.E. and V.R. Barros, 2011: Attribution of the river flow growth in the Plata basin. International Journal of Climatology, 31(15), 2234-2248.

Duarte, C.M., S. Agustí, P. Wassmann, J.M. Arrieta, M. Alcaraz, A. Coello, N. Marbà, I.E. Hendriks, J. Holding, and I. García-Zarandona, 2012a: Tipping elements in the Arctic marine ecosystem. $A M B I O, 41(1), 44-55$.

Duarte, C.M., T.M. Lenton, P. Wadhams, and P. Wassmann, 2012b: Abrupt climate change in the Arctic. Nature Climate Change, 2(2), 60-62.

Duarte, C.M., I. Hendriks, T. Moore, Y. Olsen, A. Steckenbauer, L. Ramajo, J. Carstensen, J. Trotter, and M. McCulloch, 2013: Is ocean acidification an open-ocean syndrome? Understanding anthropogenic impacts on marine pH. Estuaries and Coasts, 36(2), 221-236.

Dunne, J.P., R.J. Stouffer, and J.G. John, 2013: Reductions in labour capacity from heat stress under climate warming. Nature Climate Change, 3, 563-566

Durance, I. and S.J. Ormerod, 2007: Climate change effects on upland stream macroinvertebrates over a 25-year period. Global Change Biology, 13(5), 942957.

Durand, Y., G. Giraud, M. Laternser, P. Etchevers, L. Mérindol, and B. Lesaffre, 2009: Reanalysis of 47 years of climate in the French Alps (1958-2005): climatology and trends for snow cover. Journal of Applied Meteorology and Climatology, 48(12), 2487-2512.

Eakin, C.M., J.A. Morgan, S.F. Heron, T.B. Smith, G. Liu, L. Alvarez-Filip, B. Baca, E. Bartels, C. Bastidas, C. Bouchon, M. Brandt, A.W. Bruckner, L. Bunkley-Williams, A. Cameron, B.D. Causey, M. Chiappone, T.R.L. Christensen, M.J.C. Crabbe, O. Day, E. de la Guardia, G. Diaz-Pulido, D. DiResta, D.L. Gil-Agudelo, D.S. Gilliam, R.N. Ginsburg, S. Gore, H.M. Guzman, J.C. Hendee, E.A. Hernandez-Delgado, E. Husain, C.F.G. Jeffrey, R.J. Jones, E. Jordan-Dahlgren, L.S. Kaufman, D.I. Kline, P.A. Kramer, J.C. Lang, D. Lirman, J. Mallela, C. Manfrino, J. Marechal, K. Marks, J. Mihaly, W.J. Miller, E.M. Mueller, E.M. Muller, C.A. Orozco Toro, H.A. Oxenford, D. Ponce-Taylor, N. Quinn, K.B. Ritchie, S. Rodriguez, A. Rodriguez Ramirez, S. Romano, J.F. Samhouri, J.A. Sanchez, G.P. Schmahl, B.V. Shank, W.J. Skirving, S.C.C. Steiner, E. Villamizar, S.M. Walsh, C. Walter, E. Weil, E.H. Williams, K.W. Roberson, and Y. Yusuf, 2010: Caribbean corals in crisis: record thermal stress, bleaching, and mortality in 2005. PLOS ONE, 5(11), e13969, doi:10.1371/ journal.pone.0013969.

Ebinger, J.O. and W. Vegara, 2011: Climate Impacts on Energy Systems: Key Issues for Energy Sector Adaptation. World Bank, Energy Sector Management Assistance Program (ESMAP), The International Bank for Reconstruction and Development I The World Bank, Washington, DC, USA, 178 pp.

Eckert, N., C.J. Keylock, H. Castebrunet, A. Lavigne, and M. Naaim, 2013: Temporal trends in avalanche activity in the French Alps and subregions: from occurrences and runout altitudes to unsteady return periods. Journal of Glaciology, 59(213), 93-114.

Edwards, M. and A.J. Richardson, 2004: Impact of climate change on marine pelagic phenology and trophic mismatch. Nature, 430(7002), 881-884.

Eijgelaar, E., C. Thaper, and P. Peeters, 2010: Antarctic cruise tourism: the paradoxes of ambassadorship, 'last chance tourism' and greenhouse gas emissions. Journal of Sustainable Tourism, 18(3), 337-354.

Eira, I.M.G., 2012: Muohttaga Jávohis Giella: Sámi Árbevirolaš Máhttu Muohttaga Birra Dálkkádatrievdanáiggis (The Silent Language of Snow: Sámi Traditional Knowledge of Snow in Times of Climate Change). Ph.D. Dissertation, University of Tromsø, Tromsø, Norway.

Ekau, W., H. Auel, H.O. Pörtner, W. Gilbert, and D. Gilbert, 2010: Impacts of hypoxia on the structure and processes in pelagic communities (zooplankton, macroinvertebrates and fish). Biogeosciences, 7(5), 1669-1699.

Eliason, E.J., T.D. Clark, M.J. Hague, L.M. Hanson, Z.S. Gallagher, K.M. Jeffries, M.K. Gale, D.A. Patterson, S.G. Hinch, and A.P. Farrell, 2011: Differences in thermal tolerance among sockeye salmon populations. Science, 332(6025), 109-112.

Elliott, J.R. and J. Pais, 2006: Race, class, and Hurricane Katrina: social differences in human responses to disaster. Social Science Research, 35(2), 295-321.

Elmendorf, S.C., G.H.R. Henry, R.D. Hollister, R.G. Björk, N. Boulanger-Lapointe, E.J. Cooper, J.H.C. Cornelissen, T.A. Day, E. Dorrepaal, T.G. Elumeeva, M. Gill, W.A. Gould, J. Harte, D.S. Hik, A. Hofgaard, D. R. Johnson, J.F. Johnstone, I.S. Jónsdóttir, J.C. Jorgenson, K. Klanderud, J.A. Klein, S. Koh, G. Kudo, M. Lara, E. Lévesque, B. Magnússon, J.L. May, J.A. Mercado-Díaz, A. Michelsen, U. Molau, I.H. MyersSmith, S.F. Oberbauer, V.G. Onipchenko, C. Rixen, N.M. Schmidt, G.R. Shaver, M.J. Spasojevic, T.E. Thórhallsdóttir, A. Tolvanen, T. Troxler, C.E. Tweedie, S. Villareal, C.H. Wahren, X. Walker, P.J. Webber, J.M. Welker, and S. Wipf, 2012: Plot-scale evidence of tundra vegetation change and links to recent summer warming. Nature Climate Change, 2(6), 453-457. 
Espinoza, J.C., J. Ronchail, F. Frappart, W. Lavado, W. Santini, and J.L. Guyot, 2013: The major floods in the Amazonas River and Tributaries (Western Amazon Basin) during the 1970-2012 Period: a focus on the 2012 Flood. Journal of Hydrometeorology, 14(3), 1000-1008.

Etter, A., C. McAlpine, S. Phinn, D. Pullar, and H. Possingham, 2006: Unplanned land clearing of Colombian rainforests: spreading like disease? Landscape and Urban Planning, 77(3), 240-254.

Evans, S.G. and J.J. Clague, 1994: Recent climatic change and catastrophic geomorphic processes in mountain environments. Geomorphology, 10(1-4), 107-128.

Fajnzylber, P., D. Lederman, and N. Loayza, 2002: What causes violent crime? European Economic Review, 46(7), 1323-1357.

FAOSTAT, 2013: Food and Agriculture Organization of the United Nations Database on Agriculture. FAO, Rome, Italy, faostat.fao.org/site/291/default.aspx.

Farbotko, C., 2010: 'The global warming clock is ticking so see these places while you can': voyeuristic tourism and model environmental citizens on Tuvalu's disappearing islands. Singapore Journal of Tropical Geography, 31(2), 224-238.

Fauria, M.M. and E. Johnson, 2008: Climate and wildfires in the North American boreal forest. Philosophical Transactions of the Royal Society B, 363(1501), 2315-2327.

Feely, R.A., S.R. Alin, J. Newton, C.L. Sabine, M. Warner, A. Devol, C. Krembs, and C. Maloy, 2010: The combined effects of ocean acidification, mixing, and respiration on $\mathrm{pH}$ and carbonate saturation in an urbanized estuary. Estuarine, Coastal and Shelf Science, 88(4), 442-449.

Feng, S. and M. Oppenheimer, 2012: Applying statistical models to the climatemigration relationship. Proceedings of the National Academy of Sciences of the United States of America, 109(43), E2915, doi:10.1073/pnas.1212226109.

Feng, S., M. Oppenheimer, and W. Schlenker, 2012: Climate Change, Crop Yields, and Internal Migration in the United States. NBER Working Paper 17734, National Bureau of Economic Research (NBER), Cambridge, MA, USA, 43 pp.

Fernández, C., 2011: The retreat of large brown seaweeds on the north coast of Spain: the case of Saccorhiza polyschides. European Journal of Phycology, 46(4), 352-360.

Field, S., 1992: The effect of temperature on crime. British Journal of Criminology, 32(3), 340-351.

Fischer, L., R.S. Purves, C. Huggel, J. Noetzli, and W. Haeberli, 2012: On the influence of geological, topographic and glaciological factors on slope instabilities. Analyses of recent Alpine rock avalanches. Natural Hazards and Earth System Sciences, $12,241-254$.

Fischlin, A., G.F. Midgley, J.T. Price, R. Leemans, B. Gopal, C. Turley, M.D.A. Rounsevell, O.P. Dube, J. Tarazona, and A.A. Velichko, 2007: Ecosystems, their properties, goods, and services. In: Climate Change 2007: Impacts, Adaptation and Vulnerability. Contribution of Working Group II to the Fourth Assessment Report of the Intergovernmental Panel on Climate Change [Parry, M.L., O.F. Canziani, J.P. Palutikof, P.J. van der Linden, and C.E. Hanson (eds.)]. Cambridge University Press, Cambridge, UK and New York, NY, USA, pp. 211-272.

Fishman, J., J.K. Creilson, P.A. Parker, E.A. Ainsworth, G.G. Vining, J. Szarka, L. Booker, and X. Xu, 2010: An investigation of widespread ozone damage to the soybean crop in the upper Midwest determined from ground-based and satellite measurements. Atmospheric Environment, 44(18), 2248-2256.

Foden, W., G.F. Midgley, G. Hughes, W.J. Bond, W. Thuiller, M.T. Hoffmann, P. Kaleme, L.G. Underhill, A. Rebelo, and L. Hannah, 2007: A changing climate is eroding the geographical range of the Namib Desert tree Aloe through population declines and dispersal lags. Diversity and Distributions, 13, 645-653.

Foley, C., 2007: Mozambique: A Case Study in the Role of the Affected State in Humanitarian Action. Humanitarian Policy Working Paper, Overseas Development Institute (ODI), London, UK, 32 pp.

Forbes, D.L. (ed.), 2011: State of the Arctic Coast 2010 - Scientific Review and Outlook. International Arctic Science Committee (IASC), Land-Ocean Interactions in the Coastal Zone (LOICZ), Arctic Monitoring and Assessment Programme (AMAP), International Permafrost Association (IPA), Helmholtz-Zentrum, Geesthacht, Germany, 168 pp.

Forcada, J., P.N. Trathan, and E.J. Murphy, 2008: Life history buffering in Antarctic mammals and birds against changing patterns of climate and environmental variation. Global Change Biology, 14(11), 2473-2488.

Ford, J.D., 2009a: Vulnerability of Inuit food systems to food insecurity as a consequence of climate change: a case study from Igloolik, Nunavut. Regional Environmental Change, 9(2), 83-100.

Ford, J.D., 2009b: Dangerous climate change and the importance of adaptation for the Arctic's Inuit population. Environmental Research Letters, 4(2), 024006, doi:10.1088/1748-9326/4/2/024006.
Ford, J.D., W.A. Gough, G.J. Laidler, J. MacDonald, C. Irngaut, and K. Qrunnut, 2009: Sea ice, climate change, and community vulnerability in northern Foxe Basin, Canada. Climate Research, 38, 137-154.

Ford, J.D., W. Vanderbilt, and L. Berrang-Ford, 2011: Authorship in IPCC AR5 and its implications for content. Climate change and indigenous populations in WGII. Climatic Change, 113(2), 201-213.

Ford, M., 2012: Shoreline changes on an urban atoll in the central Pacific Ocean. Majuro Atoll, Marshall Islands. Journal of Coastal Research, 28(1), 11-22.

Forkel, M., K. Thonicke, C. Beer, W. Cramer, S. Bartalev, and C. Schmullius, 2012: Extreme fire events are related to previous-year surface moisture conditions in permafrost-underlain larch forests of Siberia. Environmental Research Letters, 7(4), 044021, doi:10.1088/1748-9326/7/4/044021.

Fouillet, A., G. Rey, F. Laurent, G. Pavillon, S. Bellec, C. Guihenneuc-Jouyaux, J. Clavel, E. Jougla, and D. Hémon, 2006: Excess mortality related to the August 2003 heat wave in France. Occupational and Environmental Health, 80, 16-24.

Fouillet, A., G. Rey, V. Wagner, K. Laaidi, P. Empereur-Bissonnet, A. le Tertre, P. Frayssinet, P. Bessemoulin, F. Laurent, P. Crouy-Chanel, E. Jougla, and D. Hémon, 2008: Has the impact of heat waves on mortality changed in France since the European heat wave of summer 2003? A study of the 2006 heat wave. International Journal of Epidemiology, 37(2), 309-317.

Fowbert, J.A. and R.I.L. Smith, 1994: Rapid population increases in native vascular plants in the Argentine Islands, Antarctic Peninsula. Arctic and Alpine Research, 26, 290-296.

Franco, G. and A.H. Sanstad, 2008: Climate change and electricity demand in California. Climatic Change, 87(1), 139-151.

Gamble, D.W., D. Campbell, T.L. Allen, D. Barker, S. Curtis, D. McGregor, and J. Popke, 2010: Climate change, drought, and Jamaican agriculture: local knowledge and the climate record. Annals of the Association of American Geographers, 100(4), 880-893.

Gamble, J.L. and J.J. Hess, 2012: Temperature and violent crime in Dallas, Texas: relationships and implications of climate change. Western Journal of Emergency Medicine, 13(3), 239-246.

García-Mozo, H., C. Galán, P. Alcázar, C. de la Guardia, D. Nieto-Lugilde, M. Recio, P. Hidalgo, F. Gónzalez-Minero, L. Ruiz, and E. Domínguez-Vilches, 2010: Trends in grass pollen season in southern Spain. Aerobiologia, 26(2), 157-169.

Gardelle, J., Y. Arnaud, and E. Berthier, 2011: Contrasted evolution of glacial lakes along the Hindu Kush Himalaya mountain range between 1990 and 2009. Global and Planetary Change, 75(1-2), 47-55.

Gardelle, J., E. Berthier, and Y. Arnaud, 2012: Slight mass gain of Karakoram glaciers in the early twenty-first century. Nature Geoscience, 5(5), 322-325.

Gardner, A.S., G. Moholdt, B. Wouters, G.J. Wolken, D.O. Burgess, M.J. Sharp, J.G. Cogley, C. Braun, and C. Labine, 2011: Sharply increased mass loss from glaciers and ice caps in the Canadian Arctic Archipelago. Nature, 473(7347), 357-360.

Gardner, A.S., G. Moholdt, J.G. Cogley, A.A. Arendt, B. Wouters, J. Wahr, W.T. Pfeffer, G. Kaser, S.R.M. Ligtenberg, T. Bolch, R. Hock, E. Berthier, M.J. Sharp, J.O. Hagen, M. van den Broeke, F. Paul, and V. Radic, 2013: A reconciled estimate of glacier contributions to sea level rise: 2003 to 2009. Science, 340(6134), 852-857.

Gardner, T.A., I.M. Côté, J.A. Gill, A. Grant, and A.R. Watkinson, 2003: Long-term region-wide declines in Caribbean corals. Science, 301(5635), 958-960.

Garrabou, J., R. Coma, N. Bensoussan, M. Bally, P. Chevaldonné, M. Cigliano, D. Diaz, J.G. Harmelin, M.C. Gambi, D.K. Kersting, J.B. Ledoux, C. Lejesune, C. Linares, C. Marschal, T. Pérez, M. Ribes, J.C. Romano, E. Serrano, N. Teixido, O. Torrents, M. Zabala, F. Zuberer, and C. Cerrano, 2009: Mass mortality in Northwestern Mediterranean rocky benthic communities: effects of the 2003 heat wave. Global Change Biology, 15(5), 1090-1103.

Gaston, A.J., H.G. Gilchrist, M.L. Mallory, and P.A. Smith, 2009: Changes in seasonal events, peak food availability, and consequent breeding adjustment in a marine bird: a case of progressive mismatching. The Condor, 111(1), 111-119.

Gaydon, R.S., H.G. Beecher, R. Reinke, S. Crimp, and S.M. Howden, 2010: Rice. In: Adapting Agriculture to Climate Change. Preparing Australian Agriculture, Forestry and Fisheries for the Future [Stokes, C. and S. Howden (eds.)]. CSIRO Publishing, Collingwood, Australia, pp. 67-83.

Gehrig-Fasel, J., A. Guisan, and N.E. Zimmermann, 2007: Tree line shifts in the Swiss Alps: climate change or land abandonment? Journal of Vegetation Science, 18(4), 571-582.

Georgakakos, A., P. Fleming, M. Dettinger, C. Peters-Lidgard, T.C. Richmond, K. Reckhow, K. White, and D. Yates, 2013: Chapter 3: Water resources. In: National Climate Assessment. U.S. Global Change Research Program, Draft for public review, pp. 107-164, ncadac.globalchange.gov/. 
Gething, P.W., D.L. Smith, A.P. Patil, A.J. Tatem, R.W. Snow, and S.I. Hay, 2010: Climate change and the global malaria recession. Nature, 465(7296), 342-345.

Global Fire Monitoring Center, 2010: Preliminary assessment of the fire situation in western Russia. International Forest Fire News, 40, 20-42, www.fire.unifreiburg.de/iffn/iffn_40/03-Russia-I.pdf.

Giannini, A., M. Biasutti, and M.M. Verstraete, 2008: A climate model-based review of drought in the Sahel. Desertification, the re-greening and climate change. Global and Planetary Change, 64(3-4), 119-128.

Gillett, N.P., A.J. Weaver, F.W. Zwiers, and M.D. Flannigan, 2004: Detecting the effect of climate change on Canadian forest fires. Geophysical Research Letters, 31(18), L18211, doi:10.1029/2004GL020876.

Gilman, E.L., J. Ellison, N.C. Duke, and C. Field, 2008: Threats to mangroves from climate change and adaptation options: a review. Aquatic Botany, 89(2), 237250.

Girardin, M.P. and M. Mudelsee, 2008: Past and future changes in Canadian boreal wildfire activity. Ecological Applications, 18(2), 391-406.

Girardin, M.P., A.A. Ali, C. Carcaillet, S. Gauthier, C. Hély, H. Le Goff, A. Terrier, and Y. Bergeron, 2013: Fire in managed forests of eastern Canada: risks and options. Special Issue: "The Mega Fire Reality" of Forest Ecology and Management, 294, 238-249.

Giri, C., E. Ochieng, L.L. Tieszen, Z. Zhu, A. Singh, T. Loveland, J. Masek, and N. Duke, 2011: Status and distribution of mangrove forests of the world using earth observation satellite data. Global Ecology and Biogeography, 20(1), 154159.

Goetz, S., M. Mack, K. Gurney, J. Randerson, and R. Houghton, 2007: Ecosystem responses to recent climate change and fire disturbance at northern high latitudes: observations and model results contrasting northern Eurasia and North America. Environmental Research Letters, 2(4), 045031, doi:10.1088/ 1748-9326/2/4/045031.

Goldblum, D. and L.S. Rigg, 2010: The deciduous forest-boreal forest ecotone. Geography Compass, 4(7), 701-717.

Gonzalez, P., C.J. Tucker, and H. Sy, 2012: Tree density and species decline in the African Sahel attributable to climate. Journal of Arid Environments, 78, 55-64.

Goodman, J., J. Maschinski, P. Hughes, J. Mcauliffe, J. Roncal, D. Powell, and L.O. Sternberg, 2012: Differential response to soil salinity in endangered key tree cactus. Implications for survival in a changing climate. PLOS ONE, 7(3), e32528, doi:10.1371/journal.pone.0032528.

Gooseff, M.N., A. Balser, W.B. Bowden, and J.B. Jones, 2009: Effects of hillslope thermokarst in Northern Alaska. EOS, Transactions of the American Geophysical Union, 90(4), 29-30, doi:10.1029/2009E0040001.

Gray, J.S., H. Dautel, A. Estrada-Peña, O. Kahl, and E. Lindgren, 2009: Effects of climate change on ticks and tick-borne diseases in Europe. Interdisciplinary Perspectives on Infectious Diseases, 2009, 593232, doi:10.1155/2009/593232.

Green, D. and G. Raygorodetsky, 2010: Indigenous knowledge of a changing climate. Climatic Change, 100(2), 239-242.

Green, K., 2010: Alpine taxa exhibit differing responses to climate warming in the Snowy Mountains of Australia. Journal of Mountain Science, 7, 167-175.

Greene, A.M., A. Giannini, and S.E. Zebiak, 2009: Drought return times in the Sahel: a question of attribution. Geophysical Research Letters, 36(12), L12701, doi:10.1029/2009GL038868.

Gregory, P.J. and B. Marshall, 2012: Attribution of climate change: a methodology to estimate the potential contribution to increases in potato yield in Scotland since 1960. Global Change Biology, 18(4), 1372-1388.

Grémillet, D. and T. Boulinier, 2009: Spatial ecology and conservation of seabirds facing global climate change. A review. Marine Ecology Progress Series, 391, 121-137.

Groisman, P.Y., B.G. Sherstyukov, V.N. Razuvaev, R.W. Knight, J.G. Enloe, N.S. Stroumentova, P.H. Whitfield, E. Førland, I. Hannsen-Bauer, H. Tuomenvirta, H. Aleksandersson, A.V. Mescherskaya, and T.R. Karl, 2007: Potential forest fire danger over Northern Eurasia: changes during the $20^{\text {th }}$ century. Global and Planetary Change, 56(3), 371-386.

Gruza, G.V. and A.V. Mescherskaya, 2008: Changes in Russian climate for the period of instrumental observations. In: Assessment Report on Climate Change and Its Consequences in Russian Federation: Vol. 1 Climate Change [Meleshko, V.P. (ed.)]. Federal Service for Hydrometeorology and Environmental Monitoring (ROSHYDROMET), Moscow, Russia, pp. 31-87.

Guis, H., C. Caminade, C. Calvete, A.P. Morse, A. Tran, and M. Baylis, 2012: Modelling the effects of past and future climate on the risk of bluetongue emergence in Europe. Journal of the Royal Society Interface, 9(67), 339-350.
Guzman, H.M., S. Benfield, O. Breedy, and J.M. Mair, 2008: Broadening reef protection across the Marine Conservation Corridor of the Eastern Tropical Pacific: distribution and diversity of reefs in Las Perlas Archipelago, Panama. Environmental Conservation, 35(1), 46-54.

Ha, J., H. Kim, and S. Hajat, 2011: Effect of previous-winter mortality on the association between summer temperature and mortality in South Korea. Enivronmental Health Perspectives, 119, 542-546.

Haeberli, W. and M. Beniston, 1998: Climate change and its impacts on glaciers and permafrost in the Alps. Ambio, 27(4), 258-265.

Haeberli, W. and R. Hohmann, 2008: Climate, glaciers and permafrost in the Swiss Alps 2050: scenarios, consequences and recommendations. In: Proceedings Ninth International Conference on Permafrost: University of Alaska, Fairbanks, Alaska, June 29-July 3, 2008 [Kane, D.L. and K.M. Hinkel (eds.)]. Institute of Northern Engineering, University of Alaska, Fairbanks, Alaska, pp. 607-612.

Haigh, I., R. Nicholls, and N. Wells, 2010: Assessing changes in extreme sea levels: application to the English Channel, 1900-2006. Continental Shelf Research, 30(9), 1042-1055.

Haigh, I., M. Eliot, C. Pattiaratchi, and T. Wahl, 2011: Regional changes in mean sea level around Western Australia between 1897 and 2008. In: Coasts and Ports 2011: Diverse and Developing: Proceedings of the $20^{\text {th }}$ Australasian Coastal and Ocean Engineering Conference and the 13th Australasian Port and Harbour Conference. Engineers Australia, Barton, ACT, Australia, pp. 280-285.

Halpern, B.S., S. Walbridge, K.A. Selkoe, C.V. Kappel, F. Micheli, C. D'agrosa, J.F. Bruno, K.S. Casey, C. Ebert, H.E. Fox, R. Fujita, D. Heinemann, H.S. Lenihan, E.M.P. Madin, M.T. Perry, E.R. Selig, M. Spalding, R. Steneck, and R. Watson, 2008: A global map of human impact on marine ecosystems. Science, 319(5865), 948-952.

Handmer, J., Y. Honda, Z.W. Kundzewicz, N. Arnell, G. Benito, J. Hatfield, I.F. Mohamed, P. Peduzzi, S. Wu, B. Sherstyukov, K. Takahashi, and Z. Yan, 2012: Changes in impacts of climate extremes. Human systems and ecosystems. In: Managing the Risks of Extreme Events and Disasters to Advance Climate Change Adaptation. A Special Report of Working Groups I and II of the Intergovernmental Panel on Climate Change [Field, C.B., V. Barros, T.F. Stocker, D. Qin, D.J. Dokken, K.L. Ebi, M.D. Mastrandrea, K.J. Mach, G.-K. Plattner, S.K. Allen, M. Tignor, and P.M. Midgley (eds.)]. Cambridge University Press, Cambridge, UK and New York, NY, USA, pp. 231-290.

Hansen, B.B., V. Grøtan, R. Aanes, B.E. Sæther, A. Stien, E. Fuglei, R.A. Ims, N.G. Yoccoz, and Å.Ø. Pedersen, 2013: Climate events synchronize the dynamics of a resident vertebrate community in the high Arctic. Science, 339(6117), 313-315.

Hansen, J., M. Sato, and R. Ruedy, 2012: Perception of climate change. Proceedings of the National Academy of Sciences of the United States of America, 109(37), E2415-E2423.

Hardoy, J. and G. Pandiella, 2009: Urban poverty and vulnerability to climate change in Latin America. Environment and Urbanization, 21(1), 203-224.

Harley, C.D., 2011: Climate change, keystone predation, and biodiversity loss. Science, 334(6059), 1124-1127.

Hawkins, S.J., P.J. Moore, M.T. Burrows, E. Poloczanska, N. Mieszkowska, R.J.H. Herbert, S.R. Jenkins, R.C. Thompson, M.J. Genner, and A.J. Southward, 2008: Complex interactions in a rapidly changing world: responses of rocky shore communities to recent climate change. Climate Research, 37, 123-133.

Hayes, J. and A. Goonetilleke, 2012: Building community resilience - learning from the 2011 floods in Southeast Queensland, Australia. In: 8th Annual Conference of International Institute for Infrastructure, Renewal and Reconstruction: International Conference on Disaster Management (IIIRR 2012) [Kakimoto, R. and F. Yamada (eds.)], Kumamoto University, Kumamoto, Japan, pp. 51-60.

Hecky, R.E., R. Mugidde, P.S. Ramlal, M.R. Talbot, and G.W. Kling, 2010: Multiple stressors cause rapid ecosystem change in Lake Victoria. Freshwater Reviews, 55, 19-42.

Hedenås, H., H. Olsson, C. Jonasson, J. Bergstedt, U. Dahlberg, and T.V. Callaghan, 2011: Changes in tree growth, biomass and vegetation over a 13-year period in the Swedish sub-Arctic. AMBIO: A Journal of the Human Environment, 40(6), 672-682.

Hegerl, G.C., O. Hoegh-Guldberg, G. Casassa, M.P. Hoerling, R.S. Kovats, C. Parmesan, D.W. Pierce, and P.A. Stott, 2010: Good practice guidance paper on detection and attribution related to anthropogenic climate change. In: Meeting Report of the Intergovernmental Panel on Climate Change Expert Meeting on Detection and Attribution of Anthropogenic Climate Change [Stocker, T.F., C.B. Field, D. Qin, V. Barros, G.-K. Plattner, M. Tignor, P.M. Midgley, and K.L. Ebi (eds.)]. IPCC Working Group I Technical Support Unit, University of Bern, Bern, Switzerland, pp. 1-8. 
Held, I., T. Delworth, J. Lu, K. Findell, and T. Knutson, 2005: Simulation of Sahel drought in the $20^{\text {th }}$ and $21^{\text {st }}$ centuries. Proceedings of the National Academy of Sciences of the United States of America, 102(50), 17891-17896.

Helmuth, B., C.D. Harley, P.M. Halpin, M. O'Donnell, G.E. Hofmann, and C.A. Blanchette, 2002: Climate change and latitudinal patterns of intertidal thermal stress. Science, 298(5595), 1015-1017.

Helmuth, B., N. Mieszkowska, P. Moore, and S.J. Hawkins, 2006: Living on the edge of two changing worlds: forecasting the responses of rocky intertidal ecosystems to climate change. Annual Review of Ecology, Evolution, and Systematics, 37 373-404.

Hémon, D. and E. Jougla, 2003: Surmortalité liée à la Canicule d'Août 2003 : Rapport d'Étape. Estimation de la Surmortalite et Principales Caracteristiques Epidemiologiques. Rapport remis au Ministre de la Santé, de la Famille et des Personnes Handicapées le 25 Septembre 2003, Institut National de la Santé et de la Recherche Médicale (INSERM), Paris, France, 59 pp.

Hemp, A., 2005: Climate change-driven forest fires marginalize the impact of ice cap wasting on Kilimanjaro. Global Change Biology, 11(7), 1013-1023.

Hendrix, C.S. and S.M. Glaser, 2007: Trends and triggers: climate, climate change and civil conflict in Sub-Saharan Africa. Political Geography, 26(6), 695-715.

Hendrix, C.S. and I. Salehyan, 2012: Climate change, rainfall, and social conflict in Africa. Journal of Peace Research, 49, 35-50.

Hennessy, K.J., P.H. Whetton, K. Walsh, I.N. Smith, J.M. Bathols, M. Hutchinson, and J. Sharples, 2008: Climate change effects on snow conditions in mainland Australia and adaptation at ski resorts through snowmaking. Climate Research, 35(3), 255-270

Henry, G.H.R. and S. Elmendorf, 2010: Greening of the Arctic. In: Arctic Biodiversity Trends 2010 - Selected Indicators of Change. Arctic Council, Conservation of Arctic Flora and Fauna Programme (CAFF), CAFF International Secretariat, Akureyri, Iceland, pp. 62-64.

Herman-Mercer, N., P.F. Schuster, and K.B. Maracle, 2011: Indigenous observations of climate change in the Lower Yukon River Basin, Alaska. Human Organization, 70, 244-252.

Hermant, M., J. Lobry, S. Bonhommeau, J. Poulard, and O. Le Pape, 2010: Impact of warming on abundance and occurrence of flatfish populations in the Bay of Biscay (France). Journal of Sea Research, 64(1), 45-53.

Hiddink, J.G. and R. ter Hofstede, 2008: Climate induced increases in species richness of marine fishes. Global Change Biology, 14(3), 453-460.

Hinzman, L.D., N.D. Bettez, W.R. Bolton, F.S. Chapin, M.B. Dyurgerov, C.L. Fastie, B. Griffith, R.D. Hollister, A. Hope, and H.P. Huntington, 2005: Evidence and implications of recent climate change in northern Alaska and other Arctic regions. Climatic Change, 72(3), 251-298.

Hockey, P.A.R. and G.F. Midgley, 2009: Avian range changes and climate change. A cautionary tale from the Cape Peninsula. Ostrich, 80, 29-34.

Hockey, P.A.R., C. Sirami, A.R. Ridley, G.F. Midgley, and H.A. Babiker, 2011: Interrogating recent range changes in South African birds. Confounding signals from land use and climate change present a challenge for attribution. Diversity and Distributions, 17, 254-261.

Hoegh-Guldberg, 0., 1999: Climate change, coral bleaching and the future of the world's coral reefs. Marine and Freshwater Research, 50(8), 839-866.

Hoegh-Guldberg, O. and J.F. Bruno, 2010: The impact of climate change on the world's marine ecosystems. Science, 328(5985), 1523-1528.

Hoegh-Guldberg, O. and G.J. Smith, 1989: The effect of sudden changes in temperature, light and salinity on the population-density and export of zooxanthellae from the reef corals Stylophora-pistillata Esper and Seriatoporahystrix Dana. Journal of Experimental Marine Biology and Ecology, 129(3), 279-303.

Hoegh-Guldberg, O., P.J. Mumby, A.J. Hooten, R.S. Steneck, P. Greenfield, E. Gomez, C.D. Harvell, P.F. Sale, A.J. Edwards, K. Caldeira, N. Knowlton, C.M. Eakin, R. Iglesias-Prieto, N. Muthiga, R.H. Bradbury, A. Dubi, and M.E. Hatziolos, 2007: Coral reefs under rapid climate change and ocean acidification. Science, 318(5857), 1737-1742.

Hoegh-Guldberg, O., G. Hegerl, T. Root, F. Zwiers, P. Stott, D. Pierce, and M. Allen, 2011: Difficult but not impossible. Nature Climate Change, 1(2), 72-72.

Hoerling, M., J. Hurrell, J. Eischeid, and A. Phillips, 2006: Detection and attribution of twentieth-century northern and southern African rainfall change. Journal of Climate, 19(16), 3989-4008.

Hoinka, K.P., A. Carvalho, and A.I. Miranda, 2009: Regional-scale weather patterns and wildland fires in central Portugal. International Journal of Wildland Fire, 18(1), 36-49.
Hollowed, A.B., S.R. Hare, and W.S. Wooster, 2001: Pacific Basin climate variability and patterns of Northeast Pacific marine fish production. Progress in Oceanography, 49, 257-282.

Horowitz, J., 2009: The income-temperature relationship in a cross-section of countries and its implications for predicting the effects of global warming. Environmental and Resource Economics, 44(4), 475-493.

Houze Jr., R.A., K.L. Rasmussen, S. Medina, S.R. Brodzik, and U. Romatschke, 2011: Anomalous atmospheric events leading to the summer 2010 floods in Pakistan. Bulletin of the American Meteorological Society, 92(3), 291-298.

Hovelsrud, G.K., M. McKenna, and H.P. Huntington, 2008: Marine mammal harvests and other interactions with humans. Ecological Applications, 18(2 Suppl.), S135-S147.

Howden, S.M., S.J. Crimp, and R. Nelson, 2010: Australian agriculture in a climate of change. In: Managing Climate Change: Papers from the GREENHOUSE 2009 Conference [Jubb, I., P. Holper, and W. Cai (eds.)]. CSIRO Publishing, Collingwood, Australia, pp. 101-111.

Hoyos, L.E., A.M. Cingolani, M.R. Zak, M.V. Vaieretti, D.E. Gorla, and M.R. Cabido, 2013: Deforestation and precipitation patterns in the arid Chaco forests of central Argentina. Applied Vegetation Science, 16(2), 260-271.

Hoyos, N., J. Escobar, J.C. Restrepo, A.M. Arango, and J.C. Ortiz, 2013: Impact of the 2010-2011 La Niña phenomenon in Colombia, South America: the human toll of an extreme weather event. Applied Geography, 39, 16-25.

Hsiang, S.M., K.C. Meng, and M.A. Cane, 2011: Civil conflicts are associated with the global climate. Nature, 476(7361), 438-441.

Hsiang, S.M., M. Burke, and E. Miguel, 2013: Quantifying the influence of climate on human conflict. Science, 341(6151), 1235367, doi:10.1126/science.1235367.

Hsieh, C.-h., C. Reiss, W. Watson, M.J. Allen, J.R. Hunter, R.N. Lea, R.H. Rosenblatt P.E. Smith, and G. Sugihara, 2005: A comparison of long-term trends and variability in populations of larvae of exploited and unexploited fishes in the Southern California region. A community approach. Progress in Oceanography, 67(1), 160-185.

Hsieh, C.-h., C.S. Reiss, R.P. Hewitt, and G. Sugihara, 2008: Spatial analysis shows that fishing enhances the climatic sensitivity of marine fishes. Canadian Journal of Fisheries and Aquatic Sciences, 65, 947-961.

Huang, X., M. Sillanpää, E.T. Gjeesing, and P.R. Vogt, 2009: Water quality in the Tibetan Plateau: major ions and trace elements in the headwaters of four major Asian rivers. Science of the Total Environment, 407(24), 6242 6254.

Huggel, C., L. Blaškovičová, H. Breien, P. Dobesberger, R. Frauenfelder, B.G. Kalsnes, A. Solheim, M. Stankoviansky, K. Hagen, and K. Kronholm, 2011: Landslide and rock slope failures. In: Impacts of Climate Change on Snow, Ice, and Permafrost in Europe: Observed Trends, Future Projections, and Socio-Economic Relevance [Voigt, T., H.M. Füssel, I. Gärtner-Roer, C. Huggel, C. Marty, and M. Zemp (eds.)]. ETC/ACC Technical Paper 2010/13, Prepared by the European Topic Centre on Air and Climate Change (ETC/ACC) with the Department of Geography of the University of Zuerich, the WSL Institute for Snow and Avalanche Research (SLF) Davos and others for the European Environment Agency (EEA), ETC/ACC, Bilthoven, Netherlands, pp. 95-101.

Huggel, C., S. Allen, P. Deline, L. Fischer, J. Noetzli, and L. Ravanel, 2012a: Ice thawing, mountains falling - are alpine rock slope failures increasing? Geology Today, 28(3), 102-108.

Huggel, C., J.J. Clague, and O. Korup, 2012b: Is climate change responsible for changing landslide activity in high mountains? Earth Surface Processes and Landforms, 37, 77-91.

Hulme, M., 2008: Geographical work at the boundaries of climate change. Transactions of the Institute of British Geographers, 33(1), 5-11.

Hulme, M., S.J. O'Neill, and S. Dessai, 2011: Is weather event attribution necessary for adaptation funding? Science, 334, 764-765.

Hunt, G.L., B.M. Allen, R.P. Angliss, T. Baker, N. Bond, G. Buck, G.V. Byrd, K.O. Coyle, A Devol, D.M. Eggers, L. Eisner, R. Feely, S. Fitzgerald, L.W. Fritz, E.V. Gritsay, C. Ladd, W. Lewis, J. Mathis, C.W. Mordy, F. Mueter, J. Napp, E. Sherr, D. Shull, P. Stabeno, M.A. Stepanenko, S. Strom, and T.E. Whitledge, 2010: Status and trends of the Bering Sea region, 2003-2008. In: Marine Ecosystems of the North Pacific Ocean, 2003-2008. [McKinnell, S.M. and M.J. Dagg (eds.)]. PICES Special Publication 4, North Pacific Marine Science Organization (PICES) at the Institute of Ocean Sciences, Sidney, BC, Canada, pp. 196-267.

Huntington, H., T. Callaghan, S. Fox, and I. Krupnik, 2004: Matching traditional and scientific observations to detect environmental change: a discussion on Arctic terrestrial ecosystems. Ambio, 13, 18-23. 
Huss, M., 2011: Present and future contribution of glacier storage change to runoff from macroscale drainage basins in Europe. Water Resources Research, 47, W07511, doi:10.1029/2010WR010299.

IntraRisk, 2002: Development of Loss Relativities for Wind Resistive Features of Residential Structures. Version 2.2, Prepared by Applied Research Associates, Inc., IntraRisk Division, for the Florida Department of Community Affairs, Tallassee, FL, USA, 294 pp.

IPCC, 2007a: Summary for policymakers. In: Climate Change 2007: Impacts, Adaptation and Vulnerability. Contribution of Working Group II to the Fourth Assessment Report of the Intergovernmental Panel on Climate Change [Parry, M.L., O.F. Canziani, J.P. Palutikof, P.J. van der Linden, and C.E. Hanson (eds.]. Cambridge University Press, Cambridge, UK, pp. 7-22.

IPCC, 2007b: Summary for Policymakers. In: Climate Change 2007: Synthesis Report. Contribution of Working Groups I, II and III to the Fourth Assessment Report of the Intergovernmental Panel on Climate Change [Core Writing Team, Pachauri, R.K. and A. Reisinger (eds.)]. IPCC, Geneva, Switzerland, 104 pp.

IPCC, 2012: Managing the Risks of Extreme Events and Disasters to Advance Climate Change Adaptation. A Special Report of Working Groups I and II of the Intergovernmental Panel on Climate Change [Field, C.B., V. Barros, T.F. Stocker, D. Qin, D.J. Dokken, K.L. Ebi, M.D. Mastrandrea, K.J. Mach, G.-K. Plattner, S.K. Allen, M. Tignor, P.M. Midgley (ed.)]. Cambridge University Press, Cambridge, UK, and New York, NY, USA, 582 pp.

Isaac, M. and D.P. van Vuuren, 2009: Modeling global residential sector energy demand for heating and air conditioning in the context of climate change. Energy Policy, 37(2), 507-521.

Jaggard, K., A. Qi, and M. Semenov, 2007: The impact of climate change on sugarbeet yield in the UK: 1976-2004. The Journal of Agricultural Science, 145(4), 367-375.

Jellyman, D.J., D.J. Booker, and E. Watene, 2009: Recruitment of Anguilla spp. glass eels in the Waikato River, New Zealand. Evidence of declining migrations? Journal of Fish Biology, 74(9), 2014-2033.

Jenkins, G.S., A.T. Gaye, and B. Sylla, 2005: Late $20^{\text {th }}$ century attribution of drying trends in the Sahel from the Regional Climate Model (RegCM3). Geophysical Research Letters, 32(22), L22705, doi:10.1029/2005GL024225.

Jenouvrier, S., H. Weimerskirch, C. Barbraud, and Y.H. Park, 2005: Evidence of a shift in the cyclicity of Antarctic seabird dynamics linked to climate. Proceedings of the Royal Society B, 272(1566), 887-895.

Jeong, S., C.H. Ho, H.J. Gim, and M. Brown, 2011: Phenology shifts at start vs. end of growing season in temperate vegetation over the Northern Hemisphere for the period 1982-2008. Global Change Biology, 17(7), 2385-2399.

Jia, G.J., H.E. Epstein, and D.A. Walker, 2009: Vegetation greening in the Canadian Arctic related to decadal warming. Journal of Environmental Monitoring, 11(12), 2231-2238.

Jiang, Y., T.H. Dixon, and S. Wdowinski, 2010: Accelerating uplift in the North Atlantic region as an indicator of ice loss. Nature Geoscience, 3(6), 404-407.

Jin, M., C. Deal, J. Wang, and C.P. McRoy, 2009: Response of lower trophic level production to long-term climate change in the southeastern Bering Sea. Journal of Geophysical Research, 114(C4), C04010, doi:10.1029/2008JC005105.

Johnson, C.R., S.C. Banks, N.S. Barrett, F. Cazassus, P.K. Dunstan, G.J. Edgar, S.D. Frusher, C. Gardner, M. Haddon, and F. Helidoniotis, 2011: Climate change cascades: shifts in oceanography, species' ranges and subtidal marine community dynamics in eastern Tasmania. Journal of Experimental Marine Biology and Ecology, 400(1), 17-32.

Jomelli, V., V.P. Pech, C. Chochillon, and D. Brunstein, 2004: Geomorphic variations of debris flows and recent climatic change in the French Alps. Climatic Change, 64(1), 77-102.

Jomelli, V., V. Favier, A. Rabatel, D. Brunstein, G. Hoffmann, and B. Francou, 2009: Fluctuations of glaciers in the tropical Andes over the last millennium and palaeoclimatic implications: a review. Palaeogeography, Palaeoclimatology, Palaeoecology, 281(3), 269-282.

Jones, B.F. and B.A. Olken, 2010: Climate shocks and exports. American Economic Review, 100(2), 454-459.

Jones, R., O. Hoegh-Guldberg, A. Larkum, and U. Schreiber, 1998: Temperature induced bleaching of corals begins with impairment to the carbon dioxide fixation mechanism of zooxanthellae. Plant, Cell and Environment, 21, 12191230.

Jump, A.S., J. Hunt, and J. Peñuelas, 2006: Rapid climate change-related growth decline at the southern range-edge of Fagus sylvatica. Global Change Biology, 12(11), 2163-2174.
Jump, A.S., T. Huang, and C. Chou, 2012: Rapid altitudinal migration of mountain plants in Taiwan and its implications for high altitude biodiversity. Ecography, 35(3), 204-210.

Jury, M.R. and A. Winter, 2010: Warming of an elevated layer over the Caribbean. Climatic Change, 99(1-2), 247-259.

Kääb, A., R. Frauenfelder, and I. Roer, 2007: On the response of rockglacier creep to surface temperature increase. Global and Planetary Change, 56(1), 172-187.

Kääb, A., E. Berthier, C. Nuth, J. Gardelle, and Y. Arnaud, 2012: Contrasting patterns of early twenty-first-century glacier mass change in the Himalayas. Nature, 488(7412), 495-498.

Karl, T.R., J.M. Melillo, and T.C. Peterson, 2009: Global Climate Change Impacts in the United States. Cambridge University Press, Cambridge, UK and New York, NY, USA, $188 \mathrm{pp}$.

Kasischke, E.S., D.L. Verbyla, T.S. Rupp, A.D. McGuire, K.A. Murphy, R. Jandt, J.L. Barnes, E.E. Hoy, P.A. Duffy, and M. Calef, 2010: Alaska's changing fire regimeimplications for the vulnerability of its boreal forests. Canadian Journal of Forest Research, 40(7), 1313-1324.

Kawachi, I., B.P. Kennedy, and R.G. Wilkinson, 1999: Crime: social disorganization and relative deprivation. Social Science \& Medicine, 48(6), 719-731.

Kay, A.L., S.M. Crooks, P. Pall, and D.A. Stone, 2011: Attribution of autumn/winter 2000 flood risk in England to anthropogenic climate change: a catchmentbased study. Journal of Hydrology, 406(1), 97-112.

Kearney, M.R., N.J. Briscoe, D.J. Karoly, W.P. Porter, M. Norgate, and P. Sunnucks, 2010: Early emergence in a butterfly causally linked to anthropogenic warming. Biology Letters, 6(5), 674-677.

Keatley, M.R. and I.L. Hudson, 2012: Detecting change in an Australian flowering record: comparisons of linear regression and cumulative sum analysis change point analysis. Austral Ecology, 37(7), 825-835.

Keith, D.A., S. Rodoreda, and M. Bedward, 2010: Decadal change in wetlandwoodland boundaries during the late $20^{\text {th }}$ century reflects climatic trends. Global Change Biology, 16(8), 2300-2306.

Kelly, A.E. and M.L. Goulden, 2008: Rapid shifts in plant distribution with recent climate change. Proceedings of the National Academy of Sciences of the United States of America, 105(33), 11823-11826.

Kharuk, V.I., S.T. Im, M.L. Dvinskaya, and K.I. Ranson, 2010: Climate-induced mountain tree-line evolution in southern Siberia. Scandinavian Journal of Forest Research, 25(5), 446-454.

Kiesecker, J.M., 2011: Global stressors and the global decline of amphibians: tipping the stress immunocompetency axis. Ecological Research, 26(5), 897-908.

Killeen, T.J., A. Guerra, M. Calzada, L. Correa, V. Calderon, L. Soria, B. Quezada, and M.K. Steininger, 2008: Total historical land-use change in Eastern Bolivia: who, where, when, and how much? Ecology and Society, 13(1), 36, www.ecology andsociety.org/vol13/iss1/art36/.

Knutson, T.R., J.L. McBride, J. Chan, K. Emanuel, G. Holland, C. Landsea, I. Held, J.P. Kossin, A. Srivastava, and M. Sugi, 2010: Tropical cyclones and climate change. Nature Geoscience, 3(3), 157-163.

Komori, D., S. Nakamura, M. Kiguchi, A. Nishijima, D. Yamazaki, S. Suzuki, A. Kawasaki, K. Oki, and T. Oki, 2012: Characteristics of the 2011 Chao Phraya River flood in Central Thailand. Hydrological Research Letters, 6, 41-46.

Kopp, R.E., J.X. Mitrovica, S.M. Griffies, J. Yin, C.C. Hay, and R.J. Stouffer, 2010: The impact of Greenland melt on local sea levels: a partially coupled analysis of dynamic and static equilibrium effects in idealized water-hosing experiments. Climatic Change, 103(3-4), 619-625.

Korup, O., T. Görüm, and Y. Hayakawa, 2012: Without power? Landslide inventories in the face of climate change. Earth Surface Processes and Landforms, 37(1), 92-99.

Koutsias, N., M. Arianoutsou, A.S. Kallimanis, G. Mallinis, J.M. Halley, and P. Dimopoulos, 2012: Where did the fires burn in Peloponnisos, Greece the summer of 2007? Evidence for a synergy of fuel and weather. Agricultural and Forest Meteorology, 156(0), 41-53.

Kovach, R.P., A.J. Gharrett, and D.A. Tallmon, 2012: Genetic change for earlier migration timing in a pink salmon population. Proceedings of the Royal Society B, 279(1743), 3870-3878.

Kovats, R.S., D.H. Campbell-Lendrum, A.J. McMichael, A. Woodward, and J.S. Cox, 2001: Early effects of climate change: do they include changes in vector-borne disease? Philosophical Transactions of the Royal Society B, 356, 1057-1068.

Krauss, K.W., D.R. Cahoon, J.A. Allen, K.C. Ewel, J.C. Lynch, and N. Cormier, 2010: Surface elevation change and susceptibility of different mangrove zones to sealevel rise on Pacific high islands of Micronesia. Ecosystems, 13(1), 129-143. 
Krepper, C.M. and G.V. Zucarelli, 2010: Climatology of water excesses and shortages in the La Plata Basin. Theoretical and Applied Climatology, 102(1-2), 13-27.

Krepper, C.M., N.O. Garcia, and P.D. Jones, 2008: Low-frequency response of the upper Parana basin. International Journal of Climatology, 28(3), 351-360.

Krishnan, P., S. Dam Roy, G. George, R.C. Srivastava, A. Anand, S. Murugesan, M. Kaliyamoorthy, N. Vikas, and R. Soundararajan, 2011: Elevated sea surface temperature during May 2010 induces mass bleaching of corals in the Andaman. Current Science, 100(1), 111-117.

Kristensen, K., K. Schelde, and J.E. Olesen, 2011: Winter wheat yield response to climate variability in Denmark. The Journal of Agricultural Science, 149(1), 33 47.

Kriz, B., M. Maly, C. Benes, and M. Daniel, 2012: Epidemiology of tick-borne encephalitis in the Czech Republic 1970-2008. Vector-Borne and Zoonotic Diseases, 12(11), 994-999.

Krupnik, I. and G.C. Ray, 2007: Pacific walruses, indigenous hunters, and climate change: bridging scientific and indigenous knowledge. Deep Sea Research Part II: Topical Studies in Oceanography, 54, 2946-2957.

Krushelnycky, P.D., L.L. Loope, T.W. Giambelluca, F. Starr, K. Starr, D.R. Drake, A.D. Taylor, and R.H. Robichaux, 2013: Climate-associated population declines reverse recovery and threaten future of an iconic high-elevation plant. Global Change Biology, 19(3), 911-922.

Kucharik, C.J. and S.P. Serbin, 2008: Impacts of recent climate change on Wisconsin corn and soybean yield trends. Environmental Research Letters, 3(3), 034003, doi:10.1088/1748-9326/3/3/034003.

Kumar, A., M. Chen, M. Hoerling, and J. Eischeid, 2013: Do extreme climate events require extreme forcings? Geophysical Research Letters, 40(13), 3340-3445.

Kundzewicz, Z.W. and V. Krysanova, 2010: Climate change and stream water quality in the multi-factor context. Climatic Change, 103(3-4), 353-362.

Kundzewicz, Z.W., I. Pińskwar, and G.R. Brakenridge, 2013: Large floods in Europe, 1985-2009. Hydrological Sciences Journal, 58(1), 1-7.

Lacombe, G., M. McCartney, and G. Forkuor, 2012: Drying climate in Ghana over the period 1960-2005: evidence from the resampling-based Mann-Kendall test at local and regional levels. Hydrological Sciences Journal, 57(8), 1594-1609.

Laidler, G.J., 2006: Inuit and scientific perspectives on the relationship between sea ice and climate change: the ideal complement? Climatic Change, 78(2-4), 407444.

Laidre, K.L., I. Stirling, L.F. Lowry, O.Wiig, M.O. Heide-Jørgensen, and S.H. Ferguson, 2008: Quantifying the sensitivity of Arctic marine mammals to climate-induced habitat change. Ecological Applications, 18(2), 97-125.

Lalande, F., S. Legrain, A.-J. Valleron, and D. Meyniel, 2003: Mission d'Expertise et d'Évaluation du Système de Santé pendant la Canicule 2003. Ministère de la Santé, de la Famille, et des Personnes Handicapées, Paris, France, 174 pp.

Lamela-Silvarrey, C., C. Fernández, R. Anadón, and J. Arrontes, 2012: Fucoid assemblages on the north coast of Spain: past and present (1977-2007) Botanica Marina, 55(3), 199-207.

Lampis, A., 2010: Challenges to adaptation for risk-prone coastal livelihoods in Tumaco, Pacific Coast (Colombia). UGEC Viewpoints, No. 3, March 2010, 1822.

Lantuit, H., P.P. Overduin, N. Couture, S. Wetterich, F. Aré, D. Atkinson, J. Brown, G. Cherkashov, D. Drozdov, D. Forbes, A. Graves-Gaylord, M. Grigoriev, H.W. Hubberten, J. Jordan, T. Jorgenson, R. Ødegård, S. Ogorodov, W. Pollard, V. Rachold, S. Sedenko, S. Solomon, F. Steenhuisen, I. Streletskaya, and A. Vasiliev, 2011: The Arctic coastal dynamics database: a new classification scheme and statistics on Arctic permafrost coastlines. Estuaries and Coasts, 35(2), 383-400.

Lasram, F.B.R. and D. Mouillot, 2009: Increasing southern invasion enhances congruence between endemic and exotic Mediterranean fish fauna. Biological Invasions, 11(3), 697-711.

Laternser, M. and M. Schneebeli, 2002: Temporal trend and spatial distribution of avalanche activity during the last 50 years in Switzerland. Natural Hazards, 27(3), 201-230.

Laybourn-Parry, J., 2003: Polar limnology, the past, the present and the future. In: Antarctic Biology in a Global Context [Huiskes, A.H.L., W.W.C. Gieskes, J. Rozema, R.M.L. Schorno, S.M. van der Vies, and W.J. Wolff (eds.)]. Backhuys Publishers, Leiden, Netherlands, pp. 321-329.

Le Polain de Waroux, Y. and E.F. Lambin, 2012: Monitoring degradation in arid and semi-arid forests and woodlands: the case of the Argan woodlands (Morocco) Applied Geography, 32(2), 777-786.

Le Quéré, C., M.R. Raupach, J.G. Canadell, and G. Marland, 2009: Trends in the sources and sinks of carbon dioxide. Nature Geoscience, 2, 831-836.
Leadley, P., H.M. Pereira, R. Alkemade, J.F. Fernandez-Manjarrés, V. Proença, J.P.W. Scharlemann, and M.J. Walpole, 2010: Biodiversity Scenarios: Projections of 21 ${ }^{\text {st }}$ Century Change in Biodiversity and Associated Ecosystem Services. CBD Technical Series No. 50, Technical Report for the Global Biodiversity Outlook 3, Secretariat of the Convention on Biological Diversity, Montreal, QC, Canada, $132 \mathrm{pp}$.

Leatherman, S.P., K. Zhang, and B.C. Douglas, 2000: Sea level rise shown to drive coastal erosion. Eos, Transactions of the American Geophysical Union, 81(6), 55-57.

Leblanc, M.J., P. Tregoning, G. Ramillien, S.0. Tweed, and A. Fakes, 2009: Basin-scale, integrated observations of the early $21^{\text {st }}$ century multiyear drought in southeast Australia. Water Resources Research, 45(4), doi:10.1029/2008WR007333.

Lenoir, J., J.C. Gegout, P.A. Marquet, P. de Ruffray, and H. Brisse, 2008: A significant upward shift in plant species optimum elevation during the $20^{\text {th }}$ century. Science, 320(5884), 1768-1771.

Lenton, T.M., 2011: Early warning of climate tipping points. Nature Climate Change, 1(4), 201-209.

Lenton, T.M., H. Held, E. Kriegler, J.W. Hall, W. Lucht, S. Rahmstorf, and H.J. Schellnhuber, 2008: Tipping elements in the Earth's climate system. Proceedings of the National Academy of Sciences of the United States of America, 105(6), 17861793.

Levin, L.A., W. Ekau, A.J. Gooday, F. Jorissen, J.J. Middelburg, S.W.A. Naqvi, C. Neira, N.N. Rabalais, and J. Zhang, 2009: Effects of natural and human-induced hypoxia on coastal benthos. Biogeosciences, 6(10), 2063-2098.

Li, Z.X., Y.Q. He, T. Pu, W.X. Jia, X.Z. He, H.X. Pang, N.N. Zhang, Q. Liu, S.J. Wang, G.F Zhu, S.X. Wang, L. Chang, J.K. Du, and H.J. Xin, 2010: Changes of climate, glaciers and runoff in China's monsoonal temperate glacier region during the last several decades. Quaternary International, 218(1-2), 13-28.

Lima, F.P. and D.S. Wethey, 2012: Three decades of high-resolution coastal sea surface temperatures reveal more than warming. Nature Communications, 3(704), 113.

Lima, F.P., P.A. Ribeiro, N. Queiroz, S.J. Hawkins, and A.M. Santos, 2007: Do distributional shifts of northern and southern species of algae match the warming pattern? Global Change Biology, 13(12), 2592-2604.

Ling, S.D., 2008: Range expansion of a habitat-modifying species leads to loss of taxonomic diversity: a new and impoverished reef state. Oecologia, 156(4), 883-894.

Ling, S.D., C.R. Johnson, S. Frusher, and K. Ridgway, 2009a: Overfishing reduces resilience of kelp beds to climate-driven catastrophic phase shift. Proceedings of the National Academy of Sciences of the United States of America, 106(52), 22341-22345.

Ling, S.D., C.R. Johnson, K. Ridgway, A.J. Hobday, and M. Haddon, 2009b: Climatedriven range extension of a sea urchin: inferring future trends by analysis of recent population dynamics. Global Change Biology, 15(3), 719-731.

Litzow, M.A., J.D. Urban, and B.J. Laurel, 2008: Increased spatial variance accompanies reorganization of two continental shelf ecosystems. Ecological Applications, 18(6), 1331-1337.

Livingstone, D.M., R. Adrian, T. Blenckner, G. George, and G.A. Weyhenmeyer, 2010: Lake ice phenology. In: The Impact of Climate Change on European Lakes [George, D.G. (ed.)]. Aquatic Ecology Series 4, Springer Science, Dordrecht, Netherlands, pp. 51-61.

Lloyd, A.H., A.G. Bunn, and L. Berner, 2011: A latitudinal gradient in tree growth response to climate warming in the Siberian taiga. Global Change Biology, 17(5), 1935-1945.

Lobell, D.B. and C.B. Field, 2007: Global scale climate - crop yield relationships and the impacts of recent warming. Environmental Research Letters, 2(1), 014002, doi:10.1088/1748-9326/2/1/014002.

Lobell, D.B., W. Schlenker, and J. Costa-Roberts, 2011: Climate trends and global crop production since 1980. Science, 333(6042), 616-620.

Loriaux, T. and G. Casassa, 2013: Evolution of glacial lakes from the Northern Patagiona Icefield and terrestrial water storage in a sea-level rise context. Global and Planetary Change, 102(3), 33-40.

Lotze, H.K., H.S. Lenihan, B.J. Bourque, R.H. Bradbury, R.G. Cooke, M.C. Kay, S.M. Kidwell, M.X. Kirby, C.H. Peterson, and J.B.C. Jackson, 2006: Depletion, degradation, and recovery potential of estuaries and coastal seas. Science, 312(5781), 1806-1809.

Lucey, S.M. and J.A. Nye, 2010: Shifting species assemblages in the Northeast US continental shelf large marine ecosystem. Marine Ecology Progress Series, 415, 23-33. 
Ludwig, F., S.P. Milroy, and S. Asseng, 2009: Impacts of recent climate change on wheat production systems in Western Australia. Climatic Change, 92(3-4), 495517.

Lugon, R. and M. Stoffel, 2010: Rock-glacier dynamics and magnitude-frequency relations of debris flows in a high-elevation watershed: Ritigraben, Swiss Alps. Global and Planetary Change, 73(3-4), 202-210.

Luyssaert, S., P. Ciais, S.L. Piao, E.D. Schulze, M. Jung, S. Zaehle, M.J. Schelhaas, M. Reichstein, G. Churkina, and D. Papale, 2010: The European carbon balance. Part 3: forests. Global Change Biology, 16(5), 1429-1450.

Ma, E.Q., M.J. Guinery, P. McCarthy, and R. Shaw, 2012: Australian floods and their impact on insurance. In: Extreme Events and Insurance: 2011 Annus Horribilis [Courbage, C. and W.R. Stahel (eds.)]. The Geneva Reports - Risk and Insurance Research No. 5, The Geneva Association, Geneva, Switzerland, pp. 81-91.

$\mathrm{Ma}$, T. and C. Zhou, 2012: Climate-associated changes in spring plant phenology in China. International Journal of Biometeorology, 56(2), 269-275.

Mack, M.C., M.S. Bret-Harte, T.N. Hollingsworth, R.R. Jandt, E.A.G. Schuur, G.R. Shaver, and D.L. Verbyla, 2011: Carbon loss from an unprecedented Arctic tundra wildfire. Nature, 475(7357), 489-492.

Maclean, K. and L. Cullen, 2009: Research methodologies for the co-production of knowledge for environmental management in Australia. Journal of the Royal Society of New Zealand, 39, 205-208.

Magrin, G.O., M.I. Travasso, W.E. Baethgen, M.O. Grondona, A. Giménez, G. Cunha, J.P. Castaño, and G.R. Rodriguez, 2007: Past and future changes in climate and their impacts on annual crops yield in south east South America. In: IPCC TGICA Expert Meeting: Integrating Analysis of Regional Climate Change and Response Options, Nadi, Fiji, 20-22 June, 2007. Meeting Report, Intergovernmental Panel on Climate Change (IPCC) Task Group on Data Scenario Support for Impact and Climate Analysis (TGICA), Sponsored by the Global Change System for Analysis, Research and Training (START) and The Pacific Center for Environment and Sustainable Development at the University of South Pacific (PACE/USP), IPCC TGICA, Geneva, Switzerland, pp. 121-124.

Malhi, Y., L. Aragao, D. Galbraith, C. Huntingford, R. Fisher, P. Zelazowski, S. Sitch, C. McSweeney, and P. Meir, 2009: Exploring the likelihood and mechanism of a climate-change-induced dieback of the Amazon rainforest. Proceedings of the National Academy of Sciences of the United States of America, 106(49), 2061020615.

Malik, N., B. Bookhagen, N. Marwan, and J. Kurths, 2011: Analysis of spatial and temporal extreme monsoonal rainfall over South Asia using complex networks. Climate Dynamics, 39(3-4), 971-987.

Mann, D.H., T.S. Rupp, M.A. Olson, and P.A. Duffy, 2012: Is Alaska's boreal forest now crossing a major ecological threshold? Arctic, Antarctic, and Alpine Research, 44(3), 319-331.

Mann, M.E. and K.A. Emanuel, 2012: Atlantic hurricane trends linked to climate change. Eos, Transactions of the American Geophysical Union, 87(24), 233241.

Manzello, D.P., J.A. Kleypas, D.A. Budd, C.M. Eakin, P.W. Glynn, and C. Langdon, 2008: Poorly cemented coral reefs of the eastern tropical Pacific: possible insights into reef development in a high- $\mathrm{CO}_{2}$ world. Proceedings of the National Academy of Sciences of the United States of America, 105(30), 10450-10455.

Maranz, S., 2009: Tree mortality in the African Sahel indicates an anthropogenic ecosystem displaced by climate change. Journal of Biogeography, 36, 11811193.

Marbà, N. and C.M. Duarte, 2010: Mediterranean warming triggers seagrass (Posidonia oceanica) shoot mortality. Global Change Biology, 16(8), 2366-2375.

Marchiori, L., J.F. Maystadt, and I. Schumacher, 2012: The impact of weather anomalies on migration in sub-Saharan Africa. Journal of Environmental Economics and Management, 63(3), 335-374.

Marcos, M., M.N. Tsimplis, and A.G.P. Shaw, 2009: Sea level extremes in southern Europe. Journal of Geophysical Research, 114, C01007, doi:10.1029/ $2008 J C 004912$.

Marengo, J.A., J. Tomasella, L.M. Alves, W.R. Soares, and D.A. Rodriguez, 2011a: The drought of 2010 in the context of historical droughts in the Amazon region. Geophysical Research Letters, 38(12), L12703, doi:10.1029/2011GL047436.

Marengo, J.A., C.A. Nobre, G. Sampaio, L.F. Salazar, and L.S. Borma, 2011 b: Climate Change in the Amazon Basin: Tipping Points, Changes in Extremes, and Impacts on Natural and Human Systems. Springer, New York, NY, USA, pp. 259-283.

Mars, J. and D. Houseknecht, 2007: Quantitative remote sensing study indicates doubling of coastal erosion rate in past $50 \mathrm{yr}$ along a segment of the Arctic coast of Alaska. Geology, 35(7), 583-586.
Marsh, P., M. Russell, S. Pohl, H. Haywood, and C. Onclin, 2008: Changes in thaw lake drainage in the Western Canadian Arctic from 1950 to 2000. Hydrological Processes, 23(1), 145-158.

Marshall, B.E., 2012: Does climate change really explain changes in the fisheries productivity of Lake Kariba (Zambia-Zimbabwe)? Transactions of the Royal Society of South Africa, 67, 45-51.

Martinez, R., C. Euscategui, E. Jaimes, G. Léon, and A. Quintero, 2011: Northern South America and the Tropical Andes. In: State of the Climate in 2010 [Blunden, J., D.S. Arndt, and M.O. Baringer (eds.)]. Special Supplement to the Bulletin of the American Meteorological Society, 92(6), S186-S187.

Marty, C., 2008: Regime shift of snow days in Switzerland. Geophysical Research Letters, 35(12), L12501, doi:10.1029/2008GL033998.

Marulanda, M.C., O.D. Cardona, and A.H. Barbat, 2010: Revealing the socioeconomic impact of small disasters in Colombia using the DesInventar database. Disasters, 34(2), 552-570.

Marzeion, B., A. Jarosch, and M. Hofer, 2012: Past and future sea-level change from the surface mass balance of glaciers. The Cryosphere Discussions, 6(4), 3177 3241.

Mathiesen, S.D., B. Alfthan, R. Corell, R.B.M. Eira, I.M.G. Eira, A. Degteva, K.I. Johnsen, A. Oskal, M. Roué, M.N. Sara, E.R. Skum, E.I. Turi, and J.M. Turi, 2013: Strategies to enhance the resilience of Sámi reindeer husbandry to rapid changes in the Arctic. In: Arctic Resilience Interim Report. Arctic Council, Stockholm Environment Institute (SEI) and Stockholm Resilience Centre, Stockholm, Sweden, pp. 109112.

Mavume, A.F., L. Rydberg, M. Rouault, and J.R. Lutjeharms, 2009: Climatology and landfall of tropical cyclones in the south-west Indian Ocean. Western Indian Ocean Journal of Marine Science, 8(1), 15-36.

McDowell, J.Z. and J.J. Hess, 2012: Accessing adaptation: Multiple stressors on livelihoods in the Bolivian highlands under a changing climate. Global Environmental Change, 22(2), 342-352.

McGrath, J. and D.B. Lobell, 2011: An independent method of deriving the carbon dioxide fertilization effect in dry conditions using historical yield data from wet and dry years. Global Change Biology, 17(8), 2689-2696.

McGuire, A.D., F. Chapin lii, C. Wirth, M. Apps, J. Bhatti, T. Callaghan, T.R. Christensen, J.S. Clein, M. Fukuda, and T. Maximov, 2007: Responses of high latitude ecosystems to global change: potential consequences for the climate system. In: Terrestrial Ecosystems in a Changing World [Canadell, J.G., D.E. Pataki, and L.F. Pitelka (eds.)]. Springer-Verlag, Berlin Heidelberg, pp. 297-310.

McIntyre, T., I.J. Ansorge, H. Bornemann, J. Plötz, C.A. Tosh, and M.N. Bester, 2011: Elephant seal dive behaviour is influenced by ocean temperature. Implications for climate change impacts on an ocean predator. Marine Ecology Progress Series, 441, 257-272.

McKee, K.L., D.R. Cahoon, and I.C. Feller, 2007: Caribbean mangroves adjust to rising sea level through biotic controls on change in soil elevation. Global Ecology and Biogeography, 16(5), 545-556.

McLeod, E., R. Moffitt, A. Timmermann, R. Salm, L. Menviel, M.J. Palmer, E.R. Selig, K.S. Casey, and J.F. Bruno, 2010: Warming seas in the Coral Triangle: coral reef vulnerability and management implications. Coastal Management, 38(5), 518539.

Menéndez, M. and P.L. Woodworth, 2010: Changes in extreme high water levels based on a quasi-global tide-gauge data set. Journal of Geophysical Research, 115(C10), C10011, doi:10.1029/2009JC005997.

Menge, B.A., F. Chan, and J. Lubchenco, 2008: Response of a rocky intertidal ecosystem engineer and community dominant to climate change. Ecology Letters, 11(2), 151-162.

Menne, M.J., C.N. Williams Jr., and R.S. Vose, 2009: The U.S. Historical Climatology Network monthly temperature data, Version 2. Bulletin of the American Meteorological Society, 90, 993-1007.

Menzel, A., T.H. Sparks, N. Estrella, E. Koch, A. Aasa, R. Ahas, K. Alm-Kübler, P. Bissolli, O. Braslavska, A. Briede, F.M. Chmielewski, Z. Crepinsek, Y. Curnel, A. Dahl, C. Defila, A. Donnelly, Y. Filella, K. Jatczak, F. Måge, A. Mestre, Ø. Nordli, J. Peñuelas, P. Pirinen, V. Remišová, H. Scheifinger, M. Striz, A. Susnik, A.J.H. Van Vliet, F.-E. Wielgolaski, S. Zach, and A. Zust, 2006: European phenological response to climate change matches the warming pattern. Global Change Biology, 12(10), 1969-1976.

Merico, A., T. Tyrrell, E.J. Lessard, T. Oguz, P.J. Stabeno, S.I. Zeeman, and T.E. Whitledge, 2004: Modelling phytoplankton succession on the Bering Sea shelf: role of climate influences and trophic interactions in generating Emiliania huxleyi blooms 1997-2000. Deep-Sea Research Part I, 51(12), 1803-1826. 
Miguel, E., S. Satyanath, and E. Sergenti, 2004: Economic shocks and civil conflict: an instrumental variables approach. Journal of Political Economy, 112(4), 725753.

Miles, B.W.J., C.R. Stokes, A. Vieli, and N.J. Cox, 2013: Rapid, climate-driven changes in outlet glaciers on the Pacific coast of East Antarctica. Nature, 500(7464), 563-566.

Miller, S., R. Muir-Wood, and A. Boissonade, 2008: An exploration of trends in normalized weather-related catastrophe losses. In: Climate Extremes and Society [Diaz, H.F. and R.J. Murnane (eds.)]. Cambridge University Press, Cambridge, UK, pp. 225-247.

Mills, G., A. Buse, B. Gimeno, V. Bermejo, M. Holland, L. Emberson, and H. Pleijel, 2007: A synthesis of AOT40-based response functions and critical levels of ozone for agricultural and horticultural crops. Atmospheric Environment, 41(12), 2630-2643.

Min, S.K., X. Zhang, F.W. Zwiers, and G.C. Hegerl, 2011: Human contribution to moreintense precipitation extremes. Nature, 470(7334), 378-381.

Moholdt, G., B. Wouters, and A.S.S. Gardner, 2012: Recent mass changes of glaciers in the Russian High Arctic. Geophysical Research Letters, 39(10), L10502, doi:10.1029/2012GL051466.

Moiseev, P.A., A.A. Bartysh, and Z.Y. Nagimov, 2010: Climate changes and tree stand dynamics at the upper limit of their growth in the North Ural Mountains. Russian Journal of Ecology, 41(6), 486-497.

Molau, U., 2010a: Long-term impacts of observed and induced climate change on tussock tundra near its southern limit in northern Sweden. Plant Ecology and Diversity, 3(1), 29-34.

Molau, U., 2010b: Recent changes of vegetation patterns in the mountains of northern Sweden. In: Europe's Ecological Backbone: Recognising the True Value of Mountains. EEA Report, No. 6/2010, European Environment Agency (EEA) Office for Official Publications of the European Union, Luxembourg, Luxembourg, pp. 159-160.

Mölg, T., N.J. Cullen, D.R. Hardy, G. Kaser, and L. Klok, 2008: Mass balance of a slope glacier on Kilimanjaro and its sensitivity to climate. International Journal of Climatology, 28, 881-892.

Mölg, T., M. Großhauser, A. Hemp, M. Hofer, and B. Marzeion, 2012: Limited forcing of glacier loss through land-cover change on Kilimanjaro. Nature Climate Change, 2(4), 254-258.

Møller, A.P., D. Rubolini, and E. Lehikoinen, 2008: Populations of migratory bird species that did not show a phenological response to climate change are declining. Proceedings of the National Academy of Sciences of the United States of America, 105(42), 16195-16200.

Moore, J.A., L.M. Bellchambers, M.R. Depczynski, R.D. Evans, S.N. Evans, S.N. Field, K.J. Friedman, J.P. Gilmour, T.H. Holmes, and R. Middlebrook, 2012 Unprecedented mass bleaching and loss of coral across $12^{\circ}$ of latitude in Western Australia in 2010-11. PloS One, 7(12), e51807, doi:10.1371/journal. pone. 0051807 .

Moore, R.D., S.W. Fleming, B. Menounos, R. Wheate, A. Fountain, K. Stahl, K. Holm, and M. Jakob, 2009: Glacier change in western North America: influences on hydrology, geomorphic hazards and water quality. Hydrological Processes, 23(1), 42-61.

Morgan, P.B., T.A. Mies, G.A. Bollero, R.L. Nelson, and S.P. Long, 2006: Season-long elevation of ozone concentration to projected 2050 levels under fully open-air conditions substantially decreases the growth and production of soybean. New Phytologist, 170(2), 333-343.

Moritz, C., J.L. Patton, C.J. Conroy, J.L. Parra, G.C. White, and S.R. Beissinger, 2008: Impact of a century of climate change on small-mammal communities in Yosemite National Park, USA. Science, 322(5899), 261-264.

Mote, P.W., 2006: Climate-driven variability and trends in mountain snowpack in western North America. Journal of Climate, 19(23), 6209-6220.

Moy, A.D., W.R. Howard, S.G. Bray, and T.W. Trull, 2009: Reduced calcification in modern Southern Ocean planktonic foraminifera. Nature Geoscience, 2(4), 276280.

Mueter, F.J. and M.A. Litzow, 2008: Sea ice retreat alters the biogeography of the Bering Sea continental shelf. Ecological Applications, 18(2), 309-320.

Müller, P., 2011: Summer 2010 - wildfires in Russia. In: Topics Geo. Natural Catastrophes 2010. Analyses, Assessments, Positions. Munich Reinsurance Company, Munich, Germany, pp. 26-28.

Müller, R., T. Laepple, I. Bartsch, and C. Wiencke, 2009: Impact of oceanic warming on the distribution of seaweeds in polar and cold-temperate waters. Botanica Marina, 52(6), 617-638.
Muscatine, L., 1986: Bioenergetics of reef-building corals. Indian Edition Series, 12, 297-306.

Myers-Smith, I.H., B.C. Forbes, M. Wilmking, M. Hallinger, T. Lantz, D. Blok, K.D. Tape, M. Macias-Fauria, U. Sass-Klaassen, and E. Lévesque, 2011: Shrub expansion in tundra ecosystems: dynamics, impacts and research priorities. Environmental Research Letters, 6(4), 045509, doi:10.1088/1748-9326/6/4/045509.

Naito, A.T. and D.M. Cairns, 2011: Patterns and processes of global shrub expansion. Progress in Physical Geography, 35(4), 423-442.

Nakazawa, Y., R. Williams, A.T. Peterson, P. Mead, E. Staples, and K.L. Gage, 2007: Climate change effects on plague and tularemia in the United States. VectorBorne and Zoonotic Diseases, 7, 529-540.

Ndebele-Murisa, M.R., E. Mashonjowa, and T. Hill, 2011: The implications of a changing climate on the Kapenta fish stocks of Lake Kariba. Transactions of the Royal Society of South Africa, 66, 105-119.

NDMA, 2011: National Disaster Management Authority. Annual Report 2010. National Disaster Management Authority (NDMA), Prime Minister's Secretariat, Islamabad, Pakistan, 78 pp.

Nepstad, D.C. and C.M. Stickler, 2008: Managing the tropical agriculture revolution. Journal of Sustainable Forestry, 27(1-2), 43-56.

Nepstad, D.C., C.M. Stickler, and O.T. Almeida, 2006: Globalization of the Amazon soy and beef industries: opportunities for conservation. Conservation Biology, 20(6), 1595-1603.

Neuheimer, A.B., R.E. Thresher, J.M. Lyle, and J.M. Semmens, 2011: Tolerance limit for fish growth exceeded by warming waters. Nature Climate Change, 1(2), 110-113.

Neumayer, E., 2003: Good policy can lower violent crime: evidence from a crossnational panel of homicide rates, 1980-97. Journal of Peace Research, 40(6), 619-640.

Neumayer, E. and F. Barthel, 2011: Normalizing economic loss from natural disasters: a global analysis. Global Environmental Change, 21(1), 13-24.

Nicholls, N., 2006: Detecting and attributing Australian climate change: a review. Australian Meteorological Magazine, 55(3), 199-211.

Nicholls, N., 2010: Local and remote causes of the southern Australian autumnwinter rainfall decline, 1958-2007. Climate Dynamics, 34(6), 835-845.

Nicholls, R.J., P.P. Wong, V.R. Burkett, J.O. Codignotto, J.E. Hay, R.F. McLean, S. Ragoonaden, and C.D. Woodroffe, 2007: Coastal systems and low-lying areas. In: Climate Change 2007: Impacts, Adaptation and Vulnerability. Contribution of Working Group II to the Fourth Assessment Report of the Intergovernmental Panel on Climate Change [Parry, M.L., O.F. Canziani, J.P. Palutikof, P.J. van der Linden, and C.E. Hanson (eds.)]. Cambridge University Press, Cambridge, UK and New York, NY, USA, pp. 315-356.

Nicholls, R.J., C. Woodroffe, and V. Burkett, 2009: Coastline degradation as an indicator of global change. In: Climate Change: Observed Impacts on Planet Earth [Letcher, T.M. (ed.)]. Elsevier, Oxford, UK, pp. 409-424.

Nichols, T., F. Berkes, D. Jolly, N.B. Snow, and The Community of Sachs Harbour, 2004: Climate change and sea ice: local observations from the Canadian Western Arctic. Arctic, 57(1), 68-79.

Nielsen, J.Ø. and A. Reenberg, 2010: Temporality and the problem with singling out climate as a current driver of change in a small West African village. Journal of Arid Environments, 74(4), 464-474.

Nightingale, A.J., 2011: Bounding difference: intersectionality and the material production of gender, caste, class and environment in Nepal. Geoforum, 42(2), 153-162.

Novelo-Casanova, D.A. and G. Suarez, 2010: Natural and man-made hazards in the Cayman Islands. Natural Hazards, 55(2), 441-466.

Nuth, C., G. Moholdt, J. Kohler, J.O. Hagen, and A. Kääb, 2010: Svalbard glacier elevation changes and contribution to sea level rise. Journal of Geophysical Research: Earth Surface, 115(F1), F01008, doi:10.1029/2008JF001223.

Nye, J.A., J.S. Link, J.A. Hare, and W.J. Overholtz, 2009: Changing spatial distribution of fish stocks in relation to climate and population size on the Northeast United States continental shelf. Marine Ecology Progress Series, 393, 111-129.

Nye, J.A., T.M. Joyce, Y. Kwon, and J.S. Link, 2011: Silver hake tracks changes in Northwest Atlantic circulation. Nature Communications, 2, 412, doi:10.1038/ncomms 1420 .

Ogawa-Onishi, Y. and P.M. Berry, 2013: Ecological impacts of climate change in Japan: the importance of integrating local and international publications. Biological Conservation, 157, 361-371.

Ogden, N.H., C. Bouchard, K. Kurtenbach, G. Margos, L.R. Lindsay, L. Trudel, S. Nguon, and F. Milord, 2010: Active and passive surveillance and phylogenetic analysis of Borrelia burgdorferi elucidate the process of lyme disease risk emergence in Canada. Environmental Health Perspectives, 118(7), 909-914. 
Okada, M., T. lizumi, Y. Hayashi, and M. Yokozawa, 2009: A climatological analysis on the recent declining trend of rice quality in Japan. Journal of Agricultural Meteorology, 65(4), 327-337.

Oliveira, P.J.C., G.P. Asner, D.E. Knapp, A. Almeyda, R. Galvan-Gildemeister, S. Keene, R.F. Raybin, and R.C. Smith, 2007: Land-use allocation protects the Peruvian Amazon. Science, 317(5842), 1233-1236.

Olsen, M.S., T.V. Callaghan, J.D. Reist, L.O. Reiersen, D. Dahl-Jensen, M.A. Granskog, B. Goodison, G.K. Hovelsrud, M. Johansson, R. Kallenborn, J. Key, A. Klepikov, W. Meier, J.E. Overland, T.D. Prowse, M. Sharp, W.F. Vincent, and J. Walsh, 2011: The changing Arctic cryosphere and likely consequences: an overview. AMBIO, 40(1), 111-118.

O'Meara, W.P., J. Nekesa Mangeni, R. Steketee, and B. Greenwood, 2010: Changes in the burden of malaria in sub-Saharan Africa. The Lancet Infectious Diseases, 10(8), 545-555.

Omumbo, J.A., B. Lyon, S.M. Waweru, S.J. Connor, and M.C. Thomson, 2011: Raised temperatures over the Kericho tea estates: revising the climate in the East African highlands malaria debate. Malaria Journal, 10(1), 12, doi:10.1186/ 1475-2875-10-12.

Oppikofer, T., M. Jaboyedoff, and H.R. Keusen, 2008: Collapse at the eastern Eiger flank in the Swiss Alps. Nature Geoscience, 1(8), 531-535.

Osbahr, H., C. Twyman, W. Neil Adger, and D.S.G. Thomas, 2008: Effective livelihood adaptation to climate change disturbance: scale dimensions of practice in Mozambique. Geoforum, 39(6), 1951-1964.

OSSO, 2013: La Ruralidad, la Fragilidad Urbana y el Fenómeno La Niña en Colombia, 1971-2011. Background paper prepared for the Global Assessment Report on Disaster Risk Reduction 2013 by Corporación OSSO, The United Nations Secretariat of the International Strategy for Disaster Reduction (UNISDR), Geneva, Switzerland, $33 \mathrm{pp}$.

Overeem, I. and J.P.M. Syvitsky, 2010: Shifting discharge peaks in Arctic rivers, 19772007. Geografiska Annaler: Series A, Physical Geography, 92(2), 285-296.

Overland, J.E., J. Alheit, A. Bakun, J.W. Hurrell, D.L. Mackas, and A.J. Miller, 2010: Climate controls on marine ecosystems and fish populations. Journal of Marine Systems, 79(3), 305-315.

Oxenford, H., R. Roach, A. Brathwaite, L. Nurse, R. Goodridge, F. Hinds, K. Baldwin, and C. Finney, 2008: Quantitative observations of a major coral bleaching event in Barbados, Southeastern Caribbean. Climatic Change, 87(3-4), 435-449.

Oxley, M., 2011: Field note from Pakistan floods: preventing future flood disasters. Jàmbá: Journal of Disaster Risk Studies, 3(2), 453-463.

Pall, P., T. Aina, D.A. Stone, P.A. Stott, T. Nozawa, A.G.J. Hilberts, D. Lohmann, and M.R. Allen, 2011: Anthropogenic greenhouse gas contribution to flood risk in England and Wales in autumn 2000. Nature, 470(7334), 382-385.

Panday, P.K. and B. Ghimire, 2012: Time-series analysis of NDVI from AVHRR data over the Hindu Kush-Himalayan region for the period 1982-2006. International Journal of Remote Sensing, 33(21), 6710-6721.

Parent, M.B. and D. Verbyla, 2010: The browning of Alaska's boreal forest. Remote Sensing, 2(12), 2729-2747.

Park, S., N. Marshall, E. Jakku, A. Dowd, S. Howden, E. Mendham, and A. Fleming, 2012: Informing adaptation responses to climate change through theories of transformation. Global Environmental Change, 22(1), 115-126.

Parker, G., 2008: Crisis and catastrophe: the global crisis of the seventeenth century reconsidered. American Historical Review, 113(4), 1053-1079.

Parmesan, C., 2006: Ecological and evolutionary responses to recent climate change. Annual Review of Ecology, Evolution, and Systematics, 37, 637-669.

Parmesan, C. and H. Galbraith, 2004: Observed Impacts of Global Climate Change in the U.S. Pew Center on Global Climate Change, Arlington, VA, USA, 55 pp.

Parmesan, C. and G. Yohe, 2003: A globally coherent fingerprint of climate change impacts across natural systems. Nature, 421(6918), 37-42.

Parmesan, C., C.M. Duarte, E. Poloczanska, A.J. Richardson, and M.C. Singer, 2011: Overstretching attribution. Nature Climate Change, 1(1), 2-4.

Parnikoza, I., P. Convey, I. Dykyy, V. Trokhymets, G. Milinevsky, O. Tyschenko, D. Inozemtseva, and I. Kozeretska, 2009: Current status of the Antarctic herb tundra formation in the Central Argentine Islands. Global Change Biology, 15(7), 1685-1693.

Parry, M.L., O.F. Canziani, J.P. Palutikof, van der Linden, P J, and C.E. Hanson, 2007: Cross-chapter case study. In: Climate Change 2007: Impacts, Adaptation and Vulnerability. Contribution of Working Group II to the Fourth Assessment Report of the Intergovernmental Panel on Climate Change [Parry, M.L., O.F. Canziani, J.P. Palutikof, P.J. van der Linden, and C.E. Hanson, (eds.)]. Cambridge University Press, Cambridge, UK and New York, NY, USA, pp. 864-868.
Pasquini, A.I. and P.J. Depetris, 2007: Discharge trends and flow dynamics of South American rivers draining the southern Atlantic seaboard: an overview. Journal of Hydrology, 333(2), 385-399.

Pathak, H., J.K. Ladha, P.K. Aggarwal, S. Peng, S. Das, Y. Singh, B. Singh, S.K. Kamra, B. Mishra, A.S.R.A.S. Sastri, H.P. Aggarwal, D.K. Das, and R.K. Gupta, 2003: Trends of climatic potential and on-farm yields of rice and wheat in the Indo-Gangetic Plains. Field Crops Research, 80(3), 223-234.

Patterson, D.L., A. Easter-Pilcher, and W.R. Fraser, 2003: The effects of human activity and environmental variability on long-term changes in Adélie penguin populations at Palmer Station, Antarctica. In: Antarctic Biology in a Global Context [Huiskes, A., W. Gieskes, J. Rozema, R. Schorno, S. van der Vies, and W. Wolff (eds.)]. Backhuys Publishers, Leiden, Netherlands, pp. 301-307.

Paul, F. and W. Haeberli, 2008: Spatial variability of glacier elevation changes in the Swiss Alps obtained from two digital elevation models. Geophysical Research Letters, 35(21), L21502, doi:10.1029/2008GL034718.

Paz, S., N. Bisharat, E. Paz, O. Kidar, and D. Cohen, 2007: Climate change and the emergence of Vibrio vulnificus disease in Israel. Environmental Research, 103(3), 390-396.

Pearce, T., B. Smit, F. Duerden, J.D. Ford, A. Goose, and F. Kataoyak, 2010: Inuit vulnerability and adaptive capacity to climate change in Ulukhaktok, Northwest Territories, Canada. Polar Record, 46(237), 157-177.

Peck, L.S., M.S. Clark, S.A. Morley, A. Massey, and H. Rossetti, 2009: Animal temperature limits and ecological relevance: effects of size, activity and rates of change. Functional Ecology, 23(2), 248-256.

Pellicciotti, F., A. Bauder, and M. Parola, 2010: Effect of glaciers on streamflow trends in the Swiss Alps. Water Resources Research, 46(10), W10522, doi:10.1029/ 2009WR009039.

Peng, C., Z. Ma, X. Lei, Q. Zhu, H. Chen, W. Wang, S. Liu, W. Li, X. Fang, and X. Zhou, 2011: A drought-induced pervasive increase in tree mortality across Canada's boreal forests. Nature Climate Change, 1(9), 467-471.

Peng, S.B., J.L. Huang, J.E. Sheehy, R.C. Laza, R.M. Visperas, X.H. Zhong, G.S. Centeno, G.S. Khush, and K.G. Cassman, 2004: Rice yields decline with higher night temperature from global warming. Proceedings of the National Academy of Sciences of the United States of America, 101(27), 9971-9975.

Peñuelas, J., J. Sardans, M. Estiarte, R. Ogaya, J. Carnicer, M. Coll, A. Barbeta, A. Rivas-Ubach, J. Llusià, and M. Garbulsky, 2013: Evidence of current impact of climate change on life: a walk from genes to the biosphere. Global Change Biology, 19(8), 2303-2388.

Perkins, S.E., L.V. Alexander, and J.R. Nairn, 2012: Increasing frequency, intensity and duration of observed global heatwaves and warm spells. Geophysical Research Letters, 39(20), L20714, doi:10.1029/2012GL053361.

Perry, A.L., P.J. Low, J.R. Ellis, and J.D. Reynolds, 2005: Climate change and distribution shifts in marine fishes. Science, 308(5730), 1912-1915.

Perry, C.L. and I.A. Mendelssohn, 2009: Ecosystem effects of expanding populations of Avicennia germinans in a Louisiana salt marsh. Wetlands, 29(1), 396406.

Peterson, T.C., R.R. Heim Jr., R. Hirsch, D.P. Kaiser, H. Brooks, N.S. Diffenbaugh, R.M. Dole, J.P. Giovannettone, K. Guirguis, T.R. Karl, R.W. Katz, K. Kunkel, D. Lettenmaier, G.J. McCabe, C.J. Paciorek, K.R. Ryberg, S. Schubert, V.B.S. Silva, B.C. Stewart, A.V. Vecchia, G. Villarini, R.S. Vose, J. Walsh, M. Wehner, D. Wolock, K. Wolter, C.A. Woodhouse, and D. Wuebbles, 2013: Monitoring and understanding changes in heat waves, cold waves, flood, and droughts in the United States: state of knowledge. Bulletin of the American Meteorological Society, 94(6), 821-834.

Petney, T.N., J. Skuballa, S. Muders, M. Pfäffle, C. Zetlmeisl, and R. Oehme, 2012: The changing distribution patterns of ticks (Ixodida) in Europe in relation to emerging tick-borne diseases. Parasitology Research Monographs, 3, 151-166.

Petrow, T. and B. Merz, 2009: Trends in flood magnitude, frequency and seasonality in Germany in the period 1951-2002. Journal of Hydrology, 371(1-4), 129-141.

Phien-Wej, N., P.H. Giao, and P. Nutalaya, 2006: Land subsidence in Bangkok, Thailand. Engineering Geology, 82(4), 187-201.

Philippart, C.J.M., R. Anadón, R. Danovaro, J.W. Dippner, K.F. Drinkwater, S.J. Hawkins, T. Oguz, G. O'Sullivan, and P.C. Reid, 2011: Impacts of climate change on European marine ecosystems: observations, expectations and indicators. Journal of Experimental Marine Biology and Ecology, 400(1-2), 52-69.

Phillimore, A.B., J.D. Hadfield, O.R. Jones, and R.J. Smithers, 2010: Differences in spawning date between populations of common frog reveal local adaptation. Proceedings of the National Academy of Sciences of the United States of America, 107(18), 8292-8297. 
Phillips, O.L., L.E.O.C. Aragão, S.L. Lewis, J.B. Fisher, J. Lloyd, G. López-González, Y. Malhi, A. Monteagudo, J. Peacock, C.A. Quesada, G. van der Heijden, S. Almeida, I. Amaral, L. Arroyo, G. Aymard, T.R. Baker, O. Bánki, L. Blanc, D. Bonal, P. Brando, J. Chave, Á.C. Alves de Oliveira, N.D. Cardozo, C.I. Czimczik, T.R. Feldpausch, M.A. Freitas, E. Gloor, N. Higuchi, E. Jiménez, G. Lloyd, P. Meir, C. Mendoza, A. Morel, D.A. Neill, D. Nepstad, S. Patiño, M.C. Peñuela, A. Prieto, F. Ramírez, M. Schwarz, J. Silva, M. Silveira, A.S. Thomas, H. ter Steege, J. Stropp, R. Vásquez, P. Zelazowski, E.A. Dávila, S. Andelman, A. Andrade, K. Chao, T. Erwin, A. Di Fiore, E. Honorio C., H. Keeling, T.J. Killeen, W.F. Laurance, A.P. Cruz, N.C.A. Pitman, P.N. Vargas, H. Ramírez-Angulo, A. Rudas, R. Salamão, N. Silva, J. Terborgh, and A. Torres-Lezama, 2009: Drought sensitivity of the Amazon rainforest. Science, 323(5919), 1344-1347.

Pielke Jr., R.A., J. Gratz, C.W. Landsea, D. Collins, M.A. Saunders, and R. Musulin, 2008: Normalised hurricane damage in the United States: 1900-2005. Natural Hazards Review, 9, 29-42.

Pielke Jr., R.A., J. Rubiera, C. Landsea, M.L. Fernandez, and R. Klein, 2003: Hurricane vulnerability in Latin America and the Caribbean: normalized damage and loss potentials. Natural Hazards Review, 4(3), 101-114.

Pitt, N.R., E.S. Poloczanska, and A.J. Hobday, 2010: Climate-driven range changes in Tasmanian intertidal fauna. Marine and Freshwater Research, 61(9), 963970.

Polidoro, B.A., K.E. Carpenter, L. Collins, N.C. Duke, A.M. Ellison, J.C. Ellison, E.J. Farnsworth, E.S. Fernando, K. Kathiresan, N.E. Koedam, S.R. Livingstone, T. Miyagi, G.E. Moore, V.N. Nam, J.E. Ong, J.H. Primavera, S.G. Salmo III, J.C. Sanciangco, S. Sukardjo, Y. Wang, and J.W.H. Yong, 2010: The loss of species: Mangrove extinction risk and geographic areas of global concern. PLOS ONE, 5(4), e10095, doi:10.1371/journal.pone.0010095.

Poloczanska, E.S., S.J. Hawkins, A.J. Southward, and M.T. Burrows, 2008: Modeling the response of populations of competing species to climate change. Ecology, 89(11), 3138-3149.

Poloczanska, E.S., S. Smith, L. Fauconnet, J. Healy, I.R. Tibbetts, M.T. Burrows, and A.J. Richardson, 2011: Little change in the distribution of rocky shore faunal communities on the Australian east coast after 50 years of rapid warming. Journal of Experimental Marine Biology and Ecology, 400(1-2), 145154.

Poloczanska, E.S., C.J. Brown, W.J. Sydeman, W. Kiessling, D.S. Schoeman, P.J. Moore, K. Brander, J.F. Bruno, L. Buckley, M.T. Burrows, C.M. Duarte, B.S. Halpern, J. Holding, C.V. Kappel, M.I. O'Connor, J.M. Pandolfi, C. Parmesan, F. Schwing, S.A. Thompson, and A.J. Richardson, 2013: Global imprint of climate change on marine life. Nature Climate Change, 3(10), 919-925.

Porter, J.R. and M. Gawith, 1999: Temperatures and the growth and development of wheat. A review. European Journal of Agronomy, 10(1), 23-36.

Pörtner, H.O., 2012: Integrating climate-related stressor effects on marine organisms: unifying principles linking molecule to ecosystem-level changes. Marine Ecology Progress Series, 470, 273-290.

Pörtner, H.O. and A.P. Farrell, 2008: Physiology and climate change. Science, 322(5902), 690-692.

Pörtner, H.O., C. Bock, R. Knust, G. Lannig, M. Lucassen, F.C. Mark, and F.J. Sartoris, 2008: Cod and climate in a latitudinal cline: physiological analyses of climate effects in marine fishes. Climate Research, 37(2-3), 253-270.

Post, E., M.C. Forchhammer, M.S. Bret-Harte, T.V. Callaghan, T.R. Christensen, B. Elberling, A.D. Fox, O. Gilg, D.S. Hik, T.T. Høye, R.A. Ims, E. Jeppesen, D.R. Klein, J. Madsen, A.D. McGuire, S. Rysgaard, D.E. Schindler, I. Stirling, M.P. Tamstorf, N.J.C. Tyler, R. van der Wal, J. Welker, P.A. Wookey, N.M. Schmidt, and P. Aastrup, 2009: Ecological dynamics across the Arctic associated with recent climate change. Science, 325(5946), 1355-1358.

Post, V. and E. Abarca, 2010: Preface: saltwater and freshwater interactions in coastal aquifers. Hydrogeology Journal, 18(1), 1-4.

Pouliotte, J., B. Smit, and L. Westerhoff, 2009: Adaptation and development: livelihoods and climate change in Subarnabad, Bangladesh. Climate and Development, 1(1), 31-46.

Pounds, J.A., M.R. Bustamante, L.A. Coloma, J.A. Consuegra, M.P.L. Fogden, P.N. Foster, E. La Marca, K.L. Masters, A. Merino-Viteri, R. Puschendorf, S.R. Ron, G.A. Sanchez-Azofeifa, C.J. Still, and B.E. Young, 2006: Widespread amphibian extinctions from epidemic disease driven by global warming. Nature, 439(7073), 161-167.

Poveda, G. and K. Pineda, 2009: Reassessment of Colombia's tropical glaciers retreat rates: are they bound to disappear during the 2010-2020 decade? Advances in Geosciences, 22, 107-116.
Powers, L.A., T.C. Johnson, J.P. Werne, I.S. Castañeda, E.C. Hopmans, J.S. Sinninghe Damsté, and S. Schouten, 2011: Organic geochemical records of environmental variability in Lake Malawi during the last 700 years, Part I: the TEX $\mathrm{X}_{86}$ temperature record. Palaeogeography, Palaeoclimatology, Palaeoecology, 303(1-4), 133-139.

Prathumratana, I., S. Sthiannopkao, and K. Woong Kim, 2008: The relationship of climatic and hydrological parameters to surface water quality in the lower Mekong River. Environment International, 34(6), 860-866.

Prioux, F., 2005: Recent demographic developments in France. Population-E, 60, 371 414.

Prowse, T.D. and K. Brown, 2010: Appearing and disappearing of lakes in the Arctic and their impacts on biodiversity. In: Arctic Biodiversity Trends 2010 - Selected Indicators of Change. Arctic Council, Conservation of Arctic Flora and Fauna Programme (CAFF), CAFF International Secretariat, Akureyri, Iceland, pp. 6870.

Pulido, F., 2007: Phenotypic changes in spring arrival: evolution, phenotypic plasticity, effects of weather and condition. Climate Research, 35, 5-23.

Quayle, W.C., L.S. Peck, H. Peat, J. Ellis-Evans, and P.R. Harrigan, 2002: Extreme responses to climate change in Antarctic lakes. Science, 295(5555), 645.

Raabe, E.A., L.C. Roy, and C.C. Mclvor, 2012: Tampa Bay coastal wetlands: nineteenth to twentieth century tidal marsh-to-mangrove conversion. Estuaries and Coasts, 35(5), 1145-1162.

Rabatel, A., B. Francou, A. Soruco, J. Gomez, B. Cáceres, J.L. Ceballos, R. Basantes, M. Vuille, J.E. Sicart, C. Huggel, M. Scheel, Y. Lejeune, Y. Arnaud, M. Collet, T. Condom, G. Consoli, V. Favier, V. Jomelli, R. Galarraga, P. Ginot, L. Maisincho, J. Mendoza, M. Ménégoz, E. Ramirez, P. Ribstein, W. Suarez, M. Villacis, and P. Wagnon, 2013: Current state of glaciers in the tropical Andes: a multi-century perspective on glacier evolution and climate change. The Cryosphere, 7, 81102.

Rahman, M., T. Lund, and I. Bryceson, 2011: Salinity impacts on agro-biodiversity in three coastal, rural villages of Bangladesh. Ocean \& Coastal Management, 54(6), 455-468.

Raitsos, D.E., G. Beaugrand, D. Georgopoulos, A. Zenetos, A.M. PancucciPapadopoulou, A. Theocharis, and E. Papathanassiou, 2010: Global climate change amplifies the entry of tropical species into the Eastern Mediterranean Sea. Limnology and Oceanography, 55(4), 1478-1484.

Rajeevan, M., A.K. Srivastava, Z. Lareef, and J. Revadekar, 2011: South Asia. In: State of the Climate in 2010 [Blunden, J., D.S. Arndt, and M.O. Baringer (eds.)]. Special Supplement to the Bulletin of the American Meteorological Society, 92(6), S217-S219.

Raleigh, C. and D. Kniveton, 2012: Come rain or shine: an analysis of conflict and climate variability in East Africa. Journal of Peace Research, 49, 51-64.

Ranasinghe, R. and M.J.F. Stive, 2009: Rising seas and retreating coastlines. Climatic Change, 97(3), 465-468.

Randolph, S.E. and D.J. Rogers, 2010: The arrival, establishment and spread of exotic diseases: patterns and predictions. 8(5), 361-371.

Rankey, E.C., 2011: Nature and stability of atoll island shorelines: Gilbert Island chain, Kiribati, equatorial Pacific. Sedimentology, 58(7), 1831-1859.

Rasheed, M.A. and R.K.F. Unsworth, 2011: Long-term climate-associated dynamics of a tropical seagrass meadow. Implications for the future. Marine Ecology Progress Series, 422, 93-103.

Raupach, M.R., J.G. Canadell, and C. Le Quéré, 2008: Anthropogenic and biophysical contributions to increasing atmospheric $\mathrm{CO}_{2}$ growth rate and airborne fraction. Biogeosciences, 5, 1601-1613.

Ravanel, L. and P. Deline, 2011: Climate influence on rockfalls in high-Alpine steep rockwalls. The north side of the Aiguilles de Chamonix (Mont Blanc massif) since the end of the 'Little Ice Age'. The Holocene, 21(2), 357-365.

Ravens, T.M., R.C. Thomas, K.A. Roberts, and P.H. Santschi, 2009: Causes of salt marsh erosion in Galveston Bay, Texas. Journal of Coastal Research, 25(2), 265-272.

Raxworthy, C.J., R.G. Pearson, N. Rabibisoa, A.M. Rakotondrazafy, J.B. Ramanamanjato, A.P. Raselimanana, S. Wu, R.A. Nussbaum, and D.A. Stone, 2008: Extinction vulnerability of tropical montane endemism from warming and upslope displacement: a preliminary appraisal for the highest massif in Madagascar. Global Change Biology, 14(8), 1703-1720.

Razumov, S.0., 2010: Permafrost as a factor of the dynamics of the coastal zone of the Russian East Arctic Seas. Oceanology, 50(2), 262-267.

Resurreccion, B.P., 2011: The Gender and Climate Debate. More of the Same or New Pathways of Thinking and Doing? Asia Security Initiative Policy Series Working Paper No.10, RSIS Center for Non-Traditional Security Studies, Singapore, 19 pp. 
Reusch, T.B., A. Ehlers, A. Hammerli, and B. Worm, 2005: Ecosystem recovery after climatic extremes enhanced by genotypic diversity. Proceedings of the National Academy of Sciences of the United States of America, 102(8), 2826-2831.

Rey, G., E. Jougla, A. Fouillet, G. Pavillon, P. Bessemoulin, P. Frayssinet, J. Clavel, and D. Hémon, 2007: The impact of major heat waves on all-cause and causespecific mortality in France from 1971 to 2003. International Archives of Occupational and Environmental Health, 80, 615-626.

Richardson, A.J., C.J. Brown, K. Brander, J.F. Bruno, L. Buckley, M.T. Burrows, C.M. Duarte, B.S. Halpern, O. Hoegh-Guldberg, J. Holding, C.V. Kappel, W. Kiessling, P.J. Moore, M.I. O'Connor, J.M. Pandolfi, C. Parmesan, D.S. Schoeman, F. Schwing, W.J. Sydeman, and E.S. Poloczanska, 2012: Climate change and marine life. Biology Letters, 8(6), 907-909.

Riordan, B., D. Verbyla, and D.A. McGuire, 2006: Shrinking ponds in subarctic Alaska based on 1950-2002 remotely sensed images. Journal of Geophysical Research, 111(G4), G02004, doi:10.1029/2005JG000150.

Rivadeneira, M.M. and M. Fernández, 2005: Shifts in southern endpoints of distribution in rocky intertidal species along the south-eastern Pacific coast. Journal of Biogeography, 32(2), 203-209.

Robards, M., 2013: Resilience of international policies to changing social-ecological systems: Arctic shipping in the Bering Strait. In: Arctic Resilience Interim Report. Arctic Council, Stockholm Environment Institute (SEI) and Stockholm Resilience Centre, Stockholm, Sweden, pp. 99-104.

Rocklöv, J., B. Forsberg, and K. Meister, 2009: Winter mortality modifies the heatmortality association the following summer. European Respiratory Journal, 33(2), 245-251.

Rodell, M., I. Velicogna, and J.S. Famiglietti, 2009: Satellite-based estimates of groundwater depletion in India. Nature, 460(7258), 999-1002.

Rodriguez-Oreggia, E., A. De La Fuente, R. De La Torre, and H.A. Moreno, 2013: Natural disasters, human development and poverty at the municipal level in Mexico. The Journal of Development Studies, 49(3), 442-455.

Roessig, J.M., C.M. Woodley, J.J. Cech, and L.J. Hansen, 2004: Effects of global climate change on marine and estuarine fishes and fisheries. Reviews in Fish Biology and Fisheries, 14, 251-275.

Romanovsky, V.E., D.S. Drozdov, N.G. Oberman, G.V. Malkova, A.L. Kholodov, S.S. Marchenko, N.G. Moskalenko, D.O. Sergeev, N.G. Ukraintseva, A.A. Abramov, D.A. Gilichinsky, and A.A. Vasiliev, 2010: Thermal state of permafrost in Russia. Permafrost and Periglacial Processes, 21(2), 136-155.

Romine, B.M., C.H. Fletcher, M.M. Barbee, T.R. Anderson, and L.N. Frazer, 2013: Are beach erosion rates and sea-level rise related in Hawaii? Global and Planetary Change, 108(9), 149-157.

Root, T.L., D.P. MacMynowski, M.D. Mastrandrea, and S.H. Schneider, 2005: Humanmodified temperatures induce species changes: joint attribution. Proceedings of the National Academy of Sciences of the United States of America, 102(21), 7465-7469.

Rosenzweig, C. and P. Neofotis, 2013: Detection and attribution of anthropogenic climate change impacts. Wiley Interdisciplinary Reviews: Climate Change, 4(2), 121-150.

Rosenzweig, C., F.N. Tubiello, R. Goldberg, E. Mills, and J. Bloomfield, 2002: Increased crop damage in the US from excess precipitation under climate change. Global Environmental Change, 12(3), 197-202.

Rosenzweig, C., G. Casassa, D.J. Karoly, A. Imeson, C. Liu, A. Menzel, S. Rawlins, T.L. Root, B. Seguin, and P. Tryjanowski, 2007: Assessment of observed changes and responses in natural and managed systems. In: Climate Change 2007: Impacts, Adaptation and Vulnerability. Contribution of Working Group II to the Fourth Assessment Report of the Intergovernmental Panel on Climate Change [Parry, M.L., O.F. Canziani, J.P. Palutikof, van der Linden, P. J., and C.E. Hanson (eds.)]. Cambridge University Press, Cambridge, U.K and New York, NY, USA, pp. 79-131.

Rosenzweig, C., D. Karoly, M. Vicarelli, P. Neofotis, Q. Wu, G. Casassa, A. Menzel, T.L. Root, N. Estrella, B. Seguin, P. Tryjanowski, C. Liu, S. Rawlins, and A. Imeson, 2008: Attributing physical and biological impacts to anthropogenic climate change. Nature, 453(7193), 353-357.

Ross, M.S., J.J. O'Brien, R.G. Ford, K. Zhang, and A. Morkill, 2009: Disturbance and the rising tide: the challenge of biodiversity management on low-island ecosystems. Frontiers in Ecology and the Environment, 7(9), 471-478.

Rothstein, H.R., A.J. Sutton, and M. Borenstein (eds.), 2005: Publication Bias in MetaAnalysis: Prevention, Assessment, and Adjustments. John Wiley \& Sons, Chichester, UK, $374 \mathrm{pp}$.

Rotton, J. and E.G. Cohn, 2001: Temperature, routine activities, and domestic violence: a reanalysis. Violence and Victims, 16(2), 203-215.
Rowland, J.C., C.E. Jones, G. Altmann, R. Bryan, B.T. Crosby, G.L. Geernaert, L.D. Hinzman, L.D. Kane, D.M. Lawrence, A. Mancino, P. Marsh, J.P. McNamara, V.E. Romanovsky, H. Toniolo, B.J. Travis, E. Trochim, and C.J. Wilson, 2010: Arctic landscapes in transition: responses to thawing permafrost. Eos, Transactions of the American Geophysical Union, 91(26), 229-236.

Rozell, D.J. and T.F. Wong, 2010: Effects of climate change on groundwater resources at Shelter Island, New York State, USA. Hydrogeology Journal, 18(7), 1657-1665.

Rubidge, E.M., W.B. Monahan, J.L. Parra, S.E. Cameron, and J.S. Brashares, 2011: The role of climate, habitat, and species co-occurrence as drivers of change in small mammal distributions over the past century. Global Change Biology, 17(2), 696-708.

Ruiz-Labourdette, D., M.F. Schmitz, and F.D. Pineda, 2013: Changes in tree species composition in Mediterranean Mountains under climate change: indicators for conservation planning. Ecological Indicators, 24, 310-323.

Saba, V.S., M.A.M. Friedrichs, M.E. Carr, D. Antoine, R.A. Armstrong, I. Asanuma, 0. Aumont, N.R. Bates, M.J. Behrenfeld, V. Bennington, L. Bopp, J. Bruggeman, E.T. Buitenhuis, M.J. Church, A.M. Ciotti, S.C. Doney, M. Dowell, J. Dunne, S. Dutkiewicz, W. Gregg, N. Hoepffner, K.J.W. Hyde, J. Ishizaka, T. Kameda, D.M. Karl, I. Lima, M.W. Lomas, J. Marra, G.A. McKinley, F. Melin, J.K. Moore, A. Morel, J. O'Reilly, B. Salihoglu, M. Scardi, T.J. Smyth, S.L. Tang, J. Tjiputra, J. Uitz, M. Vichi, K. Waters, T.K. Westberry, and A. Yool, 2010: Challenges of modeling depth-integrated marine primary productivity over multiple decades: a case study at BATS and HOT. Global Biogeochemical Cycles, 24(3), GB3020, doi:10.1029/2009GB003655.

Saldaña-Zorrilla, S. and K. Sandberg, 2009: Impact of climate-related disasters on human migration in Mexico: a spatial model. Climatic Change, 96(1-2), 97-118.

Salick, J. and N. Ross, 2009: Traditional peoples and climate change: introduction. Global Environmental Change, 19(2), 137-139.

Sander, J., J.F. Eichner, E. Faust, and M. Steuer, 2013: Rising variability in thunderstormrelated U.S. losses as a reflection of changes in large-scale thunderstorm forcing. Journal of the American Meteorological Society, 5(4), 317-331.

Sandin, S.A., J.E. Smith, E.E. DeMartini, E.A. Dinsdale, S.D. Donner, A.M. Friedlander, T. Konotchick, M. Malay, J.E. Maragos, and D. Obura, 2008: Baselines and degradation of coral reefs in the northern Line Islands. PLOS ONE, 3(2), e1548, doi:10.1371/journal.pone.0001548.

Sato, Y., D.G. Bourne, and B.L. Willis, 2009: Dynamics of seasonal outbreaks of black band disease in an assemblage of Montipora species at Pelorus Island (Great Barrier Reef, Australia). Proceedings of the Royal Society B, 276(1668), 27952803.

Saurral, R.I., V.R. Barros, and D.P. Lettenmaier, 2008: Land use impact on the Uruguay River discharge. Geophysical Research Letters, 35(12), L12401, doi:10.1029/ 2008 GL033707.

Schlenker, W. and M.J. Roberts, 2009: Nonlinear temperature effects indicate severe damages to U.S. crop yields under climate change. Proceedings of the National Academy of Sciences of the United States of America, 106(37), 15594-15598.

Schlenker, W., W.M. Hanemann, and A.C. Fisher, 2005: Will U.S. agriculture really benefit from global warming? Acounting for irrigation in the hedonic approach. The American Economic Review, 95(1), 395-406.

Schleupner, C., 2008: Evaluation of coastal squeeze and its consequences for the Caribbean island Martinique. Ocean \& Coastal Management, 51(5), 383-390.

Schmidt, S., C. Kemfert, and P. Höppe, 2010: The impact of socio-economics and climate change on tropical cyclone losses in the USA. Regional Environmental Change, $10(1), 13-26$.

Schmocker-Fackel, P. and F. Naef, 2010: More frequent flooding? Changes in flood frequency in Switzerland since 1850. Journal of Hydrology, 381(1), 1-8.

Schneider, D., C. Huggel, W. Haeberli, and R. Kaitna, 2011: Unraveling driving factors for large rock-ice avalanche mobility. Earth Surface Processes and Landforms, 36(14), 1948-1966.

Schneider, P. and S.J. Hook, 2010: Space observations of inland water bodies show rapid surface warming since 1985. Geophysical Research Letters, 37(22), L22405, doi:10.1029/2010GL045059.

Schwing, F.B., R. Mendelssohn, S.J. Bograd, J.E. Overland, M. Wang, and S. Ito, 2010: Climate change, teleconnection patterns, and regional processes forcing marine populations in the Pacific. Journal of Marine Systems, 79(3), 245-257.

Scott, D., B. Amelung, S. Becken, J.P. Ceron, G. Dubois, S. Gössling, P. Peeters, and M.C. Simpson, 2008: Climate Change and Tourism: Responding to Global Challenges. Report coordinated by UNWTO, UNEP, and WMO, Published by the World Tourism Organization (UNWTO), Madrid, Spain and the United Nations Environment Programme (UNEP), Paris, France, 256 pp. 
Senapathi, D., M.A.C. Nicoll, C. Teplitsky, C.G. Jones, and K. Norris, 2011: Climate change and the risks associated with delayed breeding in a tropical wild bird population. Proceedings of the Royal Society B, 278(1722), 3184-3190.

Seneviratne, S.I., N. Nicholls, D. Easterling, C.M. Goodess, S. Kanae, J. Kossin, Y. Luo, J. Marengo, K. McInnes, M. Rahimi, M. Reichstein, A. Sorteberg, C. Vera, and X. Zhang, 2012: Changes in climate extremes and their impacts on the natural physical environment. In: Managing the Risks of Extreme Events and Disasters to Advance Climate Change Adaptation. A Special Report of Working Groups I and II of the Intergovernmental Panel on Climate Change [Field, C.B., V. Barros, T.F. Stocker, D. Qin, D.J. Dokken, K.L. Ebi, M.D. Mastrandrea, K.J. Mach, G.-K. Plattner, S.K. Allen, M. Tignor, and P.M. Midgley (eds.)]. Cambridge University Press, Cambridge, UK and New York, NY, USA, pp. 109-230.

Sheffield, J. and E.F. Wood, 2007: Characteristics of global and regional drought, 1950-2000: analysis of soil moisture data from off-line simulation of the terrestrial hydrologic cycle. Journal of Geophysical Research: Atmospheres (1984-2012), 112(D17), D17115, doi:10.1029/2006JD008288.

Sheppard, C., M. Al-Husiani, F. Al-Jamali, F. Al-Yamani, R. Baldwin, J. Bishop, F. Benzoni, E. Dutrieux, N.K. Dulvy, S.R. Durvasula, D.A. Jones, R. Loughland, D. Medio, M. Nithyanandan, G.M. Pilling, I. Polikarpov, A.R. Price, S. Purkis, B. Riegl, M. Saburova, K.S. Namin, O. Taylor, S. Wilson, and K. Zainal, 2010: The Gulf: a young sea in decline. Marine Pollution Bulletin, 60(1), 13-38.

Shiklomanov, A.I., R.B. Lammers, M.A. Rawlins, L.C. Smith, and T.M. Pavelsky, 2007: Temporal and spatial variations in maximum river discharge from a new Russian data set. Journal of Geophysical Research, 112, G04S53, doi:10.1029/ $2006 J G 000352$.

Shrestha, U.B., S. Gautam, and K.S. Bawa, 2012: Widespread climate change in the Himalayas and associated changes in local ecosystems. PLOS ONE, 7(5), e36741, doi:10.1371/journal.pone.0036741.

Shriver, A.L., B.H. Yeo, K.O. Ting, M. Garcia, and M. Ahmed (eds.), 2006: Annotated bibliography on the economic effects of global climate change on fisheries. Prepared by the Information and Knowledge Group, World Fish Center for the Consultation on the Impact of Global Climate Change on Aquatic Resources, Food, and Income Security of Fishing-dependent Populations, San Diego, CA, USA, 24-25 August 2005, World Fish Center, Penang, Malaysia, 46 pp.

Simmons, K., D. Sutter, and R.A. Pielke Jr, 2013: Normalized tornado damage in the United States: 1950-2011. Environmental Hazards, 12(2), 132-147.

Slettebak, R.T., 2012: Don't blame the weather! Climate-related natural disasters and civil conflict. Journal of Peace Research, 49(1), 163-176.

Smith, J.B., J. Schellnhuber, M. Mirza, S. Fankhauser, R. Leemans, L. Erda, L. Ogallo, B. Pittock, R. Richels, C. Rosenzweig, U. Safriel, R.S.J. Tol, J. Weyant, and G. Yohe, 2001: Vulnerability to climate change and reasons for concern: a synthesis. In: Climate Change 2001: Impacts, Adaptation and Vulnerability . Contribution of Working Group II to the Third Assessment Report of the Intergovernmental Panel on Climate Change [McCarthy, J., O. Canziani, N. Leary, D. Dokken, and K. White (eds.)]. Cambridge University Press, Cambridge, UK and New York, NY, USA, pp. 913-967.

Smith, J.B., S.H. Schneider, M. Oppenheimer, G.W. Yohe, W. Hare, M.D. Mastrandrea, A. Patwardhan, I. Burton, J. Corfee-Morlot, C.H.D. Magadza, H.M. Füssel, A.B. Pittock, A. Rahman, A. Suarez, and J.P. Van Ypersele, 2009: Assessing dangerous climate change through an update of the Intergovernmental Panel on Climate Change (IPCC) 'Reasons for concern'. Proceedings of the National Academy of Sciences of the United States of America, 106(11), 4133-4137.

Smith, J.R., P. Fong, and R.F. Ambrose, 2006: Dramatic declines in mussel bed community diversity: response to climate change? Ecology, 87(5), 1153-1161.

Soja, A., N.M. Tchebakova, N.H.F. French, M.D. Flannigan, H.M. Shugart, B.J. Stocks, A.I. Sukhinin, E.I. Parfenova, Chapin III, F.S., and P.W. Stockhouse Jr., 2007: Climate-induced boreal forest change predictions vs. current observations. Global Planetary Change, 56, 274-296.

Somero, G.N., 2012: The physiology of global change: linking patterns to mechanisms. Annual Review of Marine Science, 4, 39-61.

Stahl, K., H. Hisdal, J. Hannaford, L. Tallaksen, H. Van Lanen, E. Sauquet, S. Demuth, M. Fendekova, and J. Jordar, 2010: Streamflow trends in Europe: evidence from a dataset of near-natural catchments. Hydrology and Earth System Sciences Discussions, 14, 2367-2382.

Stern, D.I., P.W. Gething, C.W. Kabaria, W.H. Temperley, A.M. Noor, E.A. Okiro, G.D. Shanks, R.W. Snow, and S.I. Hay, 2011: Temperature and malaria trends in highland East Africa. PLoS ONE, 6(9), e24524, doi:10.1371/journal.pone.0024524.

Stewart, I.T., D.R. Cayan, and M.D. Dettinger, 2005: Changes toward earlier streamflow timing across western North America. Journal of Climate, 18(8), 1136-1151.
Stige, L.C., G. Ottersen, K. Brander, K.S. Chan, and N.C. Stenseth, 2006: Cod and climate. Effect of the North Atlantic Oscillation on recruitment in the North Atlantic. Marine Ecology Progress Series, 325, 227-241.

Stige, L.C., G. Ottersen, P. Dalpadado, K.S. Chan, D. Hjermann, D.L. Lajus, N.A. Yaragina, and N.C. Stenseth, 2010: Direct and indirect climate forcing in a multi-species marine system. Proceedings of the Royal Society B, 277(1699), 3411-3420.

Stinson, G., W. Kurz, C. Smyth, E. Neilson, C. Dymond, J. Metsaranta, C. Boisvenue, G. Rampley, Q. Li, and T. White, 2011: An inventory-based analysis of Canada's managed forest carbon dynamics, 1990 to 2008. Global Change Biology, 17(6), 2227-2244.

Stock, C.A., M.A. Alexander, N.A. Bond, K.M. Brander, W.W.L. Cheung, E.N. Curchitser, T.L. Delworth, J.P. Dunne, S.M. Griffies, M.A. Haltuch, J.A. Hare, A.B. Hollowed, P. Lehodey, S.A. Levin, J.S. Link, K.A. Rose, R.R. Rykaczewski, J.L. Sarmiento, R.J. Stouffer, F.B. Schwing, G.A. Vecchi, and F.E. Werner, 2010: On the use of IPCCclass models to assess the impact of climate on Living Marine Resources. Progress in Oceanography, 88(1), 1-27.

Stoffel, M. and C. Huggel, 2012: Effects of climate change on mass movements in mountain environments. Progress in Physical Geography, 36(6), 421-439.

Stokes, C.R., M. Shahgedanova, I.S. Evans, and V.V. Popovnin, 2013: Accelerated loss of alpine glaciers in the Kodar Mountains, south-eastern Siberia. Global and Planetary Change, 101(2), 82-96.

Stokes, D.J., T.R. Healy, and P.J. Cooke, 2010: Expansion dynamics of monospecific, temperate mangroves and sedimentation in two embayments of a barrierenclosed lagoon, Tauranga Harbour, New Zealand. Journal of Coastal Research, 26(1), 113-122.

Stolper, D.A., N.P. Revsbech, and D.E. Canfield, 2010: Aerobic growth at nanomolar oxygen concentrations. Proceedings of the National Academy of Sciences of the United States of America, 107(44), 18755-18760.

Stone, D., M. Auffhammer, M. Carey, G. Hansen, C. Huggel, W. Cramer, D. Lobell, U. Molau, A. Solow, L. Tibig, and G. Yohe, 2013: The challenge to detect and attribute effects of climate change on human and natural systems. Climatic Change, 121(2), 381-395.

Storey, D. and S. Hunter, 2010: Kiribati: an environmental 'perfect storm'. Australian Geographer, 41(2), 167-181.

Stramma, L., G.C. Johnson, J. Sprintall, and V. Mohrholz, 2008: Expanding oxygenminimum zones in the tropical oceans. Science, 320(5876), 655-658.

Stramma, L., S. Schmidtko, L.A. Levin, and G.C. Johnson, 2010: Ocean oxygen minima expansions and their biological impacts. Deep-Sea Research Part I: Oceanographic Research Papers, 57(4), 587-595.

Stramma, L., E.D. Prince, S. Schmidtko, J. Luo, J.P. Hoolihan, M. Visbeck, D.W.R. Wallace, P. Brandt, and A. Kortzinger, 2012: Expansion of oxygen minimum zones may reduce available habitat for tropical pelagic fishes. Nature Climate Change, 2(1), 33-37.

Strong, A.E., G. Liu, W. Skirving, and C.M. Eakin, 2011: NOAA's Coral Reef Watch program from satellite observations. Annals of GIS, 17(2), 83-92.

Šumilo, D., A. Bormane, L. Asokliene, V. Vasilenko, I. Golovljova, T. Avsic-Zupanc, Z. Hubalek, and S.E. Randolph, 2008: Socio-economic factors in the differential upsurge of tick-borne encephalitis in Central and Eastern Europe. Reviews in Medical Virology, 18(2), 81-95.

Šumilo, D., A. Bormane, V. Vasilenko, I. Golovljova, L. Asokliene, M. Žygutiene, and S. Randolph, 2009: Upsurge of tick-borne encephalitis in the Baltic States at the time of political transition, independent of changes in public health practices. Clinical Microbiology and Infection, 15(1), 75-80.

Sunday, J.M., A.E. Bates, and N.K. Dulvy, 2012: Thermal tolerance and the global redistribution of animals. Nature Climate Change, 2(9), 686-690.

Supit, I., C.A. van Diepen, A.J.W. de Wit, P. Kabat, B. Baruth, and F. Ludwig, 2010: Recent changes in the climatic yield potential of various crops in Europe. Agricultural Systems, 103, 683-694.

Svensson, C., J. Hannaford, Z.W. Kundzewicz, and T.J. Marsh, 2006: Trends in river floods: why is there no clear signal in observations? IAHS Publications-Series of Proceedings and Reports, 305, 1-18.

Sydeman, W.J. and S.J. Bograd, 2009: Marine ecosystems, climate, and phenology: introduction. Marine Ecology Progress Series, 393, 185-188.

Syvitski, J.P.M., C.J. Vörösmarty, A.J. Kettner, and P. Green, 2005: Impact of humans on the flux of terrestrial sediment to the global coastal ocean. Science, 308(5720), 376-380.

Takasuka, A., Y. Oozeki, and I. Aoki, 2007: Optimal growth temperature hypothesis. Why do anchovy flourish and sardine collapse or vice versa under the same ocean regime? Canadian Journal of Fisheries and Aquatic Sciences, 64(5), 768-776. 
Takasuka, A., Y. Oozeki, and H. Kubota, 2008: Multi-species regime shifts reflected in spawning temperature optima of small pelagic fish in the western North Pacific. Marine Ecology Progress Series, 360, 211-217.

Tamisiea, M.E. and J.X. Mitrovica, 2011: The moving boundaries of sea level change: understanding the origins of geographic variability. Oceanography, 24, 24-39.

Tan, A., J.C. Adam, and D.P. Lettenmaier, 2011: Change in spring snowmelt timing in Eurasian Arctic rivers. Journal of Geophysical Research, 116(D3), D03101, doi:10.1029/2010JD014337.

Tao, F., M. Yokozawa, Y. Xu, Y. Hayashi, and Z. Zhang, 2006: Climate changes and trends in phenology and yields of field crops in China, 1981-2000. Agricultural and Forest Meteorology, 138(1), 82-92.

Tao, F., M. Yokozawa, J. Liu, and Z. Zhang, 2008: Climate-crop yield relationships at provincial scales in China and the impacts of recent climate trends. Climate Research, 38(1), 83-94.

Tao, F., Z. Zhang, S. Zhang, Z. Zhu, and W. Shi, 2012: Response of crop yields to climate trends since 1980 in China. Climate Research, 54, 233-247.

Tape, K.D., M. Sturm, and C. Racine, 2006: The evidence for shrub expansion in northern Alaska and the Pan-Arctic. Global Change Biology, 12(4), 686-702.

Tape, K.D., M. Hallinger, J.M. Welker, and R.W. Ruess, 2012: Landscape heterogeneity of shrub expansion in arctic Alaska. Ecosystems, 15(5), 1-14.

Tasker, M.L., 2008: The Effect of Climate Change on the Distribution and Abundance of Marine Species in the OSPAR Maritime Area. ICES Cooperative Research Report No. 293, International Council for the Exploration of the Sea (ICES), Copenhagen, Denmark, 45 pp.

Taylor, R.G., L. Mileham, C. Tindimugaya, and L. Mwebembezi, 2009: Recent glacial recession and its impact on alpine riverflow in the Rwenzori Mountains of Uganda. Journal of African Earth Sciences, 55(3-4), 205-213.

Taylor, R.G., B. Scanlon, P. Doll, M. Rodell, R. Van Beek, Y. Wada, L. Longuevergne, M. Leblanc, J.S. Famiglietti, M. Edmunds, L. Konikow, T.R. Green, J. Chen, M. Taniguchi, M.F.P. Bierkens, A. MacDonald, Y. Fan, R.M. Maxwell, Y. Yechieli, J.J. Gurdak, D.M. Allen, M. Shamsudduha, K. Hiscock, P.J.F. Yeh, I. Holman, and H. Treidel, 2013: Ground water and climate change. Nature Climate Change, 3(4), 322-329.

Terrier, S., F. Jordan, A. Schleiss, W. Haeberli, C. Huggel, and M. Künzler, 2011: Optimized and adaptated hydropower management considering glacier shrinkage in the Swiss Alps. In: Dams and Reservoirs under Changing Challenges [Schleiss, A. and R.M. Boes (eds.)]. Proceedings of the International Symposium on Dams and Reservoirs under Changing Challenges: $79^{\text {th }}$ Annual Meeting of ICOLD, Swiss Committee on Dams, Lucerne, Switzerland, 1 June, 2011, CRC Press, Taylor \& Francis Group, London, UK, pp. 497-508.

Terry, J.P. and A.C. Falkland, 2010: Responses of atoll freshwater lenses to storm-surge overwash in the Northern Cook Islands. Hydrogeology Journal, 18(3), 749-759.

Thaxter, C.B., A.C. Joys, R.D. Gregory, S.R. Baillie, and D.G. Noble, 2010: Hypotheses to explain patterns of population change among breeding bird species in England. Biological Conservation, 143(9), 2006-2019.

Theisen, O.M., 2012: Climate clashes? Weather variability, land pressure, and organized violence in Kenya, 1989-2004. Journal of Peace Research, 49(1), 81-96.

Theisen, O.M., H. Holtermann, and H. Buhaug, 2011: Climate wars? Assessing the claim that drought breeds conflict. International Security, 36(3), 79-106.

Thiaw, W.M., A.C. Kruger, D.M. Patricio, L. Njau, M. Kadi, and S. Tinni, 2008: Southern Africa. In: State of the Climate in 2007 [Levinson, D.H. and J.H. Lawrimore (eds.)]. Special Supplement to the Bulletin of the American Meteorological Society, 89(7), S109-S111.

Thomas, D.S.G., C. Twyman, H. Osbahr, N. Adger, and B. Hewitson, 2007: Adaptation to climate change and variability: farmer responses to intra-seasonal precipitation trends in South Africa. Climatic Change, 83(3), 301-322.

Thorburn, P.J., M.J. Robertson, B.E. Clothier, V.O. Snow, E. Charmley, J. Sanderman, E. Teixeira, R.A. Dynes, A. Hall, H. Brown, S.M. Howden, and M. Battaglia, 2012: Australia and New Zealand perspectives on climate change and agriculture. In: Handbook of Climate Change and Agroecosystems: Global and Regional Aspects and Implications [Rosenzweig, C. and D. Hillel (eds.)]. American Society of Agronomy and Imperial College Press, New York, NY, USA, pp. 107-142.

Tian, Y., H. Kidokoro, T. Watanabe, Y. Igeta, H. Sakaji, and S. Ino, 2012: Response of yellowtail, Seriola quinqueradiata, a key large predatory fish in the Japan Sea, to sea water temperature over the last century and potential effects of global warming. Journal of Marine Systems, 91(1), 1-10.

Tierney, J.E., M.T. Mayes, N. Meyer, C. Johnson, P.W. Swarzenski, A.S. Cohen, and J.M. Russell, 2010: Late-twentieth-century warming in Lake Tanganyika unprecedented since AD 500. Nature Geoscience, 3, 422-425.
Tingley, M.W., W.B. Monahan, S.R. Beissinger, and C. Moritz, 2009: Birds track their Grinnellian niche through a century of climate change. Proceedings of the National Academy of Sciences of the United States of America, 106(Suppl. 2), 19637-19643.

Tingley, M.W., M.S. Koo, C. Moritz, A.C. Rush, and S.R. Beissinger, 2012: The push and pull of climate change causes heterogeneous shifts in avian elevational ranges. Global Change Biology, 18(11), 3279-3290.

Tol, R.S.J. and S. Wagner, 2010: Climate change and violent conflict in Europe over the last millennium. Climatic Change, 99(1-2), 65-79.

Toniolo, H., P. Kodial, L.D. Hinzman, and K. Yoshikawa, 2009: Spatio-temporal evolution of a thermokarst in Interior Alaska. Cold Regions Science and Technology, 56(1), 39-49.

Trathan, P.N., P.T. Fretwell, and B. Stonehouse, 2011: First recorded loss of an emperor penguin colony in the recent period of Antarctic regional warming: implications for other colonies. PLOS ONE, 6(2), e14738, doi:10.1371/journal.pone.0014738.

Trenberth, K.E., 2011: Attribution of climate variations and trends to human influences and natural variability. Wiley Interdisciplinary Reviews: Climate Change, 2(6), 925-930.

Trivelpiece, W.Z., J.T. Hinke, A.K. Miller, C.S. Reiss, S.G. Trivelpiece, and G.M. Watters, 2011:Variability in krill biomass links harvesting and climate warming to penguin population changes in Antarctica. Proceedings of the National Academy of Sciences of the United States of America, 108(18), 7625-7628.

Tschakert, P., R. Tutu, and A. Alcaro, 2013: Embodied experiences of environmental and climatic changes in landscapes of everyday life in Ghana. Emotion, Space and Society, 7(May 2013), 13-25.

Turetsky, M.R., E.S. Kane, J.W. Harden, R.D. Ottmar, K.L. Manies, E. Hoy, and E.S. Kasischke, 2010: Recent acceleration of biomass burning and carbon losses in Alaskan forests and peatlands. Nature Geoscience, 4(1), 27-31.

Uhlmann, M., O. Korup, C. Huggel, L. Fischer, and J.S. Kargel, 2013: Supra-glacial deposition and flux of catastrophic rock-slope failure debris, south-central Alaska. Earth Surface Processes and Landforms, 38(6), 675-682.

Vadadi-Fülöp, C., C. Sipkay, G. Mészáros, and L. Hufnagel, 2012: Climate change and freshwater zooplankton: what does it boil down to? Aquatic Ecology, 46(4), 501-519.

Valt, M. and P. Cianfarra, 2010: Recent snow cover variability in the Italian Alps. Cold Regions Science and Technology, 64(2), 146-157.

Van Bogaert, R., K. Haneca, J. Hoogesteger, C. Jonasson, M. De Dapper, and T.V. Callaghan, 2011: A century of tree line changes in sub-Arctic Sweden shows local and regional variability and only a minor influence of $20^{\text {th }}$ century climate warming. Journal of Biogeography, 38(5), 907-921.

Van den Honert, R.C. and J. McAneney, 2011: The 2011 Brisbane floods: causes, impacts and implications. Water, 3(4), 1149-1173.

Van Dijk, J., N.D. Sargison, F. Kenyon, and P.J. Skuce, 2010: Climate change and infectious disease: helminthological challenges to farmed ruminants in temperate regions. Animal, 4(3), 377-392.

Van Dingenen, R., F.J. Dentener, F. Raes, M.C. Krol, L. Emberson, and J. Cofala, 2009: The global impact of ozone on agricultural crop yields under current and future air quality legislation. Atmospheric Environment, 43(3), 604-2310.

Van Mantgem, P.J., N.L. Stephenson, J.C. Byrne, L.D. Daniels, J.F. Franklin, P.Z. Fulé, M.E. Harmon, A.J. Larson, J.M. Smith, and A.H. Taylor, 2009: Widespread increase of tree mortality rates in the western United States. Science, 323(5913), 521 524.

Van Oldenborgh, G.J., A. Van Urk, and M. Allen, 2012: The absence of a role of climate change in the 2011 Thailand floods. In: Explaining extreme events of 2011 from a climate perspective [Peterson, T.C., P.A. Stone, and S. Herring (eds.)]. Bulletin of the American Meteorological Society, 93(7), 1047-1049.

Vaquer-Sunyer, R. and C.M. Duarte, 2011: Temperature effects on oxygen thresholds for hypoxia in marine benthic organisms. Global Change Biology, 17(5), 17881797.

Véran, S., O. Gimenez, E. Flint, W.L. Kendall, P.F.J. Doherty, and J.D. Lebreton, 2007: Quantifying the impact of longline fisheries on adult survival in the black-footed albatross. Journal of Applied Ecology, 44(5), 942-952.

Veron, J.E., O. Hoegh-Guldberg, T.M. Lenton, J.M. Lough, D.O. Obura, P. Pearce-Kelly, C.R. Sheppard, M. Spalding, M.G. Stafford-Smith, and A.D. Rogers, 2009: The coral reef crisis: the critical importance of $<350 \mathrm{ppm} \mathrm{CO}$. Marine Pollution Bulletin, 58(10), 1428-1436.

Vilímek, V., M.L. Zapata, J. Klimeš, Z. Patzelt, and N. Santillán, 2005: Influence of glacial retreat on natural hazards of the Palcacocha Lake area, Peru. Landslides, 2(2), 107-115. 
Villarini, G., F. Serinaldi, J.A. Smith, and W.F. Krajewski, 2009: On the stationarity of annual flood peaks in the continental United States during the $20^{\text {th }}$ century. Water Resources Research, 45(8), W08417, doi:10.1029/2008WR007645.

Voigt, T., H.M. Füssel, I. Gärtner-Roer, C. Huggel, C. Marty, and M. Zemp (eds.), 2011: Impacts of Climate Change on Snow, Ice, and Permafrost in Europe: Observed Trends, Future Projections, and Socio-Economic Relevance. ETC/ACC Technical Paper 2010/13, Prepared by the European Topic Centre on Air and Climate Change (ETC/ACC) with the Department of Geography of the University of Zuerich, the WSL Institute for Snow and Avalanche Research (SLF) Davos and others for the European Environment Agency (EEA), ETC/ACC, Bilthoven, Netherlands, $117 \mathrm{pp}$.

Vongraven, D. and E. Richardson, 2011: Biodiversity - status and trends of polar bears. In: Arctic Report Card: Update for 2011 [Richter-Menge, J., M.O. Jeffries, and J.E. Overland (eds.)]. National Oceanic and Atmospheric Administration (NOAA) Arctic Research Program, NOAA Office of Oceanic and Atmospheric Research, Silver Spring, MD, USA, pp. 75-78, www.arctic.noaa.gov/reportcard.

Vorogushyn, S. and B. Merz, 2012: What drives flood trends along the Rhine River: climate or river training? Hydrology and Earth System Sciences Discussions, 9, 13537-13567.

Vuille, M., B. Francou, P. Wagnon, I. Juen, G. Kaser, B.G. Mark, and R.S. Bradley, 2008: Climate change and tropical Andean glaciers: past, present and future. Earth Science Reviews, 89(3-4), 79-96.

Walker, D.A., H. Epstein, M. Raynolds, P. Kuss, M. Kopecky, G.V. Frost, F. Daniëls, M. Leibman, N. Moskalenko, and G. Matyshak, 2012: Environment, vegetation and greenness (NDVI) along the North America and Eurasia Arctic transects. Environmental Research Letters, 7(1), 015504, doi:10.1088/1748-9326/7/1/ 015504.

Walker, M.D., C.H. Wahren, R.D. Hollister, G.H.R. Henry, L.E. Ahlquist, J.M. Alatalo, M.S. Bret-Harte, M.P. Calef, T.V. Callaghan, A.B. Carroll, H.E. Epstein, I.S. Jónsdótttir J.A. Klein, B. Magnússon, U. Molau, S.F. Oberbauer, S.P. Rewa, C.H. Robinson, G.R. Shaver, K.N. Suding, C.C. Thompson, A. Tolvanen, Ø. Totland, P.L. Turner, C.E. Tweedie, P.J. Webber, and P.A. Wookey, 2006: Plant community responses to experimental warming across the tundra biome. Proceedings of the National Academy of Sciences of the United States of America, 103(5), 1342-1346.

Walther, G., A. Roques, P.E. Hulme, M.T. Sykes, P. Pyšek, I. Kühn, M. Zobel, S. Bacher, Z. Botta-Dukát, H. Bugmann, B. Czúcz, J. Dauber, T. Hickler, V. Jarošík, M. Kenis, S. Klotz, D. Minchin, M. Moora, W. Nentwig, J. Ott, V.E. Panov, B. Reineking, C. Robinet, V. Semenchenko, W. Solarz, W. Thuiller, M. Vilà, K. Vohland, and J. Settele, 2009: Alien species in a warmer world: risks and opportunities. Trends in Ecology \& Evolution, 24(12), 686-693.

Wang, A., D.P. Lettenmaier, and J. Sheffield, 2011: Soil moisture drought in China, 1950-2006. Journal of Climate, 24(13), 3257-3271.

Wang, G., S. Sun, and R. Mei, 2011: Vegetation dynamics contributes to the multidecadal variability of precipitation in the amazon region. Geophysical Research Letters, 38(19), L19703, doi:10.1029/2011GL049017.

Wang, M., J.E. Overland, D.B. Percival, and H.O. Mofjeld, 2006: Change in the arctic influence on Bering Sea climate during the twentieth century. International Journal of Climatology, 26(4), 531-539.

Wang, S.-Y., R.E. Davies, W.-R. Huang, and R.R. Gillies, 2011: Pakistan's two-stage monsoon and links with the recent climate change. Journal of Geophysical Research: Atmospheres, 116(D16), D16114, doi:10.1029/2011JD015760.

Wassenaar, T., P. Gerber, P.H. Verburg, M. Rosales, M. Ibrahim, and H. Steinfeld, 2007: Projecting land use changes in the Neotropics: the geography of pasture expansion into forest. Global Environmental Change: Human and Policy Dimensions, 17(1), 86-104.

Wassmann, P. and T.M. Lenton, 2012: Arctic tipping points in a Earth system perspective. Ambio, 41, 1-9.

Wassmann, R., S.V.K. Jagadish, S. Heuer, A. Ismail, E. Redona, R. Serraj, R.K. Singh, G. Howell, H. Pathak, and K. Sumfleth, 2009: Chapter 2: Climate change affecting rice production: the physiological and agronomic basis for possible adaptation strategies. In: Advances in Agronomy, Vol. 101 [Sparks, D.L. (ed.)]. Elsevier Science and Technology/Academic Press, Waltham, MA, USA, pp. 59-122.

Weatherhead, E., S. Gearheard, and R.G. Barry, 2010: Changes in weather persistence: insight from Inuit knowledge. Global Environmental Change, 20(3), 523-528.

Webb, A.P., 2006: Analysis of Coastal Change and Erosion -Tebunginako Village, Abaiang, Kiribati. EU EDF 8/9 - SOPAC Project Report 53: Reducing Vulnerability of Pacific ACP States, South Pacific Applied Geoscience Commission (SOPAC), SOPAC Secretariat, Suva, Fiji, 10 pp.
Webb, A.P., 2007: Assessment of Salinity of Groundwater in Swamp Taro (Cyrtosperma Chamissonis) "Pulaka" Pits in Tuvalu. EU EDF8 - SOPAC Project Report 75: Reducing Vulnerability of Pacific ACP States, South Pacific Applied Geoscience Commission (SOPAC), SOPAC Secretariat, Suva, Fiji, 37 pp.

Webb, L.B., P.H. Whetton, J. Bhend, R. Darbyshire, P.R. Briggs, and E.W.R. Barlow, 2012: Earlier wine-grape ripening driven by climatic warming and drying and management practices. Nature Climate Change, 2(4), 259-264.

Webster, P.J., V.E. Toma, and H.M. Kim, 2011: Were the 2010 Pakistan floods predictable? Geophysical Research Letters, 38(4), L04806, doi:10.1029/ 2010GL046346.

Wegren, S.K., 2011: Food security and Russia's 2010 drought. Eurasian Geography and Economics, 52, 140-156.

Welch, J.R., J.R. Vincent, M. Auffhammer, P.F. Moya, A. Dobermann, and D. Dawe, 2010: Rice yields in tropical/subtropical Asia exhibit large but opposing sensitivities to minimum and maximum temperatures. Proceedings of the National Academy of Sciences of the United States of America, 107(33), 14562-14567.

Welker, C. and E. Faust, 2013: Tropical cyclone-related socio-economic losses in the western North Pacific region. Natural Hazards and Earth System Sciences, 13, 115-124.

Welp, L., J. Randerson, and H. Liu, 2007: The sensitivity of carbon fluxes to spring warming and summer drought depends on plant functional type in boreal forest ecosystems. Agricultural and Forest Meteorology, 147(3), 172-185.

Wernberg, T., B.D. Russell, P.J. Moore, S.D. Ling, D.A. Smale, A. Campbell, M.A. Coleman, P.D. Steinberg, G.A. Kendrick, and S.D. Connell, 2011 a: Impacts of climate change in a global hotspot for temperate marine biodiversity and ocean warming. Journal of Experimental Marine Biology and Ecology, 400(1), 7-16.

Wernberg, T., B.D. Russell, M.S. Thomsen, C.F.D. Gurgel, C.J.A. Bradshaw, E.S Poloczanska, and S.D. Connell, 2011 b: Seaweed communities in retreat from ocean warming. Current Biology, 21(21), 1828-1832.

Wernberg, T., D.A. Smale, F. Tuya, M.S. Thomsen, T.J. Langlois, T. de Bettignies, S. Bennett, and C.S. Rousseaux, 2012: An extreme climatic event alters marine ecosystem structure in a global biodiversity hotspot. Nature Climate Change, 3(1), 78-82.

Westerling, A.L., H.G. Hidalgo, D.R. Cayan, and T.W. Swetnam, 2006: Warming and earlier spring increases Western U.S. forest fire activity. Science, 313(5789), 940-943.

Westra, S., L.V. Alexander, and F.W. Zwiers, 2013: Global increasing trends in annual maximum daily precipitation. Journal of Climate, 26(11), 3904-3918.

Wethey, D.S. and S.A. Woodin, 2008: Ecological hindcasting of biogeographic responses to climate change in the European intertidal zone. Hydrobiologia, 606(1), 139-151.

Weyhenmeyer, G.A., D.M. Livingstone, M. Meili, O. Jensen, B. Benson, and J.J. Magnuson, 2011: Large geographical differences in the sensitivity of icecovered lakes and rivers in the Northern Hemisphere to temperature changes. Global Change Biology, 17(1), 268-275.

Wezel, A. and A.M. Lykke, 2006: Woody vegetation change in Sahelian West Africa: evidence from local knowledge. Environment, Development, and Sustainability, 8, 553-567.

WGMS, 2008: Global Glacier Changes. Facts and Figures [Zemp, M., I. Roer, A. Kääb, M. Hoelzle, F. Paul, and W. Haeberli (eds.)]. World Glacier Monitoring Service (WGMS), Published by the United Nations Environment Programme (UNEP), Nairobi, Kenya and the World Glacier Monitoring Service (WGMS), University of Zurich, Zurich, Switzerland, $88 \mathrm{pp}$.

White, I. and T. Falkland, 2010: Management of freshwater lenses on small Pacific islands. Hydrogeology Journal, 18(1), 227-246.

White, I., T. Falkland, T. Metutera, E. Metai, M. Overmars, P. Perez, and A. Dray, 2007a: Climatic and human influences on groundwater in low atolls. Vadose Zone Journal, 6(3), 581-590.

White, I., T. Falkland, P. Perez, A. Dray, T. Metutera, E. Metai, and M. Overmars, 2007b: Challenges in freshwater management in low coral atolls. Journal of Cleaner Production, 15(16), 1522-1528.

White, S., 2011: The Climate of Rebellion in the Early Modern Ottoman Empire. Cambridge University Press, New York, NY, USA, 354 pp.

Wilbanks, T.J., P. Romero Lankao, M. Bao, F. Berkhout, S. Cairncross, J.-P. Ceron, M. Kapshe, R. Muir-Wood, and R. Zapata-Marti, 2007: Industry, settlement and society. In: Climate Change 2007: Impacts, Adaptation and Vulnerability. Contribution of Working Group II to the Fourth Assessment Report of the Intergovernmental Panel on Climate Change [Parry, M.L., O.F. Canziani, J.P. Palutikof, P.Van der Linden, and C.E. Hanson (eds.)]. Cambridge University Press, Cambridge, UK and New York, NY, USA, pp. 357-390. 
Wilkinson, C., O. Linden, H. Cesar, G. Hodgson, J. Rubens, and A.E. Strong, 1999: Ecological and socioeconomic impacts of 1998 coral mortality in the Indian Ocean: an ENSO impact and a warning of future change? Ambio, 28(2), 188196.

Williams, A.P., C.D. Allen, A.K. Macalady, D. Griffin, C.A. Woodhouse, D.M. Meko, T.W. Swetnam, S.A. Rauscher, R. Seager, and H.D. Grissino-Mayer, 2012: Temperature as a potent driver of regional forest drought stress and tree mortality. Nature Climate Change, 3, 292-297.

Wohling, M., 2009: The problem of scale in indigenous knowledge: a perspective from Northern Australia. Ecology and Society, 14(1), 1-14.

Wolken, J.M., T.N. Hollingsworth, T.S. Rupp, F.S. Chapin, S.F. Trainor, T.M. Barrett, P.F. Sullivan, A.D. McGuire, E.S. Euskirchen, P.E. Hennon, E.A. Beever, J.S. Conn, L.K. Crone, D.V. D'Amore, N. Fresco, T.A. Hanley, K. Kielland, J.J. Kruse, T. Patterson, E.A.G. Schuur, D.L. Verbyla, and J. Yarie, 2011: Evidence and implications of recent and projected climate change in Alaska's forest ecosystems. Ecosphere, 2(11), 124, doi:10.1890/ES11-00288.1.

Woodworth, P.L., M. Menéndez, and W. Roland Gehrels, 2011: Evidence for centurytimescale acceleration in mean sea levels and for recent changes in extreme sea levels. Surveys in Geophysics, 32(4), 603-618.

Wootton, J.T., C.A. Pfister, and J.D. Forester, 2008: Dynamic patterns and ecological impacts of declining ocean $\mathrm{pH}$ in a high-resolution multi-year dataset. Proceedings of the National Academy of Sciences of the United States of America, 105(48), 18848-18853.

World Bank, 2012: Thai Flood 2011: Rapid Assessment for Resilient Recovery and Reconstruction Planning. Working Paper No. 69822, Vol. 2, The International Bank for Reconstruction and Development / The World Bank, World Bank Publishing, Washington, DC, USA, 377 pp., documents.worldbank.org/curated/en/ docsearch/report/69822.

World Bank and ADB, 2010: Pakistan Floods 2010: Preliminary Floods Damage and Needs Assessment. Asian Development Bank (ADB) and the World Bank, Islamabad, Pakistan, $184 \mathrm{pp}$.

Wulf, H., B. Bookhagen, and D. Scherler, 2012: Climatic and geologic controls on suspended sediment flux in the Sutlej River Valley, western Himalaya. Hydrology and Earth System Sciences, 16(7), 2193-2217.

Xu, J., R.E. Grumbine, A. Shrestha, M. Eriksson, X. Yang, Y. Wang, and A. Wilkes, 2009: The melting Himalayas: cascading effects of climate change on water, biodiversity, and livelihoods. Conservation Biology, 23(3), 520-530.

Xu, K., J.D. Milliman, Z. Yang, and H. Xu, 2008: Climatic and anthropogenic impacts on water and sediment discharges from the Yangtze River (Changjiang), 19502005. In: Large Rivers: Geomorphology and Management [Gupta, A. (ed.)]. John Wiley \& Sons, Chichester, UK, pp. 609-626.

Xu, L., R.B. Myneni, F.S. Chapin III, T.V. Callaghan, J.E. Pinzon, C.J. Tucker, Z. Zhu, J. Bi, P. Ciais, H. Tommervik, E.S. Euskirchen, B.C. Forbes, S.L. Piao, B.T. Anderson, S. Ganguly, R.R. Nemani, S.J. Goetz, P.S.A. Beck, A.G. Bunn, C. Cao, and J.C. Stroeve, 2013: Temperature and vegetation seasonality diminishment over northern lands. Nature Climate Change, 3, 581-586.

Yamano, H., H. Kayanne, T. Yamaguchi, Y. Kuwhara, H. Yokoki, H. Shimazaki, and M. Chicamori, 2007: Atoll island vulnerability to flooding and inundation revealed by historical reconstruction. Fongafale Island, Funafuti Atoll, Tuvalu. Global and Planetary Change, 57(3-4), 407-416.
Yamano, H., K. Sugihara, and K. Nomura, 2011: Rapid poleward range expansion of tropical reef corals in response to rising sea surface temperatures. Geophysical Research Letters, 38(4), L04601, doi:10.1029/2010GL046474.

Yang, Z., J. Gao, L. Zhao, X. Xu, and H. Ouyang, 2013: Linking thaw depth with soil moisture and plant community composition: effects of permafrost degradation on alpine ecosystems on the Qinghai-Tibet Plateau. Plant and Soil, 367(1-2), 687-700.

Yao, T., L. Thompson, W. Yang, W. Yu, Y. Gao, X. Guo, X. Yang, K. Duan, H. Zhao, B. Xu, J. Pu, A. Lu, Y. Xiang, D.B. Kattel, and D. Joswiak, 2012: Different glacier status with atmospheric circulations in Tibetan Plateau and surroundings. Nature Climate Change, 2(9), 663-667.

Yli-Panula, E., D.B. Fekedulegn, B.J. Green, and H. Ranta, 2009: Analysis of airborne betula pollen in Finland; a 31-year perspective. International Journal of Environmental Research and Public Health, 6(6), 1706-1723.

You, L., M.W. Rosegrant, S. Wood, and D. Sun, 2009: Impact of growing season temperature on wheat productivity in China. Agricultural and Forest Meteorology, 149(6), 1009-1014.

Zemp, M., M. Hoelzle, and W. Haeberli, 2009: Six decades of glacier mass-balance observations: a review of the worldwide monitoring network. Annals of Glaciology, 50(50), 101-111.

Zhang, D.D., H.F. Lee, C. Wang, B. Li, Q. Pei, J. Zhang, and Y. An, 2011: The causality analysis of climate change and large-scale human crisis. Proceedings of the National Academy of Sciences of the United States of America, 108(42), 1729617301.

Zhang, G.H., S.H. Fu, W.H. Fang, H. Imura, and X.C. Zhang, 2007: Potential effects of climate change on runoff in the yellow river basin of China. Transactions of the American Society of Agricultural and Biological Engineers (ABASE), 50(3), 911 . 918.

Zhang, S., X.X. Lu, D.L. Higgitt, C.T.A. Chen, J. Han, and H. Sun, 2008: Recent changes of water discharge and sediment load in the Zhujiang (Pearl River) Basin, China. Global and Planetary Change, 60(3), 365-380.

Zhang, Y., S. Liu, J. Xu, and D. Shangguan, 2008: Glacier change and glacier runoff variation in the Tuotuo River basin, the source region of Yangtze River in western China. Environmental Geology, 56(1), 59-68.

Ziervogel, G. and A. Opere (eds.), 2010: Integrating Meteorological and Indigenous Knowledge-Based Seasonal Climate Forecasts for the Agricultural Sector: Lessons from Participatory Action Research in sub-Saharan Africa. CCAA Learning Paper Series, Climate Change Adaptation in Africa (CCAA) Program, UK Department for International Development (DIFD) and the International Development Research Centre (IDRC), IDRC, Ottawa, ON, Canada, 19 pp.

Ziska, L., K. Knowlton, C. Rogers, D. Dalan, N. Tierney, M.A. Elder, W. Filley, J. Shropshire, L.B. Ford, C. Hedberg, P. Fleetwood, K.T. Hovanky, T. Kavanaugh, G. Fulford, R.F. Vrtis, J.A. Patz, J. Portnoy, F. Coates, L. Bielory, and D. Frenz, 2011: Recent warming by latitude associated with increased length of ragweed pollen season in central North America. Proceedings of the National Academy of Sciences of the United States of America, 108(10), 4248-4251.

Zwiers, F.W., X. Zhang, and Y. Feng, 2011: Anthropogenic influence on long return period daily temperature extremes at regional scales. Journal of Climate, 24(3), 881-892. 